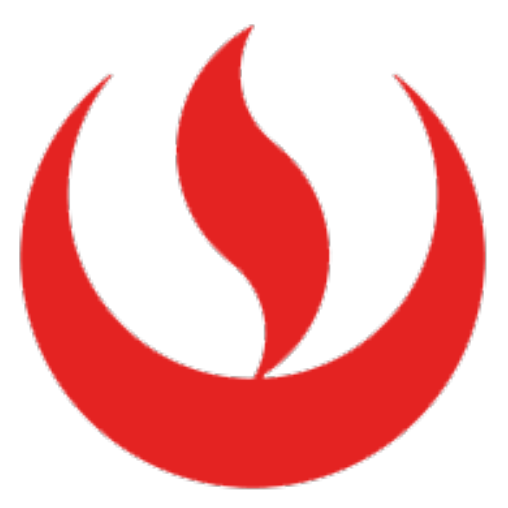

UNIVERSIDAD PERUANA DE CIENCIAS APLICADAS

ESCUELA DE POSGRADO

PROGRAMA DE MAESTRÍA EN DIRECCIÓN DE LA CONSTRUCCIÓN

\title{
MEJORA DE LA RENTABILIDAD EN PROYECTOS DE VIVIENDA SOCIAL EN LA ZONA RURAL DE LA SIERRA SUR DEL PERÚ, APLICANDO LAS METODOLOGÍAS BIM-LEAN CONSTRUCTION PARA MEDIANAS EMPRESAS
}

\author{
TRABAJO DE INVESTIGACIÓN \\ Para optar el grado académico de Maestro en Dirección de la Construcción \\ Integrantes: \\ Ortiz Cruz, Jesseliz Beatriz (0000-0002-8847-8505) \\ Escalante Luna, Patricia (0000-0003-4727-7093) \\ Gallegos Llacta, Deniht (0000-0002-8863-0263) \\ Asesor: \\ Salinas Saavedra, José Roberto (0000-0001-7075-595X)
}

Cusco, 10 de agosto de 2018 
Al Mg. Ing. José Roberto Salinas Saavedra, por apoyarnos en la revisión y asesoramiento del presente trabajo de investigación, y por compartir sus conocimientos en BIM y LEAN CONSTRUCTION. 
A nuestro Padre Celestial por iluminarme en cada paso que doy. A mis Padres Néstor y Lucila porque siempre están apoyándome y son mi orgullo de ser lo que soy, infinitas gracias.

A mis queridos hermanos Victor, Elisa, Alex, Jacqueline, Luceida, Yanina por ser mis fuentes de motivación y en especial a mi Angelito Rubén Dario, que nos enseñó siempre a luchar a pesar de la adversidad, todo este esfuerzo es para ti mi querido guerrero. A una persona especial con mucho amor y cariño, Mario, por su apoyo incondicional.

$Y$ sin dejar atrás a toda mi familia por confiar en mí, a mis sobrinos Leonardo y Gabriela, gracias por ser parte de mi vida.

JESSELIZ ORTIZ

A mis padres, Abel y Ruth, por sus enseñanzas y por ser la fuerza que me impulsa a seguir adelante.

A mis hermanas, Marinés y Valeria, por su apoyo incondicional y por el estímulo, comprensión y paciencia que me dieron permanentemente.

PATRICIA ESCALANTE

A mis adorados padres, Andrea Llacta y Eulogio Gallegos por haberme dado la vida y guiado siempre con valores.

A mis hermanos Ruth, Yovana, Yeni, Roger, por apoyarme siempre y ser mi ejemplo a seguir.

A una gran persona, Diana R. por su apoyo constante durante mi desarrollo profesional, y en especial a dos ángeles que guían mi camino, María y Juan. 


\section{TABLA DE CONTENIDOS}

RESUMEN

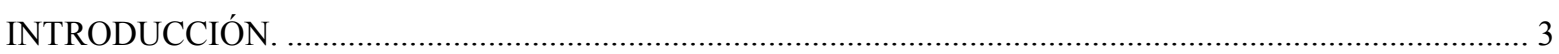

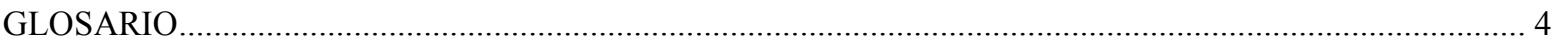

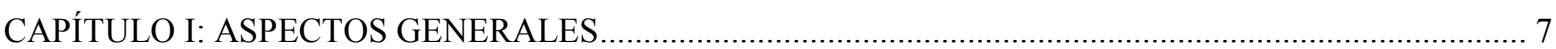

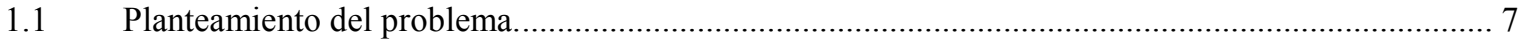

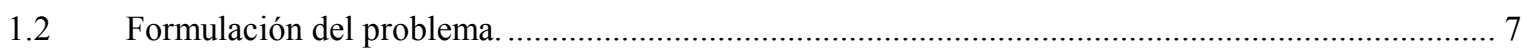

$1.3 \quad$ Objetivo general y específicos............................................................................................ 7

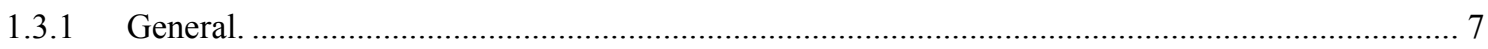

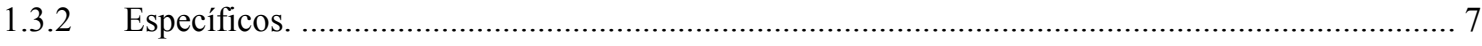

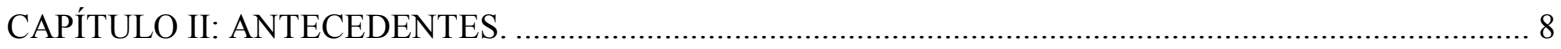

2.1 Situación actual de la vivienda rural en el sur del Perú. .................................................................... 8

2.2 Participación del Estado peruano en proyectos de vivienda social....................................................10

2.3 Entorno demográfico, geográfico y económico ………..............................................................11

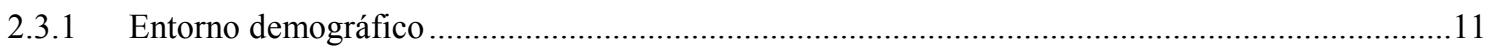

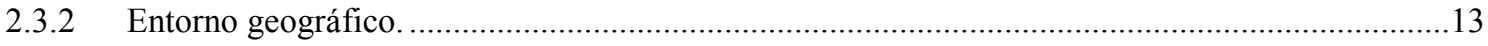

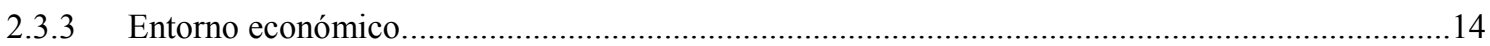

2.4 Entorno del sector construcción e inmobiliario en proyectos de vivienda social................................16

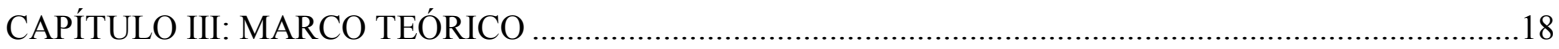

3.1 Enfoques y metodologías actuales de la construcción. .......................................................................18

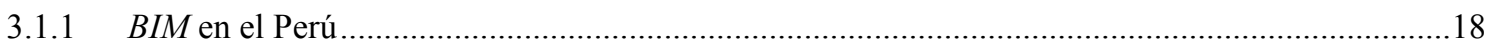

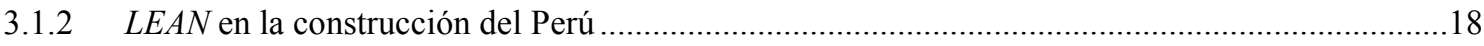

3.2 Problemática actual en proyectos de vivienda social .......................................................................

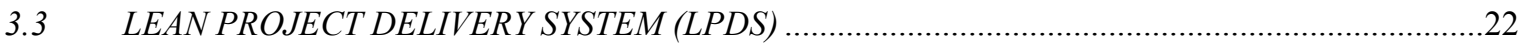

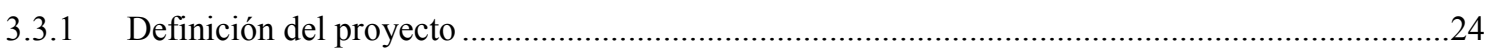

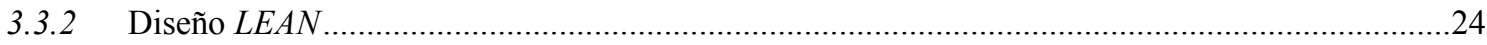

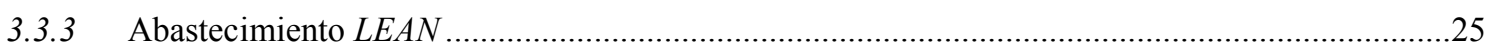

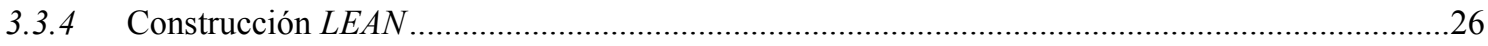

3.4 Plan de implementación del BUILDING INFORMATION MODELING en la empresa....................27

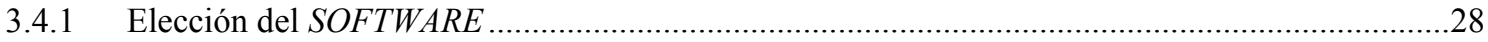

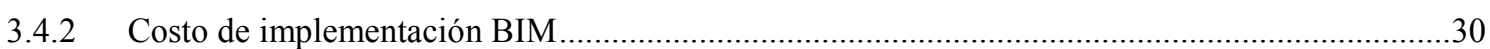

3.5 Plan de ejecución del BUILDING INFORMATION MODELING ………....................................

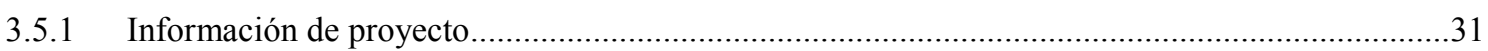

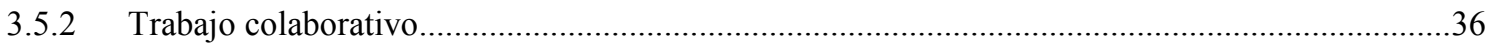

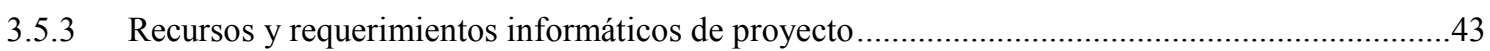

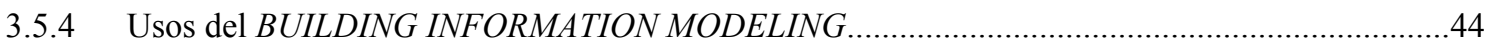

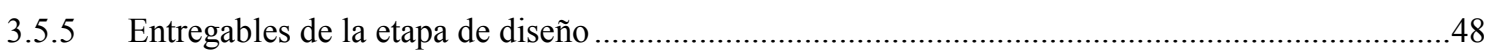

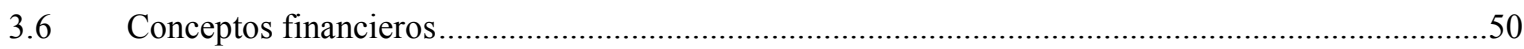

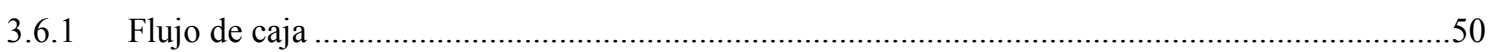

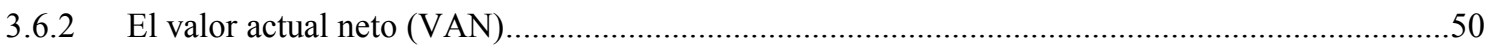




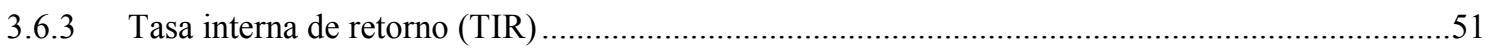

CAPÍTULO IV: PROPUESTA PARA EL MEJORAMIENTO DE LA RENTABILIDAD .............................52

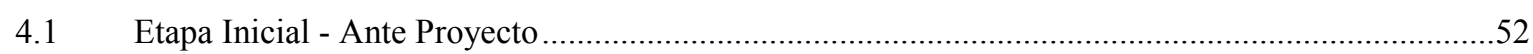

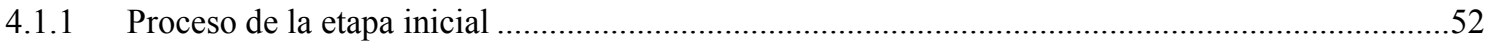

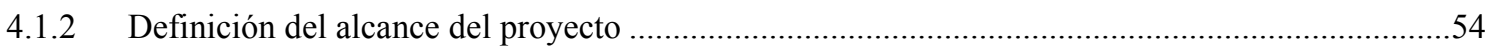

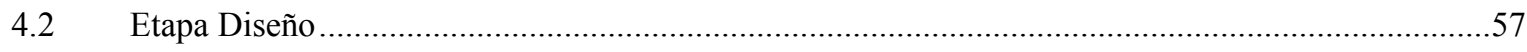

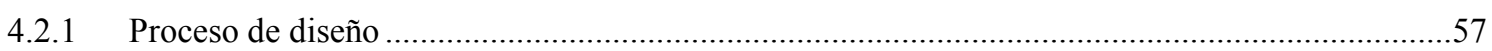

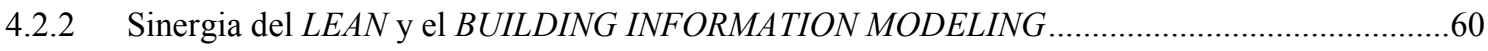

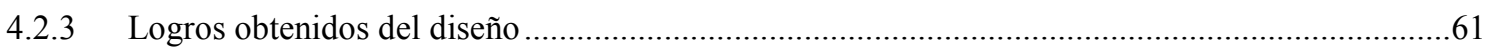

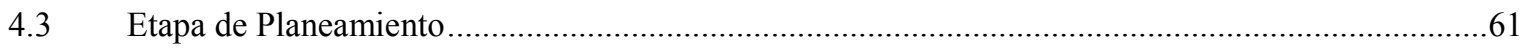

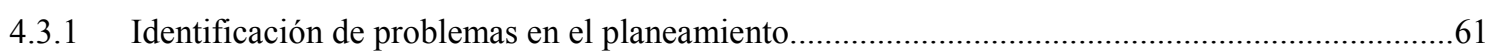

4.3.2 WORK BREAKDOWN STRUCTURE (WBS) y Cronograma General ......................................65

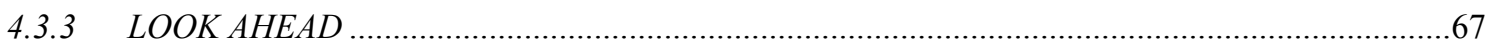

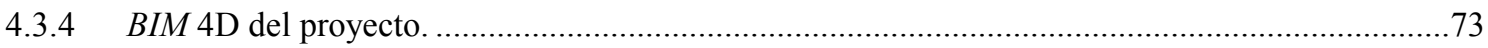

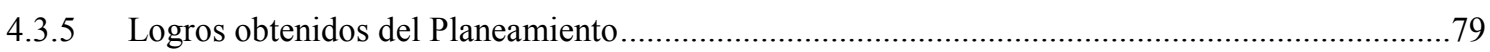

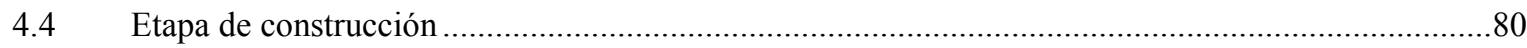

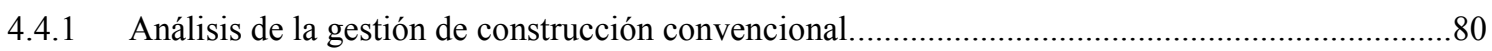

4.4.2 Propuesta de mejora para la etapa de construcción. ................................................................80

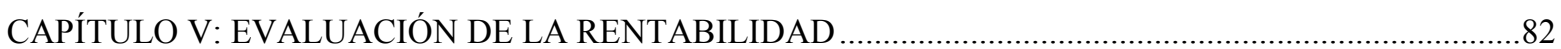

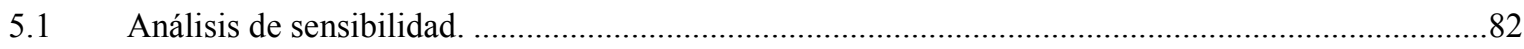

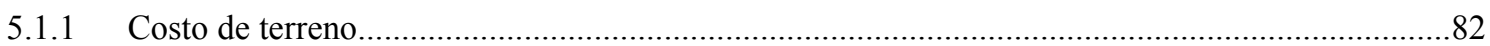

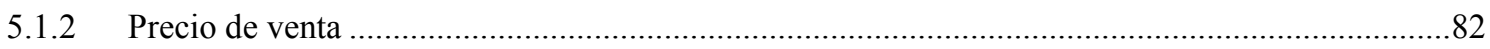

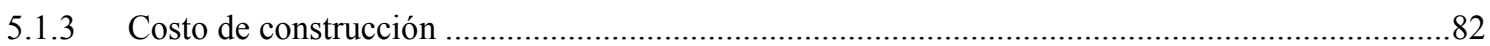

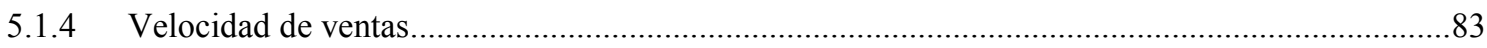

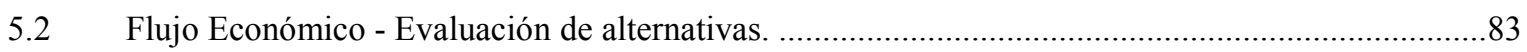

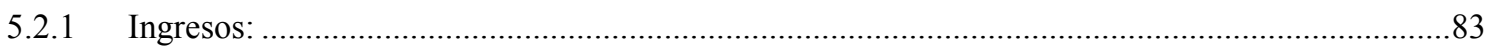

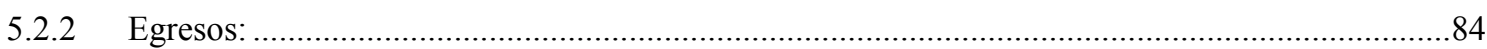

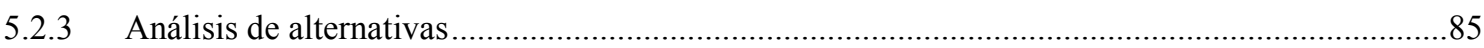

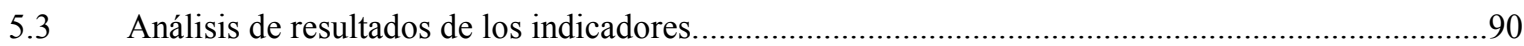

CAPÍTULO VI: CONCLUSIONES Y RECOMENDACIONES. .......................................................... 91

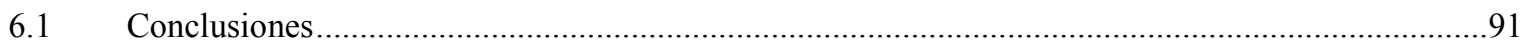

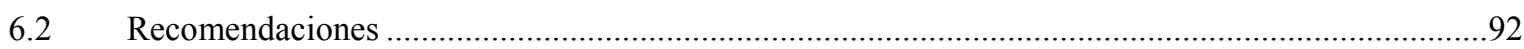

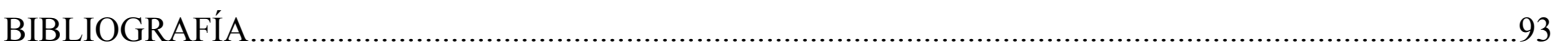




\section{ÍNDICE DE GRÁFICOS}

Gráfico 1: Situación actual de la vivienda rural en la sierra sur del Perú......................................................... 8

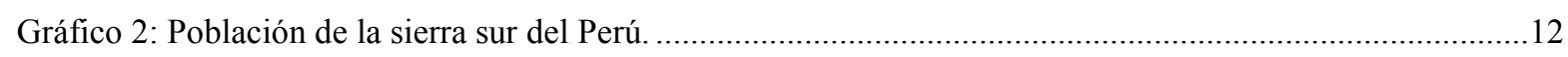

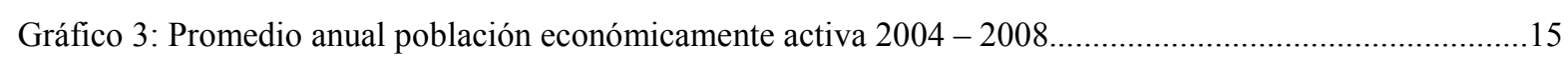

Gráfico 4: Problemas ocurridos en proyectos de vivienda social.....................................................................20

Gráfico 5: Ciclo del Proyecto con enfoques LEAN CONSTRUCTION y BIM ...............................................21

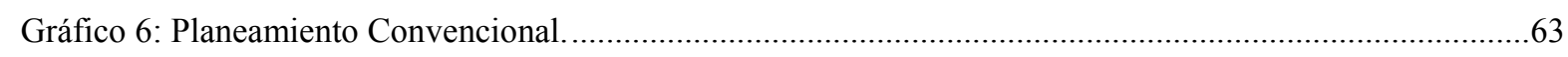

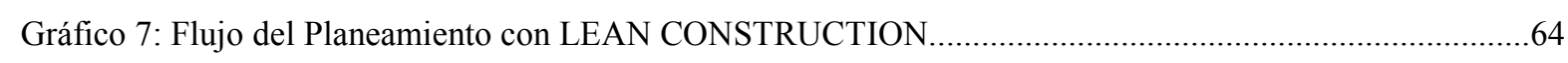

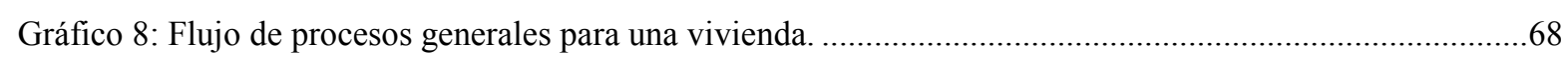

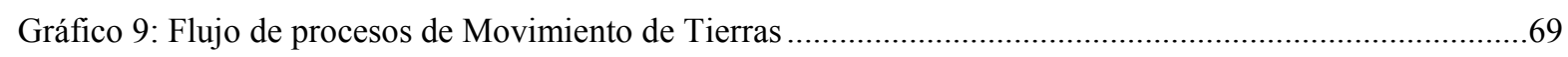

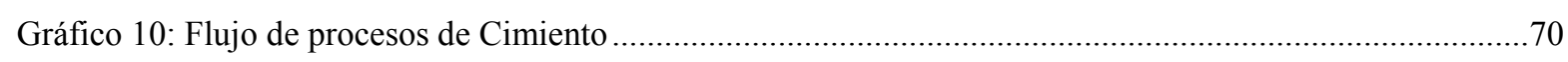

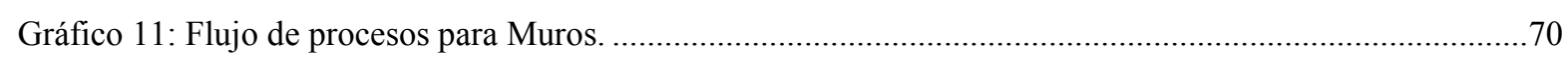

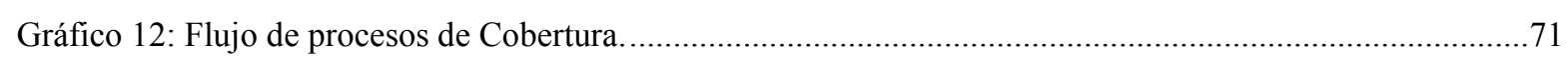

\section{ÍNDICE DE FOTOGRAFÍAS}

Fotografía 1: Vivienda de adobe de la zona rural de Cusco.......................................................................... 9

Fotografía 2: Vivienda de piedra de la zona rural de Cusco......................................................................... 9

Fotografía 3: Paisaje típico de la sierra sur del Perú. ....................................................................................14

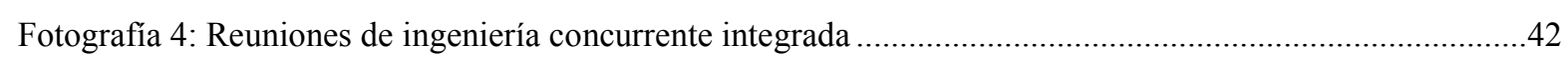

\section{ÍNDICE DE TABLAS}

Tabla 1: Valores para las Modalidades de Aplicación al Bono Familiar Habitacional (BFH).............................11

Tabla 2: Población total que cuentan con vivienda de la sierra sur del Perú....................................................12

Tabla 3: Tasa de crecimiento medio anual de la sierra sur del Perú.................................................................13

Tabla 4: Crecimiento del PBI por sectores al interior de cada departamento: 2004 - 2008 (promedio anual)...15

Tabla 5: Características de los proyectos de Techo Propio en la sierra sur del Perú. 


\section{ÍNDICE DE IMÁGENES}

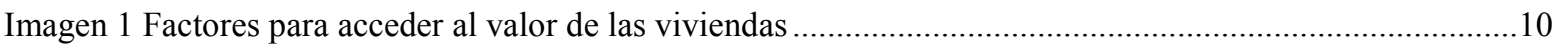

Imagen 2: Proyectos de vivienda social a nivel de todo el país........................................................................16

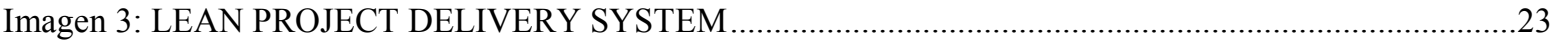

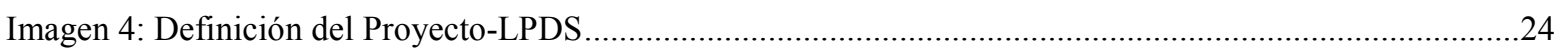

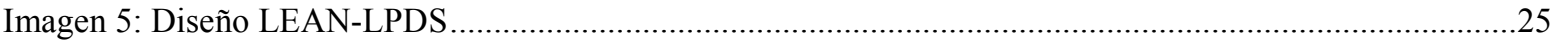

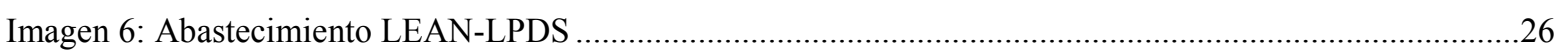

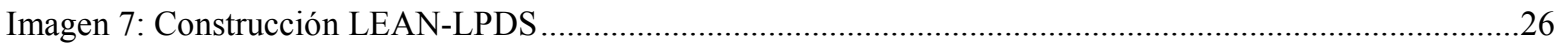

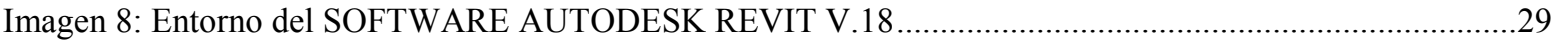

Imagen 9: Visualización del modelo 3D en el SOFTWARE AUTODESK NAVISWORKS V.18 .....................30

Imagen 10: Programación de objetivos y metas del proyecto ............................................................................35

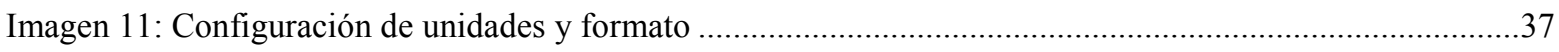

Imagen 12: Trabajar en coordenadas compartidas. (Punto base del proyecto y punto de superficie)..................38

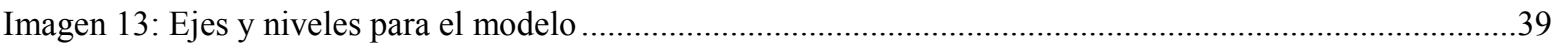

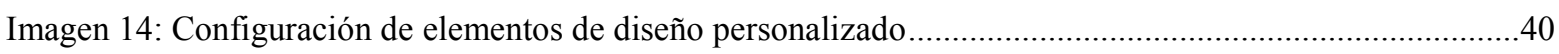

Imagen 15: Flujo colaborativo en metodología BIM sobre un modelo principal...............................................41

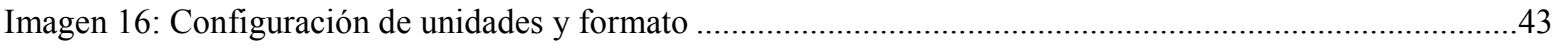

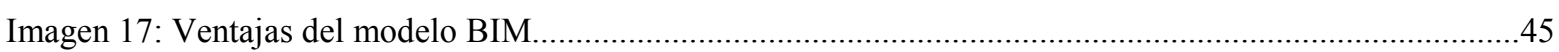

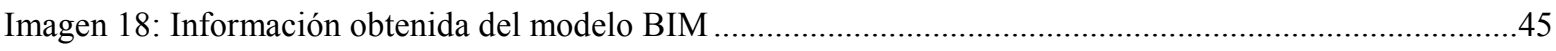

Imagen 19: Interferencia entre el diseño de instalaciones y diseño estructural ................................................46

Imagen 20: Diseño de instalaciones de agua incompatibles con los muros estructurales. .....................................47

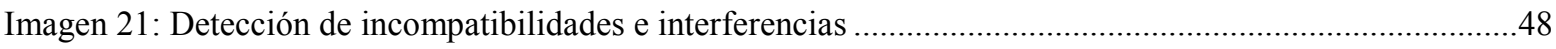

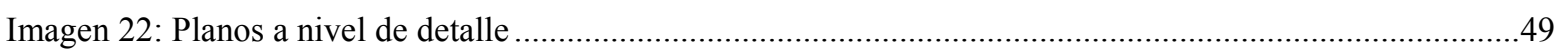

Imagen 23: Metrado de elementos en el SOFTWARE Autodesk REVIT ……...........................................50

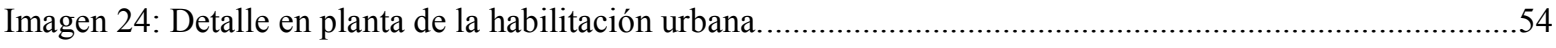

Imagen 25: Alternativa $\mathrm{N}^{\circ} 01$ distribución en planta y vista 3D del módulo de vivienda sistema muros de

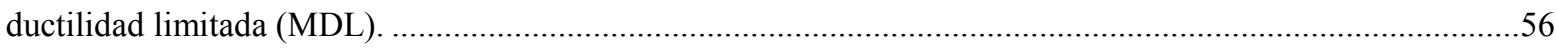

Imagen 26: Alternativa $\mathrm{N}^{\circ} 02$ distribución en planta del módulo de vivienda sistema aporticado.....................57

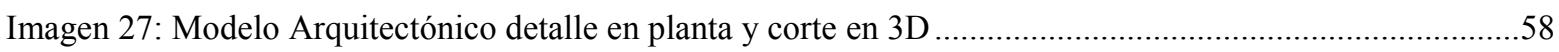

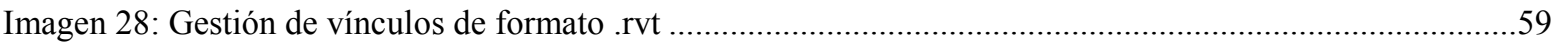

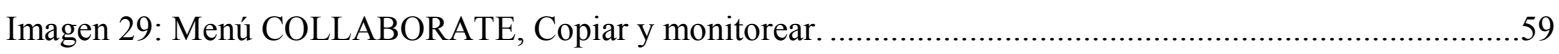

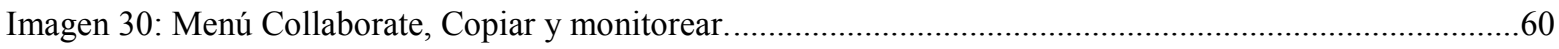

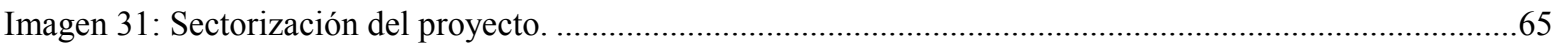

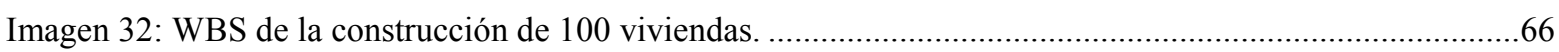

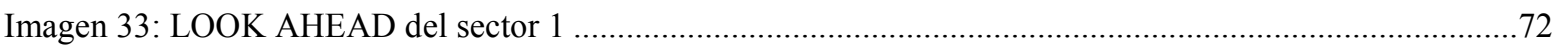

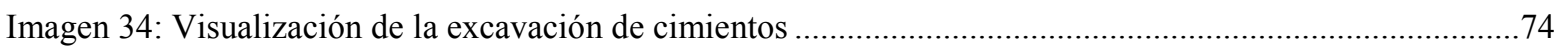

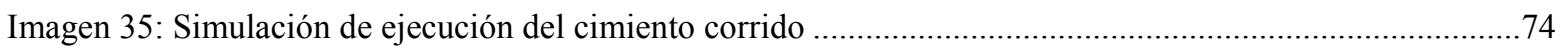

Imagen 36: Simulación del encofrado y vaciado de concreto de sobrecimiento.................................................75

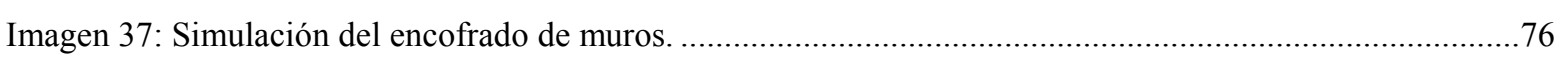

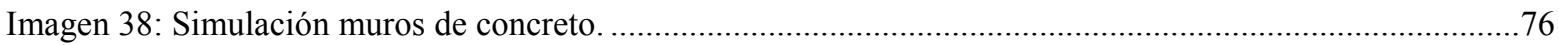




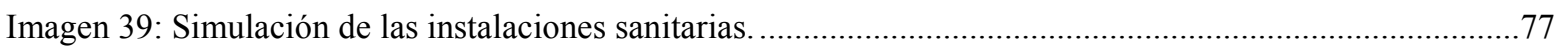

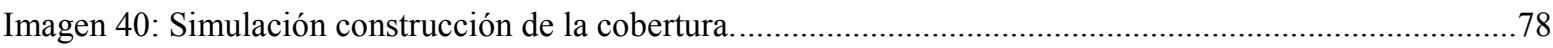

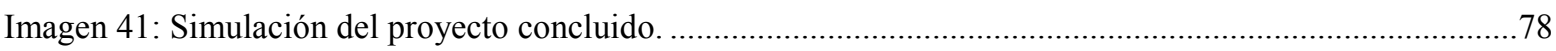

\section{ÍNDICE DE CUADROS}

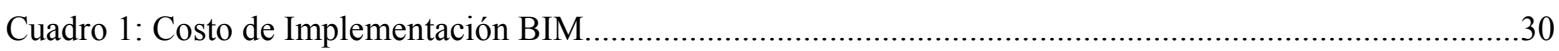

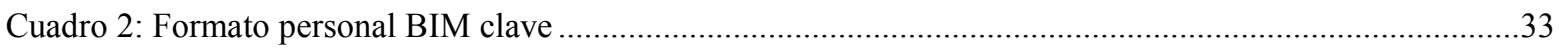

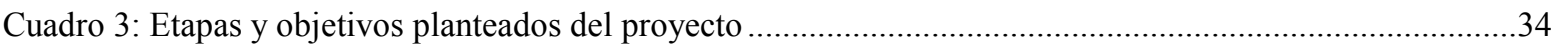

Cuadro 4: Problemas en proyectos de la sierra sur del Perú.........................................................................62

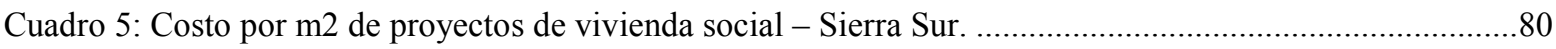

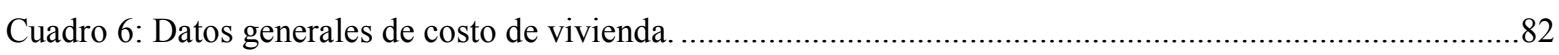

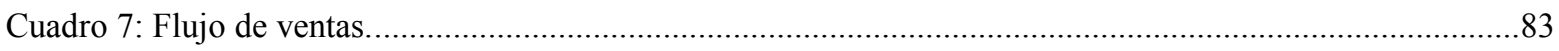

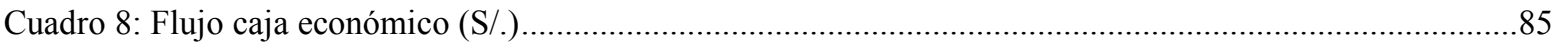

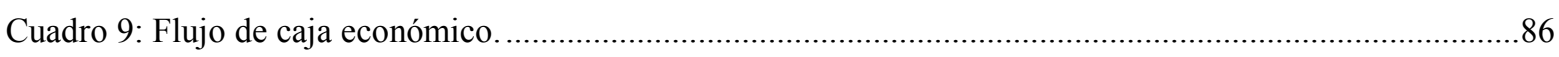

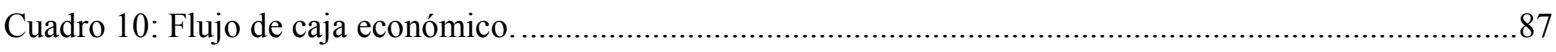

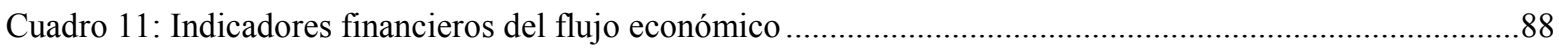

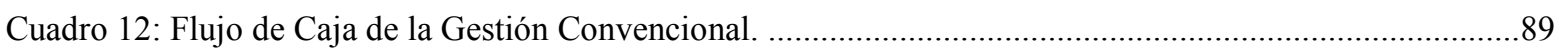

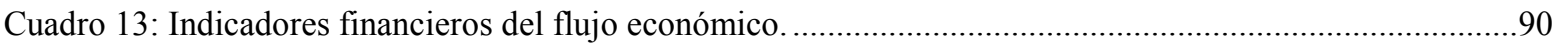

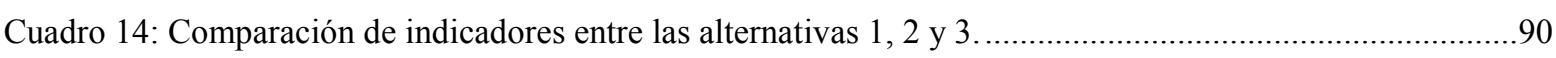

Cuadro 15: Comparación de indicadores entre la alternativa $1 \mathrm{y}$ la construcción convencional.......................90

\section{ÍNDICE DE ANEXOS}

Anexo 1: Flojograma De Procesos De La Etapa Inicial .........................................................................94

Anexo 2: Plano De Arquitectura De La Alternativa De Diseño $\mathrm{N}^{\circ} 1$............................................................95

Anexo 3: Plano De Arquitectura De La Alternativa De Diseño N ${ }^{\circ} 2$........................................................96

Anexo 4: Plano De Estructuras De La Alternativa De Diseño $\mathrm{N}^{\circ} 1$.........................................................97

Anexo 5: Plano De Estructuras De La Alternativa De Diseño N ${ }^{\circ} 1$ : E-2 ......................................................98

Anexo 6: Plano De Instalaciones De Agua Fría De La Alternativa De Diseño $\mathrm{N}^{\circ} 1$...................................99

Anexo 7: Plano De Agua Fría Y Desagüe De La Alternativa De Diseño N ${ }^{\circ} 1$...........................................100

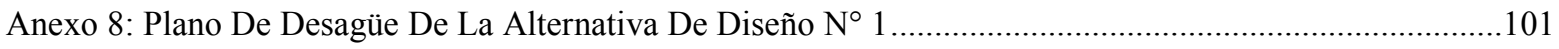

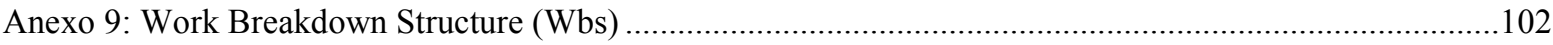

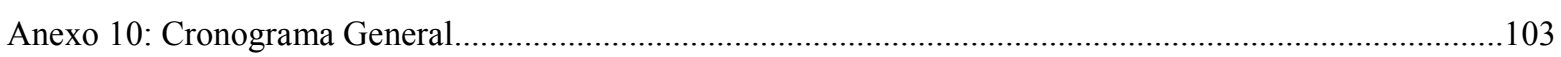

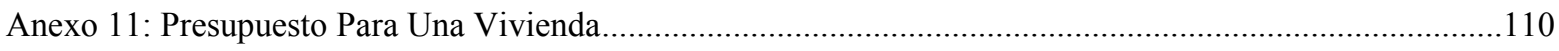

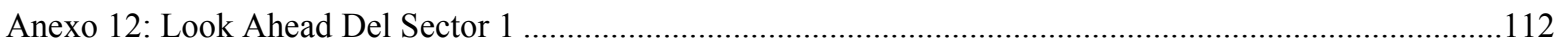

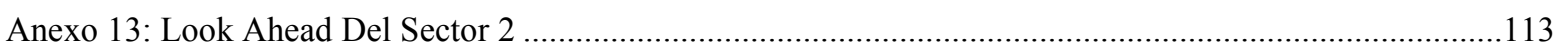

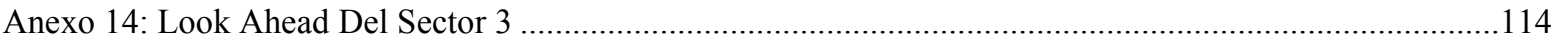

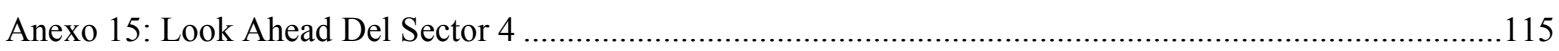

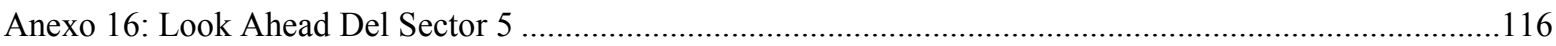




\section{RESUMEN}

Ante la problemática del déficit de viviendas en la sierra sur del Perú y la baja rentabilidad de las constructoras en este tipo de proyectos, el presente trabajo de investigación busca mejorar la rentabilidad en proyectos de vivienda social en la zona rural de la sierra sur del Perú, aplicando las metodologías BIM-LEAN CONSTRUCTION para medianas empresas; se busca reducir los costos, agregando valor al producto, eliminando desperdicios y pérdidas, incrementando la colaboración entre los involucrados, simplificando procesos innecesarios y optimizando tiempos de ejecución. Se inicia con la etapa de ante-proyecto, donde se realizó un análisis del proceso de obtención del terreno, habilitación urbana y licencias requeridas con el fin de determinar costos más reales del desarrollo de proyectos de viviendas. Además, la investigación busca incrementar la productividad, aplicando herramientas de gestión para las etapas de diseño, planeamiento y construcción; analizando los requerimientos básicos de diseño como son las características mínimas de los ambientes de la vivienda, tipo de instalaciones, acabados, entre otras, se realizó la propuesta de diseño con herramientas BIM y posteriormente se plantea la programación con la herramienta $L O O K A H E A D$. Finalmente, se elaboró el flujo de caja para el análisis económico, comparando los indicadores financieros entre la propuesta del trabajo de investigación y la construcción convencional. De esta manera, se logra tomar el control efectivo de los proyectos de vivienda social, garantizando el cumplimiento de los costos y tiempos de ejecución.

Palabras clave: Rentabilidad, vivienda social, BIM, LEAN CONSTRUCTION, diseño, planeamiento, construcción, productividad, análisis económico. 


\begin{abstract}
Given the problem of housing deficit in the southern highlands of Peru and the low profitability of construction companies in this type of project, this research work seeks to improve profitability in social housing projects in the rural area of the southern highlands of Peru, applying the BIM-LEAN CONSTRUCTION methodologies for medium-sized companies; it seeks to reduce costs, adding value to the product, eliminating waste and losses, increasing collaboration among those involved, simplifying unnecessary processes and optimizing execution times. It begins with the ante-project stage, where an analysis of the process of obtaining the land, urban authorization and required licenses was carried out in order to determine more real costs of the development of housing projects. In addition, the research seeks to increase productivity, applying management tools for the design, planning and construction stages; analyzing the basic requirements of design such as the minimum characteristics of the housing environments, type of facilities, finishes, among others, the design proposal was made with BIM tools and later the programming with the LOOK AHEAD tool is considered. Finally, the cash flow for the economic analysis was elaborated, comparing the financial indicators between the proposal of the research work and the conventional construction. In this way, it is possible to take effective control of social housing projects, guaranteeing compliance with costs and execution times.
\end{abstract}

Keywords: Profitability, social housing, BIM, LEAN CONSTRUCTION, design, planning, construction, productivity, economic analysis. 


\section{INTRODUCCIÓN.}

La realidad de nuestro país refleja que existe alto nivel de pobreza y necesidad de vivienda, principalmente en las zonas rurales de la sierra sur del Perú, la calidad de vida de las familias es muy precaria ya que viven en condiciones inhabitables de hacinamiento, carencia de servicios básicos, escases de programas de apoyo del Estado para el sector salud, educación, vivienda y saneamiento, asimismo, el Estado no promueve el desarrollo económico en las zonas rurales.

La vivienda es el pilar fundamental para el desarrollo socio-económico de las población rural e integración en el plan de desarrollo del país, buscando mejorar la calidad de vida, por otra parte, al desarrollar los proyectos sociales incentivan al gobierno a desarrollar proyectos de servicios básicos generando empleo local.

El Perú es el tercer país de Latinoamérica con mayor déficit habitacional, alcanzando 1'860,692 unidades de vivienda, de los cuales el 35.10 \% pertenece a la zona rural. Esto demuestra que existe alta demanda de viviendas de interés social que no es abastecido siendo el sector más necesitado. (INEI, 2009)

El Perú tuvo un crecimiento económico importante que se evidenció entre los últimos años con el denominado boom de la construcción, que se inició entre el año 2005 al 2012, el sector construcción es uno de los sectores más dinámicos de nuestra economía al igual que el sector minero. Los proyectos de vivienda se desarrollaron principalmente en la ciudad de Lima, reflejándose este crecimiento en menor escala en provincias y en especial en las zonas rurales del sur del país. Los sectores socio-económicos más beneficiados fueron el sector $\mathrm{B}$ y $\mathrm{C}$ debido a que fácilmente acceden a créditos hipotecarios, dejando de lado al sector D y E.

El Estado peruano a través de los programas de vivienda popular, tal como el del programa Mi Vivienda y Techo Propio busca fortalecer el crecimiento de la economía en los sectores de menores ingresos, la finalidad de estos programas es lograr que la población pueda acceder a viviendas propias y dignas a través de subsidios otorgados por el Estado; asimismo, estimular la participación de las empresas privadas en desarrollar proyectos inmobiliarios de interés social. 


\section{GLOSARIO}

Vivienda Social: una Vivienda de Interés Social (VIS) es una solución habitacional cuyo valor máximo es de catorce (14) UIT o S/. 51,800 Nuevos Soles. Las características de las VIS se encuentran detalladas en los Reglamentos Operativos del Bono Familiar Habitacional (BFH), según la modalidad de aplicación. (Fondo MiVivienda, 2013)

BUILDING INFORMATION MODELING (BIM): es una metodología/proceso colaborativo para desarrollar y utilizar modelos inteligentes que contienen información para apoyar decisiones y procesos de diseño, construcción y operación durante todo el ciclo de vida de un proyecto, lo que implica una integración y gestión de información provista y usada en diversos formatos y por diferentes actores del proyecto. (BIM Forum, 2018)

BIM 4D: es la gestión del modelo 3D involucrando la programación (gestión de tiempo).

INDUSTRY FOUNDATION CLASSES (IFC): es un formato de datos que tiene como finalidad permitir el intercambio de un modelo informativo sin la pérdida o la distorsión de datos o informaciones. También se define como un formato neutro, no controlado por los productores de SOFTWARE, que busca facilitar la interoperabilidad entre varios operadores. (EMAGISTER, 2017)

Ingeniería Concurrente Integrada (ICE): “es una metodología para el desarrollo efectivo, rápido y confiable de cualquier tipo de ingeniería y/o diseño" (Arbulu, 2012).

INTEGRATED PROJECT DELIVERY (IPD): contratos colaborativos, es un enfoque de gestión de proyectos que integra personas, sistemas, empresas y prácticas en un proceso colaborativo que aprovecha los diferentes puntos de vista de todos los participantes para optimizar los resultados del proyecto, aumentando el valor al producto final, reduciendo los desperdicios y maximizando la eficiencia en todas las fases del proyecto. (Lean Bim Construction, 2015)

Compatibilización: es el proceso de integración de las diferentes especialidades del proyecto, durante la etapa de diseño, para minimizar o eliminar las interferencias.

REQUEST FOR INFORMATION (RFI): es la solicitud de información referente al proyecto que no está claramente definido y que se requiere durante el desarrollo del mismo durante la fase de diseño y construcción.

VIRTUAL DESIGN AND CONSTRUCTION (VDC): es el uso integrado de modelos multidisciplinarios que permitan medir el desempeño del diseño y construcción de proyectos incluyendo modelos de los productos (obras), las organizaciones y los procesos de trabajo para lograr los objetivos del negocio. (Saavedra, 2017)

Constructabilidad: es el uso óptimo del conocimiento y experiencia de construcción en la planificación, en el diseño, en la adquisición y en el manejo de las operaciones de construcción para lograr los objetivos del proyecto. (Institute, 1986) 
Tecnología de la Información (TI): es el conjunto de conocimientos relacionados con la producción, distribución, almacenamiento, recuperación e utilización; cuyos principales elementos son las personas, procesos y herramientas. (Rischmoller, 2017)

Plan de implementación BIM (PIB): es un documento que contiene los objetivos a lograr en el tiempo con la implementación de la metodología $B I M$ en una empresa, involucra las personas, herramientas y procesos.

Plan de ejecución BIM (PEB): es un documento que contiene los pasos a seguir para la gestión de la información al desarrollar la metodología BIM en los procesos de un proyecto, asimismo se indica los roles y responsabilidades.

LEAN CONSTRUCTION: también conocida como construcción sin perdidas, es una metodología de construcción basada en los principios de LEAN MANUFACTURING de la Toyota. (Garcia Diaz, 2012)

LEAN PROJECT DELIVERY SYSTEM (LPDS): secuencia de elaboración de actividades o tareas dentro de LEAN CONSTRUCTION. (Garcia Diaz, 2012)

WORK BREAKDOWN STRUCTURE (WBS): estructura de descomposición de trabajo. Es una herramienta que permite la disgregación jerárquica, dirigida a los entregables, del trabajo a ejecutarse para el cumplimiento de los objetivos de éste. Su objetivo principal es ordenar y definir el alcance total del proyecto.

LOOK $\boldsymbol{A H E A D}$ : Es el segundo nivel en la jerarquía del sistema de planificación. Resalta las actividades que deberían hacerse en un futuro cercano.

Ultimo Planificador (LAST PLANNER): control que se hace durante la ejecución de las actividades semanalmente de acuerdo a la programación intermedia. (Garcia Diaz, 2012)

Planificación: consiste en determinar lo que se debe hacer, cómo se debe hacer, qué acción debe tomarse, quién es el responsable de ella y por qué.

Programación: es una etapa en la que sé que planea cada componente de la gerencia de construcción como la logística, recursos humanos, calidad, tiempo, costos, riesgos, la seguridad, el medio ambiente, la comunicación, las finanzas, negociaciones y controversias para finalmente integrarlos formando un sistema.

Productividad: la medición de la eficiencia con que los recursos son administrados para completar un producto específico, dentro de un plazo establecido y con un estándar de calidad dado. (Serpell B., 2002)

Rendimiento: es la cantidad producida por unidad de tiempo. (Velocidad de avance).

Variabilidad: es la incertidumbre de no saber qué es lo que va a acontecer en las próximas horas, días, etc., en un determinado proyecto. (Delgado Barrio de Mnedoza, 2013) 
Precio: en términos generales, el precio es el valor de una cosa expresada en dinero. Para los economistas el precio es el nivel de intercambio que se establece entre los bienes y servicios económicos por una parte y el dinero por otra. El precio expresa el valor de intercambio de los bienes. En una economía de libre mercado, la formación de los precios está condicionada por el reajuste más o menos flexible de la oferta. (Irías Giron, 2002)

Costo: cantidad que se da o se paga por una cosa. Conjunto de gastos realizados en el proceso productivo de un bien o un servicio. También se le denominan "coste", tiene una gran cantidad de conceptos, lo que hace difícil reducir a una sola definición, para una fácil determinación es preferible agregarle otro término que lo califique, ejemplo: costo directo, costo fijo, etc. (Irías Giron, 2002)

Venta: todo acto o contrato que sirve para transferir a título oneroso el dominio parcial o total de bienes inmuebles o muebles situados en el territorio nacional o derechos reales sobre ellos. (Irías Giron, 2002)

Flujo de Caja: son los flujos de efectivo esperados, que se programan para una adecuada administración de los fondos por parte de la tesorería, a través de cuentas de disponibilidad y obligaciones de desembolsos, con diversos niveles de agregación. (Irías Giron, 2002)

Flujo de caja económico: suma del beneficio y aquellos gastos que no suponen desembolso tales como las amortizaciones y ciertas provisiones. Informa de los recursos generados por la empresa. (Casa Ribé, 2008)

Ingreso: acción y afecto de ingresar. Efectuar un ingreso. Aumento de bienes o derechos sin entregar ningún otro valor patrimonial a cambio. Equivalente monetario de la venta. (Casa Ribé, 2008)

Egresos: el concepto de egreso se refiere al momento de pago, salida de fondos o disminución de pasivos; ya sea para cancelar obligaciones directamente, o para entregar fondos a responsables de su manejo. (Irías Giron, 2002)

Gastos: conjunto de desembolsos pecuniarios o de valores y bienes equivalentes, realizados en el ejercicio o desempeño de una actividad periódica, permanente o compleja, o a veces discontinua. (Irías Giron, 2002)

Valor Actual Neto (VAN): es el valor, puesto al día, de todos los flujos de caja esperados de un proyecto de inversión. Sirve básicamente para escoger el costo de oportunidad de un proyecto y escoger el mejor. (Irías Giron, 2002)

Tasa Interna de Retorno (TIR): tipo de descuento o interés, para efectos de estimación, con la que se igualan los flujos de caja positivos y negativos de un proyecto de inversión. Para que un proyecto sea rentable, esta debe ser superior al costo del capital empleado. (Irías Giron, 2002)

Utilidad: aptitud que atribuimos a una cosa como medio de satisfacción directa o indirecta, de una o varias necesidades de acuerdo con la cantidad de las cosas y con la importancia que a ellas se le asigne. (Irías Giron, 2002) 


\section{CAPÍTULO 1: ASPECTOS GENERALES}

\subsection{Planteamiento del problema.}

En la actualidad, en la zona rural de la sierra sur del Perú existe un déficit de vivienda con limitada oferta de proyectos de vivienda social, debido a la baja rentabilidad que se obtiene de estos proyectos como consecuencia de elevados costos de habilitación urbana y pérdidas durante la construcción.

\subsection{Formulación del problema.}

¿Cuánto mejoraría la rentabilidad de los proyectos en vivienda social en la zona rural de la sierra sur del Perú, aplicando las metodologías BIM - LEAN CONSTRUCTION, para medianas empresas?

\subsection{Objetivo general y específicos.}

\subsubsection{General.}

Mejorar la rentabilidad en proyectos de vivienda social en la zona rural de la sierra sur del Perú, aplicando las metodologías BIM - LEAN CONSTRUCTION.

Se busca reducir los costos y tiempos en la etapa de diseño, planeamiento y construcción de los proyectos de viviendas sociales para incrementar la rentabilidad del proyecto.

\subsubsection{Específicos.}

- Incrementar la oferta de vivienda social en la zona rural de la sierra sur del Perú.

- Implementar una propuesta de gestión aplicando enfoques de BIM -LEAN CONSTRUCTION para medianas empresas. 


\section{CAPÍTULO 2: ANTECEDENTES.}

2.1 Situación actual de la vivienda rural en el sur del Perú.

La vivienda rural en el Perú viene desarrollándose muy lentamente debido a la poca importancia por parte del Estado. Por ello, el enfoque del tema de investigación busca promover el desarrollo de la zona rural incentivando la inversión de empresas públicas y privadas.

Para realizar un adecuado análisis situacional de la vivienda rural en la sierra sur, se muestra datos estadísticos, características de las viviendas, programas del Estado, entre otros, para ello se delimitará el área de estudio a los departamentos: Apurímac, Arequipa, Ayacucho, Cusco, Moquegua, Puno y Tacna.

Según el Censo Nacional 2007: XI de Población y VI de Vivienda, el 29\% de las viviendas a nivel nacional pertenecen al sector rural, de ellas el 10\% se encuentran en la sierra sur; es decir, 758,213 viviendas. En el siguiente cuadro se presenta, por el tipo de viviendas, la cantidad de viviendas que existe en cada departamento.

\section{Gráfico 1: Situación actual de la vivienda rural en la sierra sur del Perú}

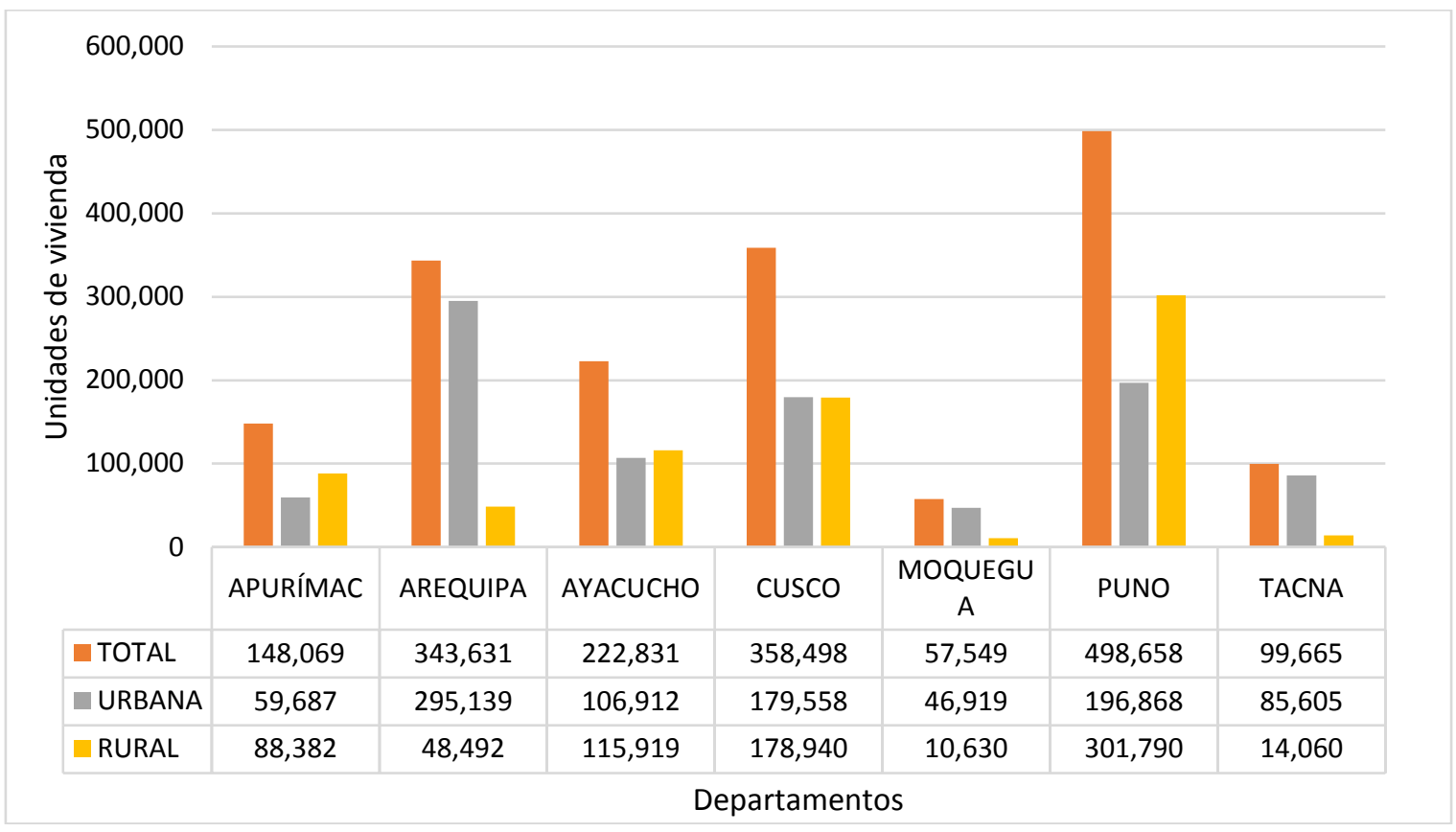

Fuente: (INEI, 2007)

Según el Gráfico 1, un mínimo porcentaje de la población rural migra a las zonas urbanas en busca de una mejor calidad de vida; sin embargo, la mayoría se mantiene viviendo en condiciones precarias sin contar con los servicios básicos. Por este motivo, el Estado ha creado diversos programas de apoyo a la población más necesitada, entre ellos se encuentra el Programa Nacional de Vivienda Rural promovido por el Ministerio de Vivienda, Construcción y Saneamiento, el cual tiene como objetivo mejorar, reconstruir y reforzar las condiciones de la vivienda rural de los pobladores que se encuentran en 
situación de pobreza y pobreza extrema logrando mejorar su calidad de vida, generando igualdad de oportunidades, desarrollo y fortaleza de sus capacidades individuales y comunitarias.

Por otro lado, las viviendas rurales en la sierra sur del Perú son vulnerables estructuralmente, como se muestra en las siguientes fotografias, ya que se desarrollan mediante la autoconstrucción sin la asesoría técnica de profesionales; además, son propensos a ser afectados por diversos fenómenos climáticos (lluvias, heladas) y fenómenos naturales (huaicos, sismos, deslizamientos, entre otros); asimismo carecen de servicios básicos. (Ministerio de Vivienda, Construcción y Saneamiento, 2015)

Fotografía 1: Vivienda de adobe de la zona rural de Cusco.

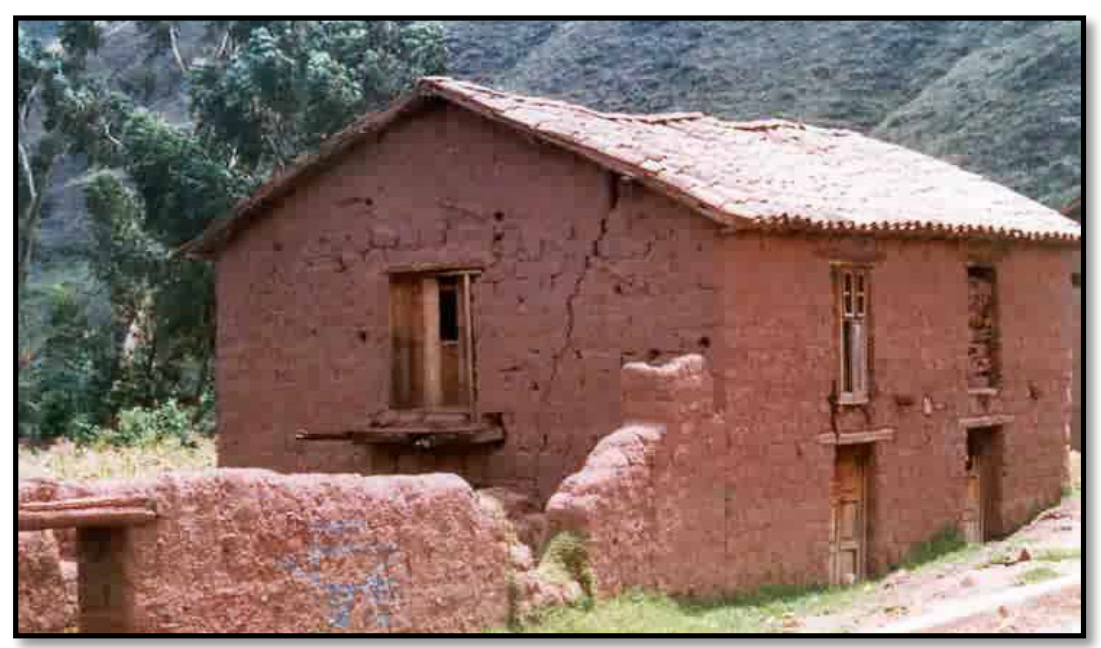

Fuente: (CERESIS, 2015)

Fotografia 2: Vivienda de piedra de la zona rural de Cusco.

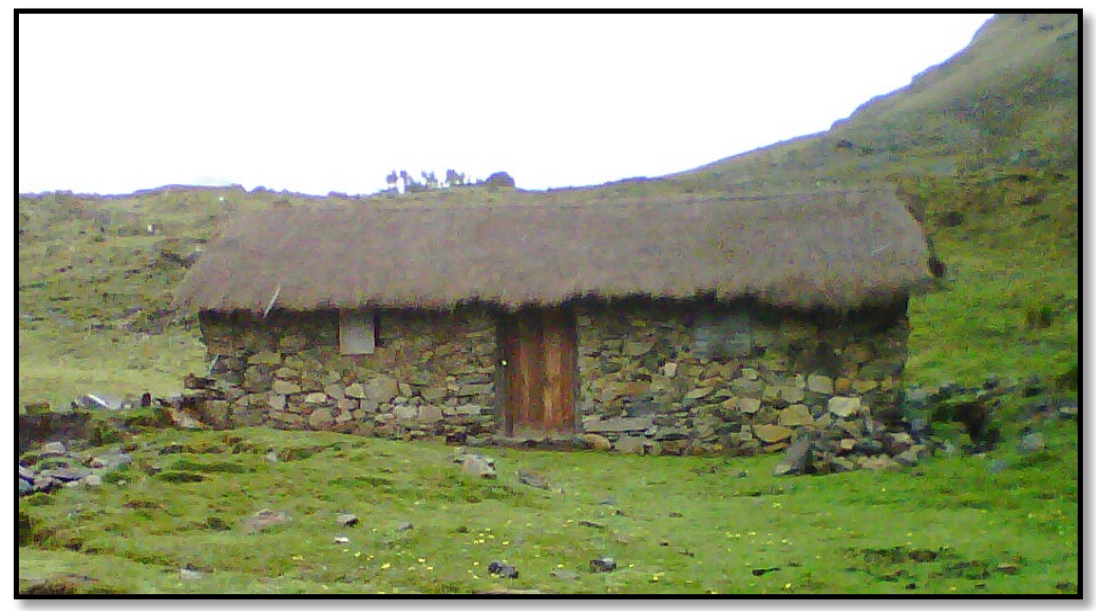

Fuente propia.

En la fotografía 1 se aprecia la típica vivienda de adobe de la sierra del Perú, y en la fotografía 2 se observa una vivienda de piedras, común en los sectores de mayor altitud. Estas viviendas no cuentan con un diseño estructural adecuado, lo cual puede provocar desplomes ante movimientos sísmicos. 
2.2 Participación del Estado peruano en proyectos de vivienda social.

Existen diversos programas sociales que brinda el Estado como ayuda para la población; de los cuales los más importantes para obtener una vivienda digna son: Nuevo Crédito MIVIVIENDA, MISMATERIALES, Techo Propio, Bono de Reforzamiento Estructural, MiTerreno; financiados por el Fondo MiVivienda. El trabajo de investigación se enfocará exclusivamente en el programa Techo Propio, ya que las viviendas planteadas estarán dirigidas para familias del sector socioeconómico $\mathrm{D}$ y E.

El Programa Techo Propio está dirigido a familias con ingresos mensuales menores a $\mathrm{S} / .3,626.00$ para comprar, construir o mejorar su vivienda, la cual contará con servicios básicos de agua, luz y desagüe. (Fondo MiVivienda, 2018)

Los principales objetivos del programa Techo Propio son promover mecanismos para que sectores populares obtengan una vivienda propia y estimular la participación del sector privado en la construcción de viviendas de interés social; para lo cual se creó el Bono Familiar Habitacional (BFH), el cual es una ayuda económica otorgada por el Estado para la obtención de una vivienda.

Existen tres modalidades para adquirir el BFH:

- Adquisición de Vivienda Nueva (AVN): dirigido a familias que no tienen vivienda ni terreno donde construirla.

- Construcción en Sitio Propio (CSP): dirigido a familias que no tienen vivienda pero tienen un terreno o areas independizados donde construir.

- Mejoramiento de Vivienda (MV): dirigido a familias que tienen vivienda, pero necesitan terminarla, ampliarla o mejorarla.

Para el trabajo de investigación se desarrollará la modalidad Adquisición de Vivienda Nueva, ya que el enfoque de nuestro trabajo considera la obtención del terreno, construcción y venta de las viviendas.

El valor de la vivienda consta de 3 factores puntuales:

- Ahorro: es el aporte del grupo familiar como una inicial al costo total de la vivienda.

- Bono: es el aporte brindado por el Estado Peruano como ayuda económica al ahorro y esfuerzo del grupo familiar.

- Crédito: abonado por alguna entidad bancaria en caso sea necesario, para cubrir costos que por ciertos motivos no puedan ser cubiertos por el grupo familiar.

Imagen 1 Factores para acceder al valor de las viviendas

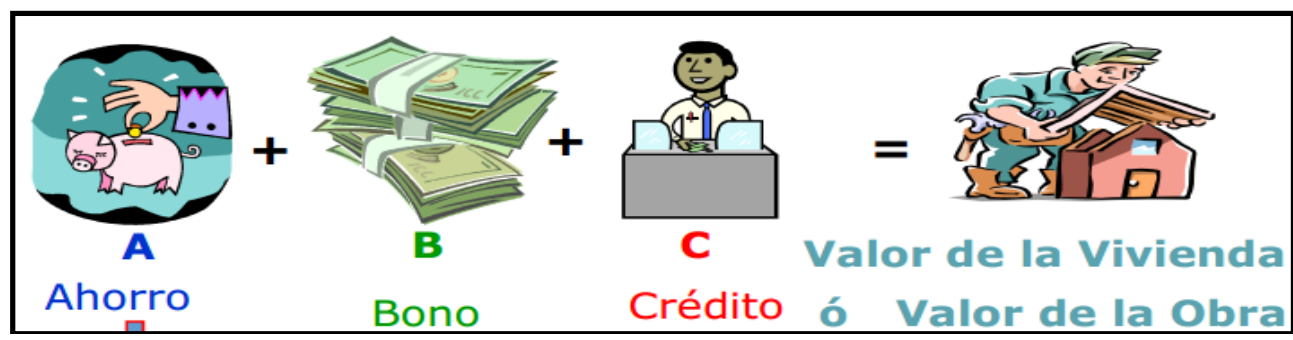

Fuente: (Fondo MiVivienda, 2018) 
Se muestran los valores del Bono Familiar Habitacional (BFH) según la Resolución Ministerial 327-2017-VIVIENDA, se clasifica según la modalidad de aplicación, el ahorro mínimo y el aporte del grupo familiar.

Tabla 1: Valores para las Modalidades de Aplicación al Bono Familiar Habitacional (BFH)

\begin{tabular}{|c|c|c|c|}
\hline MODALIDADES & $\begin{array}{l}\text { VALOR DE LA } \\
\text { VIVIENDA }\end{array}$ & $\begin{array}{c}\text { BONO } \\
\text { FAMILIAR } \\
\text { HABITACIONAL }\end{array}$ & $\begin{array}{l}\text { AHORRO } \\
\text { MINIMO }\end{array}$ \\
\hline \multirow{2}{*}{$\begin{array}{l}\text { ADQUISICIÓN } \\
\text { DE VIVIENDA } \\
\text { NUEVA (AVN) }\end{array}$} & $\mathrm{S} / . \mathbf{8 3 , 0 0 0}$ & $\mathrm{S} / . \mathbf{3 3 , 2 0 0}$ & \multirow{8}{*}{$\begin{array}{l}\text { Mínimo } 3 \% \\
\text { del precio de } \\
\text { la vivienda }\end{array}$} \\
\hline & Hasta 20 UIT & $8 \mathrm{UIT}$ & \\
\hline \multirow{4}{*}{$\begin{array}{c}\text { CONSTRUCCIÓN } \\
\text { EN SITIO } \\
\text { PROPIO (CSP) }\end{array}$} & $\mathrm{S} / . \mathbf{2 0 , 3 3 5}-\mathrm{S} / . \mathbf{3 7 , 3 5 0}$ & S/. 19,505 & \\
\hline & $\begin{array}{c}\text { Desde } 4.9 \text { UIT hasta } 9 \\
\text { UIT }\end{array}$ & 4.7 UIT & \\
\hline & $\mathrm{S} / . \mathbf{3 7 , 5 0 0}-\mathrm{S} / . \mathbf{8 3 , 0 0 0}$ & S/. 14,525 & \\
\hline & Desde 9 UIT hasta 20 UIT & $3.5 \mathrm{UIT}$ & \\
\hline \multirow{2}{*}{$\begin{array}{c}\text { MEJORAMIENTO } \\
\text { DE VIVIENDA } \\
\text { (MV) } \\
\end{array}$} & S/. 10,375 & $\mathrm{S} / .9,545$ & \\
\hline & Valor de la Obra 2.5 UIT & 2.3 UIT & \\
\hline
\end{tabular}

Fuente: (El Peruano, 2017)

Para el trabajo de investigación se ejecutará la modalidad de Adquisición de Vivienda Nueva, por lo que el BFH será de S/. 33,200.00.

El Gobierno proyecta otorgar, el año 2018: 27,500 bonos familiares habitacionales para la modalidad de adquisición de vivienda nueva, de los cuales tan sólo el $15 \%$ está destinado a proyectos desarrollados en la zona centro y sur del Perú esto significa el 136’950,000.00 soles. (Diario Gestión, 2018)

\subsection{Entorno demográfico, geográfico y económico}

\subsubsection{Entorno demográfico}

En el Perú, la población rural, según los datos estadísticos del INEI, se ha ido reduciendo; en el año 1940 se calculó un $64.60 \%$ de la población, el cual se redujo al año 2007 a un $24.0 \%$, estas cifras no representan la realidad ya que el INEI considera como zona urbana a aquellos sectores que cuenten con al menos 100 viviendas.

En la siguiente tabla se muestra la población de los departamentos de Apurímac, Arequipa, Ayacucho, Cusco, Moquegua, Puno y Tacna según el sexo y área urbana o rural. 
Gráfico 2: Población de la sierra sur del Perú.

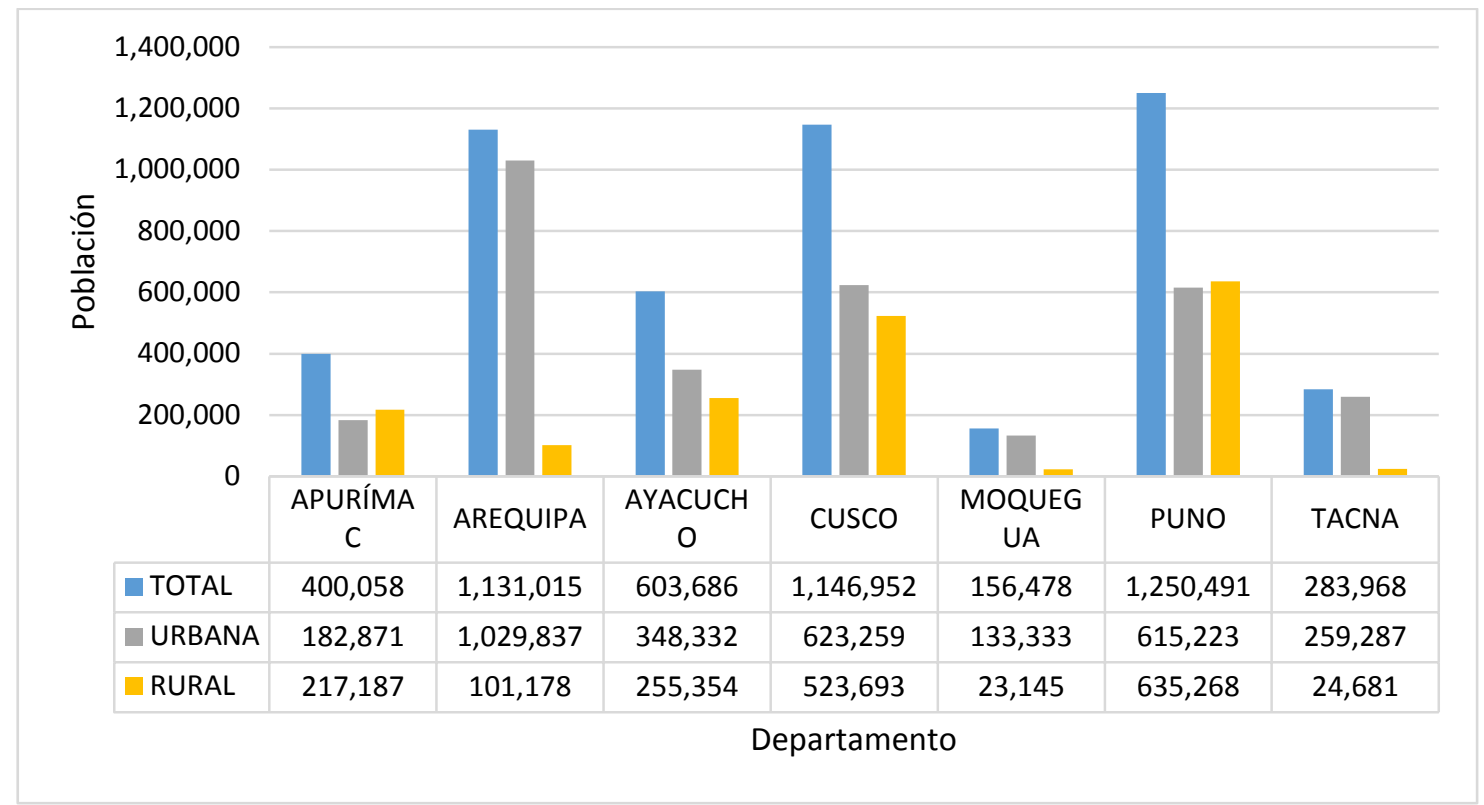

Fuente: (INEI, 2007)

Según el gráfico $\mathrm{N}^{\circ} 02$, la población en la sierra sur del Perú es de 5'059,140 habitantes de los cuales el $64.44 \%$ pertenece a la zona urbana y el $35.56 \%$ a la zona rural. Además, se observa que los departamentos de Arequipa, Cusco y Puno son los más poblados de la sierra sur, con el $22.78 \%, 23.15 \%$ y $25.07 \%$ respectivamente; y el menos poblado es el departamento de Moquegua con tan solo el 3.19\%.

Asimismo, de la población total de la sierra sur, el $98.29 \%$ cuentan con viviendas particulares entre ellas casa independiente, departamento en edificio, vivienda en quinta, vivienda en casa de vecindad, choza o cabaña, vivienda improvisada, local no destinado para habitantes, entre otros. El resto de la población, 86,492 habitantes, no cuentan con una vivienda particular.

Tabla 2: Población total que cuentan con vivienda de la sierra sur del Perú.

\begin{tabular}{c|ccc} 
DEPARTAMENTO & TOTAL & URBANA & RURAL \\
\hline APURÍMAC & 400,058 & 182,871 & 217,187 \\
AREQUIPA & $1,131,015$ & $1,029,837$ & 101,178 \\
AYACUCHO & 603,686 & 348,332 & 255,354 \\
CUSCO & $1,146,952$ & 623,259 & 523,693 \\
MOQUEGUA & 156,478 & 133,333 & 23,145 \\
PUNO & $1,250,491$ & 615,223 & 635,268 \\
TACNA & 283,968 & 259,287 & 24,681
\end{tabular}

Fuente: (INEI, 2007)

Según la tabla $\mathrm{N}^{\circ} 02$, de la población total que cuentan con vivienda particular, el $64.19 \%$ pertenece a la zona urbana y el $35.81 \%$ pertenece a la zona rural; asimismo, 18,275 habitantes de la zona rural no cuentan con vivienda particular. 
Con respecto al crecimiento poblacional anual, se ha determinado que, a nivel nacional hubo un descenso; entre los años 1995 al 2000, la tasa de crecimiento anual fue de 1.7\% y para el periodo del 2010 al 2015 redujo al 1.3\%, siendo los departamentos de la sierra, los que tuvieron menor tasa, principalmente los departamentos de Ancash, Ayacucho, y Pasco. En cuanto a la sierra sur se notó un incremento en el departamento de Ayacucho, y una notable reducción en los departamentos de Arequipa, Cusco, Moquegua, Puno y Tacna; como se muestra en la siguiente tabla.

Tabla 3: Tasa de crecimiento medio anual de la sierra sur del Perú.

TASA DE CRECIMIENTO MEDIO

\begin{tabular}{c|cccc}
\multirow{2}{*}{ DEPARTAMENTO } & \multicolumn{4}{c}{ ANUAL } \\
\cline { 2 - 5 } & $\mathbf{1 9 9 5}-$ & $\mathbf{2 0 0 0}-$ & $\mathbf{2 0 0 5}-$ & $\mathbf{2 0 1 0}-$ \\
APURÍMAC & $\mathbf{2 0 0 0}$ & $\mathbf{2 0 0 5}$ & $\mathbf{2 0 1 0}$ & $\mathbf{2 0 1 5}$ \\
AREQUIPA & $0.90 \%$ & $1.00 \%$ & $1.00 \%$ & $1.00 \%$ \\
AYACUCHO & $1.80 \%$ & $1.70 \%$ & $1.50 \%$ & $1.30 \%$ \\
CUSCO & $0.10 \%$ & $0.30 \%$ & $0.40 \%$ & $0.40 \%$ \\
MOQUEGUA & $1.20 \%$ & $1.20 \%$ & $1.10 \%$ & $1.00 \%$ \\
PUNO & $1.70 \%$ & $1.60 \%$ & $1.40 \%$ & $1.30 \%$ \\
TACNA & $1.20 \%$ & $1.20 \%$ & $1.10 \%$ & $1.00 \%$ \\
& $3.00 \%$ & $2.70 \%$ & $2.40 \%$ & $2.10 \%$ \\
& Fuente: (INEI, 2007$)$ & & \\
\hline
\end{tabular}

El departamento de Ayacucho, como se muestra en la tabla 3, tiene una tasa baja de crecimiento poblacional debido, principalmente, a las altas migraciones causados por sucesos de violencia política y social. Es por ello que es importante incentivar programas de apoyo para estos sectores logrando reestablecer la equidad poblacional a lo largo de todo el territorio peruano y mitigando la centralización en las capitales, principalmente en Lima.

\subsubsection{Entorno geográfico.}

La sierra del Perú es la región más montañosa, la Cordillera de los Andes se extiende por todo su territorio, se divide en 3 ecorregiones en sus diferentes niveles de altitud, los Andes del norte son más bajos y húmedos, los Andes del centro son los más altos y empinados, los Andes del sur son de mayor espesor, a este se le conoce como el Altiplano.

La sierra sur del Perú cuenta con un relieve complejo y variado debido a los accidentes morfológicos como las altas montañas, grandes mesetas, estrechas quebradas, profundos valles, entre otros; esta área territorial se ubica por encima de los 2,000 m.s.n.m. El clima se caracteriza por ser frío, con aire muy seco y tiene tan solo 2 estaciones, una lluviosa y una seca. 
Fotografia 3: Paisaje típico de la sierra sur del Perú.

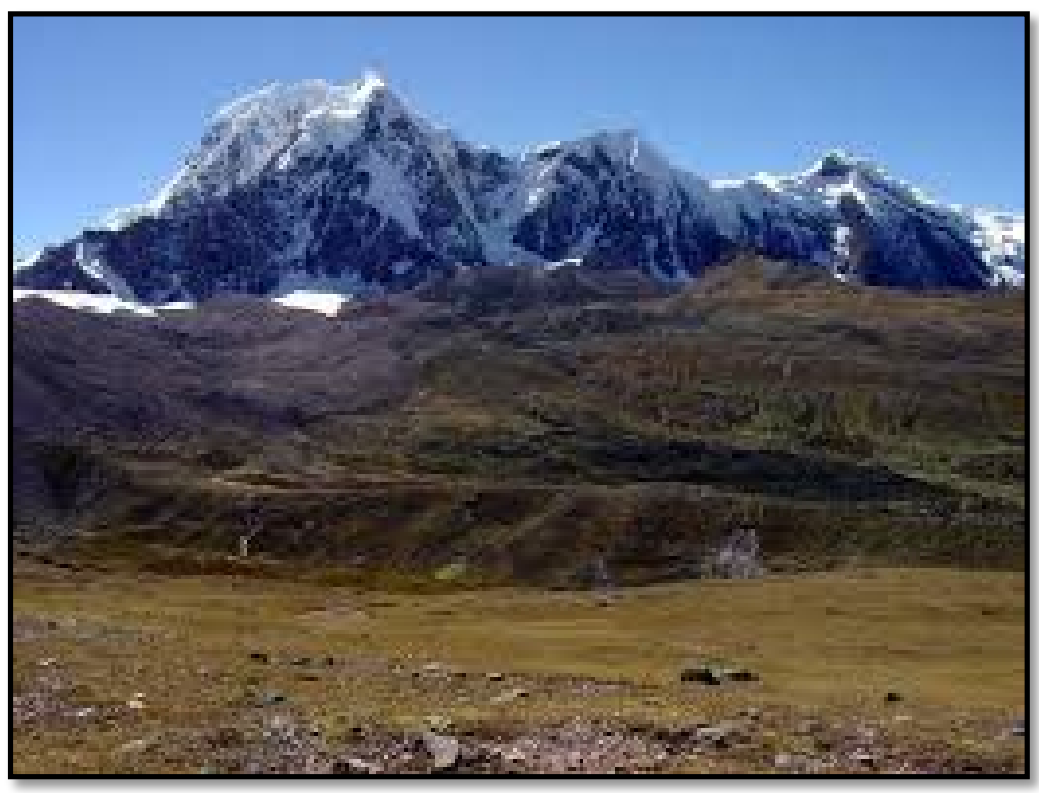

Fuente: (Glogster, 2018)

En la fotografía 3 se observa las características típicas de los paisajes serranos del Perú. Se observa montañas, nevados, ciertas planicies; el suelo se ve rocoso; entre otras características.

\subsubsection{Entorno económico.}

El crecimiento económico del Perú en las últimas décadas y las políticas sociales han permitido que se reduzca los niveles de pobreza, principalmente en el sector urbano, lo cual permitió el desarrollo para diferentes mercados; sin embargo, no sucedió lo mismo en el sector rural, donde los niveles de pobreza redujeron lentamente por falta de la distribución equitativa de los recursos del Estado. Los departamentos con más alto nivel de pobreza son Apurímac, Puno y Cusco.

La actividad económica en la sierra sur del Perú ha mostrado un crecimiento positivo en los últimos años, siendo los departamentos de Arequipa, Cusco y Puno los que generaron mayor PBI en las actividades de agricultura, caza y silvicultura. A continuación, se muestra el crecimiento del PBI en los departamentos del sur del Perú. 
Tabla 4: Crecimiento del PBI por sectores al interior de cada departamento: 2004 - 2008 (promedio anual).

\begin{tabular}{|c|c|c|c|c|c|c|}
\hline Sectores & Apurímac & Arequipa & Cusco & Moquegua & Puno & Tacna \\
\hline $\begin{array}{c}\text { Agricultura, caza y } \\
\text { silvicultura }\end{array}$ & $15.90 \%$ & $16.80 \%$ & $9.74 \%$ & $5.08 \%$ & $19.88 \%$ & $7.85 \%$ \\
\hline Pesca & $0.03 \%$ & $0.71 \%$ & $0.09 \%$ & $2.10 \%$ & $0.33 \%$ & $0.48 \%$ \\
\hline Minería & $4.43 \%$ & $8.46 \%$ & $43.59 \%$ & $25.37 \%$ & $9.14 \%$ & $21.03 \%$ \\
\hline Manufactura & $7.02 \%$ & $24.14 \%$ & $5.15 \%$ & $30.23 \%$ & $13.60 \%$ & $8.98 \%$ \\
\hline Electricidad y agua & $0.64 \%$ & $2.09 \%$ & $0.60 \%$ & $8.37 \%$ & $2.33 \%$ & $0.98 \%$ \\
\hline Construcción & $5.45 \%$ & $9.17 \%$ & $3.37 \%$ & $10.71 \%$ & $5.67 \%$ & $7.71 \%$ \\
\hline Comercio & $37.56 \%$ & $1.21 \%$ & $10.29 \%$ & $4.92 \%$ & $14.44 \%$ & $15.14 \%$ \\
\hline Restaurante y hoteles & $2.96 \%$ & $3.24 \%$ & $5.22 \%$ & $1.03 \%$ & $3.04 \%$ & $3.75 \%$ \\
\hline $\begin{array}{c}\text { Transportes y } \\
\text { Comunicaciones }\end{array}$ & $2.38 \%$ & $9.74 \%$ & $7.08 \%$ & $3.00 \%$ & $11.94 \%$ & $13.69 \%$ \\
\hline $\begin{array}{c}\text { Servicios } \\
\text { Gubernamentales }\end{array}$ & $15.89 \%$ & $4.90 \%$ & $0.00 \%$ & $0.00 \%$ & $0.00 \%$ & $0.00 \%$ \\
\hline Otros servicios & $7.74 \%$ & $19.54 \%$ & $14.87 \%$ & $9.19 \%$ & $19.63 \%$ & $20.39 \%$ \\
\hline & $\mathbf{1 0 0 . 0 0 \%}$ & $\mathbf{1 0 0 . 0 0 \%}$ & $\mathbf{1 0 0 . 0 0 \%}$ & $\mathbf{1 0 0 . 0 0 \%}$ & $\mathbf{1 0 0 . 0 0 \%}$ & $\mathbf{1 0 0 . 0 0 \%}$ \\
\hline
\end{tabular}

Fuente: (INEI, 2007)

Según la tabla 4, en el departamento de Apurímac el sector que aporta más al PBI es el comercio, en Arequipa y Moquegua es la manufactura, en Cusco, en Tacna es la minería, en Puno la agricultura, caza y silvicultura. La contribución del sector pesquero de los departamentos mencionados es muy baja, en la mayoría es menor al 1\%, a excepción de Moquegua que registra el $2.10 \%$.

Con respecto a la condición de empleo, el sector sur del Perú cuenta con una tasa de desempleo por debajo del 6\%; sin embargo, la tasa de subempleo es elevada en Moquegua y Puno. En la siguiente tabla se muestra el porcentaje de desempleados, subempleados y adecuadamente empleados para cada departamento.

Gráfico 3: Promedio anual población económicamente activa 2004 - 2008.

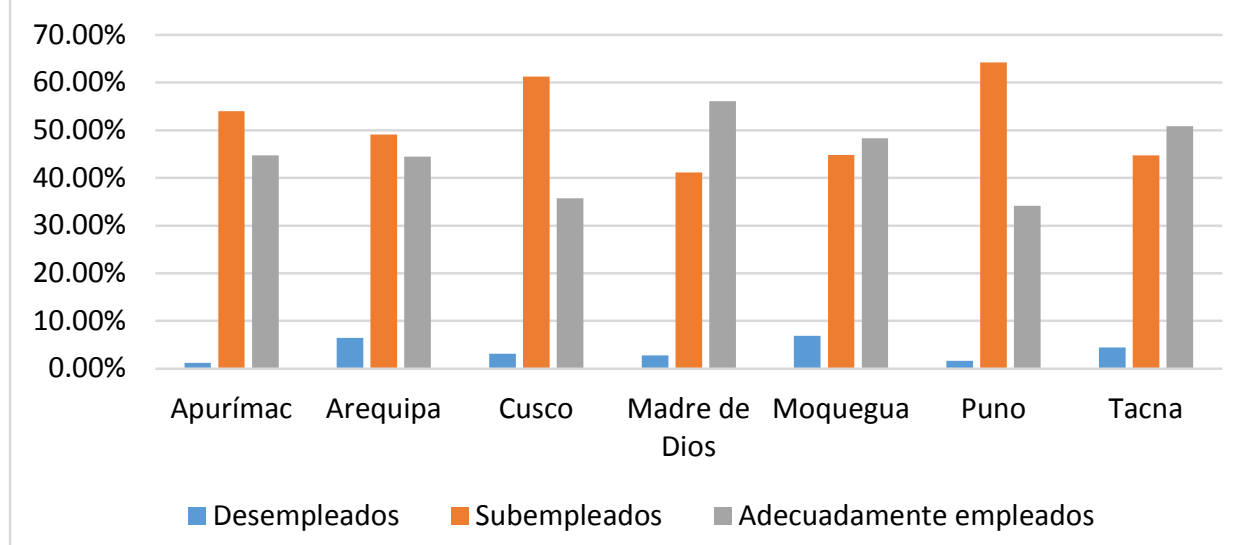

Fuente: (INEI, 2007) 
Se considera como adecuadamente empleados a aquellos que voluntariamente trabajan un número de horas menor a la de un jornal normal. La condición laboral es muy variable, existe una correlación positiva entre la tasa de subempleo promedio y la tasa de pobreza; los departamentos más pobres tienen altas tasas de subempleo, mientras que Arequipa, Madre de Dios, Moquegua y Tacna, como se muestra en el gráfico 3, tienen bajas tasas de pobreza y desempleo; estos resultados indican que los hogares dedicados a la agricultura tienen elevadas tasas de desempleo y pobreza. Por otro lado, el departamento de Apurímac y Puno tienen el menor porcentaje de desempleo y mayor porcentaje de subempleo. Por lo tanto, los mejores departamentos para desarrollar proyectos de vivienda social, con respecto a la capacidad de pago de los beneficiarios, son Tacna, Cusco y Puno.

\subsection{Entorno del sector construcción e inmobiliario en proyectos de vivienda social.}

Actualmente, existen 7 proyectos de viviendas sociales con el programa Techo Propio ejecutándose en la sierra sur del Perú. A continuación, se muestra un mapa y resumen de dichos proyectos.

Imagen 2: Proyectos de vivienda social a nivel de todo el país.

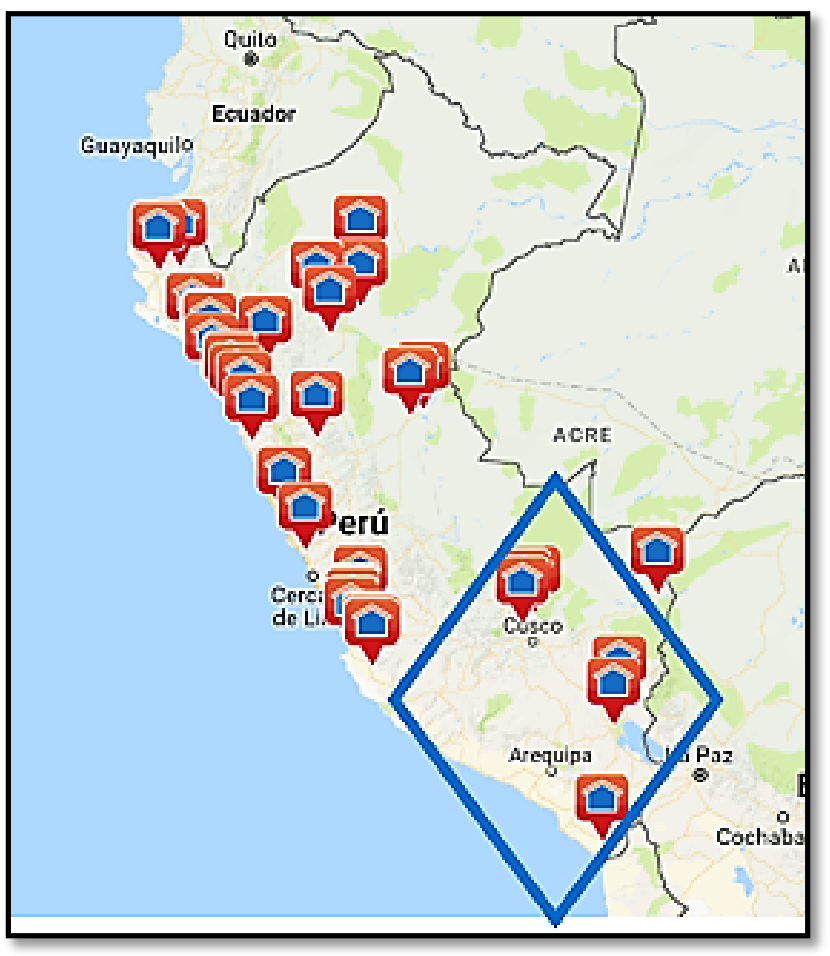

Fuente: (Fondo MiVivienda, 2017)

En la imagen 2 se muestra todos los proyectos desarrollados en el Perú para el programa Techo Propio, se puede observar que la mayoría de los proyectos se desarrolla en la costa norte, siendo los principales departamentos Piura y La Libertad. En el rombo azul se observan los proyectos desarrollados en la sierra sur, los cuales se describen en la siguiente tabla. 
Tabla 5: Características de los proyectos de Techo Propio en la sierra sur del Perú.

\begin{tabular}{|c|c|c|c|c|}
\hline No & $\begin{array}{c}\text { Nombre de } \\
\text { Proyecto }\end{array}$ & Ubicación & $\begin{array}{c}\text { No de } \\
\text { viviendas }\end{array}$ & $\begin{array}{c}\text { \% de } \\
\text { Avance a } \\
\text { Enero 2018 }\end{array}$ \\
\hline $\mathbf{1}$ & Inkaq Samanan & $\begin{array}{c}\text { C.C. Yanamayo, Urubamba - } \\
\text { Cusco }\end{array}$ & 110 & $85 \%$ \\
\hline $\mathbf{2}$ & Tirikway & $\begin{array}{c}\text { C.C. Qelqanqa, Urubamba - } \\
\text { Cusco }\end{array}$ & 180 & $28 \%$ \\
\hline $\mathbf{3}$ & $\begin{array}{c}\text { Residencial Torres } \\
\text { de Anta }\end{array}$ & $\begin{array}{c}\text { Valle Cachimayo, Anta - } \\
\text { Cusco }\end{array}$ & 540 & $0 \%$ \\
\hline $\mathbf{4}$ & $\begin{array}{c}\text { Residencial } \\
\text { Collasuyo I Etapa }\end{array}$ & $\begin{array}{c}\text { Urb. Residencial Collasuyo, } \\
\text { San Román - Puno }\end{array}$ & 261 & $73 \%$ \\
\hline $\mathbf{5}$ & $\begin{array}{c}\text { Residencial Villa } \\
\text { Médica I Etapa }\end{array}$ & $\begin{array}{c}\text { Parcialidad Esquén, San } \\
\text { Román - Puno }\end{array}$ & 609 & $98 \%$ \\
\hline $\mathbf{6}$ & $\begin{array}{c}\text { Condominio San } \\
\text { Jacinto I Etapa }\end{array}$ & $\begin{array}{c}\text { Sector Corape, Tacna - } \\
\text { Tacna }\end{array}$ & 121 & $80 \%$ \\
\hline $\mathbf{7}$ & $\begin{array}{c}\text { Condominio San } \\
\text { Jacinto I Etapa }\end{array}$ & $\begin{array}{c}\text { Sector Corape, Tacna - } \\
\text { Tacna }\end{array}$ & 121 & $80 \%$ \\
\hline
\end{tabular}

Fuente: (Fondo MiVivienda., 2018)

El déficit habitacional en la zona rural es del 653,082 viviendas (35.10\% del total a nivel nacional); en la actualidad, tan solo 2 de los proyectos mencionados, según la tabla 5 , están ubicados en la zona rural, siendo la oferta de 290 viviendas que equivale al $0.04 \%$, es decir, la demanda de vivienda en la zona rural es mucho más alta a la oferta; por lo que se plantea, con este trabajo de investigación, incentivar a las empresas privadas a invertir en proyectos de vivienda social en zonas rurales y de este modo reducir el déficit de vivienda. 


\section{CAPÍTULO 3: MARCO TEÓRICO}

3.1 Enfoques y metodologías actuales de la construcción.

\subsubsection{BIM en el Perú}

La metodología BIM en el Perú en el sector construcción se viene implementando de manera progresiva, el cambio de la forma tradicional de trabajar con herramientas $2 \mathrm{D}$ de dibujo y la gestión tradicional resolviendo problemas de incompatibilidades y deficiencias del proyecto durante la etapa de ejecución generaba pérdidas de tiempo y dinero, ahora con el enfoque $B I M$ estos problemas pueden controlarse, minimizarse o evitarse por completo.

Se tiene experiencias positivas de la aplicación de $B I M$ en algunos proyectos de edificaciones en el Perú, podemos mencionar uno de los más importantes:

Edificio del Banco de la Nación: En el proyecto del banco de la nación se utilizó el BIM para la definición del diseño y la ejecución del proyecto, en la definición de diseño se utilizó la metodología para realizar un seguimiento semanal a los proyectistas involucrados. A través de una cuenta en el programa AUTODESK BIM 360 GLUE.

\subsubsection{LEAN en la construcción del Perú}

En el Perú el 2011 se forma el Capitulo Peruano de LEAN CONSTRUCTION (CPLC), desde su inicio esta organización tiene como objetivo la implementación de conceptos $L E A N$ en la industria de la construcción, buscando el incremento de la productividad, para lograr dicha meta difunde el conocimiento a través de capacitaciones, congresos e investigaciones que involucra a profesionales del rubro de la construcción.

La construcción en nuestro país no tuvo cambios significativos con la globalización y la transformación de la tecnología, aun se podría considerar que es artesanal, con mínima renovación de materiales empleados, poca capacitación de los actores y por otro lado es una de las industrias que dinamiza la economía del país generando sinergia en las otras industrias.

Aplicando los nuevos enfoques y metodologías buscamos hacer a un lado la construcción artesanal y pensar en producir en serie, para ello es importante entender que debemos cambiar de mentalidad y ver los procesos de manera diferente y no hacer las mismas cosas esperando resultados diferentes.

El LEAN busca eliminar los desperdicios y reducir pérdidas en el proceso y agregar valor al producto.

El principal objetivo del $L E A N$ en la construcción es lograr incrementar la productividad simplificando procesos innecesarios, optimizando tiempos en la ejecución de un proceso, así mismo incrementar el trabajo productivo (TP) reduciendo los trabajos contributorios (TC), trabajos no contributorios (TNC), además de ello minimizando las perdidas por el acarreo, esperas y reprocesos. 
El LEAN CONSTRUCTION según (Ohno, 1995) considera siete tipos de pérdidas:

- Sobreproducción

- Defectos

- Esperas

- Reparaciones

- Transporte

- Exceso de inventario

- Movimientos superfluos

Los procesos anteriormente a la filosofía $L E A N$ se consideraban: Entrada, transformación y salida; bajo esta forma de ver el proceso no se percibía claramente donde existían fallas o deficiencias que causaban la demora y el problema con el producto.

Los procesos basados en los enfoques LEAN CONSTRUCTION consideran que existen varios componentes luego de la entrada antes de la salida, se visualiza como un flujo que considera todos los trabajos necesarios (TP, TC, TNC), de esta forma podemos analizar si nuestro proceso es eficiente o si se podría mejorar.

Los aspectos más importantes para la implementación de la metodología $L E A N$ en la construcción es conocer los principios fundamentales de esta filosofía y orientarlas a la solución de los problemas que se tiene actualmente en la construcción, debemos conocer todo el proceso y analizar cuales afectan a nuestra gestión.

Los principios bajo los cuales se enfoca la filosofía LEAN CONSTRUCTION son:

- Reducción de elementos que no suman valor.

- Aumentar el valor de los productos según las necesidades del cliente.

- Reducir la variabilidad

- Reducir tiempos de ciclos.

- Simplificar el número de pasos

- Incrementar la flexibilidad de salida.

- Incrementar el proceso de transparencia.

- Enfocarse en el control del proceso completo

- Mejoramiento continuo del proceso.

- Mantener un equilibrio entre las mejorías de flujo y de conversiones.

- Benchmark.

\subsection{Problemática actual en proyectos de vivienda social}

En los proyectos que se vienen ejecutando actualmente, se ha identificado diversos problemas debido, principalmente, a no utilizar los enfoques BIM - LEAN CONSTRUCTION en el ciclo del proyecto. A continuación se muestra los porcentajes de ocurrencias de los problemas identificados en los proyectos de viviendas sociales. 
Gráfico 4: Problemas ocurridos en proyectos de vivienda social.

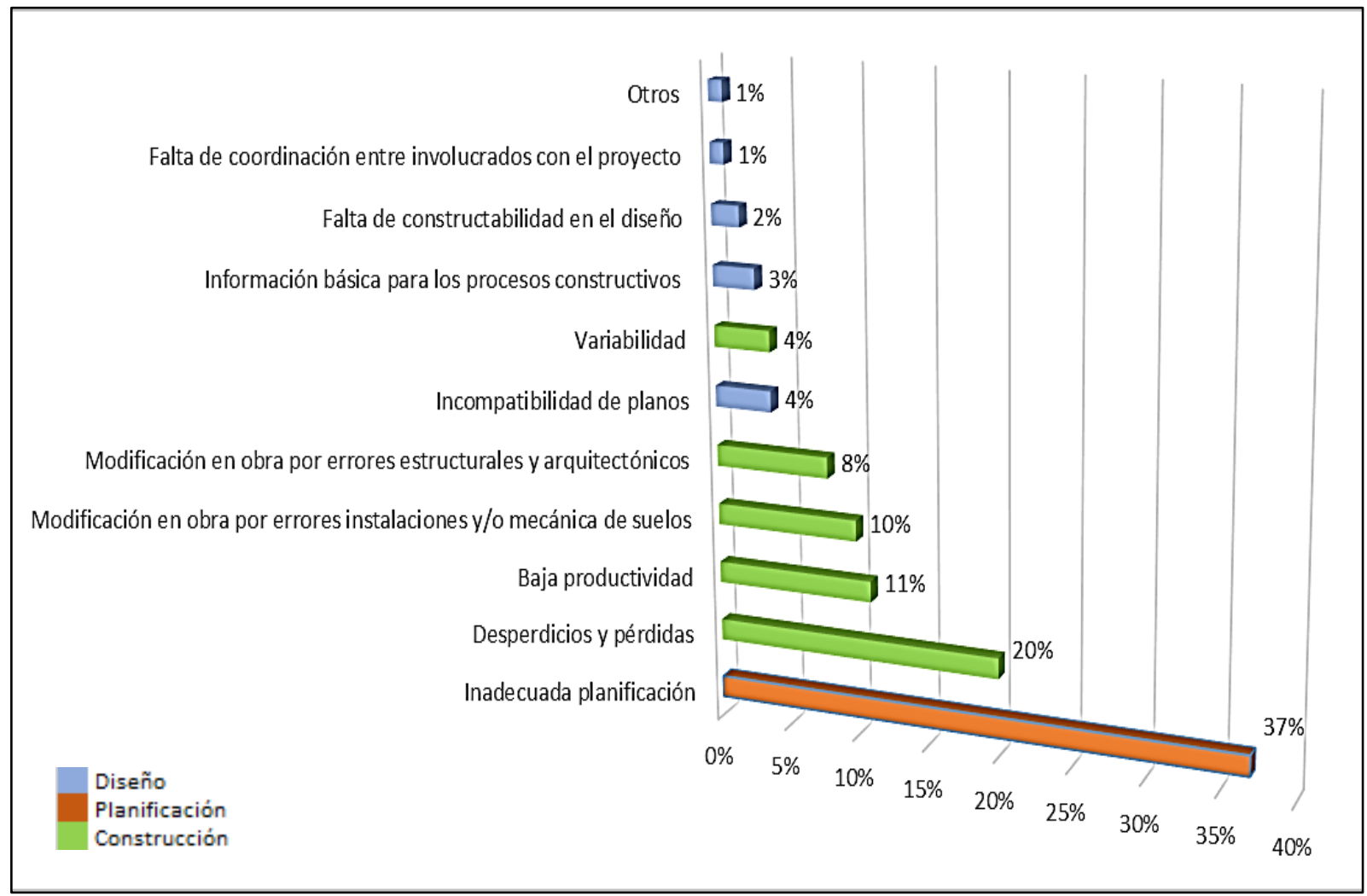

Fuente: Elaboración Propia en base a los proyectos "INKAQ SAMANAN" y "TIRIKWAY".

La mayor cantidad de problemas ocurren debido a una inadecuada planificación inicial, la cual no representa la realidad al momento de la ejecución del proyecto. Es por ello que se desarrollará los enfoques BIM para una planificación más clara y certera.

Para desarrollar de mejor manera la propuesta planteada de mejoramiento de la rentabilidad en viviendas sociales se divide el proyecto en cuatro etapas, en las cuales se describe la utilización de los enfoques BIM y LEAN CONSTRUCTION, según sea necesario. A continuación, se muestra el ciclo del proyecto con los enfoques señalados. 


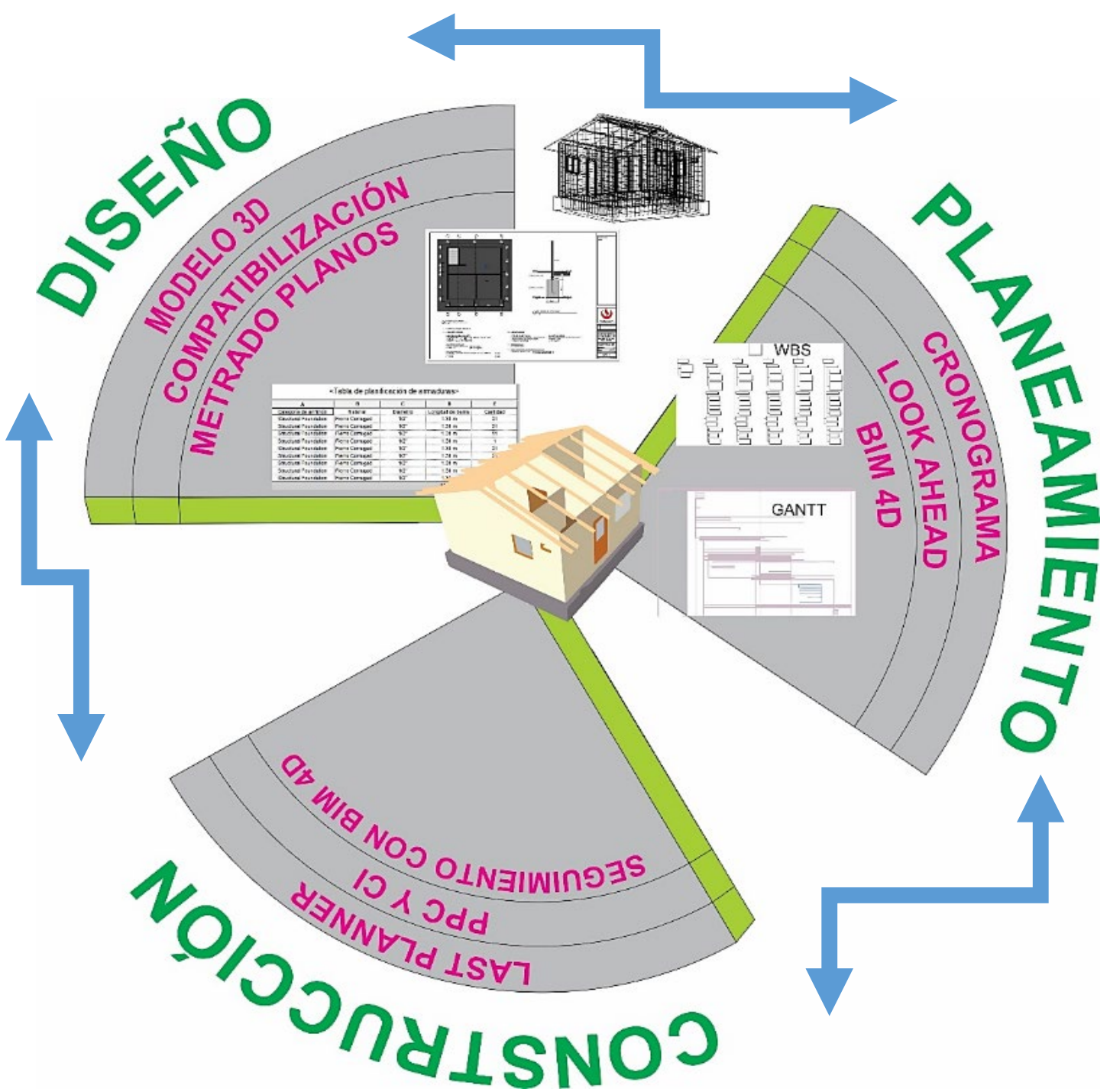

Fuente: Elaboración Propia.

Como se muestra en el gráfico 5, el ciclo del proyecto consta de tres etapas importantes: Diseño, Planeamiento y Construcción. En la primera etapa se realiza el diseño de las especialidades en un modelo $3 \mathrm{D}$ con las herramientas $B I M$, en la cual se muestra lo planteado en el alcance según el requerimiento de los clientes buscando tener un diseño optimizado, agregando valor al producto y eliminando desperdicios; luego se realiza la compatibilización de las especialidades para identificar y eliminar interferencias; una vez obtenido el modelamiento definitivo en 3D se continúa con la obtención de las planillas de metrados para la elaboración del cronograma.

En la segunda etapa que se muestra en el gráfico 5 referente al planeamiento, inicia con la información obtenida del modelo 3D para realizar el cronograma general de obra, en el cual se muestra los plazos de entrega e inicios de actividades a nivel general; a continuación, se desarrolla el LOOK AHEAD para determinar los tiempos necesarios para adquirir la información que elimine las incertidumbres del proyecto, identificar y controlar 
las restricciones, asimismo, esta herramienta de gestión muestra con más detalle la ejecución de las actividades, como las cantidades exactas de metrado, recursos necesarios, esto se realiza con enfoques de la filosofía LEAN CONSTRUCTION. Para lograr los mayores beneficios en la etapa de planeamiento, en base al modelo 3D se realiza el modelo $B I M 4 D$, que contiene la información necesaria del proyecto y la programación; la relación que existe del modelo $B I M 4 D$ con el $L O O K A H E A D$ es la obtención de la secuencia constructiva más eficiente.

La tercera etapa que se muestra en el grafico 5 se enfoca principalmente el seguimiento y control de la ejecución de lo planeado, con ayuda de las herramientas BIM y las herramientas de gestión LEAN CONSTRUCTION.

\subsection{LEAN PROJECT DELIVERY SYSTEM (LPDS)}

Según (Ballard, 2008), el LEAN PROJECT DELIVERY SYSTEM (LPDS) o Sistema de Entrega de Proyectos Sin Perdidas, surgió en 2000 a partir de investigaciones teóricas y prácticas y está en proceso de desarrollo a través de la experimentación en muchas partes del mundo. En los últimos años, los experimentos se han centrado en la definición y fase de diseño de los proyectos, aplicando los conceptos y métodos derivados del sistema de desarrollo de producción de la Toyota, sobre todo costeo objetivo y conjunto basado en el diseño.

La misión del LEAN CONSTRUCTION INSTITUTE es desarrollar una nueva y mejor manera de diseñar y construir instalaciones que la llamamos el Sistema de Entrega de Proyectos sin perdidas (LPDS). El actual modelo consta de 13 módulos, organizados en 5 triadas o fases que se extienden desde la definición del proyecto de interconexión, diseño de 2 módulos de control de producción, suministro y montaje, además de la estructuración y el trabajo modulo, tanto concebido para extenderse a través de todas las fases del proyecto y la evaluación posterior a la ocupación modulo, que une el extremo de un proyecto para el comienzo del siguiente. 
Imagen 3: LEAN PROJECT DELIVERY SYSTEM

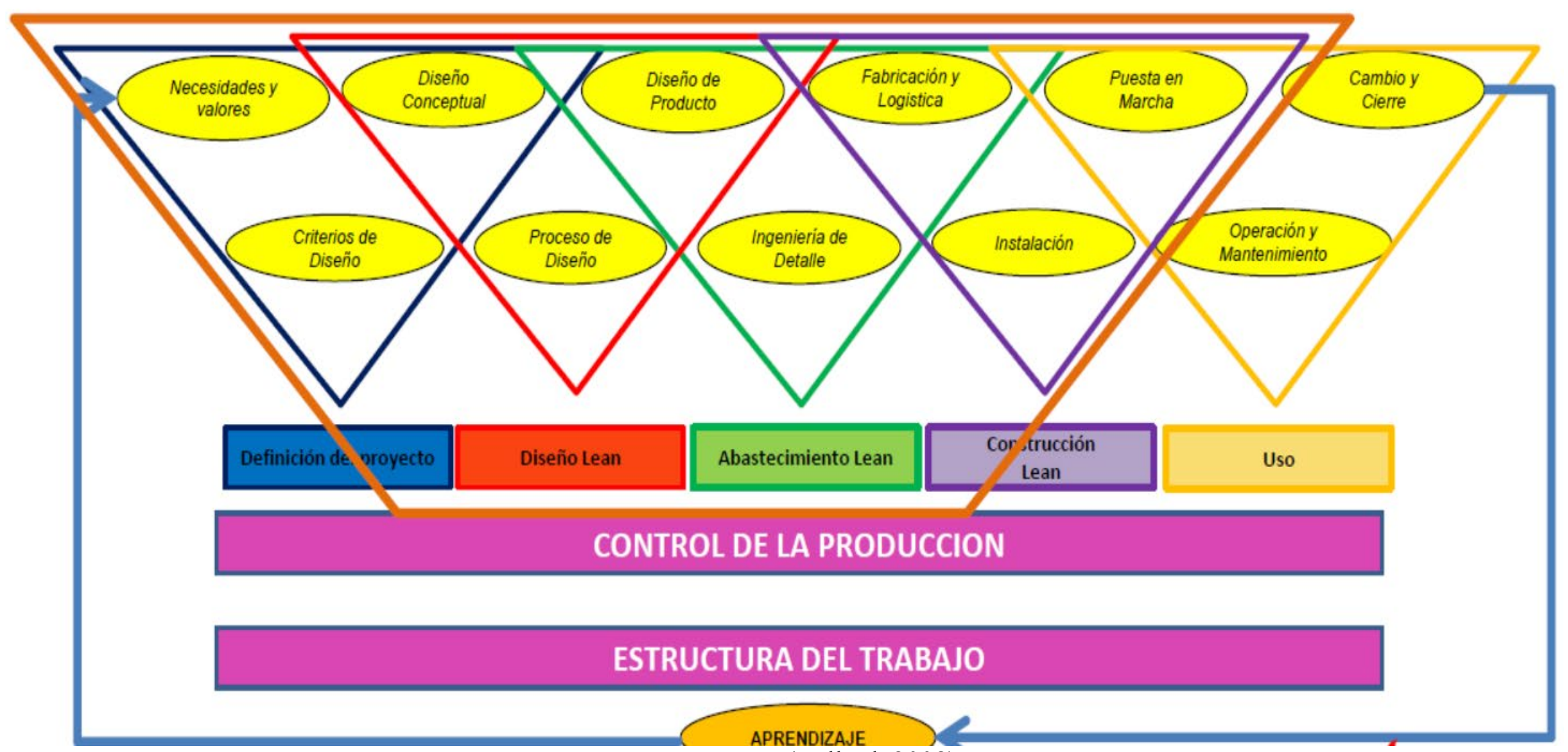

Fuente (Ballard, 2008)

Según la imagen 3 el LPDS toma lo mejor del LEAN CONSTRUCTION y el IPD (INTEGRATED PROJECT DELIVERY), alineando personas, procesos y herramientas con la finalidad de aprovechar las optimizaciones de los participantes generando utilidades al cliente a través de todas las etapas de construcción. 


\subsubsection{Definición del proyecto}

Así mismo, (Ballard, 2008), indica que la definición del proyecto es administrado por el director del proyecto responsable ante el cliente para todo el proyecto, incluyendo tanto el diseño y la construcción.

Se producirán criterios de diseño de productos y procesos.

Múltiples diseños conceptuales serán generados y evaluados. Cuando sea apropiado, más de uno va a ser llevada a la fase de diseño de Lean.

Imagen 4: Definición del Proyecto-LPDS

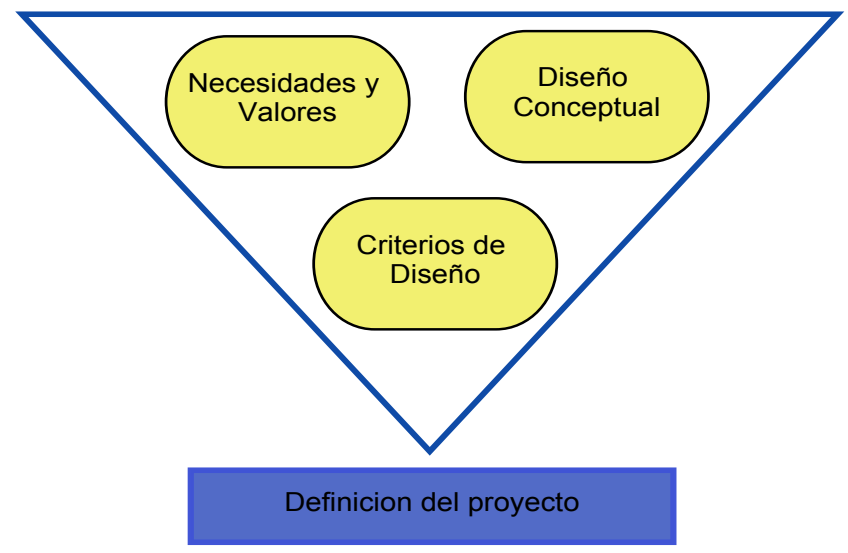

Fuente (Ballard, 2008)

En la imagen 4 se analiza las necesidades de los clientes como se describe en el párrafo alcances del proyecto.

- Necesidades y valores

Una necesidad es el estado de privacidad que siente un individuo, los valores son los atributos o particularidades que el cliente percibe del producto entregado y por el cual está dispuesto pagar para satisfacer su necesidad.

\section{- Criterios de diseño}

Son las consideraciones que debe percibir el proyectista para conceptualizar el producto orientado a satisfacer la necesidad del cliente, con el valor que está dispuesto pagar.

Estos criterios estarán acordes con las reglamentaciones y normativas específicas.

\section{- Diseño conceptual}

Es el resultado de la iteración entre la satisfacción de las necesidades del cliente interno (mandante) y el cliente externo y la diversidad de criterios de diseño.

\subsubsection{Diseño $L E A N$}

Los productos, procesos y decisiones de diseño se hacen con vistas a las necesidades del cliente, así como los criterios de diseño. En caso de que surja una oportunidad para incrementar el valor del cliente mediante la ampliación de las necesidades del cliente (y si hay suficiente tiempo y dinero), el proceso de definición del proyecto será re comprometido para alinear las necesidades, criterios y conceptos de diseño. 
Las decisiones de diseño de productos y los procesos se realizan de forma simultánea en lugar de producir un diseño satisfactorio para el proceso de diseño y fabricación de ese producto.

En esta etapa al igual que el primero los tres elementos interactúan ente sí; partimos del diseño conceptual planteado durante la definición del proyecto con la finalidad de obtener el diseño del producto, teniendo siempre en cuenta las necesidades del cliente y optimizando los recursos, según (Ballard, 2008).

Imagen 5: Diseño LEAN-LPDS

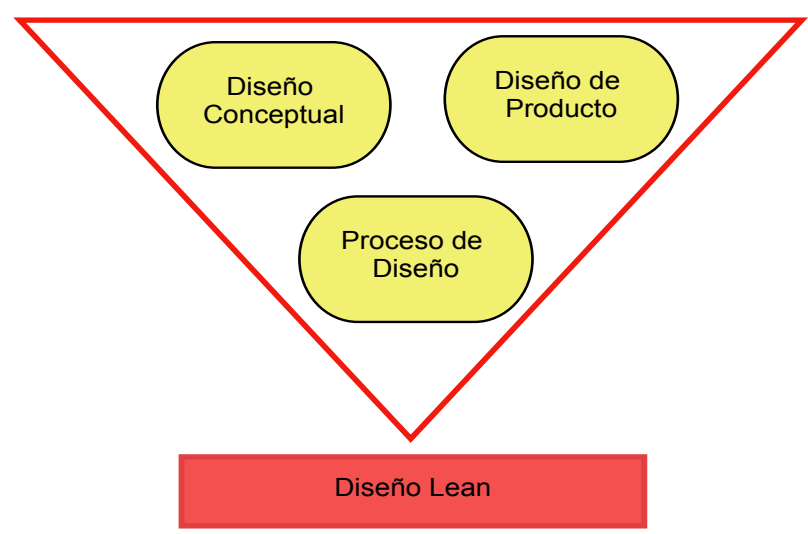

Fuente (Ballard, 2008)

En la imagen 5 se utiliza las herramientas del último planificador y $L O O K A H E A D$, así también como las herramientas informáticas como los diseños 3D para mejor visualización y agilizar la información.

\section{- Proceso de diseño}

Comprende la elaboración del producto acorde a las necesidades del cliente.

Todos los involucrados en este proceso deben tener claro el alcance del producto a fin de que este sea de entera satisfacción, por lo que se deben iterar diversas propuestas de diseño multidisciplinarias hasta lograr el balance deseado.

\section{- Diseño del producto}

Es el desarrollo de la mejor propuesta de ingeniería que ha sido iterada, compartida y consensuada con los involucrados.

\subsubsection{Abastecimiento $L E A N$}

Consiste en la ingeniería de detalle del diseño del producto producido en diseño $L E A N$, a continuación, la fabricación o compra de componentes y materiales, y la gestión de la logística de las entregas e inventarios.

Modelado en 3D se utiliza para la ingeniería de detalle.

Siempre que sea posible, la fabricación será conducido directamente del modelo 3D, según (Ballard, 2008). 
Imagen 6: Abastecimiento LEAN-LPDS

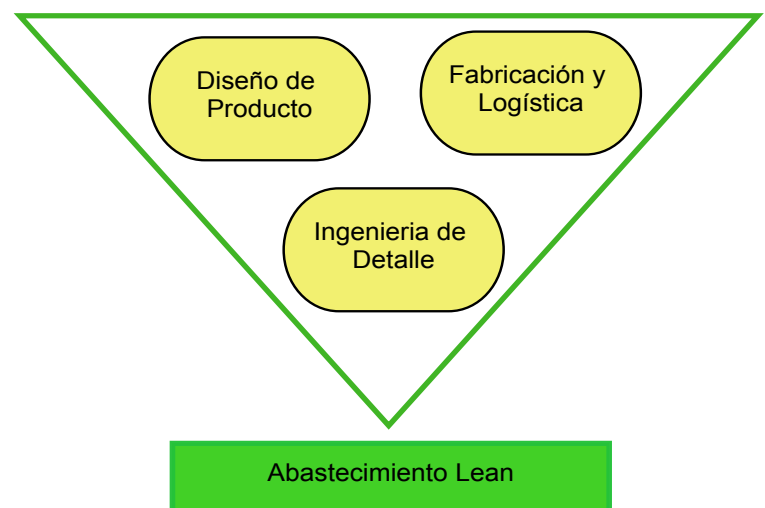

Fuente (Ballard, 2008)

Según la imagen 6 la etapa consiste en la ingeniería de detalle del diseño $L E A N$, disponiendo un flujo de trabajo óptimo para mejorar la productividad.

\section{- Ingeniería de detalle}

Participación activa de los contratistas, proveedores y fabricantes aportando a mejora del producto.

Esta etapa se dinamiza con la visualización de modelos BIM y se enriquece con el aporte de los modelos de los proveedores.

\section{- Fabricación y logística}

Se establecen las mejores alternativas para el proceso constructivo con uso de 4D y la participación de constructor y proveedores estableciéndose los tiempos adecuados para el ingreso oportuno a obra de los materiales, sub contratistas y equipamiento.

\subsubsection{Construcción $L E A N$}

En esta fase se busca la prefabricación, que permita operar de una manera " $L E A N$ " mediante la reducción de muchos pasos, teniendo en cuenta que los trabajos en obra se ven afectados por condiciones de incertidumbre, como las variaciones del clima y las limitaciones de mano de obra especializada, materiales y equipos, según (Ballard, 2008).

Imagen 7: Construcción LEAN-LPDS

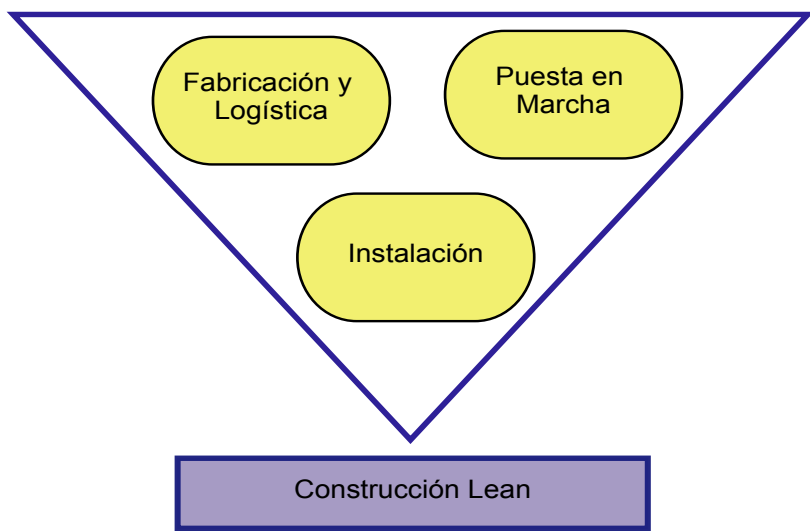

Fuente (Ballard, 2008) 
En el presente trabajo no profundizamos en esta etapa, pero tenemos en cuenta que la filosofía $L E A N$ no son pasos a seguir sino una manera de optimizar la producción de los proyectos constructivos, imagen 7.

\section{- Instalación}

En este nuevo enfoque se busca mejorar los tiempos de producción a través de la pre fabricación como por ejemplo de partes de las instalaciones que son llevadas a su posición final pre armadas. Las herramientas $B I M$ son aprovechadas para la mejora de los flujos de trabajo.

\subsection{Plan de implementación del BUILDING INFORMATION MODELING en la empresa}

Para la implementación del $B I M$ en la empresa se debe tener claro que existe un proceso secuencial y que los beneficios no se verán reflejados de forma inmediata, que será de forma gradual; por otro lado, se requiere el compromiso de la alta dirección de la empresa en buscar nuevas formas de elaborar, planificar y gestionar los proyectos apoyados de nuevas metodologías y tecnología.

Es importante tener objetivos a lograr en las diferentes etapas del proyecto a corto, mediano y largo plazo, que deben estar claramente establecidos en el plan de implementación $B I M$ de la empresa, otro factor muy importante es identificar a los profesionales que formarán parte del equipo BIM, que estén dispuestos a afrontar estos cambios y que tengan el deseo de mejorar y lograr los objetivos planteados.

Las capacitaciones son muy importantes para difundir el conocimiento de las metodologías $B I M$ y el uso de las herramientas $B I M$ entre los involucrados de los proyectos de la empresa, que permitan el trabajo más eficiente; esto se dará gradualmente debido a que muchos de los profesionales aún desconocen de las nuevas metodologías y herramientas que existen en el mercado de SOFTWARE, es por ello necesario la implementación de un área $B I M$ en la empresa, donde se cuente con los recursos necesarios para la difusión, preparación y puesta en práctica de la metodología BIM.

Para lograr grandes beneficios en la ejecución de las diferentes etapas del proyecto es muy importante trabajar bajo estándares, los cuales deben estar establecidos en el plan de implementación BIM para la empresa, tener claro que se busca mejorar u optimizar con la aplicación de las nuevas metodologías y herramientas BIM.

Para el proyecto de investigación la implementación BIM se considera en los procesos de diseño, planeamiento en medianas empresas inmobiliarias y constructoras, como inserción de la mejora de la productividad y análisis del impacto en la organización, ya que con las metodologías convencionales se observa las deficiencias como falta de detalles, incompatibilidades, interferencias entre especialidades e inconsistencias que genera problemas que repercuten en la etapa de construcción.

Como parte del desarrollo se está proponiendo mapear e identificar los procesos de diseño, planeamiento estableciendo procedimientos para la implementación del BIM realizando métricas, cuantificando los costos y beneficios, estableciendo en qué medida deben cambiar las políticas, los procesos y cuáles serán las herramientas adecuadas para iniciar la implementación de BIM. Con esta metodología se busca lograr eficiencia en las 
diferentes etapas del proyecto que se alinean en el logro de objetivos como buen diseño, buena planificación y eficiente proceso en la construcción, lo que podemos traducir a constructabilidad del proyecto, adecuada secuencia constructiva simulada $\mathrm{y}$ cumplimiento de plazo.

\subsubsection{Elección del SOFTWARE}

Existen en el mercado diferentes tipos de SOFTWARE para diseño correspondiente a cada especialidad, para la elección se considera diferentes criterios (disponibilidad de acceso al SOFTWARE, facilidad de uso, interoperabilidad, soporte técnico, requerimientos de hardware, facilidad de aprendizaje, etc.).

Para el diseño de la especialidad de arquitectura tenemos disponible los siguientes SOFTWARES:

- REVIT ARCHITECTURE (AUTODESK), este SOFTWARE especializado para el diseño arquitectónico brinda muchas herramientas de modelado, trabaja con elementos paramétricos; asimismo, posee el formato de exportación IFC 2X3, para la interoperatibilidad con otros SOFTWARES, este SOFTWARE interactúa con las versiones de REVIT STRUCTURE y REVIT MEP de forma directa, también exporta en formatos diversos .dxf, .pdf, .dgn.

- ARCHICAD (GRAPHISOFT), es uno de los primeros SOFTWARES de diseño que es muy utilizado por los profesionales de arquitectura, posee herramientas de modelado similares a la de REVIT, trabaja con elementos paramétricos y posee el formato de interoperatibilidad IFC 2X3 para la integración con otro SOFTWARE de diseño, así mismo puede exportar los formatos .dwg, .dxf, SketchUp.

- ALLPLAN (NEMETSCEK), es también un SOFTWARE de diseño muy utilizado para la especialidad de arquitectura, trabaja de forma similar a los otros SOFTWARE mencionados, posee el formato de interoperatibilidad IFC 2X3, también tiene los formatos de exportación .dxf, .pdf, .dgn, .plt, .c4d, .3ds, .u3D.

Para el diseño de la especialidad de Estructuras tenemos disponible los siguientes SOFTWARES:

- REVIT ESTRUCTURE (AUTODESK), es un SOFTWARE dedicado para el diseño de elementos estructurales, trabaja con elementos paramétricos, así mismo posee el formato de exportación IFC 2X3, para la interoperatibilidad con otros SOFTWARES, es posible trabajar a través de vínculos entre modelos arquitectónicos y de instalaciones de forma directa desarrollados en REVIT ARCHITECTURE y REVIT MEP, también posee la herramienta de importación para formatos dwg, dwf, $I F C$, pdf, jpg.

- TEKLA STRUCTURES (TEKLA), este SOFTWARE es similar a los ya mencionados, trabaja con elementos paramétricos que permiten una creación y edición fácil y rápida de modelos $3 \mathrm{D}$, las bondades de este SOFTWARE es que se 
puede diseñar, detallar, realizar el despiece, de todo tipo de estructuras. La interoperatibilidad de este SOFTWARE también se da a través del formato IFC.

Por las bondades, facilidad de uso, disponibilidad en el mercado y soporte se eligió las herramientas BIM de AUTODESK, para el diseño del proyecto se utilizará el SOFTWARE AUTODESK REVIT que contiene las especialidades de arquitectura, estructuras e instalaciones en general.

Para la visualización y simulación constructiva se eligió el SOFTWARE AUTODESK NAVISWORKS ambos en la versión 18 en el idioma inglés.

Imagen 8: Entorno del SOFTWARE AUTODESK REVIT V.18

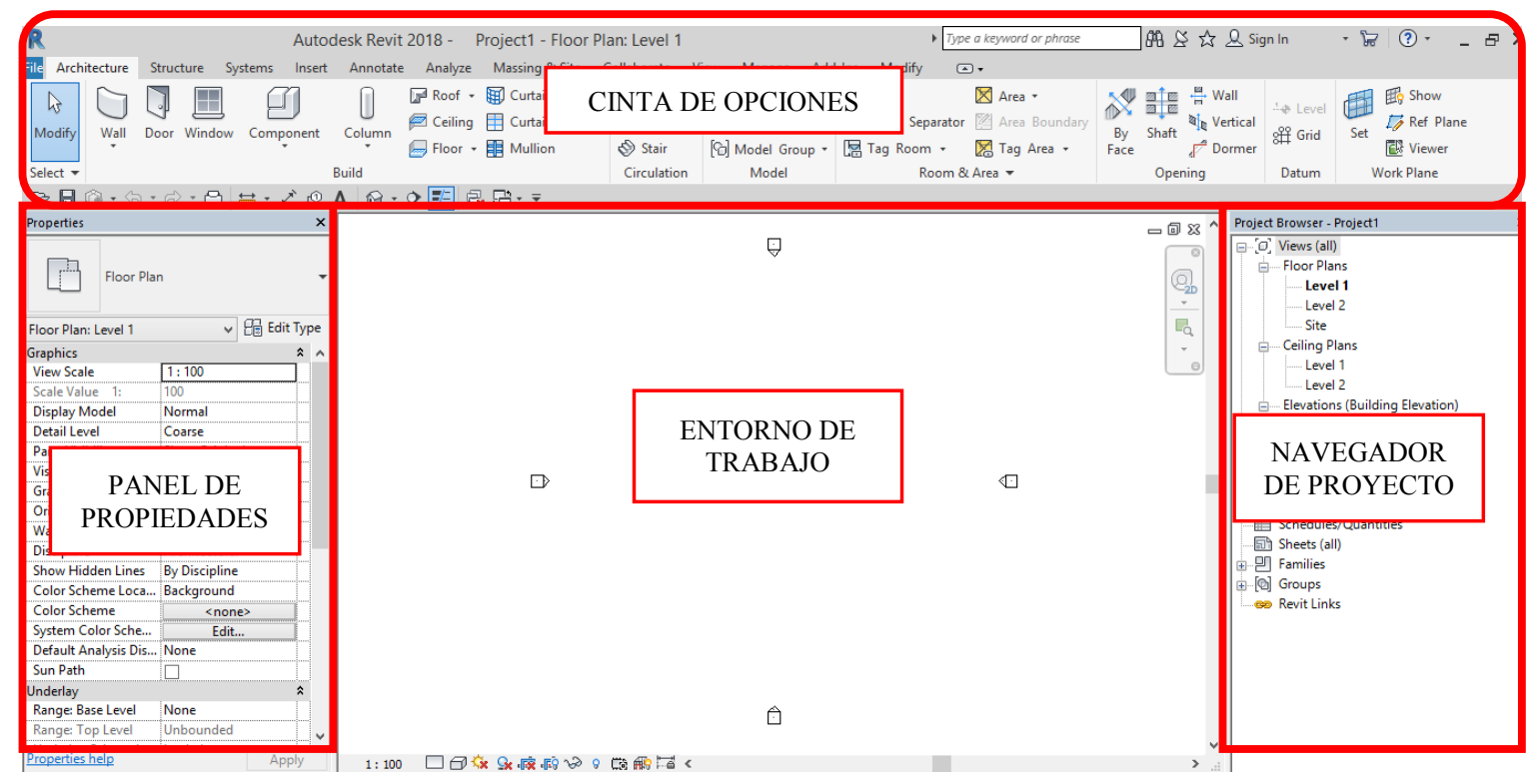

Fuente: (Elaboración Propia)

En la imagen 8 se muestra el entorno del SOFTWARE REVIT el cual está completamente organizado, cada herramienta necesaria se encuentra en la cinta de opciones, cada uno de estos se despliega para mostrar más opciones, es importante señalar que en el SOFTWARE se encuentran las plantillas correspondientes a la especialidad de arquitectura, estructuras e instalaciones, por ello al momento de crear un nuevo modelo se debe elegir adecuadamente el tipo de plantilla. 
Imagen 9: Visualización del modelo 3D en el SOFTWARE AUTODESK NAVISWORKS V.18

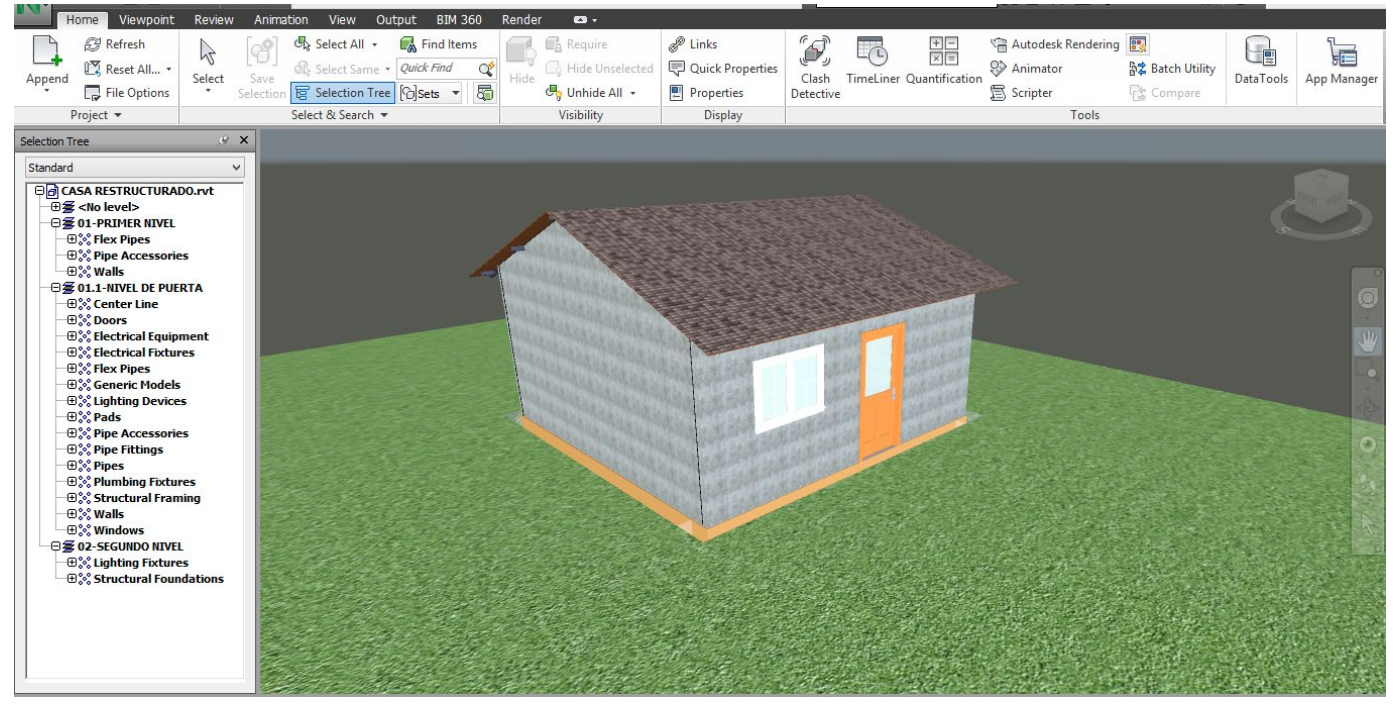

Fuente: (Elaboración Propia)

En la imagen 9 se muestra la visualización del modelo 3D, los elementos paramétricos del modelo se muestran en el árbol de selección, desde este panel es posible configurar la visualización y color del elemento para mejor interpretación.

\subsubsection{Costo de implementación BIM}

El costo de implementación BIM será variable para cada empresa, según los requerimientos que se desee lograr, como referencia se menciona estimaciones de costo en recursos y capacitación para un proyecto realizado por una mediana empresa.

\section{Cuadro 1: Costo de Implementación BIM}

\begin{tabular}{|l|c|r|rr|rr|}
\hline RECURSO HUMANO & UNIDAD & \multicolumn{1}{c|}{ HH } & \multicolumn{2}{|c|}{ S/UNIDAD } & \multicolumn{2}{|l|}{ PARCIAL (S/.) } \\
\hline $\begin{array}{l}\text { Modelado Arq-Estruct-REVIT } \\
\text { MEP }\end{array}$ & $\mathrm{HH}$ & 192.00 & $\mathrm{~S} /$ & 30.00 & $\mathrm{~S} /$ & $5,760.00$ \\
\hline BIM Manager & $\mathrm{HH}$ & 1152.00 & $\mathrm{~S} /$ & 50.00 & $\mathrm{~S} /$ & $57,600.00$ \\
\hline
\end{tabular}

\begin{tabular}{|c|c|c|c|c|c|c|}
\hline RECURSO MATERIAL & UNIDAD & UNIDAD & & UNIDAD & \multicolumn{2}{|c|}{ PARCIAL (S/.) } \\
\hline SOFTWARE (suscripción anual) & Und & 4.00 & $\mathrm{~S} /$ & $20,000.00$ & $\mathrm{~S} /$ & $80,000.00$ \\
\hline Ordenadores & Und & 4.00 & $\mathrm{~S} /$ & $6,000.00$ & $\mathrm{~S} /$ & $24,000.00$ \\
\hline Monitores & Und & 8.00 & $\mathrm{~S} /$ & $1,000.00$ & $\mathrm{~S} /$ & $8,000.00$ \\
\hline Proyectores & Und & 1.00 & $\mathrm{~S} /$ & $1,500.00$ & $\mathrm{~S} /$ & $1,500.00$ \\
\hline Ecrans & Und & 1.00 & $\mathrm{~S} /$ & $1,000.00$ & $\mathrm{~S} /$ & $1,000.00$ \\
\hline Mobiliario & Und & 1.00 & $\mathrm{~S} /$ & $1,500.00$ & $\mathrm{~S} /$ & $1,500.00$ \\
\hline Tablet & Und & 4.00 & $\mathrm{~S} /$ & 600.00 & $\mathrm{~S} /$ & $2,400.00$ \\
\hline Internet Satelital & Glb & 1.00 & $\mathrm{~S} /$ & $10,000.00$ & $\mathrm{~S} /$ & $10,000.00$ \\
\hline \multirow{2}{*}{\multicolumn{5}{|c|}{ Recurso material a asignar al proyecto ( $10 \%$ total) }} & S/ & $128,400.00$ \\
\hline & & & & & $\mathrm{S} /$ & $12,840.00$ \\
\hline
\end{tabular}




\begin{tabular}{|c|c|c|c|c|c|}
\hline $\begin{array}{l}\text { CAPACITACION AL } \\
\text { PERSONAL }\end{array}$ & UNIDAD & CANTIDAD & S/UNIDAD & \multicolumn{2}{|c|}{ PARCIAL (S/.) } \\
\hline \multirow[t]{2}{*}{$\begin{array}{l}\text { Ingeniero de campo, Ingeniero de } \\
\text { Calidad, Maestro de Obra, } \\
\text { Operarios, Topógrafo, etc. }\end{array}$} & Glb & 1.00 & $5,500.00$ & $\mathrm{~S} /$ & $5,500.00$ \\
\hline & & & & $\mathrm{S} /$ & $5,500.00$ \\
\hline \multicolumn{3}{|c|}{ COSTO TOTAL DE IMPLEMENTACIÓN BIM } & \multicolumn{3}{|c|}{$81,700.00$} \\
\hline
\end{tabular}

Fuente: (Elaboración propia)

El plan de implementación BIM, según el cuadro 1, debe contener la información necesaria, los objetivos planteados, el proceso de desarrollo, la función de los integrantes, los recursos necesarios (SOFTWARE, licencias, infraestructura, soporte, etc.), y capacitación al personal; la inversión debe considerarse a largo plazo y su costo debe ser considerado solo como un porcentaje para cada proyecto según la experiencia.

\subsection{Plan de ejecución del BUILDING INFORMATION MODELING}

El plan de ejecución $B I M$ es el documento que contiene los pasos necesarios a desarrollar en función de los objetivos BIM planteados para el proyecto, asimismo se define las responsabilidades y funciones de los involucrados. El plan de ejecución contiene la siguiente información:

Para el desarrollo del plan de ejecución BIM se toma como referencia la estructura del plan de ejecución proyecto BIM elaborado por AEC Shift Ltda versión 1.

\subsubsection{Información de proyecto}

\section{Descripción del proyecto}

En este ítem se indica la siguiente información:

- Dueño del proyecto.

- Nombre del proyecto.

- Tipo de Proyecto.

- Ubicación geográfica del proyecto.

Para el presente trabajo de investigación no se considera un proyecto en particular.

Alcances del proyecto

El alcance del proyecto se desarrolla en cuatro etapas importantes desde la obtención del terreno con habilitación urbana, los cuales son: 
Etapa Inicial:

En esta etapa se obtiene los requerimientos mínimos para el desarrollo del proyecto, como es la obtención del terreno con habilitación urbana, aprobación de los beneficiarios y presentación del proyecto al ministerio de vivienda.

Etapa de diseño:

Abarca desde el diseño conceptual hasta la elaboración de la propuesta de módulos de vivienda adaptando a los requerimientos del cliente (Mivivienda y beneficiarios), se propone viviendas de $37 \mathrm{~m} 2$ de área construida, la cantidad de viviendas que contempla el proyecto son 100 unidades, los proyectos de servicios básicos no forman parte del alcance solo se considera el costo que representan para el análisis financiero (serán realizados por subcontratistas), por otro lado, el área de cada lote donde se desarrollará la construcción de cada vivienda es de $200 \mathrm{~m} 2$ cada una dando la posibilidad de futuras ampliaciones a los propietarios.

Etapa de planeamiento para la construcción:

El proyecto será planificado considerando la optimización de recursos y tiempo, para ello se utilizará las metodologías de LEAN CONSTRUCTION y BIM, se planea la construcción de 100 viviendas en cinco meses.

Etapa de construcción:

La etapa de construcción no se desarrollará en el presente trabajo; sin embargo, se realizará la propuesta de gestión eficiente para lograr los objetivos planteados en la fase de planeamiento.

\section{Desafíos únicos de proyecto}

El principal desafío para la etapa inicial del proyecto es la ubicación del terreno para el desarrollo de las unidades de vivienda, el cual debe cumplir con los requerimientos mínimos para poder ser ejecutado de manera exitosa (Ver capitulo IV, ítem 4.1.1 Análisis del estado del terreno ), para nuestro caso el proyecto se desarrollará en la sierra sur del Perú, donde la topografía es por lo general muy accidentada; de igual forma, los accesos son escasos debido a la falta de proyectos de inversión para el desarrollo de vías de comunicación, bajo estos puntos importantes se propone desarrollar el proyecto en zonas llanas y con proximidad a rutas de accesos, siempre evaluando que no exista algún tipo de riesgo para el proyecto (zonas con fallas geológicas, proximidad a riberas de ríos, zonas restringidas, zonas intangibles, etc). Otro desafío para el proyecto se presenta durante la etapa de diseño, debido a que en esta etapa surgen los principales problemas que se ven reflejados en la etapa de construcción con un impacto negativo al proyecto (costo y tiempo) que afectan la rentabilidad de las empresas constructoras; estos problemas obligan a los administradores de la construcción a requerir soluciones con los proyectistas mediante requerimiento de información (RFI: Request For Information), que puede detener el proceso de la construcción hasta ser resuelto y muchas veces se opta por realizar soluciones costosas e improvisadas para no detener el proceso de la construcción, se ha identificado que estos problemas son de diferente índole y surgen debido a la conceptualización de las especialidades del proyecto de forma independiente por cada especialista. 
Los principales problemas que se presentan en la etapa de diseño desarrollado de la forma tradicional sin los enfoques BIM son:

- Diseño no estandarizado (dimensiones de elementos variables).

- Elementos de diseño sin información técnica suficiente o limitada (planos en 2D).

- Interpretación de planos de forma diferente de las especialidades (Percepción 3D diferente de los planos 2D).

- Omisiones y errores en los planos.

- Incompatibilidades entre especialidades (planos de especialidades vs especificaciones técnicas).

- Interferencias entre elementos de diseño entre especialidades.

- No existe información para elaborar el presupuesto (tablas de cantidades de materiales), se requiere realizar el metrado a partir de planos.

Con la aplicación de la metodología BIM y la aplicación adecuada de las herramientas, procesos y el equipo de personas comprometido se lograra desarrollar exitosamente el proyecto.

\section{Partes involucradas claves}

El proyecto será desarrollado por el equipo BIM de la empresa en las diferentes etapas y especialidades, en caso de subcontratos para la elaboración de alguna fase y/o especialidad del proyecto se tendrá documentado los detalles que serán desarrollados por los involucrados donde se contará con la información importante como: rubro de la compañía, nombre de los involucrados, contacto (número de teléfono y correo electrónico).

\section{Personal BIM clave}

En este punto se detalla la información del personal BIM que será responsable de cada disciplina para ello se realiza el siguiente cuadro:

Cuadro 2: Formato personal BIM clave

\begin{tabular}{|l|c|c|c|c|}
\hline $\begin{array}{l}\text { Área de } \\
\text { responsabilidad } \\
/ \text { Especialidad }\end{array}$ & Nombre & Empresa & Correo Electrónico & $\begin{array}{c}\text { Número } \\
\text { de } \\
\text { teléfono }\end{array}$ \\
\hline Arquitectura & $\begin{array}{c}\text { Patricia } \\
\text { Escalante }\end{array}$ & - & Pat_489@hotmail.es & - \\
\hline Estructuras & $\begin{array}{c}\text { Deniht } \\
\text { Gallegos }\end{array}$ & - & deniht@gmail.com & - \\
\hline $\begin{array}{l}\text { Instalaciones } \\
\text { Eléctricas y } \\
\text { Sanitarias }\end{array}$ & $\begin{array}{c}\text { Jesseliz } \\
\text { Ortiz }\end{array}$ & - & jesselizortiz@gmail.com & - \\
\hline
\end{tabular}

(Fuente: elaboración propia)

En el cuadro 2 se presenta el formato sugerido para indicar la información necesaria del personal que será responsable de las diferentes áreas. 
Se debe indicar el nombre y la empresa a la que pertenece el profesional o profesionales del área/ especialidad.

Se debe tener una forma de comunicación con los integrantes del proyecto, por lo cual se debe tener un correo electrónico como requisito para mantener la comunicación formal durante el desarrollo del proyecto.

Para tener una comunicación rápida con los integrantes de las especialidades para discutir temas del proyecto se debe contar con un número telefónico de los integrantes de cada especialidad, para el presente cuadro no se indica los números telefónicos.

\section{Objetivos de proyecto}

Se debe plantear los objetivos a lograr en cada etapa del proyecto, los cuales deben ser alcanzables por los STAKEHOLDERS; a continuación, se plantean los objetivos principales a lograr en las etapas de diseño, planeamiento y construcción.

\section{Cuadro 3: Etapas y objetivos planteados del proyecto}

\begin{tabular}{|c|c|c|}
\hline Etapa / objetivos & Especialidad & Responsable \\
\hline \multicolumn{3}{|l|}{ Etapa de diseño } \\
\hline $\begin{array}{l}\text { 1. Planta arquitectónica del módulo de } \\
\text { vivienda (distribución de áreas) }\end{array}$ & Arquitectura & $\begin{array}{c}\text { Patricia } \\
\text { Escalante (PE) }\end{array}$ \\
\hline $\begin{array}{l}\text { Elaboración del modelo arquitectónico } \\
\text { (modelo 3D) }\end{array}$ & Arquitectura & $\begin{array}{c}\text { Patricia } \\
\text { Escalante }(\mathrm{PE})\end{array}$ \\
\hline 4. Elaboración del modelo estructural & Estructuras & $\begin{array}{c}\text { Deniht } \\
\text { Gallegos (DG) }\end{array}$ \\
\hline 5. Elaboración del modelo MEP & Instalaciones & $\begin{array}{l}\text { Jesseliz Ortiz } \\
\text { (JO) }\end{array}$ \\
\hline $\begin{array}{l}\text { 6. Verificación de interferencias y } \\
\text { compatibilización }\end{array}$ & Todos & PE, DG, JO \\
\hline 7. Planos a nivel de detalle & Todos & PE, DG, JO \\
\hline Tabla de cantidades (metrados) & Todos & $\mathrm{PE}, \mathrm{DG}, \mathrm{JO}$ \\
\hline \multicolumn{3}{|l|}{ Etapa de Planeamiento para la construcción } \\
\hline 1. Sectorización del proyecto & Todos & PE, DG, JO \\
\hline 2. Elaboración del WBS & Todos & PE, DG, JO \\
\hline 3. Elaboración del cronograma de obra & Todos & $\mathrm{PE}, \mathrm{DG}, \mathrm{JO}$ \\
\hline 4. Elaboración del Look Ahead & Todos & $\mathrm{PE}, \mathrm{DG}, \mathrm{JO}$ \\
\hline 5. Elaboración del Modelo BIM 4D & Todos & $\mathrm{PE}, \mathrm{DG}, \mathrm{JO}$ \\
\hline \multicolumn{3}{|l|}{ Etapa de Construcción } \\
\hline $\begin{array}{l}\text { 1. Seguimiento y control de avance con el } \\
\text { modelo BIM 4D }\end{array}$ & Todos & PE, DG, JO \\
\hline $\begin{array}{l}\text { 2. Control de cantidad de avance en el modelo } \\
\text { BIM 3D }\end{array}$ & Todos & PE, DG, JO \\
\hline
\end{tabular}

(Fuente: elaboración propia)

En el cuadro 3 se muestra los objetivos a lograr en cada una de las etapas del proyecto, se identifica a que especialidad pertenece y quien es el responsable de realizar. 
Programación

Los objetivos que se plantearon para cada una de las etapas del proyecto serán medibles en el tiempo, para ello se plantea una programación de entrega de los mismos a nivel de etapas y principales objetivos señalados para el proyecto.

Imagen 10: Programación de objetivos y metas del proyecto

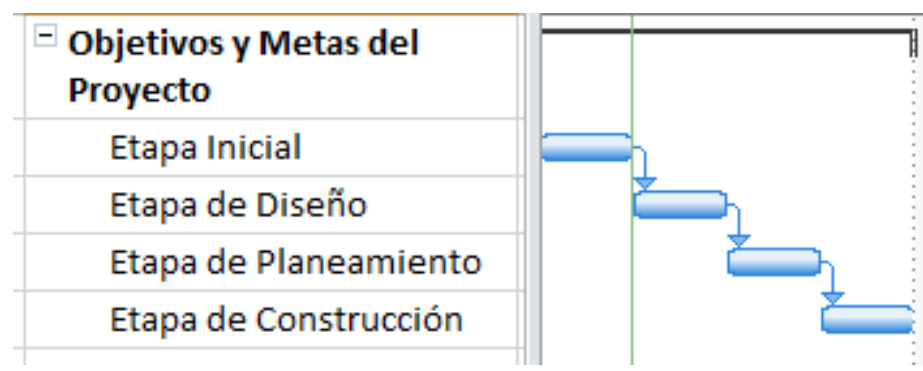

(Fuente: elaboración propia)

Se debe realizar una programación considerando los objetivos a lograr en el proyecto, como se muestra en la imagen 10 se planteó para el proyecto objetivos a lograr en cada etapa.

Matriz de nivel de detalle

En este punto se indica los responsables del desarrollo de cada elemento, cuando se debe desarrollar, a qué nivel de detalle debe modelarse.

Para el trabajo de investigación el nivel de detalle del modelo a realizar es LOD300, en cada uno de los modelos de las especialidades.

El modelo de arquitectura será desarrollado por un especialista en diseño arquitectónico, quien estará encargado de plantear la adecuada distribución de espacios en el área determinada para la unidad de vivienda modelo respetando las consideraciones mínimas exigidas en los reglamentos vigentes. Este modelo se debe realizar inicialmente para poder desarrollar los modelos de las otras especialidades, el tiempo de entrega debe ser de acuerdo a la programación de objetivos, el uso que se le dará a este modelo será como base de los modelos de las especialidades de estructuras e instalaciones, y se vincularán a través de la opción copia y monitoreo para identificar cambios que pudieran surgir durante el desarrollo de los modelos de especialidad.

El modelo estructural será desarrollado por un especialista, tomando las consideraciones mínimas de diseño según el Reglamento Nacional de Edificaciones, el modelo de estructuras se desarrollará cuando se tenga elaborado el modelo de arquitectura, el cual será vinculado para obtener toda la información necesaria de planta y elevaciones para desarrollar el modelo de la especialidad de estructuras. 
El modelo de instalaciones será desarrollado por un especialista en instalaciones, quien tiene la responsabilidad de plantear la solución más óptima al sistema de instalaciones tanto sanitarias como eléctricas, que se adapten al proyecto, este modelo será desarrollado paralelo al desarrollo de la especialidad de estructuras, el modelo de arquitectura es necesario para proceder con el diseño de esta especialidad.

Durante el desarrollo del modelado de las especialidades existirá un trabajo coordinado y colaboración entre los especialistas, el propósito es obtener un modelo sin interferencias y compatibilizado al culminar esta etapa, para ello se propone las reuniones de ingeniería concurrente integrada (ICE).

\subsubsection{Trabajo colaborativo}

\section{Estándares de proyecto}

Una vez determinado el SOFTWARE adecuado a nuestras necesidades de diseño, el primer paso a considerar antes de realizar el trabajo con los especialistas de diseño es determinar un mismo estándar de trabajo (nomenclatura para la documentación, técnicas de modelado, colores, sistema de unidades, identificación de planos de especialidades, sistema de coordenadas, idioma del SOFTWARE, etc.), estos aspectos básicos e importantes para el desarrollo del modelo BIM es necesario cumplirlos para un adecuado modelado.

Para el desarrollo del modelo se eligió el SOFTWARE Autodesk REVIT en su versión 18 en el idioma inglés, de igual forma para la compatibilización se eligió el SOFTWARE de AUTODESK NAVISWORKS en su versión 18 en el idioma inglés.

Para la identificación de los planos se antepondrá la especialidad, seguida del número de plano.

Los otros estándares se desarrollarán en el ítem estándares de modelamiento.

Coordenadas de proyecto

Para que el modelo esté integrado correctamente entre especialidades, se debe elegir las coordenadas del punto base del proyecto y el punto de superficie similares y con valores de $(0,0,0)$, las cuales deben ser idénticas en cada especialidad antes de iniciado el diseño, de esta forma garantizamos que al integrar los modelos en un SOFTWARE de visualización (AUTODESK NAVISWORKS, SYNCRO PRO, etc.) no existan desplazamientos en el modelo que generen interferencias erróneas. 
Imagen 11: Configuración de unidades y formato

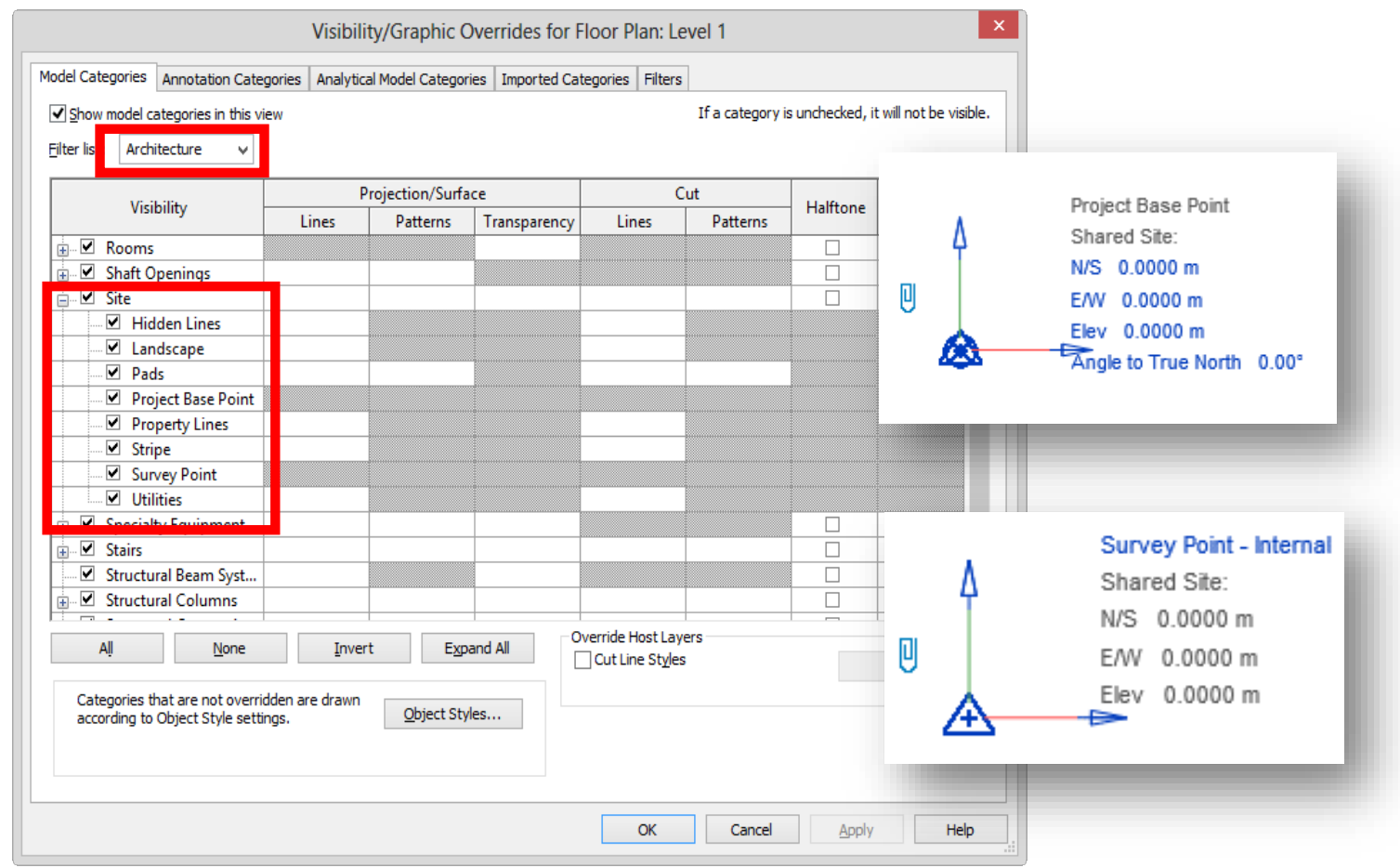

Fuente: (elaboración propia)

La imagen 11 muestra la activación de los puntos de superficie y punto base del proyecto, las coordenadas de proyecto en cada especialidad son similares para la compatibilización.

Por lo general este punto de inicio de modelo se determina eligiendo una esquina del proyecto que se puede identificar claramente en el entorno de trabajo, la visualización del punto de proyecto y de superficie está desactivado la mayoría de las veces y requiere ser activado desde la herramienta de visibilidad de gráficos al cual se puede acceder de forma rápida a través del comando de teclado $(\mathrm{V}+\mathrm{V}$ o $\mathrm{V}+\mathrm{G})$ en la versión en inglés del SOFTWARE. 
Imagen 12: Trabajar en coordenadas compartidas. (Punto base del proyecto y punto de superficie).

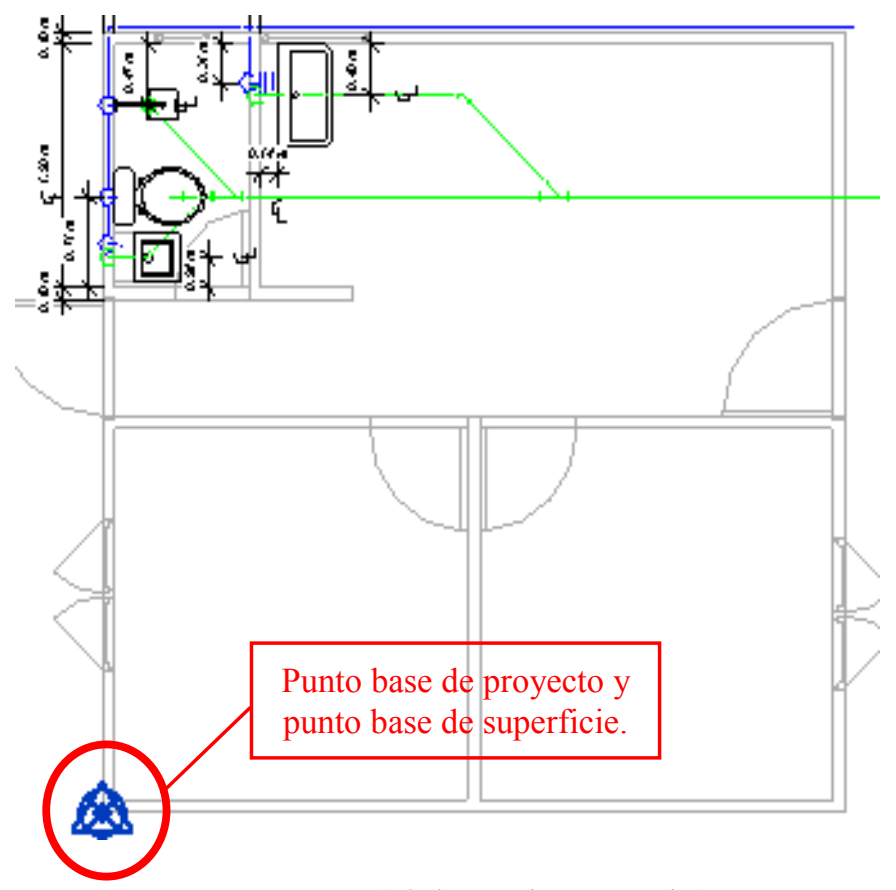

Fuente: (elaboración propia)

Es importante considerar un punto conocido en el proyecto como punto base y punto de superficie, para evitar desfases esté punto se debe bloquear.

Estándares de modelamiento

Para proyectos que serán desarrollados repetidas veces es muy importante concentrarse en un modelo optimizado, buscar lograr eliminar las deficiencias de diseño, eliminar las interferencias y compatibilizar las especialidades debido a que un error que se presente en el modelo principal se masificará en cada una de las unidades a construir, para controlar los posibles problemas se considera:

- Definir el nivel de detalle que se busca para el proyecto (LOD), para nuestro proyecto se realizara un LOD 300.

- Utilizar la misma versión de SOFTWARE o que soporte el formato IFC de interoperatibilidad, para el caso de utilizar SOFTWARE diferente para cada especialidad, para el proyecto se eligió el SOFTWARE Autodesk REVIT v.18.

- Trabajar con un sistema de unidades adecuado y adaptado a la realidad donde se está diseñando.

- Trabajo colaborativo, como ya se indicó en párrafos anteriores el diseño del modelo debería trabajarse colaborativamente entre especialidades, es decir el Arquitecto realiza la propuesta arquitectónica basado en los requerimientos del cliente, este modelo arquitectónico es vinculado con en el modelo de estructuras, se vincula cada elemento estructural con los elementos arquitectónicos (copiar y monitorear) para que se observe cada cambio y se informe al especialista de alguna modificación que impacte en el diseño de su 
especialidad, de la misma forma entre el modelo arquitectónico y el modelo de instalaciones, así mismo, entre la especialidad de estructuras e instalaciones.

- Elegir una coordenada de diseño del proyecto, para evitar desplazamientos del modelo de cada especialidad al momento de integrarlos para verificar las interferencias con un SOFTWARE de visualización y compatibilización, las ventajas de vincular un modelo de otra especialidad es que puede conservar no solo las coordenadas, también las características paramétricas de cada elemento vinculado.

- Es indispensable trabajar con ejes y niveles determinados en el modelo, los elementos paramétricos se podrán diseñar con facilidad sobre ejes y niveles en el entorno de trabajo.

Imagen 13: Ejes y niveles para el modelo

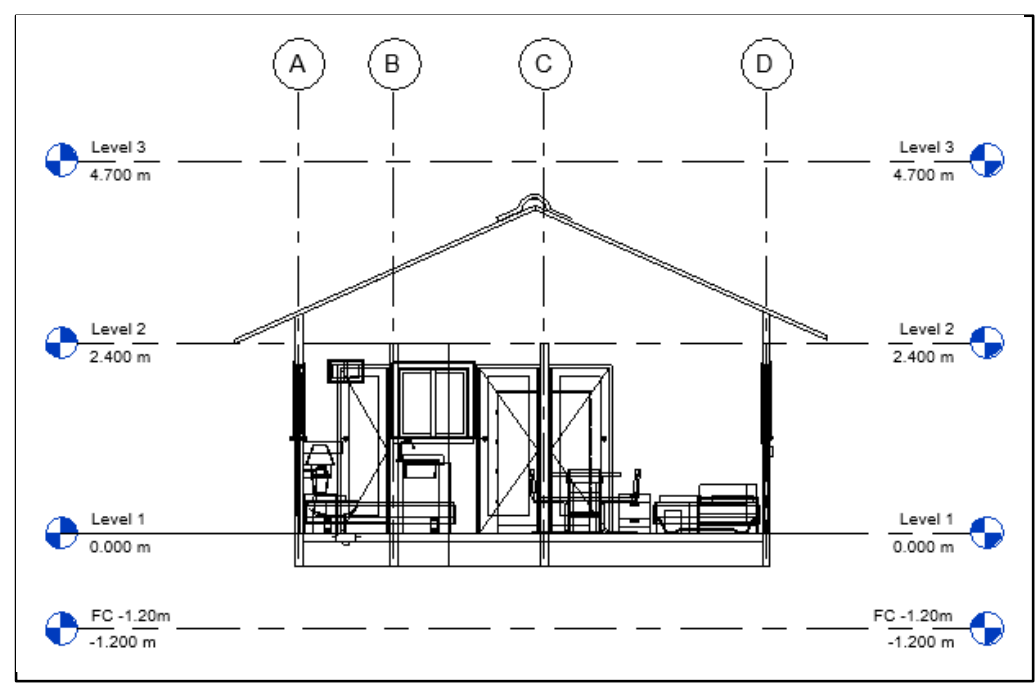

(Fuente: elaboración propia)

En la imagen 13, se muestra los ejes y niveles principales del proyecto, el flujo de trabajo para la colocación de elementos de diseño se desarrolla con mayor facilidad a través de estos elementos.

- Para el diseño se define los materiales paramétricos con las especificaciones técnicas definidas en las propiedades, por lo general se edita los elementos que posee el SOFTWARE, a través de duplicado obtenemos las propiedades personalizadas para nuestro proyecto, esto es muy importante para generar información para cuantificaciones a través de filtros que posee el SOFTWARE. 
Imagen 14: Configuración de elementos de diseño personalizado

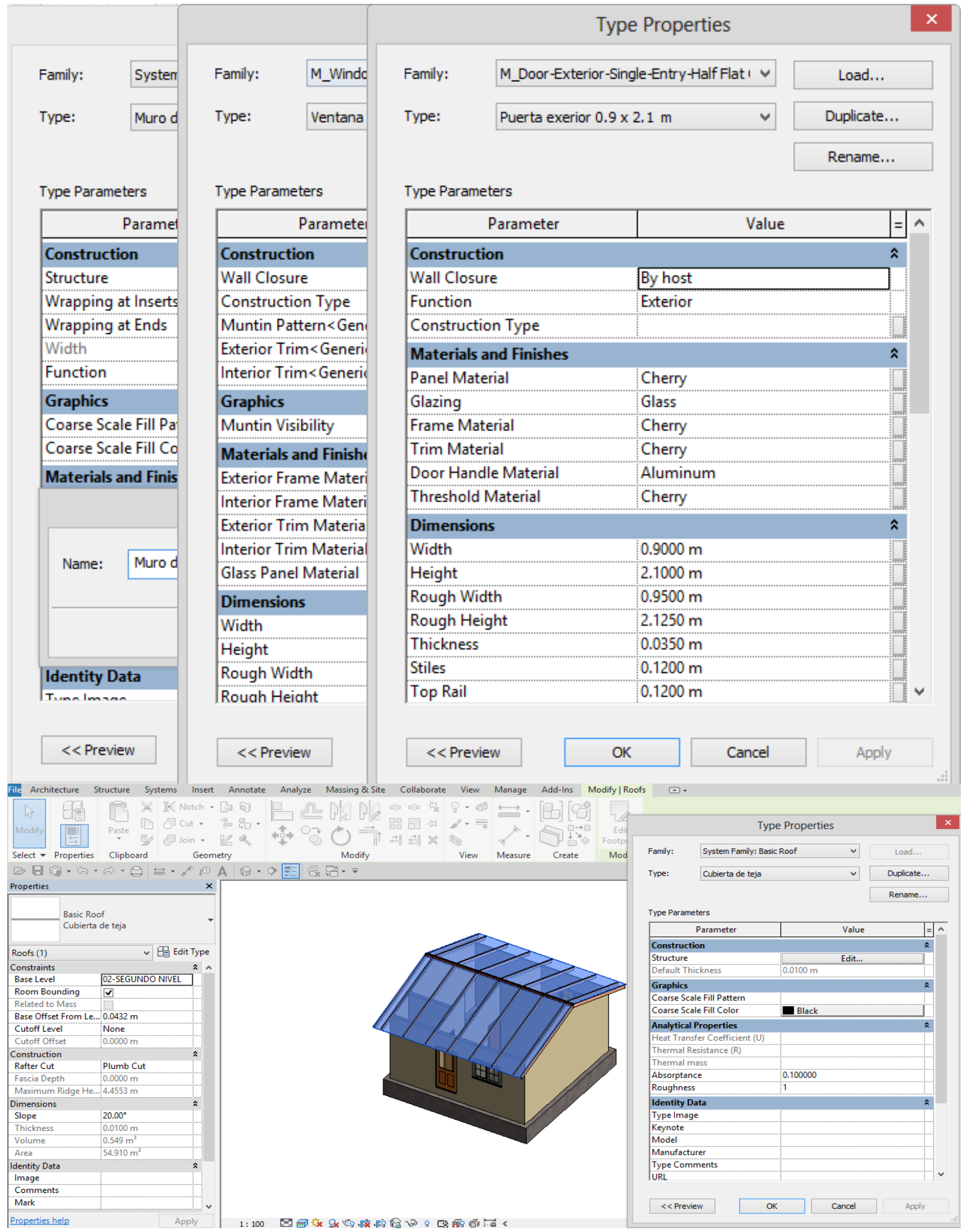

(Fuente: elaboración propia)

En la imagen $\mathrm{N}^{\circ} 14$ se muestra la configuración de elementos paramétricos personalizados para el proyecto, en el SOFTWARE se tiene familias prestablecidas cuyos elementos son editables. 
En la etapa de diseño en el modelado se debe tomar información ya desarrollada (elementos parametrizados, familias parametrizadas del SOFTWARE), en la etapa de implementación del $B I M$ en la empresa se genera esta información que optimiza el tiempo al desarrollar nuevos proyectos, por ello, se debe utilizar el tiempo en el modelado que agrega valor al proyecto, realizar un modelo $B I M$ se centra en tener la información necesaria para la construcción, mucha información BIM solo distrae al constructor del objetivo principal que es la optimización del tiempo, recursos y la eliminación de los desperdicios durante la construcción.

\section{$>$ Comunicación y reuniones}

La metodología de diseño que propone $B I M$ es el trabajo coordinado y colaborativo, existe varias formas de trabajo que optimizan el diseño en el modelo que se construirá, utilizando las herramientas BIM se busca generar un modelo único integrado, la especialidad de arquitectura se vincula con las otras especialidades y propone cambios que se reflejen para todos los especialistas, esto se puede realizar en una oficina donde se puede coordinar directamente resolviendo los problemas, también es posible trabajar desde diferentes lugares a través de un modelo en una base local que se vincula al trabajo de los otros especialistas a través de internet.

\section{Imagen 15: Flujo colaborativo en metodología BIM sobre un modelo principal}

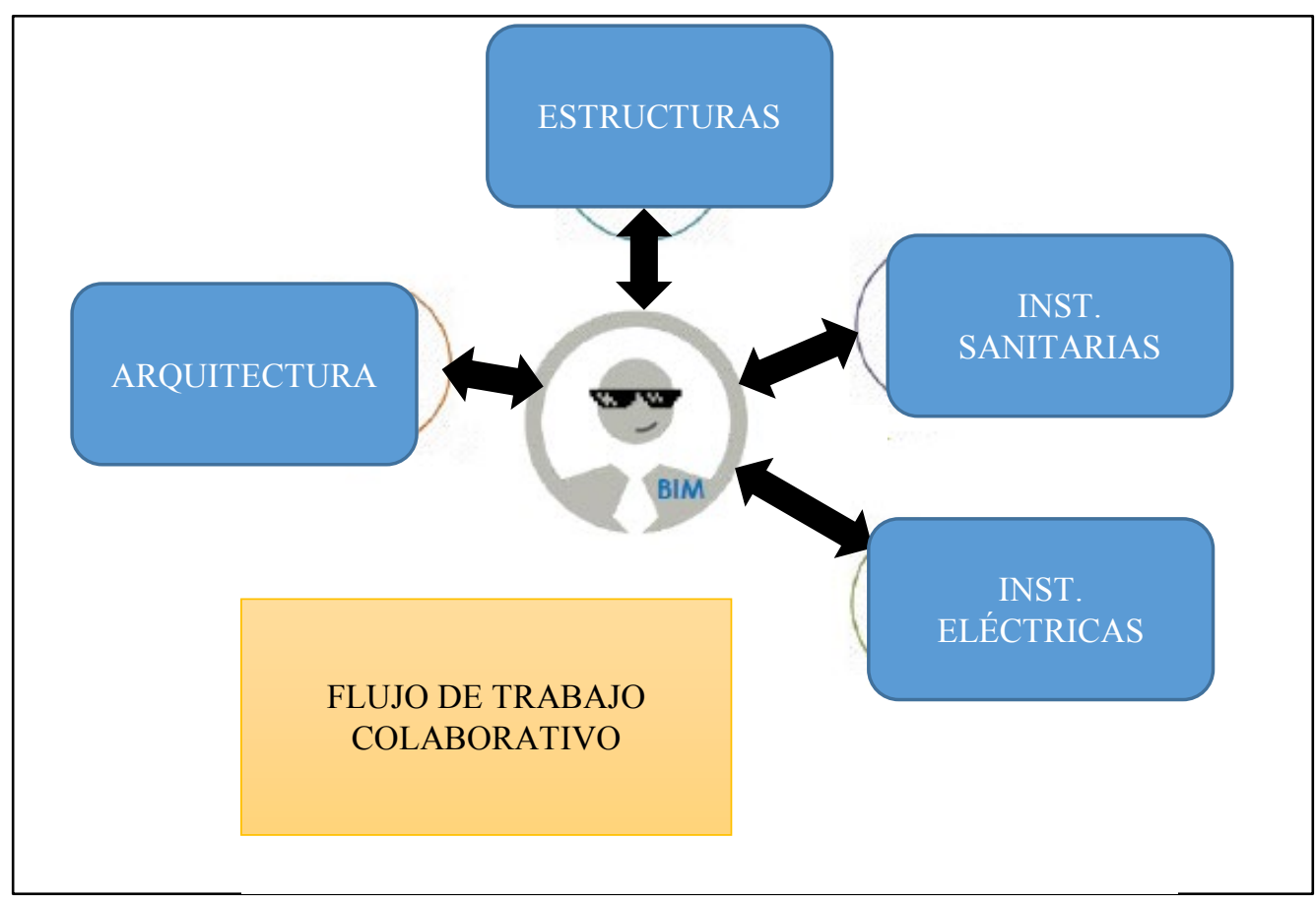

(Fuente: elaboración propia)

En la imagen 15 se muestra el flujo de trabajo que propone la metodología BIM, la interacción entre las especialidades es muy beneficiosa durante el diseño del proyecto. 
Fotografía 4: Reuniones de ingeniería concurrente integrada

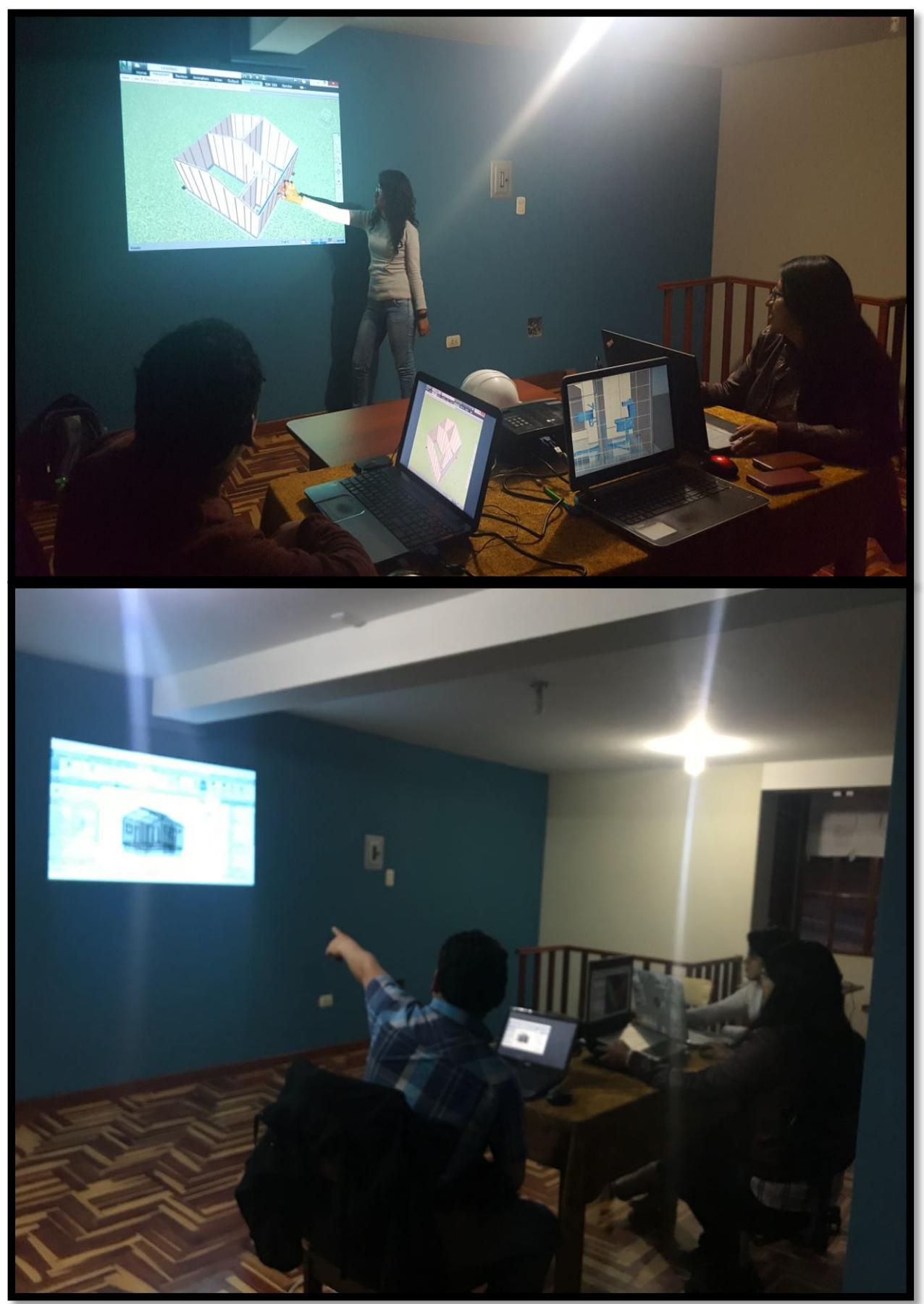

Fuente: (elaboración propia)

En la fotografia $\mathrm{N}^{\circ} 04$ se muestra las reuniones de ingenieria concurrente integrada realizadas durante la elaboracion del diseño del proyecto, el principal objetivo de juntar a los especialistas fue lograr un diseño optimo de todos los componentes del proyecto. 
Unidades de modelos

Se configura las unidades con las que se trabajara en el modelo, esto es muy importante para no tener incompatibilidades al momento de integrar con las otras especialidades.

Imagen 16: Configuración de unidades y formato

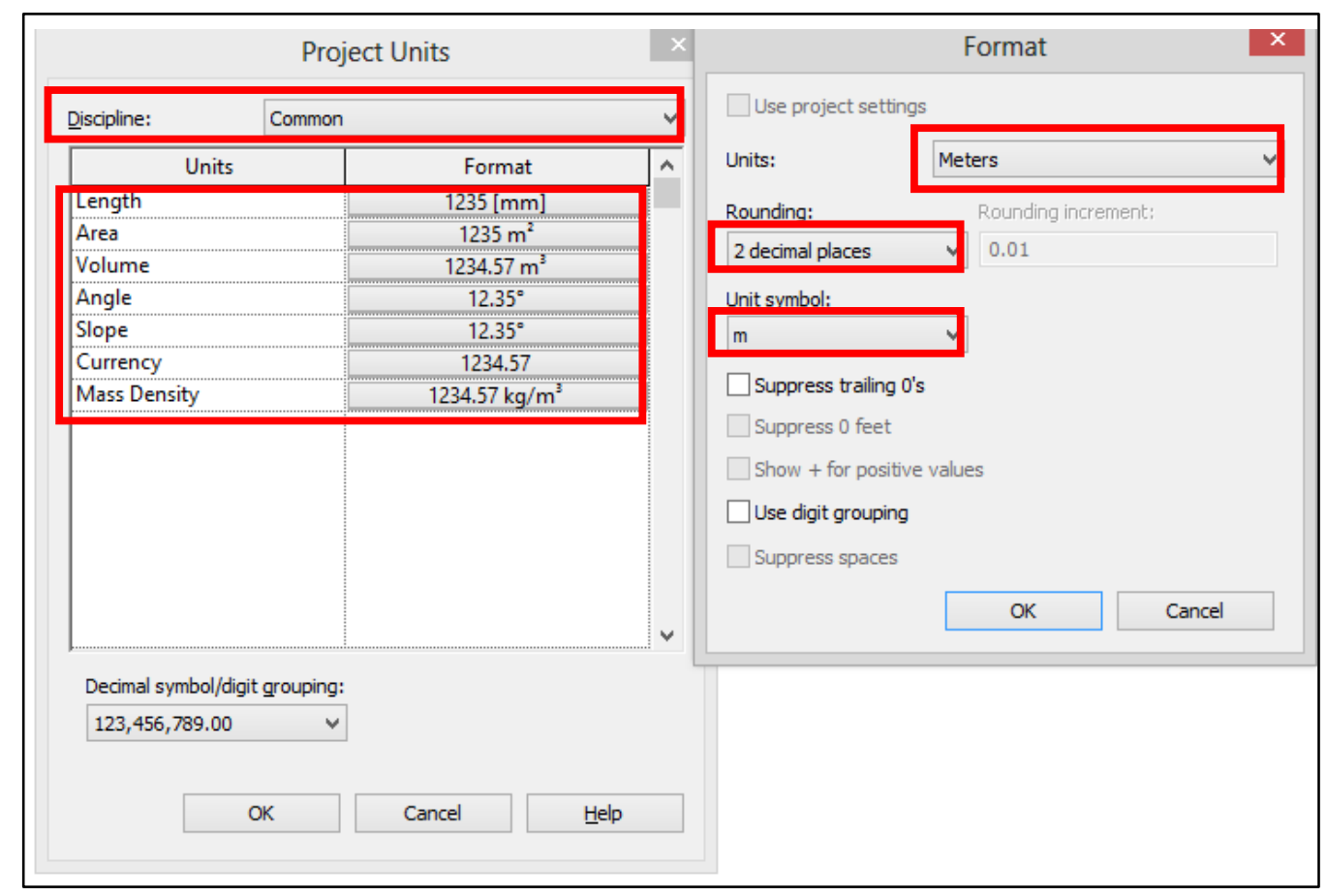

Fuente: (elaboración propia)

En la imagen 16 se muestra la configuración de las unidades y formato del proyecto, en el SOFTWARE de Autodesk REVIT se cuenta con varios formatos que permiten trabajar adecuadamente cada detalle de diseño.

\subsubsection{Recursos y requerimientos informáticos de proyecto}

Capacidad BIM de partes involucradas

Para el desarrollo de los objetivos BIM planteados se contará con los especialistas capacitados en el dominio de las herramientas $B I M$ y en el conocimiento de la metodología.

Es importante contar con todas las capacidades BIM que requiera el proyecto, en caso sea necesario se debe subcontratar las que sean necesarias.

Ambiente de información comunitaria

Para obtener los máximos beneficios de la aplicación de la metodología BIM en la ejecución del proyecto a través del intercambio de información entre los involucrados 
es importante contar con procesos definidos que estén claramente establecidos en el plan, para la facilidad de intercambio de información durante el desarrollo del diseño y durante la construcción se propone utilizar redes internas y herramientas de la nube.

$>$ Requerimiento de infraestructura HARDWARE y SOFTWARE

Para el logro de los entregables que se plantean para un proyecto aplicando la metodología BIM se requiere contar con infraestructura de HARDWARE y tecnología, para ello es indispensable suministrar la infraestructura adecuada como: Estaciones de trabajo (workstations), que serán utilizadas como servidores, además es necesario establecer puntos de conectividad interna y externa.

\section{SOFTWARE (partes involucradas)}

El SOFTWARE que emplean los involucrados en el desarrollo del proyecto, deben ser compatibles o poseer un medio de interoperabilidad entre ellos como por ejemplo tener un formato $I F C$, además tener importante cuidado al trabajar con una versión de SOFTWARE, asimismo es importante el idioma del SOFTWARE para garantizar flujos de trabajo más eficientes entre los involucrados.

Para el presente trabajo de investigación se estableció el uso del SOFTWARE Autodesk REVIT, en la versión 18 en el idioma inglés, para el desarrollo del modelado de las especialidades de arquitectura, estructuras e instalaciones.

Para la visualización se elige el SOFTWARE AUTODESK NAVISWORKS, por la facilidad de interoperatibilidad que existe entre los dos SOFTWARE de la misma compañía, por otro lado es importante señalar la existencia de otras opciones en cuanto a SOFTWARE se refiere.

\subsubsection{Usos del BUILDING INFORMATION MODELING}

Obtención del modelo 3D

El modelo 3D se realiza buscando obtener la mayor cantidad de información que beneficie al proyecto durante la etapa de diseño, facilite el planeamiento y mejore la gestión durante la construcción. Para lograr el modelo 3D es necesario la participación colaborativa de los especialistas. Otra ventaja es que a partir del modelo 3D, podemos generar el modelo 4D (gestión del tiempo). 
Imagen 17: Ventajas del modelo BIM

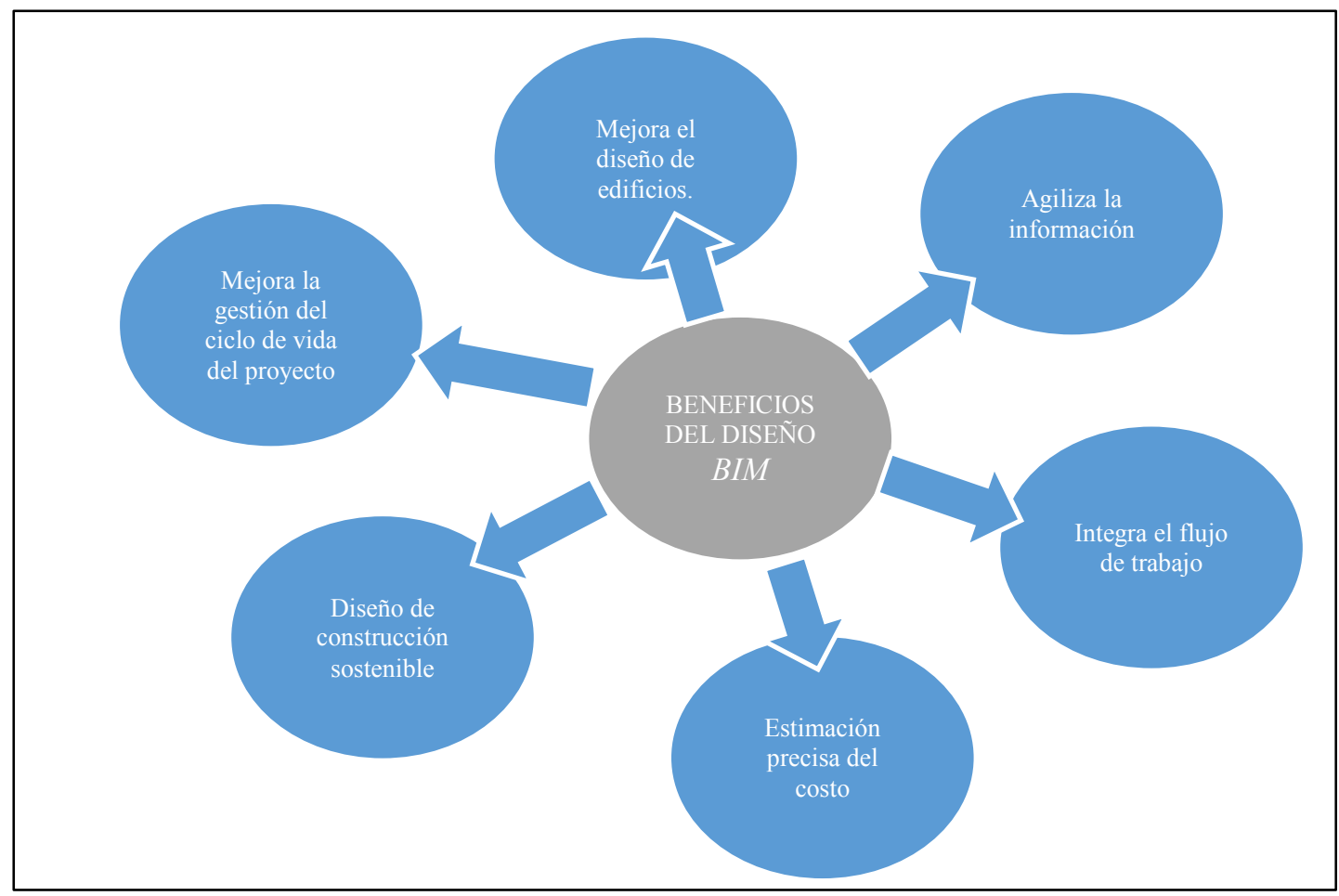

(Fuente Innova Training Center)

En la imagen 17 se muestra los beneficios de realizar el diseño con la metodología BIM, se optimiza el tiempo de diseño gracias al trabajo colaborativo, se agiliza la información y se logra mejorar la gestión durante el ciclo de vida del proyecto.

\section{Imagen 18: Información obtenida del modelo BIM}

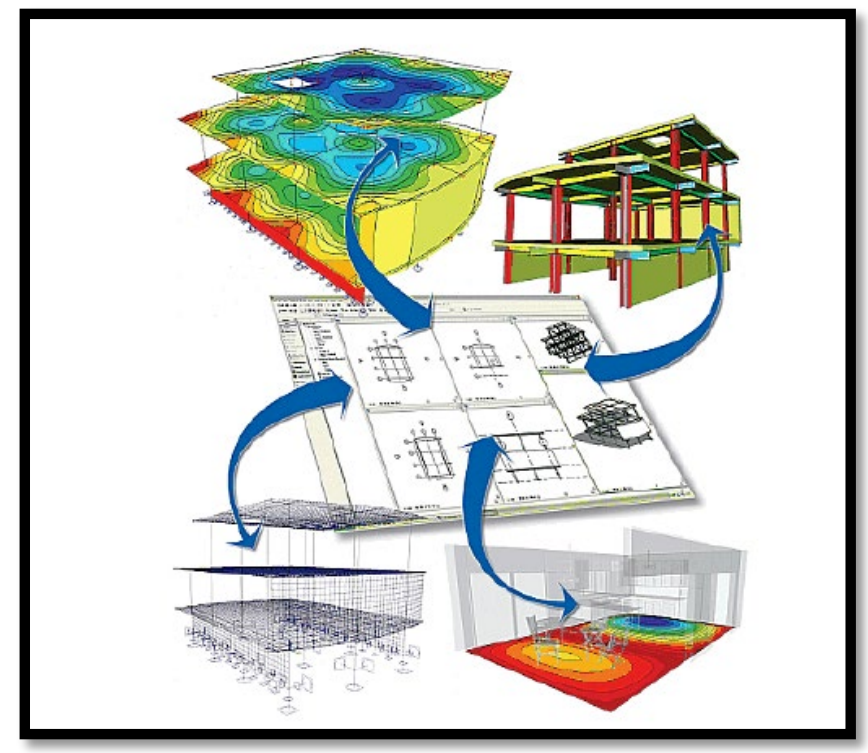

(Fuente Innova Training Center) 
Como se muestra en la imagen 18, existe mucha información que se obtiene del modelo 3D, desde planos a detalle, tabla de cantidades, modelo analítico para el cálculo estructural, etc.

\section{Compatibilización}

La presentación del modelo compatibilizado es un objetivo que se busca al aplicar los enfoques BIM a través de modelos que brinden la información requerida a través de los planos y detalles para la etapa de construcción.

Podemos mencionar que el diseño colaborativo optimiza el tiempo y reduce la incompatibilidad del proyecto entre las otras especialidades, con el soporte de herramientas de visualización de modelos $3 \mathrm{D}$, en cada fase de diseño podemos detectar las interferencias del diseño de cada especialidad, por ejemplo si se diseña en paralelo la arquitectura, estructuras e instalaciones, cada especialidad se puede vincular para coordinar con el modelo de arquitectura como base, controlando los cambios en cada especialidad para actualizarlo oportunamente en el modelo anfitrión, la visualización integra todas las especialidades y la potencia de poder integrar y controlar las características paramétricas y modificar propiedades del elemento nos facilita visualmente ver las interferencias y plantear soluciones.

La ventaja de trabajar con un modelo 3D vinculado y coordinado es que los cambios se reflejan en cada especialidad permitiéndonos actualizar oportunamente la información para la construcción.

\section{Imagen 19: Interferencia entre el diseño de instalaciones y diseño estructural}

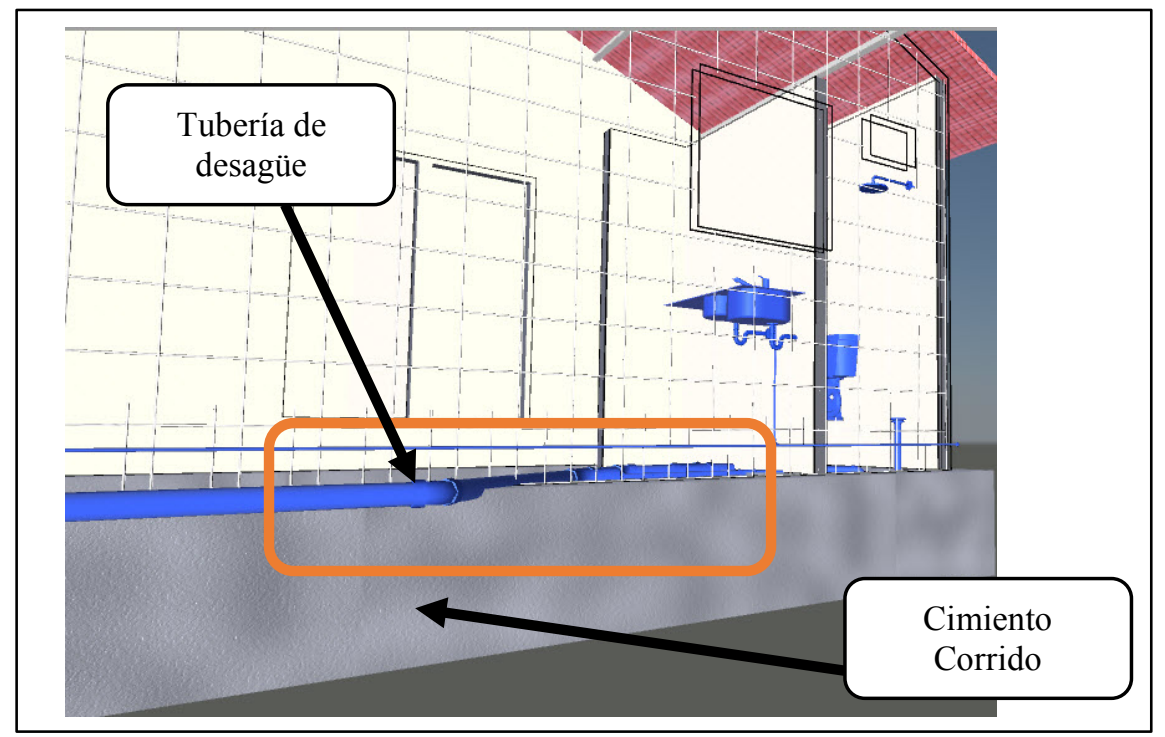

Fuente: (elaboración propia)

En la imagen 19 se muestra la detección y visualización de interferencias entre elementos del modelo estructural e instalaciones sanitarias, la imagen corresponde a una vista en el SOFTWARE AUTODESK NAVISWORKS. 
Imagen 20: Diseño de instalaciones de agua incompatibles con los muros estructurales.

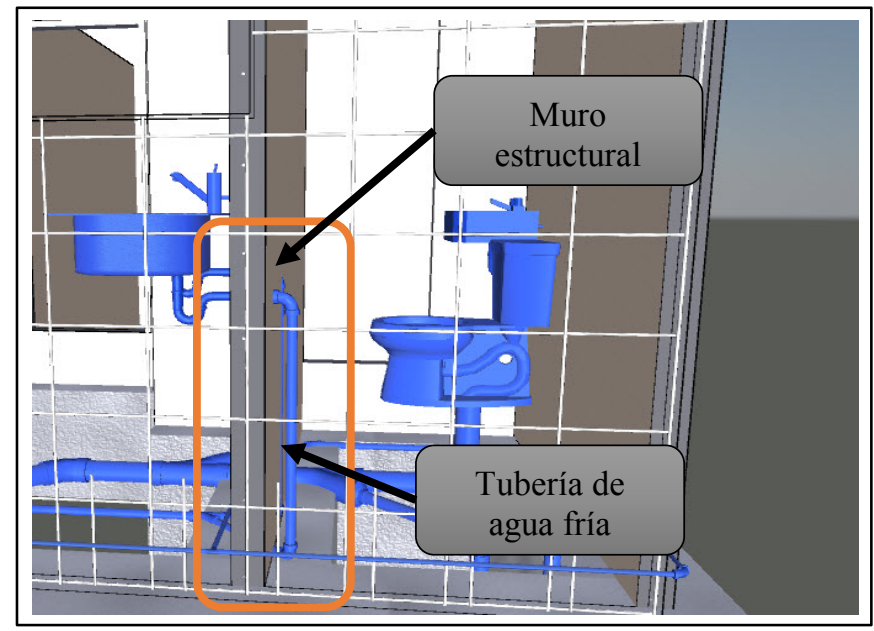

Fuente: (elaboración propia)

En la imagen 20 se muestra la facilidad de detección de las interferencias entre especialidades, la integración de modelos durante la etapa de diseño facilita realizar los cambios y mejoras para obtener el modelo compatibilizado sin interferencias.

Realizando este proceso de visualización del modelo en un determinado SOFTWARE de integración (ejemplo AUTODESK NAVISWORKS) podemos detectar interferencias e incompatibilidades entre las especialidades en una fase temprana del diseño y poder decidir las mejores soluciones con un impacto en costo mucho menor, para el caso de viviendas que serán construidas por un modelo estandarizado la existencia de un error en el diseño se refleja en cada unidad de vivienda a construir, impactando en costo y tiempo si no se detecta en la etapa inicial de construcción, es por ello que surge la necesidad de tener un modelo completamente optimizado buscando la constructabilidad.

El diseño culmina cuando se resuelven las interferencias e incompatibilidades, elaborando los planos, detalles y especificaciones técnicas para la construcción, reduciendo o eliminando los posibles RFI's (Request For Information) que se presentaran en la etapa de construcción debido a los problemas de incompatibilidades e interferencias que surgen en la etapa de diseño al desarrollar con metodologías tradicionales y que serán resueltas al realizar un diseño bajo los enfoques BIM.

Existen varias herramientas $B I M$ para la detección temprana de incompatibilidades e interferencias entre especialidades, para nuestro análisis utilizamos las bondades del SOFTWARE AUTODESK NAVISWORKS, a través de la herramienta clashdetection podemos establecer revisiones entre cada especialidad que se requiera, el SOFTWARE nos genera los $R F I$ que se detecten bajo los criterios que establecemos, se evalúa cada $R F I$ detectado y los especialistas deciden si la solución es un cambio o si es posible manejar en la construcción. 
Imagen 21: Detección de incompatibilidades e interferencias

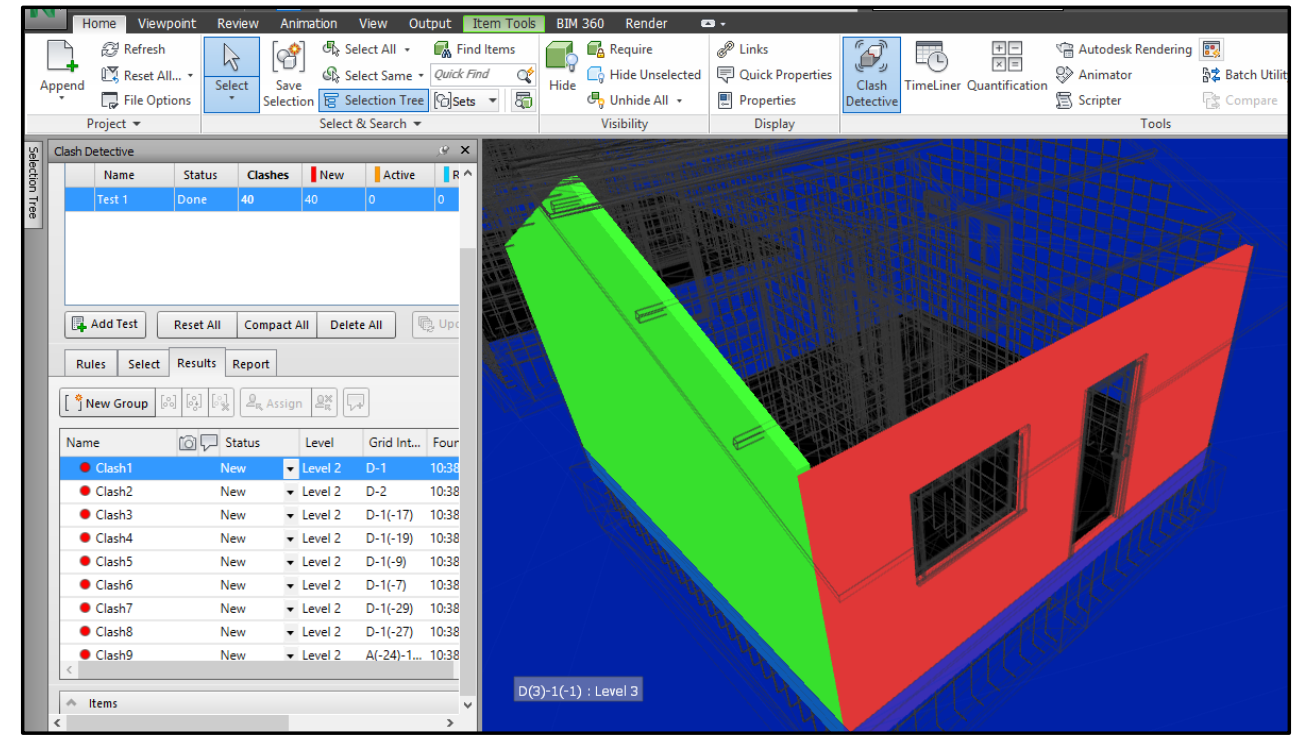

Fuente: (elaboración propia)

Se muestra en la imagen $\mathrm{N}^{\circ} 21$ la visualización de incompatibilidades e interferencias en el SOFTWARE AUTODESK NAVISWORKS, el SOFTWARE posee herramientas para generar reportes y seleccionar las especialidades entre las que se desea detectar interferencias.

\section{Elaboración del modelo BIM 4D}

Uno de los usos más importantes que se le da al BIM es la gestión de la información a través de un modelo $B I M 4 \mathrm{D}$, el cual integra el modelo 3D con la programación, el objetivo de este modelo es mostrar la ejecución. (integración del modelo 3D planificación).

\subsubsection{Entregables de la etapa de diseño}

La presentación de la información para construcción como planos y detalles brindan al constructor información de fácil interpretación, el gran aporte de trabajar con modelos $B I M$ es la obtención y gestión de la información.

La principal información luego de culminado el diseño es la obtención de planos a nivel de detalle requerido, es posible tener las secciones en 3D, planos en planta, incluir las especificaciones técnicas, cortes de los elementos complejos a interpretar; además, se tiene la geometría y dimensiones podemos generar cantidades de cuantificación (tablas de metrados para realizar el presupuesto) con mayor precisión. 


\section{Imagen 22: Planos a nivel de detalle}

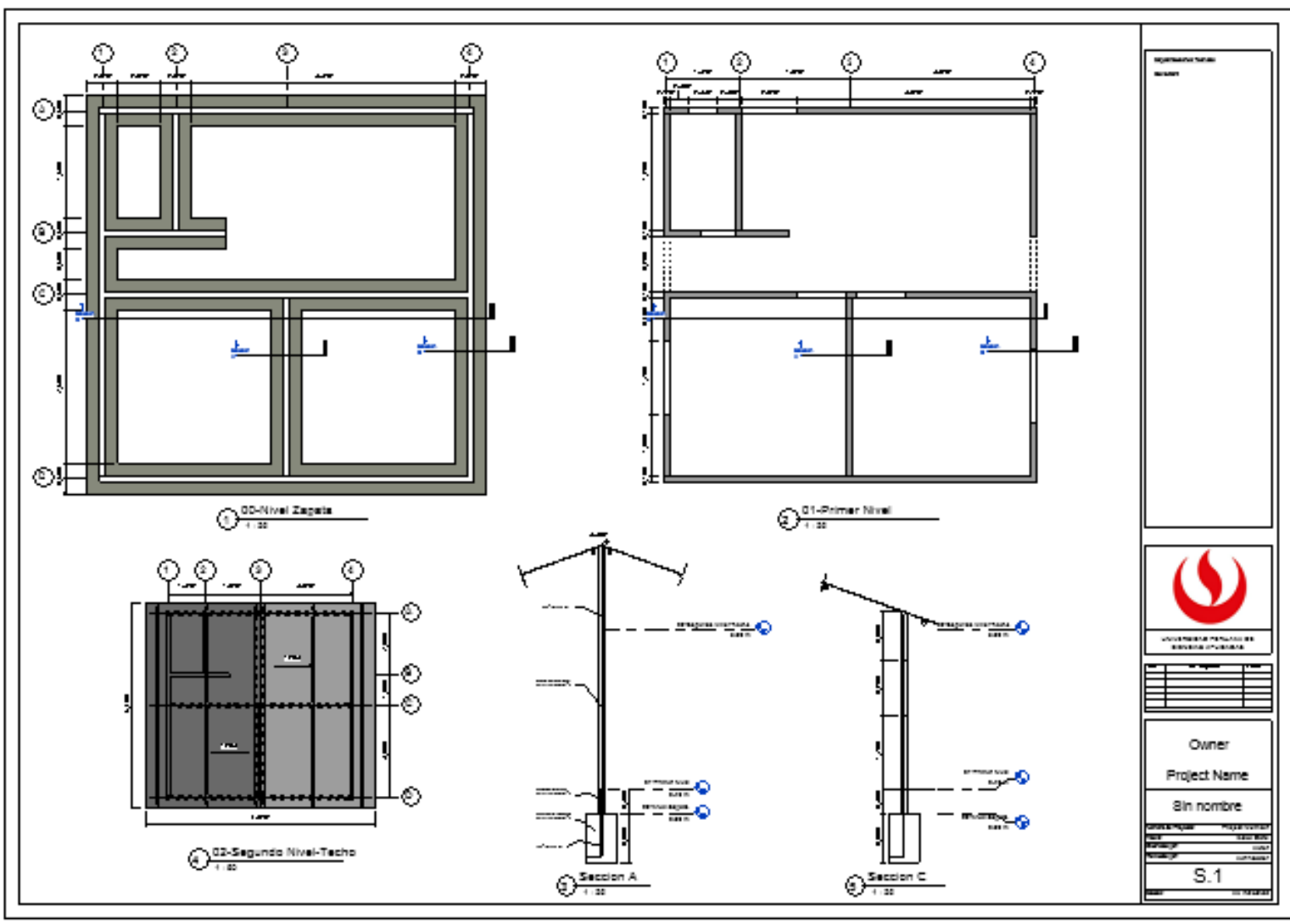

Fuente: (elaboración propia)

En la imagen 22 se muestra un plano de detalle de la especialidad de estructuras, a través del modelo BIM es posible generar planos con la información técnica que se requiera, se puede generar todo tipo de detalle que ayude a interpretar de mejor manera el proyecto. 
Imagen 23: Metrado de elementos en el SOFTWARE Autodesk REVIT

$<$ Tabla de planificación de cimentación estructural>

\begin{tabular}{|c|c|c|c|c|}
\hline A & B & C & D & E \\
\hline Tipo & Anchura & Longitud & Área & Volumen \\
\hline Cimiento corrido de $0.5 \times 0.8 \mathrm{~m}$ & $0.50 \mathrm{~m}$ & & & $14.10 \mathrm{~m}^{3}$ \\
\hline \hline
\end{tabular}

<Tabla de planificación de muros>

\begin{tabular}{||c|c|c|c|}
\hline A & B & C & D \\
\hline Tipo & Anchura & Longitud & Volumen \\
\hline Muro estructural de $0.10 \mathrm{~m}$ & $\mathbf{0 . 1 0 \mathrm { m }}$ & & $12.17 \mathrm{~m}^{\mathbf{3}}$ \\
\hline
\end{tabular}

\begin{tabular}{|c|c|c|c|c|}
\hline \multicolumn{5}{|c|}{$<$ Tabla de planificación de armaduras $>$} \\
\hline A & B & C & D & $\mathrm{E}$ \\
\hline Categoría de anfitrión & Material & Diametro & Longitud de barra & Cantidad \\
\hline \multirow[t]{2}{*}{ Structural Foundation } & Acero Corrugado & $1 / 2^{\prime \prime}$ & $11.79 \mathrm{~m}$ & 134 \\
\hline & & & $11.79 \mathrm{~m}$ & 134 \\
\hline \multirow[t]{2}{*}{ Wall } & Acero Corrugado & $3 / 8^{\prime \prime}$ & $261.11 \mathrm{~m}$ & 158 \\
\hline & & & $261.11 \mathrm{~m}$ & 158 \\
\hline \multirow[t]{2}{*}{ Wall } & Acero Corrugado & $8 \mathrm{~mm}$ & $123.01 \mathrm{~m}$ & 156 \\
\hline & & & $123.01 \mathrm{~m}$ & 156 \\
\hline
\end{tabular}

(Fuente: elaboración propia)

La imagen 23 muestra las tablas de cuantificación que se puede obtener del modelo 3D en el SOFTWARE AUTODESK REVIT, se puede generar tablas por tipo de elemento, familia, especialidad y múltiple de acuerdo a la necesidad.

3.6 Conceptos financieros

\subsubsection{Flujo de caja}

Es una herramienta que mide la liquidez de una empresa en un proyecto, es importante para la toma de decisiones. Es un informe financiero que muestra el detalle de ingresos y egresos netos de dinero para un proyecto en un periodo determinado, es conocido como el saldo disponible para pagar a accionistas y cubrir el servicio de la deuda de la empresa, después de descontar las inversiones realizadas en activos fijos y en necesidades operativas de fondos. En resumen, el Flujo de Caja Libre FCL, representa los beneficios antes de intereses después de impuestos al que se le descuenta la inversión neta, también se podría afirmar que es la remuneración de los propietarios del capital, accionistas y acreedores.

\subsubsection{El valor actual neto (VAN)}

Según (Court M., Aching G., \& Aching Samatelo, 2009), el valor actual neto o VAN actualiza a valor presente los flujos de caja futuros de un proyecto, descontados a un 
cierto tipo de interés y/o tasa de descuento, para compararlos con el valor inicial de la inversión. Como tasa de descuento se utiliza corrientemente el costo promedio ponderado del capital (WACC) de la empresa que realiza la inversión. Mide la rentabilidad del proyecto en valores monetarios deducida la inversión.

Al calcular el VAN de un flujo neto (ingresos menos egresos), se obtiene un valor inferior al que se tendría por la simple suma de esos valores actuales. Esto se debe a la sustracción de la inversión del flujo. La regla del VAN, que indica qué decisión tomar, es:

- Si el VAN es mayor que cero, se debe aceptar.

- Si el VAN es igual a cero, se debe ser indiferente.

- Si el VAN es menor que cero, se debe rechazar.

\subsubsection{Tasa interna de retorno (TIR)}

Según (Court M., Aching G., \& Aching Samatelo, 2009), la TIR hace que el VAN sea igual a cero. La TIR mide la rentabilidad como un porcentaje, que se calcula sobre los saldos no recuperados en cada período. Muestra el porcentaje de rentabilidad promedio por período.

La tasa interna de retorno TIR, complementa casi siempre la información proporcionada por el VAN. Independientemente de los resultados de la TIR que se obtenga, éste deberá confrontarse con la tasa de descuento del proyecto.

La regla de la TIR, que indica qué decisión tomar, es:

- Si la TIR es mayor que la tasa de descuento, se debe aceptar.

- Si la TIR es igual a la tasa de descuento, se debe ser indiferente.

- Si la TIR es menor que la tasa de descuento, se debe rechazar. 


\section{CAPÍTULO 4: PROPUESTA PARA EL MEJORAMIENTO DE LA RENTABILIDAD}

\subsection{Etapa Inicial - Ante Proyecto}

La etapa inicial del proyecto consiste en obtener los requerimientos necesarios para el planteamiento del proyecto, como son la adjudicación del terreno, estudios preliminares, trámites y licencias requeridas, definición del alcance, entre otros.

\subsubsection{Proceso o Fases de la etapa inicial}

La etapa inicial de los proyectos de viviendas sociales consta de cinco fases:

- Análisis del Estado del Terreno

- Estudios Preliminares

- Estudio de Mercado

- Obtención del Terreno

- Habilitación Urbana.

El flujograma de los procedimientos a seguir para las cinco fases se desarrolla en el Anexo $\mathrm{N}^{\circ} 01$

\section{Fase 1: Análisis del Estado del Terreno.}

La adjudicación del terreno se puede dar de diversas maneras, ya sea por compra del terreno, convenios, donaciones, entre otros; para ello es importante que dicho terreno cumpla las siguientes condiciones:

- Área suficiente y libre de riesgos: debe existir un área mínima, dependiendo de la cantidad de lotes determinados en el proyecto, que respete los reglamentos y normas de habilitaciones urbanas con respecto a las áreas libres y vías; además, el terreno debe estar libre de riesgos como deslizamientos, inundaciones, entre otros.

- Existencia de población interesada (Demanda): al menos el 70\% de lotes debe estar asegurado por la población existente en el terreno, es decir, se debe realizar un estudio inicial, según la cantidad de familias, para determinar la cantidad de viviendas a ejecutar, de esta manera se garantiza su venta.

- Factibilidad de servicios: es necesario la existencia de servicios básicos como son las redes de agua potable y redes de electrificación. De no ser el caso, debe existir fuentes de agua o redes principales de electrificación cercanas.

- Facilidad de materiales de construcción: en caso de que la construcción sea de concreto armado, como es el caso del trabajo de investigación, es importante que existan facilidades para conseguir agregado como canteras, ríos, etc.; y deben existir vías de acceso aptas para transportar cemento y acero. 
- Terreno Matriz: es importante que, por lo menos, el terreno matriz se encuentre inscrito en la SUNARP, de esta manera se facilitan los trámites necesarios para la obtención del terreno, en caso de que no se tenga título de propiedad.

- Consejo Directivo de la Comunidad Campesina: así como es importante la inscripción del terreno matriz en casos que no se tenga título de propiedad, también es importante que la comunidad campesina tenga una junta directiva reconocida en la SUNARP, de lo contrario sería poco factible realizar los trámites de obtención del terreno.

Fase 2: Estudios Preliminares:

Comprende los estudios básicos para proyectos de construcción de edificaciones, los cuales son el Estudio de Impacto Ambiental, Estudio de Suelos, Estudio de Canteras para extracción de hormigón, Estudio de Factibilidad de Servicios tanto de luz, agua, desagüe, y el Levantamiento Topográfico. Con esta información se elaboran el plano perimétrico, ubicación y el plano de desmembramiento, de ser necesario; además se realiza el diseño base del proyecto. Esta fase puede durar de 2 a 3 meses, dependiendo la complejidad del proyecto.

\section{Fase 3: Estudio de Mercado:}

En esta fase se hace un análisis de la demanda de viviendas sociales, según la ubicación del proyecto, en la cual se determina el alcance del proyecto como es el número de viviendas requeridas, el área mínima de vivienda y de lote, el costo máximo de las viviendas, el sistema constructivo, entre otros. Se calcula que puede durar un mes y se puede realizar en paralelo con la fase de los estudios preliminares del proyecto.

\section{Fase 4: Obtención del Terreno:}

Dependerá del tipo de adjudicación del terreno, si el terreno es comprado con el título de propiedad completamente saneado, esta fase se omite; pero si es por donación o por convenio con la comunidad campesina, el procedimiento para legalizar la obtención del terreno será de la siguiente manera. Primero se inscribe ante la SUNARP el acta de donación de terreno, en paralelo se hace la búsqueda catastral para verificar que no exista ningún predio registrado. Segundo, se solicita la independización al Ministerio de Agricultura, el cual emite el Certificado de Inexistencia de Posesiones Informales en Territorios de Comunidades Campesinas y el Certificado Negativo de Zona Catastrada. Con todos los mencionados documentos se procede a realizar la Escritura Pública, con ello se inscribe a la SUNARP y se obtiene el Título Independizado.

\section{Fase 5: Habilitación Urbana:}

Antes de solicitar la aprobación de la habilitación urbana se debe tener en cuenta su reglamentación (Ley $\mathrm{N}^{\circ} 29090$ Regulación de Habilitaciones Urbanas y de Edificaciones y sus modificaciones) y posteriormente solicitarlo ante la municipalidad local, es necesario realizar el planeamiento integral para el cual se solicita el Certificado de Inexistencia de Restos Arqueológicos en el Ministerio de Cultura, además se solicita el Certificado de Servicios de Agua Potable y Electrificación a las concesionarias 
encargadas o, de ser el caso, a la municipalidad. Si existen ríos en el área del proyecto es necesario realizar las recomendaciones del ANA ante posibles riesgos. Asimismo, si existen carreteras es necesario solicitar ante el Ministerio de Transporte y Telecomunicaciones las dimensiones de derecho de vías troncales y secundarias. Con todos los documentos obtenidos se elabora el expediente técnico para la habilitación urbana, esto comprende los planos de manzaneo y lotización; planos, memoria descriptiva y presupuesto de redes de agua potable, redes de electrificación y redes de alcantarillado; plano de vías; entre otros. Una vez obtenido la aprobación de habilitación urbana, la cual puede demorar entre 4 a 6 meses, se solicita la aprobación del proyecto ante el Ministerio de Vivienda, Construcción y Saneamiento, el cual otorga un código de proyecto después de 3 meses de presentado el expediente técnico; con este documento se puede iniciar la construcción de las viviendas. Mientras se espera la aprobación de la habilitación urbana se realiza el expediente técnico del proyecto, es decir, el diseño de los módulos de vivienda, el presupuesto y el planeamiento.

\subsubsection{Definición del alcance del proyecto}

Dentro del alcance del proyecto se considera los siguientes entregables:

\section{Habilitación urbana del terreno.}

- Para el desarrollo del presente trabajo de investigación, se propone un proyecto de habilitación urbana que contempla 100 lotes con áreas de cada terreno de $200 \mathrm{~m} 2$ para la construcción de las viviendas, el cual se ha diseñado cumpliendo los requisitos establecidos en el Reglamento Nacional de Edificaciones, considerando áreas mínimas para educación, zonas recreativas, ancho de vía mínimo requerido, densidad poblacional, entre otros.

- Para determinar la incidencia en costo y tiempo que representan las habilitaciones urbanas para los proyectos de vivienda social se asume ratios de costo y tiempo de proyectos similares para la evaluación de la rentabilidad.

Imagen 24: Detalle en planta de la habilitación urbana.

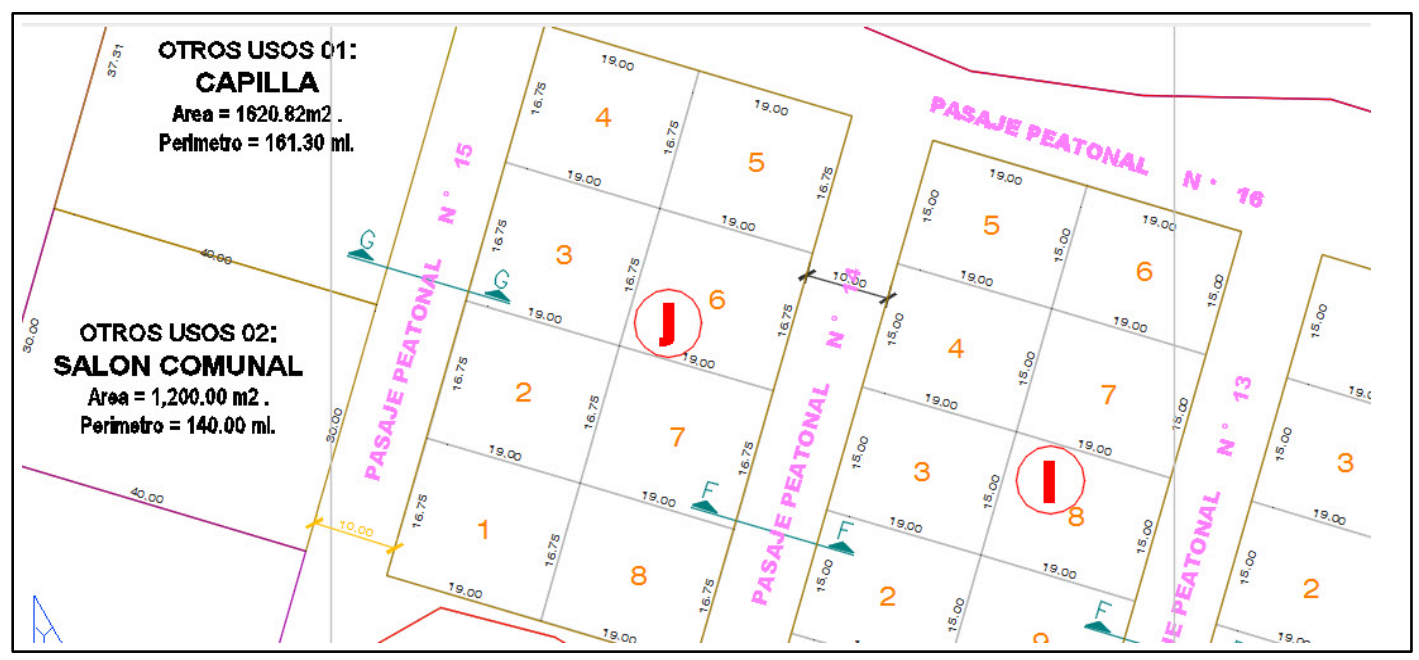

Fuente: (Elaboración Propia). 
Los módulos de vivienda y alternativas

- Se proyecta la construcción de 100 módulos de vivienda de $37 \mathrm{~m} 2$ de un solo nivel, que cuentan con 02 dormitorios, 01 sala-comedor-cocina, 01 baño, 01 lavandería y 01 patio; los cuales cumplen con lo exigido en el reglamento nacional de edificaciones.

- Las puertas son de madera maciza en el ingreso, para el interior se considera puertas contraplacadas, tendrán un marco de madera de 3"x2". Las ventanas están estandarizadas, son de madera de 2"x2". La cerrajería de las puertas exteriores se considera cerradura de tres golpes, para interiores se considera del tipo bola y en las ventanas se considera picaportes de 2". Los vidrios para las ventanas serán semidoble.

- Los aparatos sanitarios que se instalarán son 01 inodoro, 01 lavadero de loza blanca en SS.HH. Se instalará 01 lavaplatos de fibra en cocina. Se utilizará grifería de metal en lavadero de SS.HH; grifería de PVC en lavaplatos y lavadero de ropas. Las instalaciones estarán empotradas con red de agua fría y red de desagüe. No incluye medidor de agua.

- Las instalaciones eléctricas estarán empotradas, se utilizará suministro monofásico que contará con 06 puntos de luz, 09 puntos de tomacorriente, 01 salidas para calentador, 05 sockets. contará con tablero eléctrico de PVC con 03 llaves termo magnéticas. Se considera el cableado, No incluye medidor de luz.

- Las excepciones al proyecto son los obras complementarias como son los servicios básicos como el sistema de abastecimiento de agua, red de desagüe, electrificación (postes para el cableado por la empresa suministradora de energía eléctrica), pistas y veredas; los cuales solo se estiman en costo para el desarrollo del análisis del flujo económico - financiero.

\section{Alternativas de diseño}

- Alternativa $\mathrm{N}^{\circ}$ 01: el sistema constructivo de esta alternativa está formado por muros de ductilidad limitada (MDL), los muros son de concreto armado de resistencia a la compresión $\mathrm{f}^{\prime} \mathrm{c}=210 \mathrm{~kg} / \mathrm{cm} 2$ con un espesor $\mathrm{E}=0.10 \mathrm{~m}$, la cobertura estará conformada por una estructura de perfiles metálicos y cobertura de teja castellana adecuándose en el color para armonizar con el entorno, los acabados son muros de concreto solaqueados y pintados en todos sus ambientes. Los pisos son de concreto con acabado semipulido en los ambientes de cocina, comedor y dormitorio, el piso de los servicios higiénicos es revestido con cerámico antideslizante, se muestra en el anexo $\mathrm{N}^{\circ} 02$. 
Imagen 25: Alternativa $N^{\circ} 01$ distribución en planta y vista $3 D$ del módulo de vivienda sistema muros de ductilidad limitada (MDL).

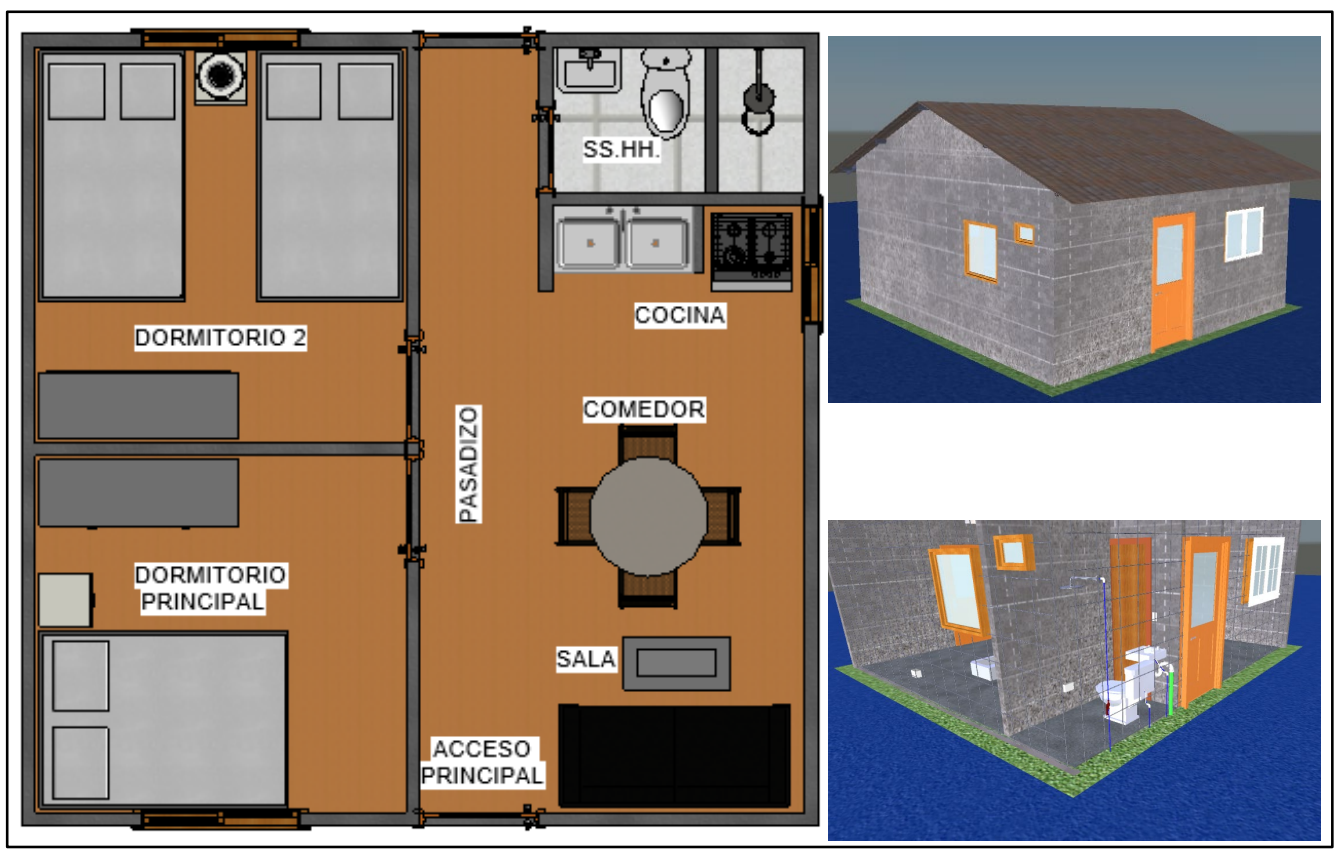

(Fuente: elaboración propia)

En la imagen 25 se muestra la distribución en planta y vista 3D de la alternativa $\mathrm{N}^{\circ} 01$, el área de la vivienda es de $37 \mathrm{~m} 2$.

- Alternativa $\mathrm{N}^{\circ}$ 02: el sistema constructivo es aporticado (columnas y vigas), las columnas y vigas son de sección $0.25 \mathrm{mx} 0.25 \mathrm{~m}$ de concreto armado de resistencia a la compresión $\mathrm{f}^{\prime} \mathrm{c}=210 \mathrm{~kg} / \mathrm{cm} 2$, la cobertura estará conformada por una estructura de perfiles metálicos y cobertura de teja castellana adecuándose en el color para armonizar con el entorno, los acabados son muros de albañilería solaqueados y pintados en todos sus ambientes. Los pisos son de concreto con acabado semipulido en los ambientes de cocina, comedor y dormitorio, el piso de los servicios higiénicos es revestido con cerámico antideslizante, se muestra en el anexo $\mathrm{N}^{\circ} 03$. 
Imagen 26: Alternativa $N^{\circ} 02$ distribución en planta del módulo de vivienda sistema aporticado.

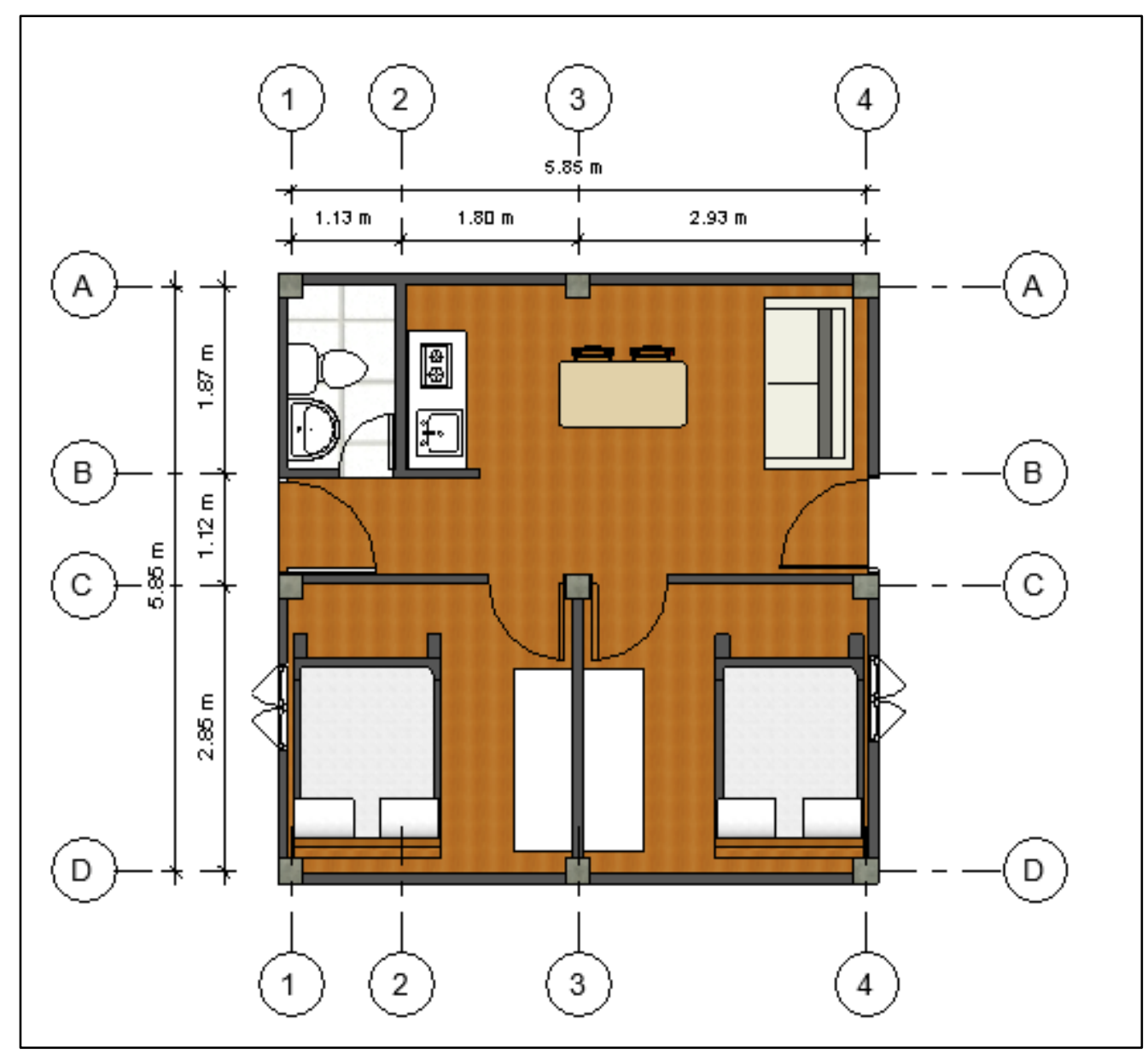

Fuente: (elaboración propia)

La imagen 26 muestra la distribución en planta de la alternativa $\mathrm{N}^{\circ} 02$, el área de la vivienda es de $37 \mathrm{~m} 2$, los elementos estructurales principales son vigas y columnas, zapatas aisladas.

De las alternativas para el módulo de vivienda se elige la alternativa $\mathrm{N}^{\circ} 01$, por tener menor costo de construcción por $\mathrm{m}^{2}$ igual a $\mathrm{S} / .800 .00$, vs el costo de construcción de la alternativa $\mathrm{N}^{\circ} 2$ de S/. 950.00; por lo tanto, constructivamente es más fácil de ejecutar.

\subsection{Etapa Diseño}

\subsubsection{Proceso de diseño}

Diseño del proyecto y elaboración del modelo 3D

Definido todos los estándares entre los especialistas; asimismo, configuración de parámetros de los elementos se obtiene el modelo arquitectónico (muros, losas, cobertura, puertas, ventanas, aparatos sanitarios, objetos varios, etc.), es preciso mencionar que desde la plantilla de arquitectura es posible acceder a los elementos 
estructurales y de instalaciones en REVIT, los cuales se pueden utilizar sin ningún problema, no debemos confundir que al diseñar un muro, losa u otro elemento ya sea de la especialidad estructural o instalaciones desde la plantilla arquitectónica, lo único que se realiza es la representación de la geometría del elemento que por supuesto no tendrá el comportamiento y las características de su especialidad, ejemplo el muro estructural diseñado desde la especialidad de arquitectura solo será geometría al cual no se le puede asignar refuerzo, otro ejemplo que podemos mencionar referente a los aparatos sanitarios insertados desde la plantilla arquitectónica es que no tendrán los puntos de conexión para la unión de tuberías, es por ello que cada especialidad se diseña en su propia plantilla.

Imagen 27: Modelo Arquitectónico detalle en planta y corte en 3D

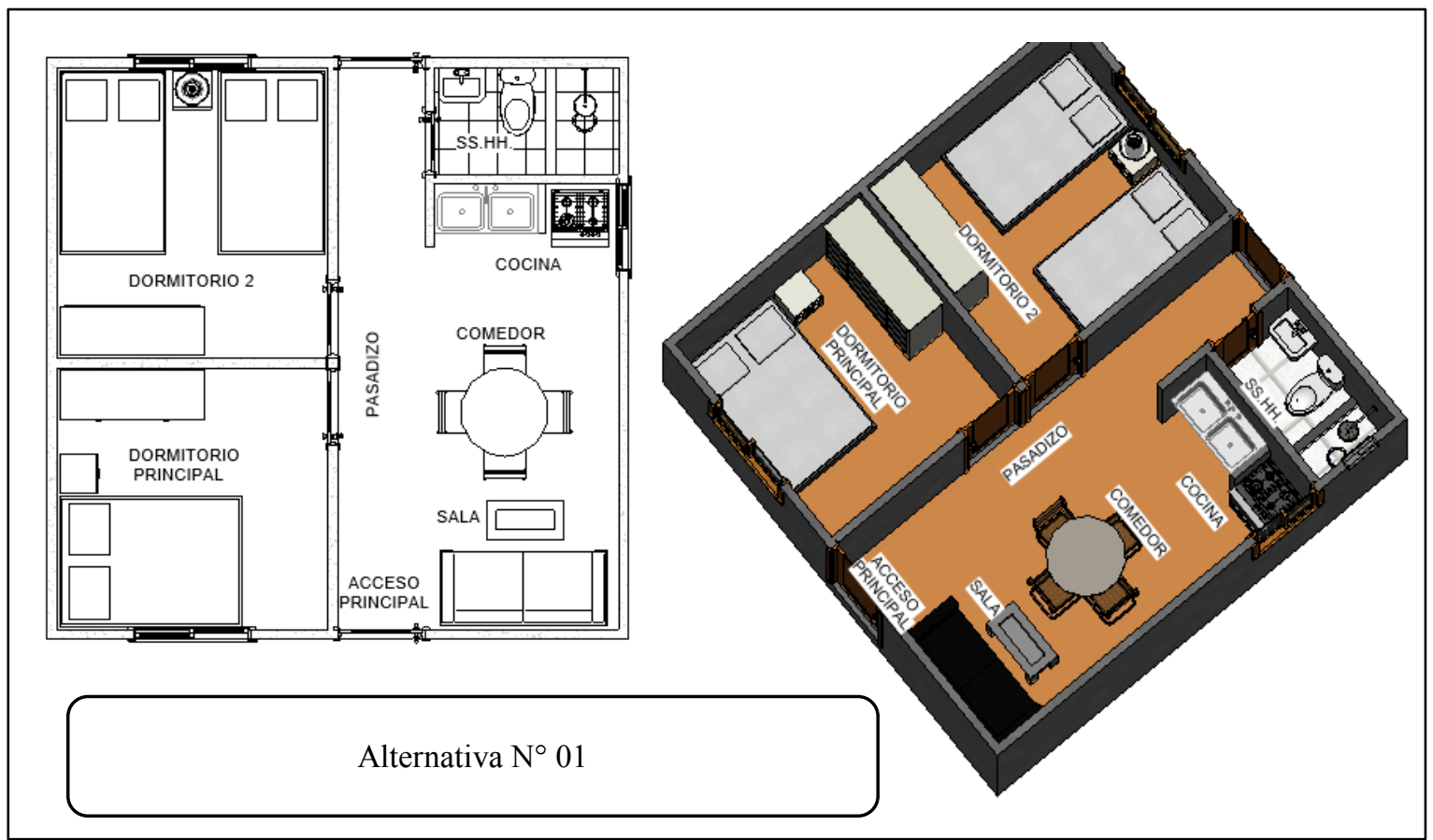

Fuente: (elaboración propia)

La imagen 27 muestra la distribución en planta y el corte del modelo 3D de la especialidad de arquitectura.

Culminado el diseño arquitectónico se procede a vincular el modelo para el diseño de la especialidad de estructuras e instalaciones, esta es una forma de trabajo coordinado, en proyectos complejos se sugiere trabajar de forma colaborativa sobre un modelo principal ya sea de forma presencial o virtual, en este caso se diseñará la especialidad de estructuras a través de vínculos entre modelos para ello utilizamos la herramienta $M A N A G E$ (Gestionar).

Al vincular la arquitectura en nuestro modelo estructural estamos garantizando que los elementos coincidan, es por ello que al momento de gestionar los vínculos al momento de cargar se debe considerar la selección Project Base Point to Project Base Point (de punto base para punto base del proyecto), por otro lado no debemos olvidar antes de importar el vínculo, realizar la configuración de unidades en el modelo estructural de la misma forma como se procedió en la especialidad de arquitectura. 
Imagen 28: Gestión de vínculos de formato .rvt

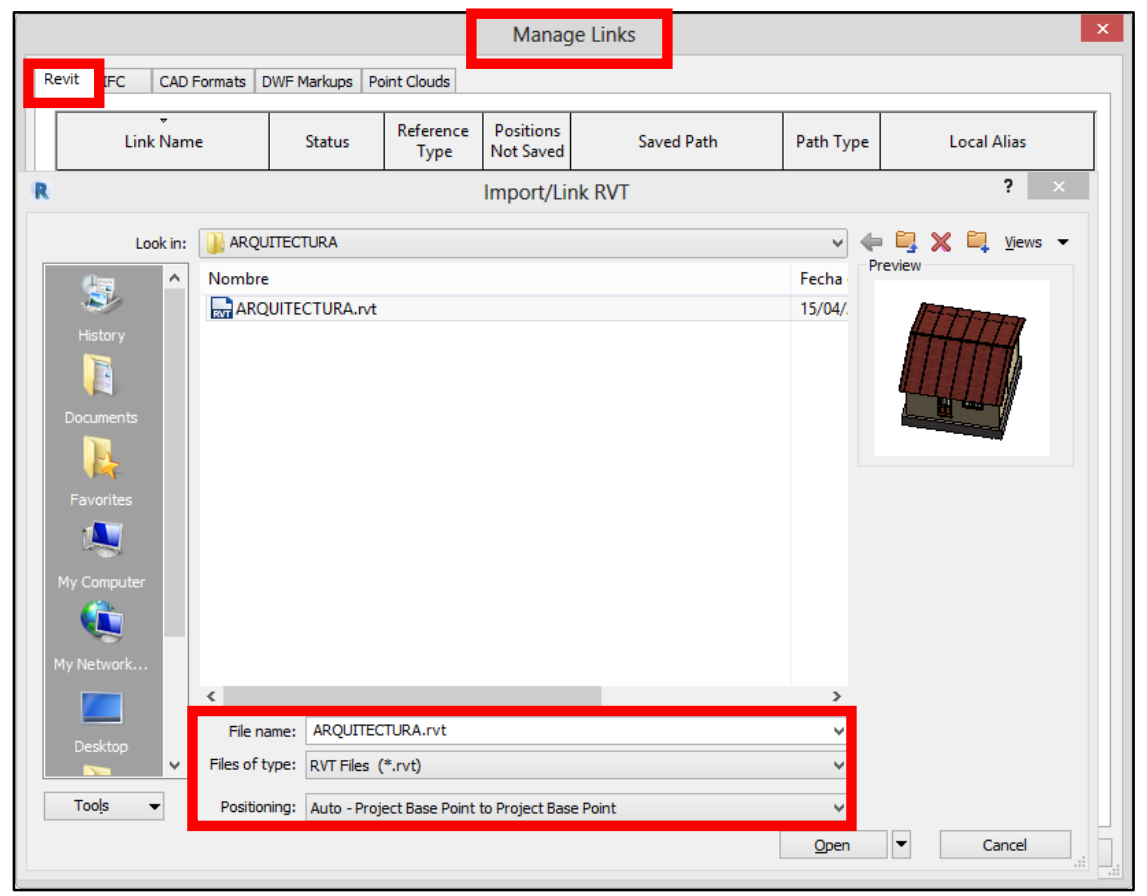

Fuente: (elaboración propia)

En la imagen 28 muestra la herramienta de gestión de vínculos, el SOFTWARE permite la elección del tipo de formato a vincular en el proyecto, se tiene las opciones de formato REVIT, cad, dwf.

Después de tener el link del modelo arquitectónico, en el modelo estructural se procede a copiar los elementos que se reutilizarán en el diseño estructural (ejes, niveles, muros, losas, etc.), ubicamos el menú COLLABORATE (Colaborar) de la cinta de opciones y seleccionamos la herramienta Copy/Monitor (copiar y monitorear) como se muestra en la imagen $\mathrm{N}^{\circ} 29$, luego seleccionamos el Link del vínculo. Es importante solo copiar elementos que podrían sufrir cambios en las especialidades, la principal ventaja de realizar este monitoreo es para controlar los cambios que sucedieran en la especialidad de arquitectura que pudieran afectar el modelo estructural (modificación de ejes, cambio de altura entre niveles, espesores de muros, modificación en la distribución, etc.)

Imagen 29: Menú COLLABORATE, Copiar y monitorear.

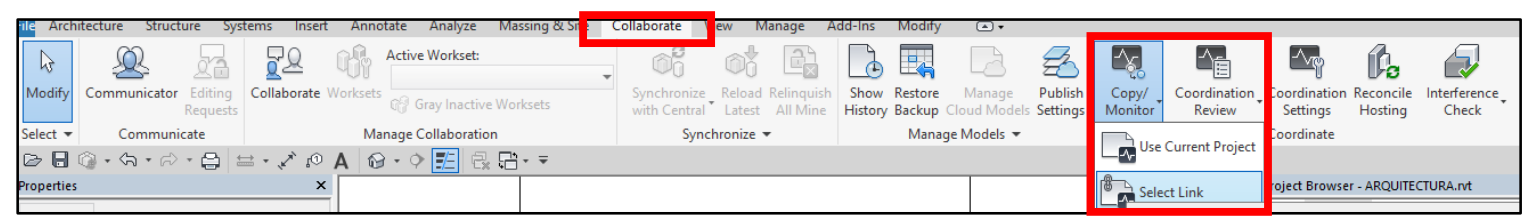

Fuente: (elaboración propia) 
Imagen 30: Menú Collaborate, Copiar y monitorear.

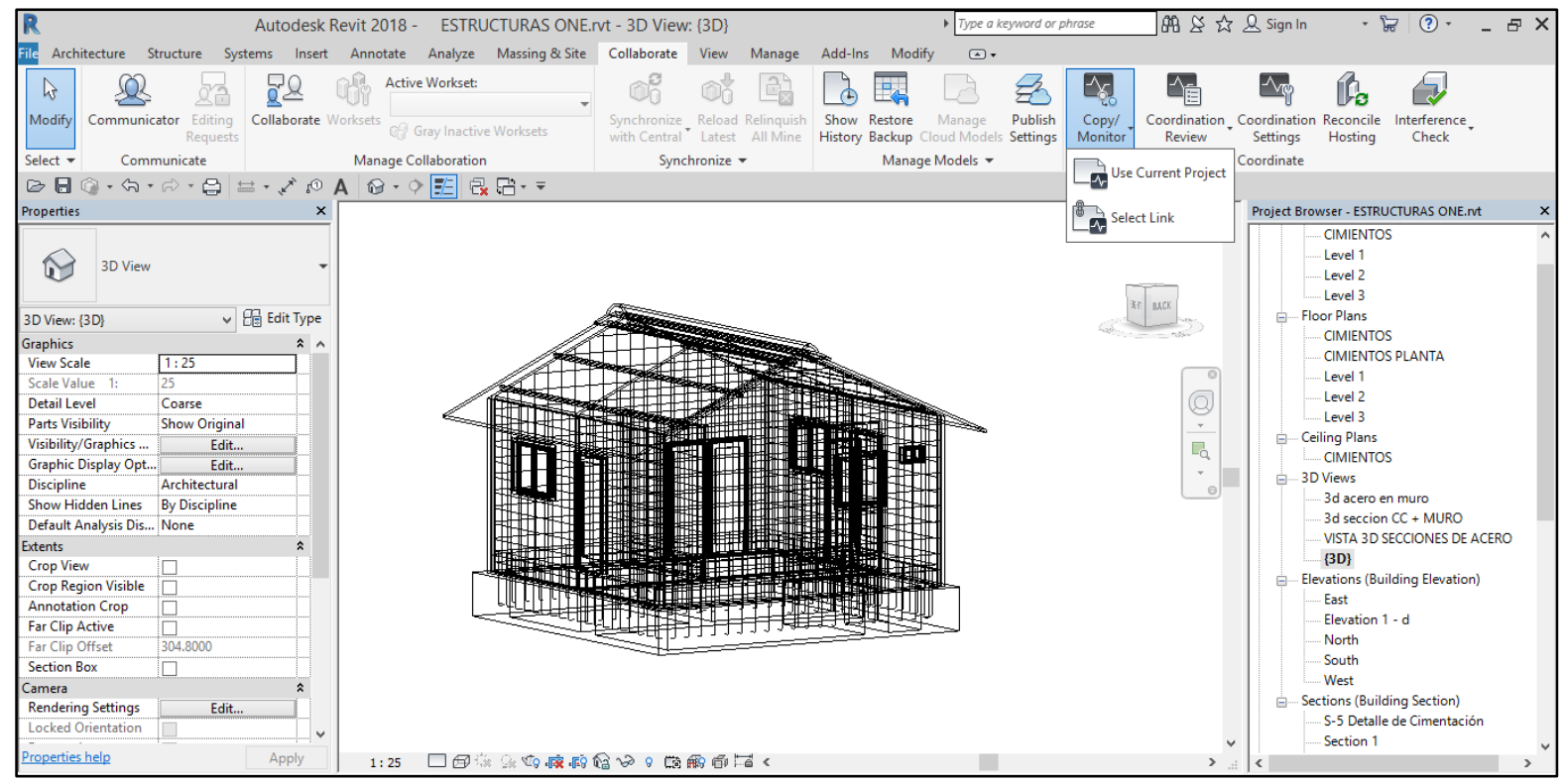

Fuente: (elaboración propia)

La imagen 30 muestra el proceso de copiar elementos y monitoreo desde el modelo principal, toda actualización que se realice en el modelo que se trabaja se verá reflejado en el modelo que posee el vínculo dando la opción de actualizar.

\subsubsection{Sinergia del LEAN y el BUILDING INFORMATION MODELING}

En los proyectos convencionales como se vienen desarrollado en la actualidad con los proyectos de viviendas sociales en la sierra sur del Perú la filosofía $L E A N$ CONSTRUCTION se desarrollará independientemente de la metodología BIM, no obteniéndose proyectos exitosos, en la actualidad se sabe que el BIM será cada vez más sustancial, convirtiéndose en una herramienta vinculada dentro de la filosofía LEAN CONSTRUCTION, reflejándose mediante las buenas prácticas y documentaciones de los proyectos, ahorrando tiempo, reduciendo desperdicios e involucrando a todos los colaboradores; buscando la utilización de un flujo único que involucre el aprendizaje basándose en la retroalimentación del trabajo satisfaciendo las expectativas del cliente y generando mayores rentabilidades.

Existen muchas funciones de BIM y LEAN CONSTRUCTION que han sido identificadas y aplicadas en nuestro presente trabajo de investigación como se muestra en el Gráfico 5 Ciclo del Proyecto con enfoques LEAN CONSTRUCTION y BIM, logrando mejores beneficios y mayor rentabilidad en los proyectos de Viviendas Sociales, viéndose reflejado en buenas prácticas y documentaciones indicando ahorro de tiempo, desperdicios y una gran colaboración entre los involucrados, existiendo interacciones en la planificación, coordinación de recursos, optimización organizacional, mayor colaboración entre participantes para que puedan compartir sus errores y oportunidades de aprendizaje de los proyectos ejecutados y los por ejecutar basándose en la retroalimentación satisfaciendo los requisitos y expectativas del proyecto, permitiendo desarrollar y mejorar los principios LEAN CONSTRUCTION 
mediante la herramienta del Look Ahead permitiéndonos visualizar entre 4 a 6 semanas antes de sus ejecución analizando las tareas a ejecutar, restricciones a identificar.

De esta manera la interacción permite que con el BIM podamos facilitar el seguimiento y generación de reportes en tiempo real dando soporte a la realidad aumentada permitiendo monitorear el progreso de la construcción en tiempo real, con el propósito de evaluar el avance y tomar decisiones futuras anticipadamente.

\subsubsection{Logros obtenidos del diseño}

Los principales logros obtenidos en esta etapa son:

- Ahorro de tiempo en el diseño.

Se realizó el diseño a través del trabajo coordinado y colaborativo, optimizándose el tiempo en dos semanas.

- Integración de especialidades de diseño en un modelo único (modelo 3D).

A través de un modelo anfitrión (modelo arquitectónico) se procedió a realizar el diseño de las especialidades, para la correcta concepción del proyecto se tuvo la participación de los STAKEHOLDER a través de las reuniones ICE, lográndose tener el modelo final con lo requerido por el cliente.

- Eliminación de interferencias entre especialidades.

Se logró eliminar las interferencias entre las especialidades de estructuras e instalaciones sanitarias, que es lo más común en este tipo de sistema constructivo (MDL) donde la estructura principal está compuesta por muros.

- Planos compatibilizados. (Ver anexos 4, 5, 6, 7 y 8)

Culminado el proceso se obtuvo planos compatibilizados de las especialidades del proyecto, los cuales contienen la información necesaria para la planificación y construcción, se logró coherencia entre los planos y especificaciones técnicas.

- Detalles con mayor información técnica.

Los detalles que se realizó tienen perspectiva en $2 \mathrm{D}$ y $3 \mathrm{D}$, lo que facilita la interpretación.

- Metrados.

Se obtuvo la planilla de metrados con las cantidades requeridas por el proyecto, lo cual facilitó la elaboración del presupuesto.

\subsection{Etapa de Planeamiento}

\subsubsection{Identificación de problemas en el planeamiento}

En la actualidad, en la mayoría de los proyectos de vivienda, la planificación se ha desarrollado de forma deficiente debido a muchos errores en la etapa de planificación. En el siguiente cuadro se describen los principales problemas y causas identificados en los proyectos ejecutados en la sierra sur del Perú. 
Cuadro 4: Problemas en proyectos de la sierra sur del Perú.

\section{PROBLEMA}

Hitos y entregables no
determinados
adecuadamente.

Inadecuada planificación inicial.

CAUSA

Mala planificación, no se utiliza adecuadas herramientas de gestión.

- La planificación se realiza en gabinete sin considerar las restricciones de obra.

- No se consideran las variabilidades externas.

- No se consideran a los STAKEHOLDERS.

\begin{tabular}{|c|c|c|}
\hline $\begin{array}{l}\text { Asignación de mano de } \\
\text { obra en varias } \\
\text { actividades a la vez de } \\
\text { ejecución simultánea. }\end{array}$ & $\begin{array}{l}\text { Sobreasignación de recursos } \\
\text { humanos por desconocimiento } \\
\text { de procedimientos de las } \\
\text { actividades. }\end{array}$ & $\begin{array}{c}\text { Se pierde tiempo } \\
\text { capacitando al nuevo } \\
\text { personal, y se vuelve a } \\
\text { desarrollar la curva de } \\
\text { aprendizaje. }\end{array}$ \\
\hline $\begin{array}{l}\text { Desconocimiento de } \\
\text { restricciones y riesgos. }\end{array}$ & $\begin{array}{l}\text { Falta de análisis de } \\
\text { restricciones y matriz de } \\
\text { riesgos. }\end{array}$ & $\begin{array}{l}\text { Paralizaciones, atrasos al } \\
\text { inicio de obra, actividades } \\
\text { postergadas. }\end{array}$ \\
\hline $\begin{array}{l}\text { Desconocimiento de } \\
\text { proveedores de } \\
\text { materiales de } \\
\text { construcción y mano de } \\
\text { obra disponibles. }\end{array}$ & $\begin{array}{l}\text { Falta de un estudio del entorno } \\
\text { del proyecto. }\end{array}$ & $\begin{array}{c}\text { Atrasos de obra, actividades } \\
\text { postergadas, altos costos y } \\
\text { tiempos. }\end{array}$ \\
\hline $\begin{array}{l}\text { Liquidez insuficiente } \\
\text { para el suministro de } \\
\text { los recursos en las } \\
\text { cantidades requeridas. }\end{array}$ & $\begin{array}{l}\text { Falta de liquidez ya que el flujo } \\
\text { de caja se proyecta en base a } \\
\text { una mala planificación. }\end{array}$ & $\begin{array}{c}\text { Atrasos de obra, actividades } \\
\text { postergadas. }\end{array}$ \\
\hline Sectorización deficiente & $\begin{array}{l}\text { No se analiza adecuadamente } \\
\text { la cuantificación de los } \\
\text { sectores. }\end{array}$ & $\begin{array}{l}\text { Demora en los entregables e } \\
\text { incumplimiento de plazo }\end{array}$ \\
\hline
\end{tabular}

Fuente: (Elaboración propia) ${ }^{1}$.

Como se muestra en el cuadro 4, los principales problemas presentados en la construcción de viviendas sociales son causados por la mala planificación inicial; por ello, la principal propuesta para la mejora es la implementación de LAST PLANNER con la herramienta $L O O K A H E A D$ en la planificación del proyecto.

\footnotetext{
${ }^{1}$ Se toma de referencia los proyectos de Techo Propio "Inkaq Samanan" y "Tirikway".
} 
Gráfico 6: Planeamiento Convencional.

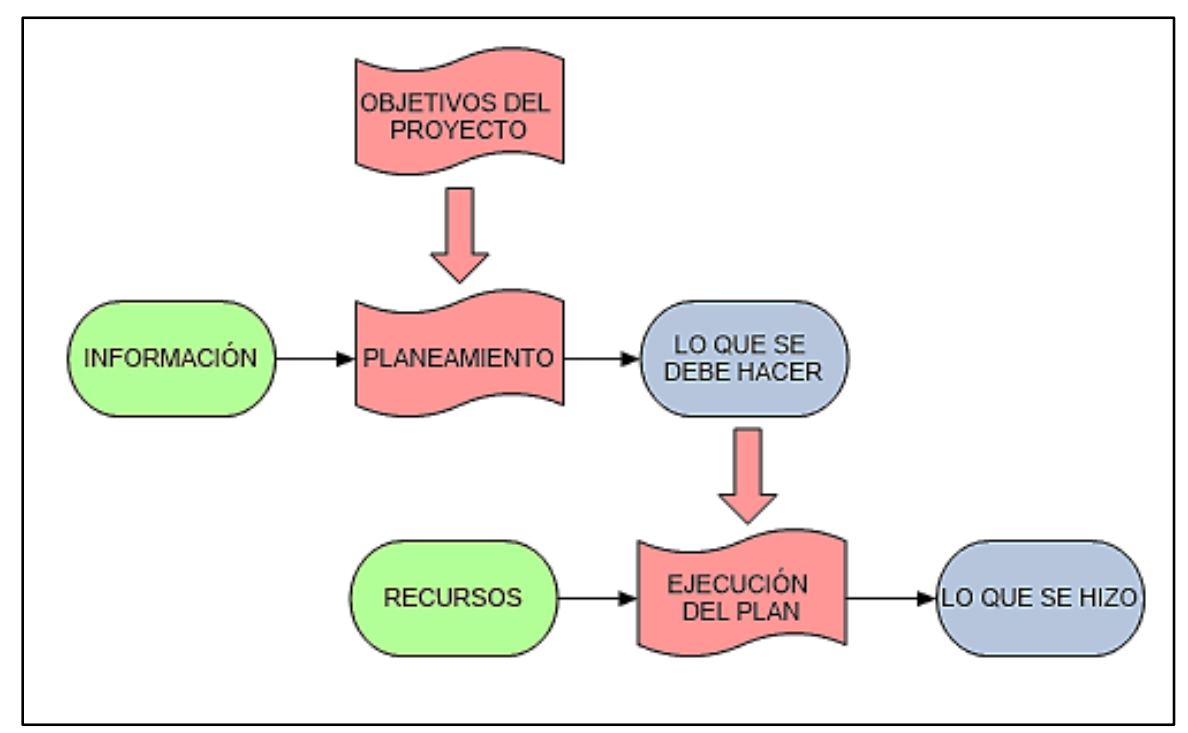

Fuente: (Elaboración propia).

Según el gráfico 6, el flujo de planeamiento de los proyectos tradicionales se efectúa de forma lineal sin realizar una mejora continua entre cada etapa del proyecto; además, se efectúa de forma general sin considerar restricciones, cantidades de ejecución exacta por día, etc.; por lo cual, la ejecución del proyecto se hace de forma improvisada, no existe una buena gestión de inventarios, el ciclo de producción es semanal o mensual. En consecuencia, se producen atrasos y paralizaciones.

La planificación contempla la idealización de lo que se quiere lograr en el proyecto con el tiempo, partiendo de la información brindada del modelo BIM, podemos cuantificar adecuadamente las cantidades de producción diaria, semanal, mensual, anual, etc., y basados en los enfoques LEAN CONSTRUCTION como base del planeamiento del proyecto, utilizando la herramienta $L O O K A H E A D$ para gestionar los recursos partiendo de la identificación de los entregables y requerimientos del proyecto. Asimismo, toda la información obtenida se utilizará para el BIM $4 D$ con la gestión del tiempo.

Con la información anterior, se realiza la planificación a detalle buscando optimizar los tiempos de ejecución, reducir la variabilidad, reducir los desperdicios, optimizar procesos, agregar valor a la gestión, incremento de control de procesos, introducir procesos con mejora continua; para lograr los objetivos planteados se hará uso de la herramienta $L O O K A H E A D$ partiendo del cronograma general de obra. 
Gráfico 7: Flujo del Planeamiento con LEAN CONSTRUCTION.

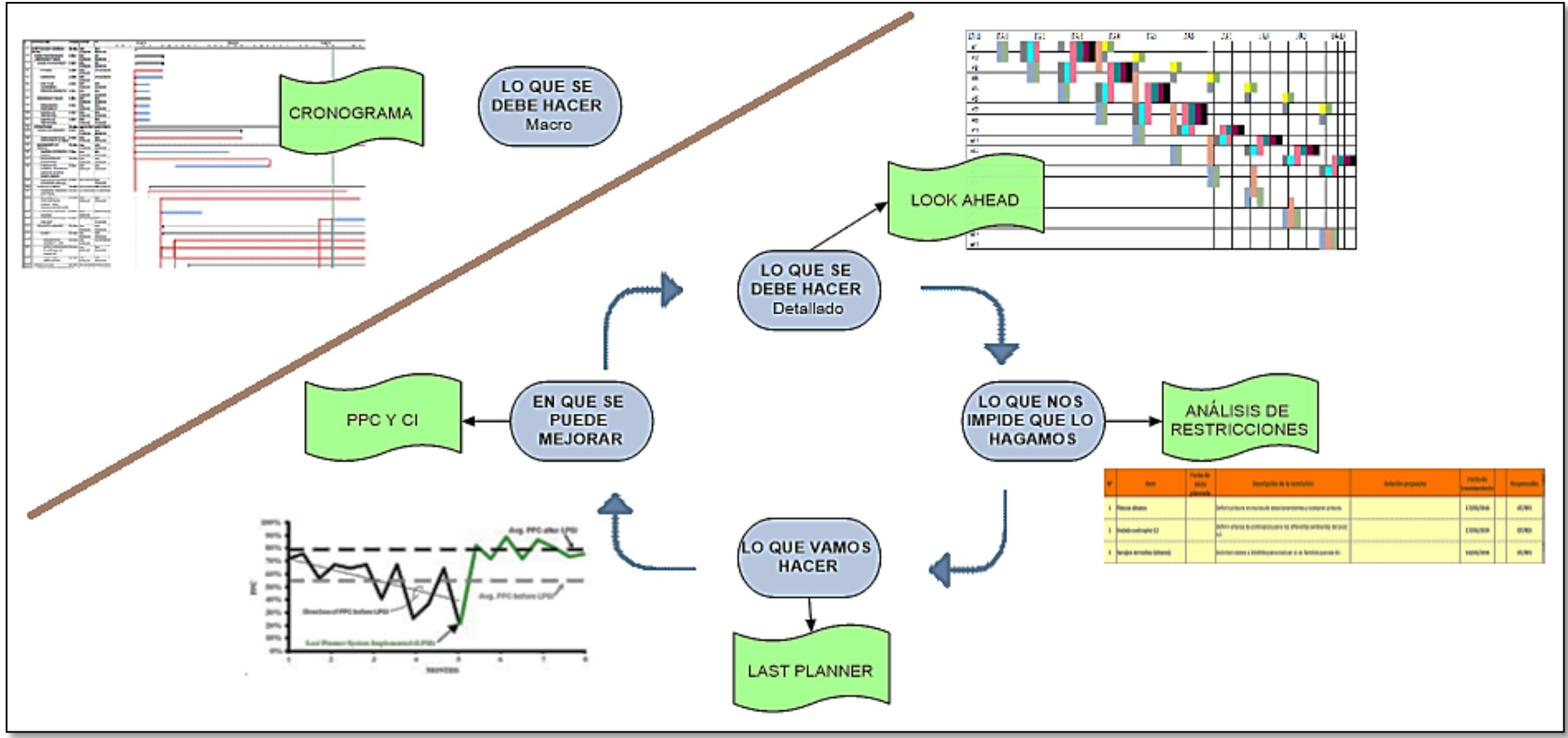

Fuente: (Oroz Tito, 2015)

En el gráfico 7 se presenta el ciclo de las etapas de planeamiento del proyecto a partir del cronograma general de obra; en primer lugar, se tiene el $L O O K$ AHEAD donde se describe lo que se debe hacer. En segundo lugar, se tiene el análisis de restricciones donde se evalúa y minimiza las restricciones. En tercer lugar se tiene el LAST PLANNER, que describe lo que hará. Finalmente, se identifican los indicadores PPC y CI en la etapa de construcción para analizar en qué se puede mejorar. 


\subsubsection{WORK BREAKDOWN STRUCTURE (WBS) y Cronograma General}

Para realizar una visualización más controlable de las actividades para la ejecución de la construcción, se plantea una sectorización considerando que todas las unidades de vivienda tienen el mismo metrado y actividades, por lo tanto se consideran 5 sectores de 20 viviendas cada una.

Las consideraciones que se tomaron para realizar la sectorización fueron las siguientes:

- Las unidades de vivienda tienen el mismo metrado y las mismas actividades, es por ello que se fraccionan en 5 sectores de 20 viviendas cada una.

- Se agrupó los sectores tomando en cuenta la cercanía entre ellas, de esta manera se reducen el tiempo de los trabajos no contributorios.

- La secuencia de construcción de los sectores se determina en base al LAYOUT de obra donde se ubican las áreas principales (almacenes, oficinas, campamentos, acopios de materiales, entre otros), distancias de transporte y movilización de equipos, accesos, etc. Por ello, se prioriza los sectores que se encuentran más alejados al acceso principal para evitar las interferencias en el flujo de procesos.

Imagen 31: Sectorización del proyecto.

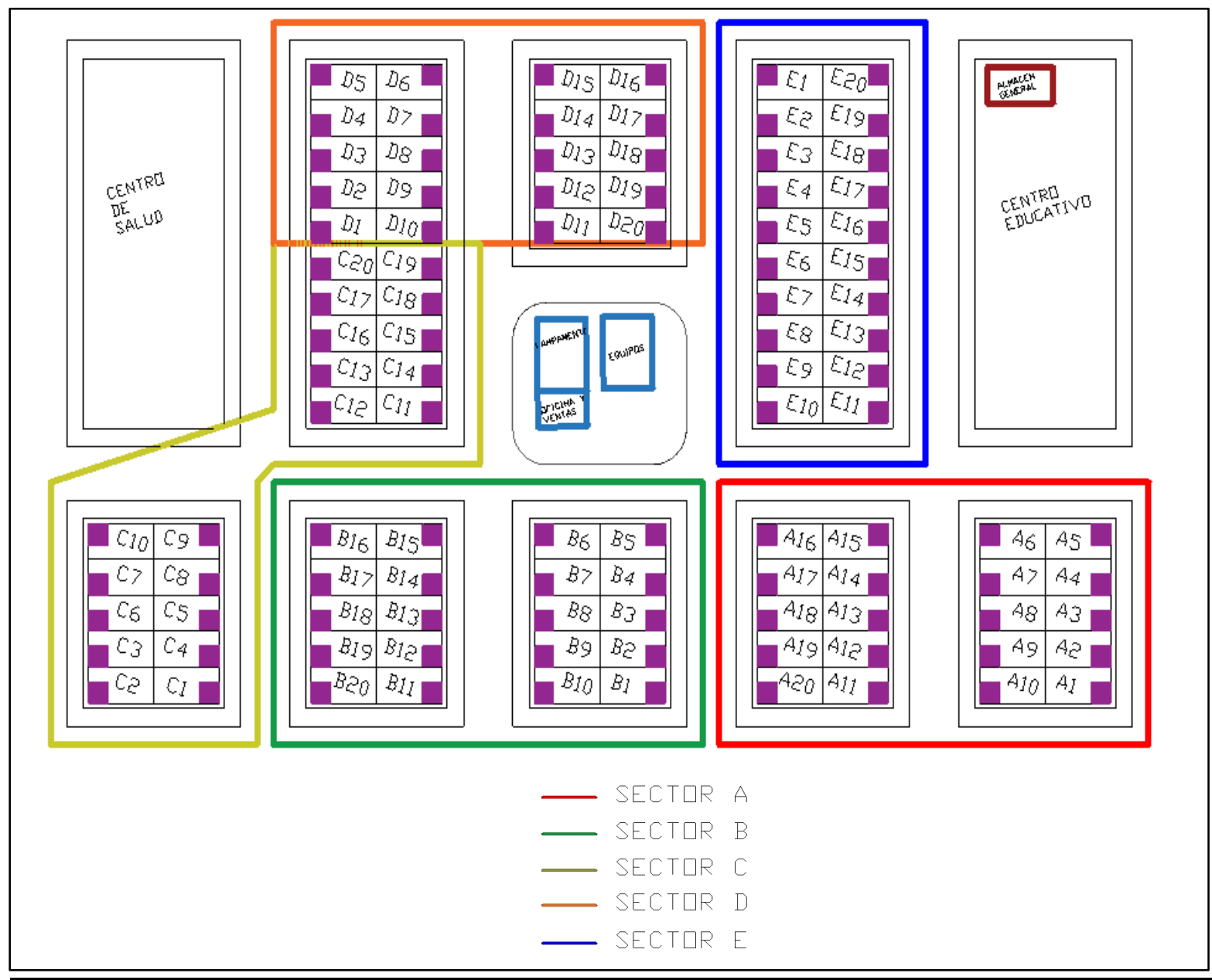

Fuente: (Elaboración propia). 
Una vez determinado los sectores se procede a identificar los entregables del proyecto, utilizando la herramienta WBS (WORK BREAKDOWN STRUCTURE), se consideró los 5 sectores anteriormente determinados y se dividió según las especialidades de estructuras, arquitectura, instalaciones eléctricas e instalaciones sanitarias; de esta manera se controla mejor la ejecución de la obra. A continuación, se muestra el WBS de la construcción de 100 módulos de vivienda.

Imagen 32: WBS de la construcción de 100 viviendas.

\begin{tabular}{|c|c|c|c|c|c|}
\hline \multirow[b]{2}{*}{\begin{tabular}{|l|} 
PROVBRAS \\
POVISIOAALES \\
\end{tabular}} & \multirow[b]{2}{*}{ 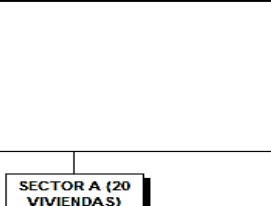 } & \multirow[b]{2}{*}{ 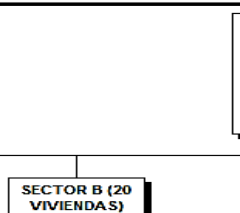 } & \multirow[b]{2}{*}{ 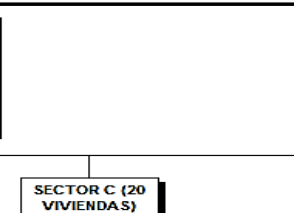 } & \multirow[b]{2}{*}{ 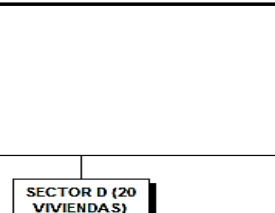 } & \multirow[b]{2}{*}{ 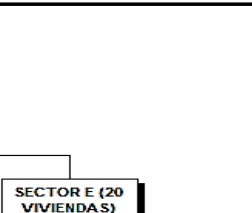 } \\
\hline & & & & & \\
\hline \begin{tabular}{|c|} 
OBRAS \\
PPOVISOOASY
\end{tabular} & Estructuras o1 & EstruCtuRAS (B) & EstruCturAs (C) & EsTructurAs (D) & ESTRuCTURAS (E) \\
\hline $\begin{array}{c}\text { TRAAAJOS } \\
\text { PRELMINARES } \\
\end{array}$ & \begin{tabular}{|c|} 
MOVIMELETT DE \\
TIERRAS (A)
\end{tabular} & \begin{tabular}{|c|} 
MOOMMEENTO DE \\
TIERRAS $(B)$
\end{tabular} & \begin{tabular}{|c|} 
MOVIMIENTO DE \\
TIERRAS IC)
\end{tabular} & \begin{tabular}{|c|} 
MOVIMEENT DE \\
TIERAAS (D)
\end{tabular} & $\sqrt{\text { MOVIMENATO DE }}$ \\
\hline $\begin{array}{c}\text { SEGURIDADY } \\
\text { SALUD }\end{array}$ & $\begin{array}{l}\text { OBRAS DE } \\
\text { concRe } \\
\text { (A) }\end{array}$ & 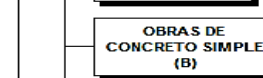 & $\begin{array}{l}\text { OBRRS DE } \\
\text { concrero } \\
\text { (C) }\end{array}$ & 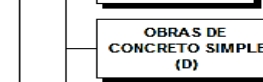 & \begin{tabular}{|c|} 
OBRAAS DE \\
CoNCRTO SIIMPLE \\
(E)
\end{tabular} \\
\hline & 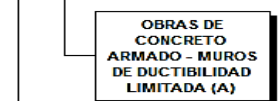 & 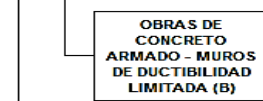 & 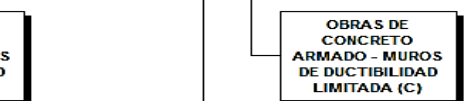 & 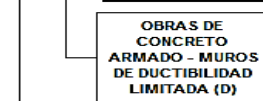 & 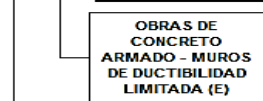 \\
\hline & ARQuUrECTURA 01 & ARQuUrtecturA (B) & ARQuUrectura (C) & ARQUITECTURA (D) & ARQuUTECTURA (E) \\
\hline & 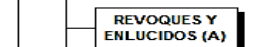 & 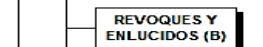 & 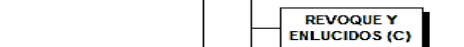 & 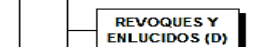 & $\mid$\begin{tabular}{|c|c|} 
REVOOUES Y \\
ENLLCIDOS SEE
\end{tabular} \\
\hline & \begin{tabular}{|l|} 
PaISOSY \\
pavimENTOS $(A)]$
\end{tabular} & $\begin{array}{c}\text { PISOSY } \\
\text { PAVIMENTOS (B) }\end{array}$ & $\begin{array}{l}\text { PISOSY Y } \\
\text { PAVIMENTOS (C) }\end{array}$ & $\begin{array}{l}\text { PISOSY Y } \\
\text { PAVIMENTOS (D) }\end{array}$ & \begin{tabular}{|l|} 
PISOSY Y \\
PAVIMENTOS (E) \\
Pals
\end{tabular} \\
\hline & CUBERTAS (A) & CUIIERTAS (B) & CuBiERAS (C) & CUBIERTAS (D) & CUBIERTAS (E) \\
\hline & $\begin{array}{c}\text { CARPRINTERAA DDE } \\
\text { MADERA (A) } \\
\end{array}$ & 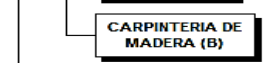 & $\begin{array}{l}\text { CARPRTIERAA DE } \\
\text { MADERA (C) } \\
\end{array}$ & 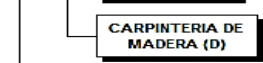 & $\begin{array}{l}\text { CARPRTEREA DE } \\
\text { MADERA }(E)\end{array}$ \\
\hline & $\begin{array}{l}\text { IISTALACCONES } \\
\text { ELETTRRCAS (A) }\end{array}$ & $\begin{array}{l}\text { INSTALACIONES } \\
\text { ELETTICAS (B) }\end{array}$ & $\begin{array}{l}\text { INSTALACIONES } \\
\text { ELETTRICAS (C) }\end{array}$ & $\begin{array}{l}\text { INSTALACCONES } \\
\text { ELECTRICAS (D) }\end{array}$ & $\begin{array}{l}\text { INSTALACIONES } \\
\text { ELECTRICAS (E) }\end{array}$ \\
\hline & 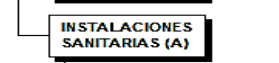 & 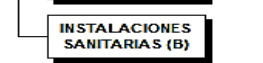 & 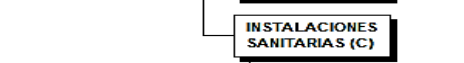 & 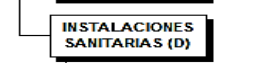 & \begin{tabular}{|l|} 
INSTALACIONES \\
SANITARIAS (E) \\
SAIS
\end{tabular} \\
\hline & $\begin{array}{c}\text { SIITEMAA DEAGUA } \\
\text { FRiA }(A)\end{array}$ & 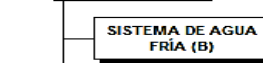 & SISTEMAAEAGUA & $\begin{array}{l}\text { SISTEMA DEA DUA } \\
\text { FRiA (D) }\end{array}$ & $\begin{array}{c}\text { SISTTEMA DE AG AGA } \\
\text { FRiA }(E) \text { (I) }\end{array}$ \\
\hline & 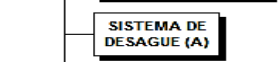 & 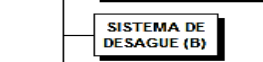 & \begin{tabular}{|l|} 
SISTEMA DE \\
DESAGUE (C) \\
\end{tabular} & 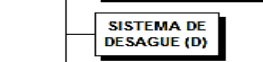 & 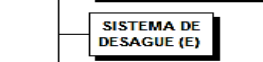 \\
\hline & 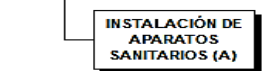 & 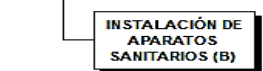 & 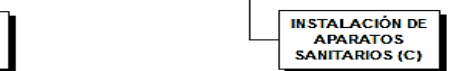 & 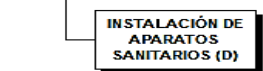 & 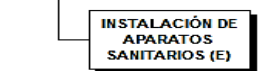 \\
\hline
\end{tabular}

Fuente: (Elaboración Propia.) 
A partir de los entregables identificados en el WBS, se procede a desglosarlos a nivel de actividades para desarrollar el cronograma de ejecución de obra, considerando las duraciones de las actividades, como se muestra en el anexo $\mathrm{N}^{\circ} 9$.

El cronograma de obra contempla las actividades, hitos, metrados, costos y tiempos; iniciando el ciclo para la gestión de ejecución de obra. En el siguiente cuadro se muestra el cronograma propuesto para la ejecución de 100 viviendas.

\subsubsection{LOOK AHEAD}

El objetivo de utilizar la herramienta $L O O K A H E A D$ en el proyecto es garantizar la efectividad de la planificación, para el cumplimiento de plazo del proyecto, mejorar la productividad de los procesos, agregar valor, reducir pérdidas, optimizar gastos de operación; logrando incrementar la rentabilidad del proyecto siendo este el objetivo principal. La forma más adecuada de lograr lo indicado es identificar, analizar, controlar y/o mitigar las restricciones involucrando a los responsables. Asimismo, es importante determinar un cronograma de costos y de recursos.

Para obtener una propuesta eficiente de $L O O K$ AHEAD se analizó cada proceso constructivo que involucra la construcción de las viviendas sociales, se identificó los trabajos no contributorios que generan desperdicios; asimismo, se determinaron los entregables principales que conforman la ruta crítica optimizando el tiempo de ejecución de cada uno, de esta manera se agrega valor al producto final. Se muestra los flujos de procesos de los entregables principales. 
Gráfico 8: Flujo de procesos generales para una vivienda.

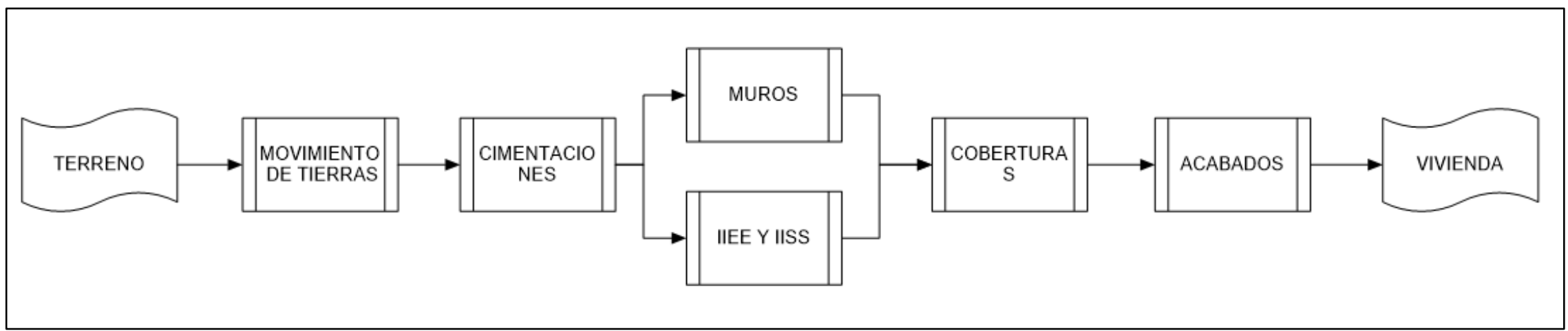

Fuente: (Elaboración propia).

En el gráfico 8 se muestra el flujo de procesos necesarios para la construcción de una vivienda social. Como entrada se tiene el terreno saneado, del cual se realiza el movimiento de tierra cuya actividad principal es la excavación para cimentaciones; a continuación se realizan los cimientos corridos, teniendo al vaceado de concreto como actividad principal. La elaboración de los muros es el siguiente entregable, el cual tiene 3 actividades principales: colocación del acero, encofrado y vaceado de concreto, ésta es el entregable que marca el ritmo de la ejecución de todos los módulos de vivienda debido a la escasa disponibilidad del encofrado. Las instalaciones eléctricas y sanitarias se ejecutan en paralelo con la colocación de acero en los muros. Seguidamente se realiza la estructura para la cobertura y la posterior instalación de la misma. Finalmente se ejecutan los acabados de la vivienda como enchapes, colocación de aparatos sanitarios, colocación de accesorios para instalaciones eléctricas, resanes, carpintería, entre otros. Con todos estos procesos se obtiene el producto final el cual es el módulo de vivienda.

A continuación se describirán los principales entregables que comprenden la elaboración de una vivienda social. 
Gráfico 9: Flujo de procesos de Movimiento de Tierras

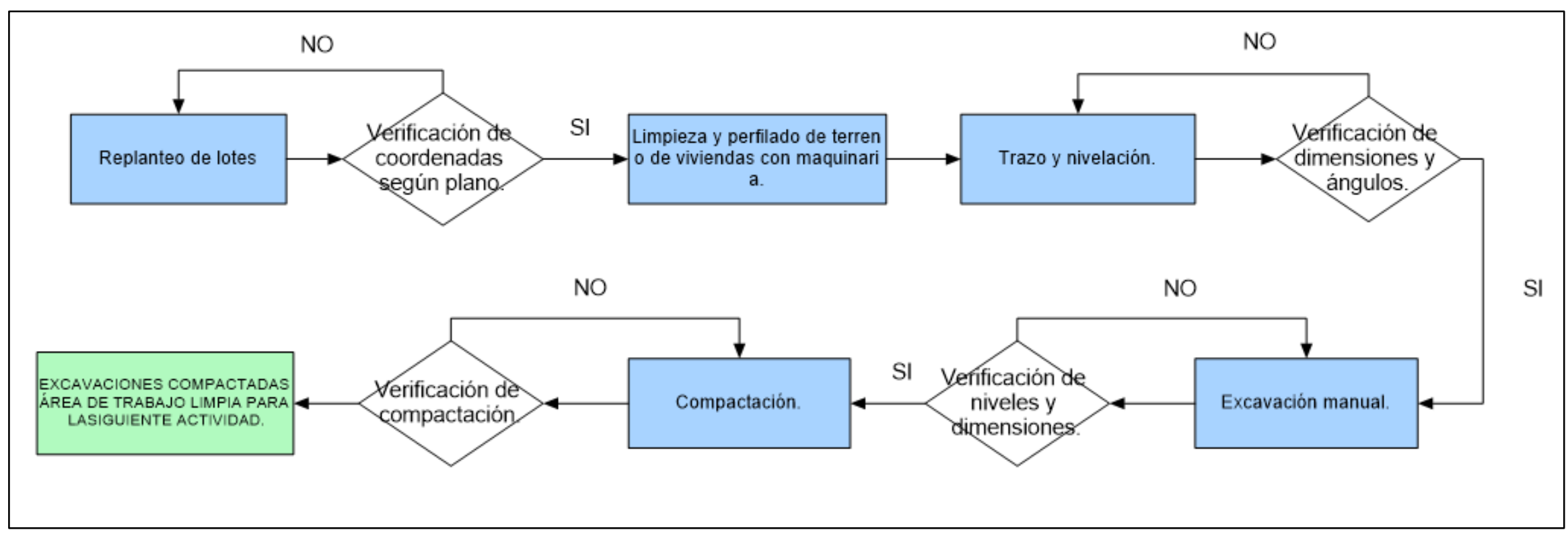

Fuente: (Elaboración propia).

Para el entregable de movimiento de tierra, como se muestra en el gráfico 9, se realiza el replanteo de lotes, para el cual es necesario la verificación de las coordenadas para evitar futuras demoliciones y retrabajos. Seguidamente, se realiza la limpieza y perfilado del terreno para el trazo y nivelación del mismo. Continúa la excavación y compactación del terreno para las cimentaciones; para el trabajo de investigación se plantea realizar la excavación con maquinaria para ahorrar tiempo y acelerar los trabajos posteriores. Finalmente, se obtiene como salida a las excavaciones compactadas y limpias, listas para las cimentaciones.

Es importante realizar las verificaciones correspondientes a cada actividad para evitar futuras complicaciones. 


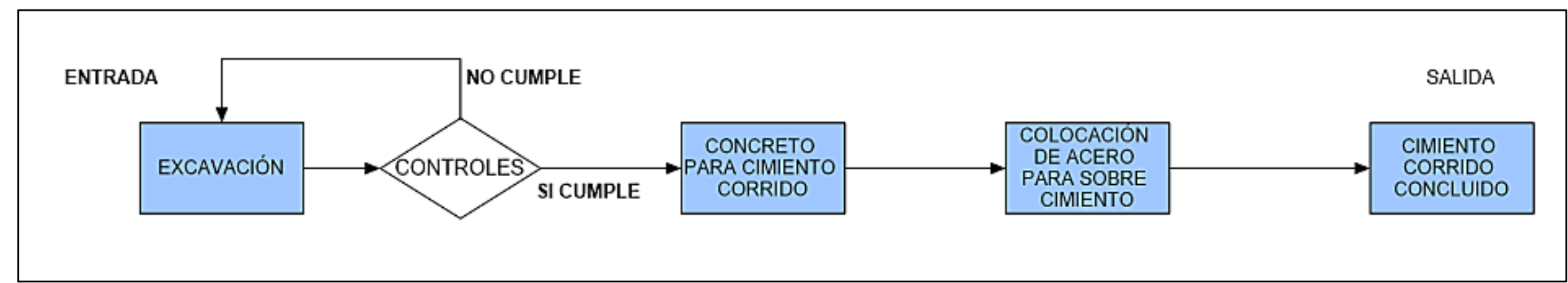

En las cimentaciones, según el gráfico 10, la entrada son las excavaciones limpias y compactadas terminadas en el proceso de movimiento de tierra; a partir de ésta se realiza el vaceado de concreto de los cimientos. Mientras el concreto se mantiene fresco se colocan las varillas de acero vertical de los muros. Se deben realizar los controles de dimensiones, distancias, entre otros. Finalmente, se obtiene el cimiento y sobrecimiento terminados para los muros.

Gráfico 11: Flujo de procesos para Muros.

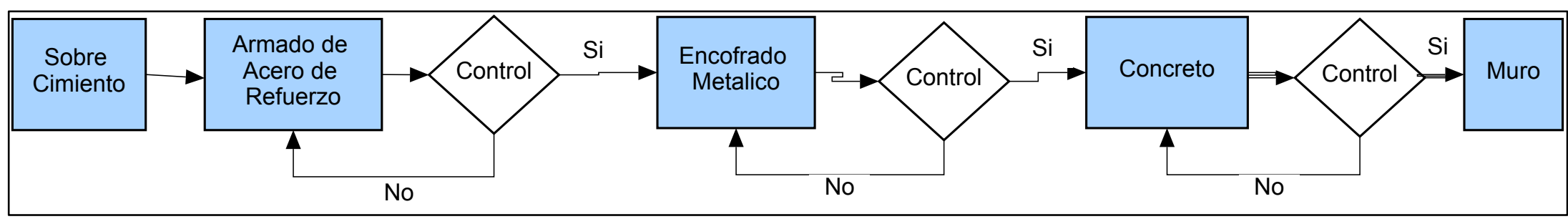

A partir del sobrecimiento se continúa con el armado horizontal de la malla de acero, paralelamente se colocan las tuberías de muro de las instalaciones eléctricas y sanitarias. Una vez realizada las verificaciones correspondientes, se procede con el encofrado de muros; seguidamente, se realiza el vaceado de concreto. Finalmente, se obtiene el muro terminado y correctamente verificado para las coberturas. 
Para el trabajo de investigación, se propone utilizar mallas de acero electro soldadas, con dimensiones estandarizadas y de fácil transporte para adquirirlos directamente de las fábricas de acero. De esta manera, se ahorra el tiempo de habilitación e instalación de acero.

\section{Gráfico 12: Flujo de procesos de Cobertura.}

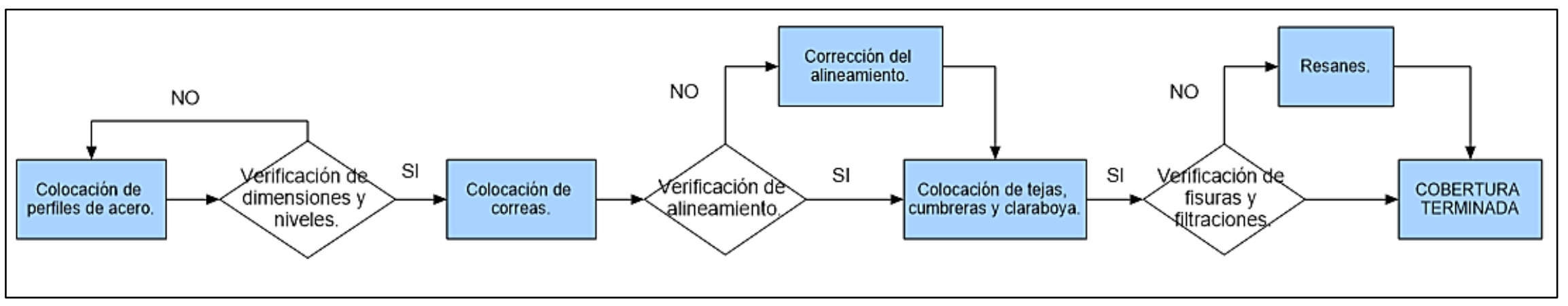

Para el entregable de cobertura, se tiene como entregable los muros correctamente nivelados y lo suficientemente fraguados para soportar la estructura de la cobertura. Para la colocación de los perfiles de acero, se debe considerar que éstos deben tener las dimensiones correctas y el tratamiento adecuado para la corrosión. Con respecto a la instalación de las tejas, se debe verificar que se encuentren en buen estado, sin fisuras, para disminuir los futuros resanes. Terminado la colocación de coberturas, se procede con la ejecución de los acabados.

Los entregables anteriormente descritos forman parte de la ruta crítica, es por ello que se analizaron y plantearon estrategias necesarias para la reducción de tiempos, desperdicios y costos.

Se ha planteado los flujos de procesos de tal modo que se ejecuten de manera secuencial, sin interrupciones, eliminando la variabilidad minimizando las restricciones, (balanceando la cantidad de trabajos realizados por días, la mano de obra y recursos) En los proyectos de viviendas sociales, la variabilidad es mínima, ya que las actividades son repetitivas

Una de las propuestas para eliminar la variabilidad en los procesos es considerar buffers en la planificación; por ejemplo, se amplió el tiempo planificado de las actividades para prever posibles atrasos; asimismo, se planificó iniciar con tres vaciados de cimientos el primer día para no tener inconvenientes por atrasos o paralizaciones en las excavaciones y cimentaciones, de esta manera el ritmo de los muros no se detiene. 
Tren de actividades

Una vez analizado y determinado los tiempos de cada actividad, se realiza la secuencia de trabajo con ayuda de la estrategia "Trenes de Actividades", aplicable principalmente en proyectos en los que la variabilidad es reducida y físicamente el trabajo es divisible en partes iguales, como sucede en nuestro caso. Se ha planteado la secuencia del tren de actividades por días para cada unidad de vivienda, representado las partidas principales con un color específico. Como se muestra en la imagen 33. De esta manera resulta más sencillo el control del avance de los entregables, así como el cronograma de recursos y de mano de obra requerido.

Imagen 33: LOOK AHEAD del sector 1
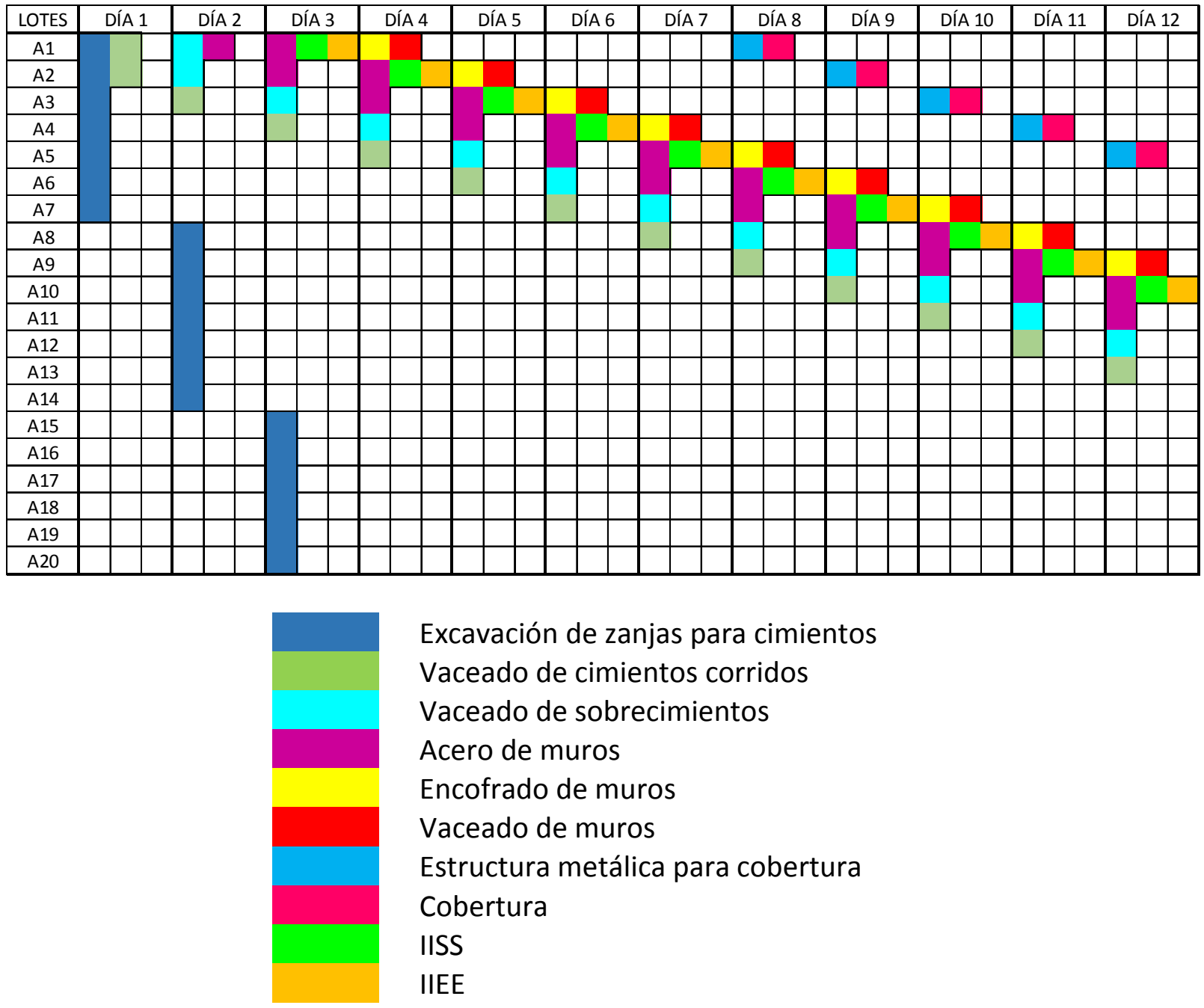

Excavación de zanjas para cimientos

Vaceado de cimientos corridos

Vaceado de sobrecimientos

Acero de muros

Encofrado de muros

Vaceado de muros

Estructura metálica para cobertura

Cobertura

IISS

IIEE

Fuente: (Elaboración Propia).

Como se muestra en la imagen 33, a partir del cuarto día, se realizan las mismas actividades utilizando la misma cantidad de mano de obra y recursos; por lo que muestra que cada cuadrilla realizará la misma cantidad de trabajo todos los días. De esta manera se logra minimizar desperdicios y restricciones, además se logra mejorar la productividad. Además, se redujo el tiempo en excavaciones a 3 días por sector, 
utilizando maquinaria; de esta manera, se reduce la cantidad de mano de obra innecesaria. La maquinaria será utilizada para otras actividades del proyecto como el perfilado del terreno, obras de saneamiento, entre otros. Con el tren de actividades definido se realiza el $L O O K A H E A D$, con la cual se prevé las necesidades de cada partida. El detalle del $L O O K A H E A D$ por sectores se encuentra en los anexos 10, 11, 12,13 y 14 .

\section{Restricciones}

El análisis de restricciones es importante en la etapa de planificación, ya que permite dejar libre de necesidades al $L O O K$ AHEAD permitiendo cumplir con lo planificado en el tiempo previsto.

Para el caso de las viviendas sociales las principales restricciones se presentan son las siguientes:

- El abastecimiento de materiales a obra, debido a la lejanía y poca accesibilidad de dichos proyectos. Con la utilización adecuada del LOOK AHEAD y LAST PLANNER se lograría reducir esta restricción, ya que se tienen fechas definidas del requerimiento de materiales permitiendo prever la compra y envío de los mismos.

- Escasez de mano de obra calificada, principalmente para el encofrado metálico de muros e instalaciones. Al ser proyectos desarrollados en comunidades campesinas alejadas a las ciudades, la mano de obra calificada es mínima; por ello, a partir del $L O O K A H E A D$, se determina las fechas estimadas para requerir mano de obra especializada por lo que es importante prever las capacitaciones antes de dichas fechas.

- Disponibilidad de prefabricados. Al trabajar con algunos elementos prefabricados como son las mallas de muros, estructura metálica de techo, puertas y ventanas, es necesario tener claros las fechas de requerimiento con los proveedores para evitar futuros retrasos. Esta información se encuentra en el $L O O K A H E A D$.

En general, con el $L O O K A H E A D$ desarrollado se logra mitigar las restricciones. De esta manera, se logra obtener una mejora continua en todos los procesos.

\subsubsection{BIM 4D del proyecto.}

El modelo BIM 4D del proyecto se desarrolló a partir del modelo 3D compatibilizado que se realizó en la etapa de diseño, para determinar la correcta simulación constructiva en el modelo se realizó la programación de la obra utilizando las herramientas del LAST PLANNER, donde se determinó el tiempo para cada actividad evaluando las restricciones que pudieran existir, distribución uniforme de recursos, se buscó la forma más eficiente de construcción lo cual se llevó al modelo para realizar seguimiento durante la construcción.

La herramienta con la que se realizó el modelo BIM 4D fue el SOFTWARE AUTODESK NAVISWORKS, en esta herramienta se integró las especialidades del 
proyecto y se simulo la ejecución según lo programado, la ventaja de realizar esta simulación fue evaluar la secuencia constructiva más eficiente para el proyecto; por otra parte, se pudo evaluar la necesidad de los recursos durante el proceso (encofrados, maquinaria, mano de obra), este modelo 4D puede ser mostrado a todos los involucrados del proyecto para que tengan claro cuáles son los objetivos planteados para la etapa de la construcción y cómo se llevará a cabo cada proceso para lograr concluir en el plazo establecido.

Se muestra la simulación constructiva que se desarrolló para un módulo de vivienda el cual se replicará en las 100 viviendas que se plantea para el presente trabajo de investigación.

Imagen 34: Visualización de la excavación de cimientos

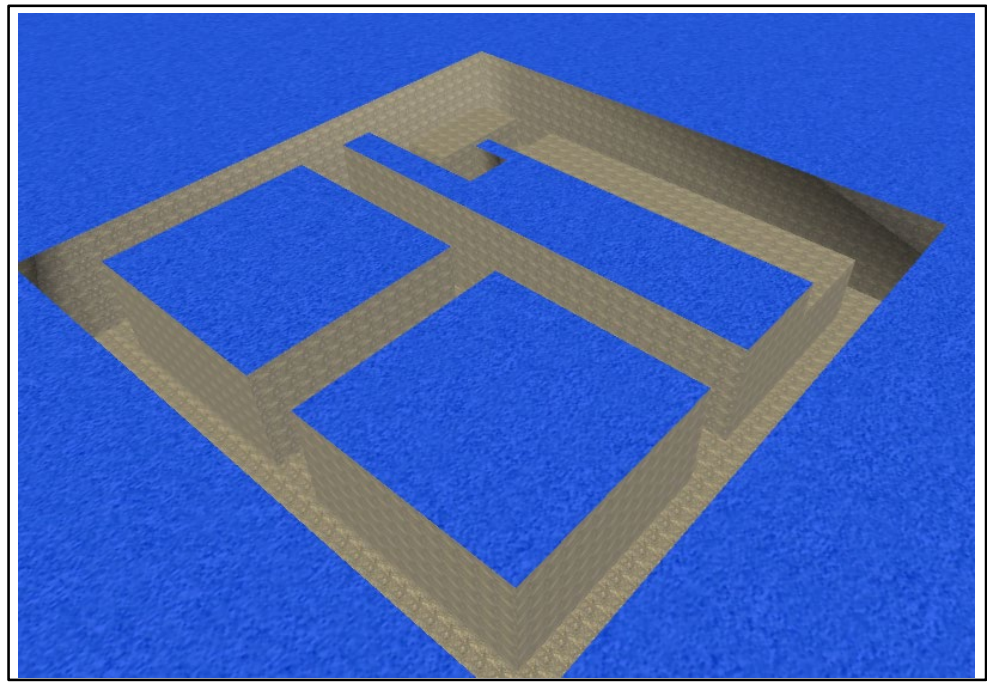

Fuente: (Elaboración propia).

Se muestra en la imagen 34 el inicio de la construcción con la simulación de la excavación, se utilizó el SOFTWARE AUTODESK NAVISWORKS.

Imagen 35: Simulación de ejecución del cimiento corrido

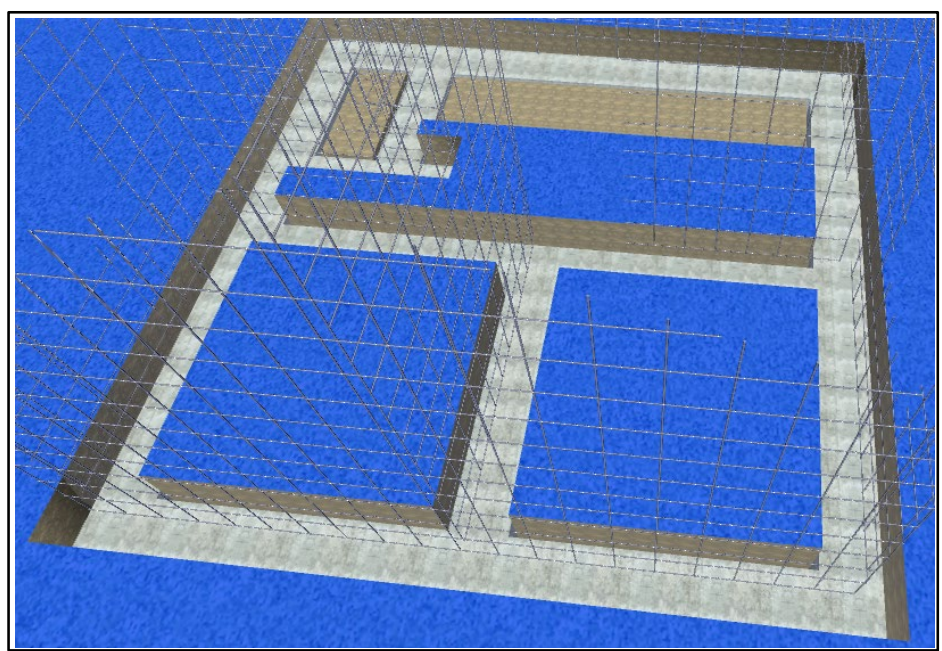

Fuente: (Elaboración propia). 
En la imagen 35 se muestra el desarrollo de la partida de cimientos corridos y colocación de malla de acero.

Imagen 36: Simulación del encofrado y vaciado de concreto de sobrecimiento.
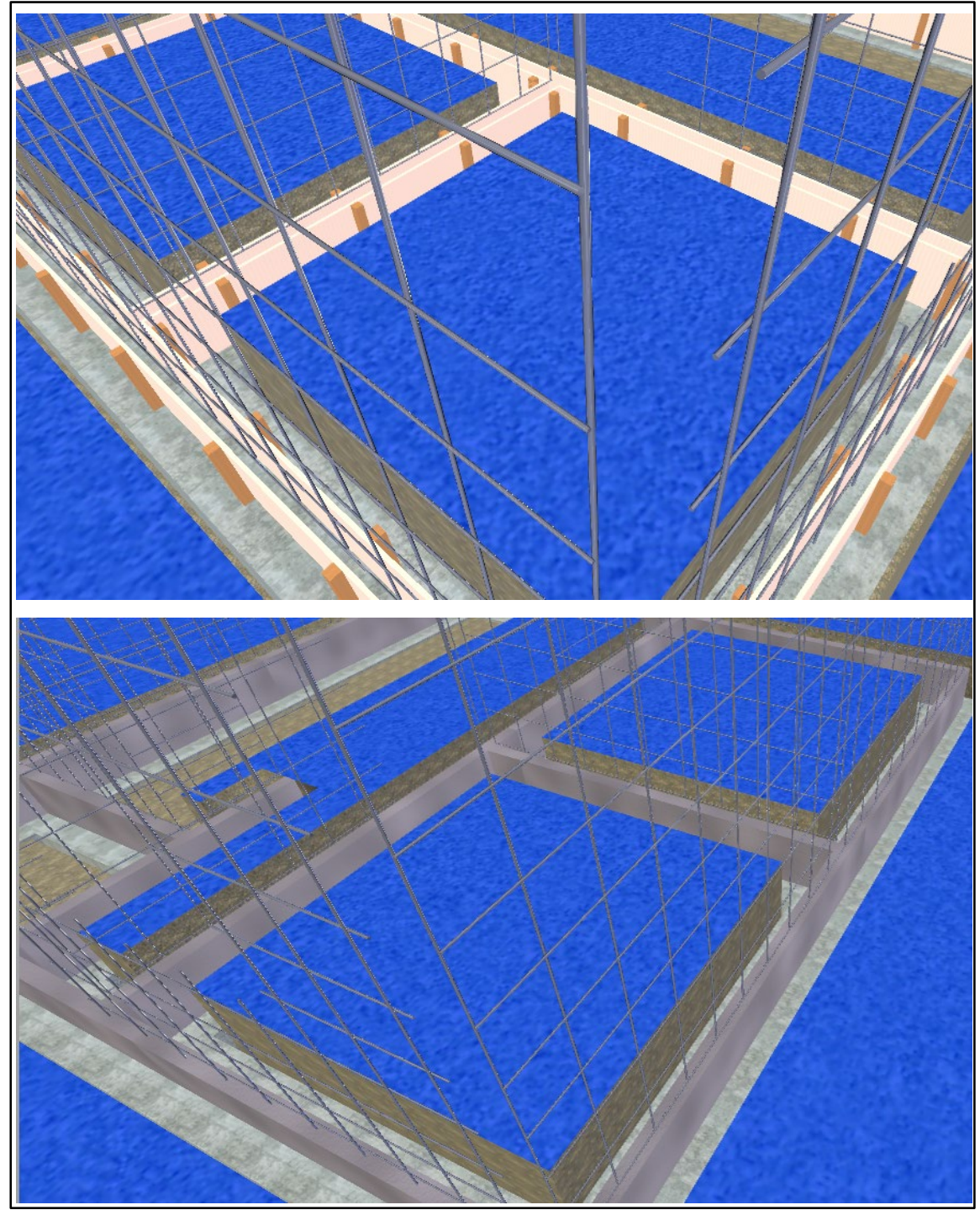

Fuente: (Elaboración propia).

La imagen 36 muestra la secuencia constructiva de la partida de encofrado de sobrecimiento, el cual se desarrolla como sucesora a la ejecución del cimiento corrido, se desarrolla ambas actividades en un solo día (encofrado y vaciado de concreto), la ventaja del SOFTWARE de visualización ayuda a entender la secuencia constructiva más eficiente. 
Imagen 37: Simulación del encofrado de muros.

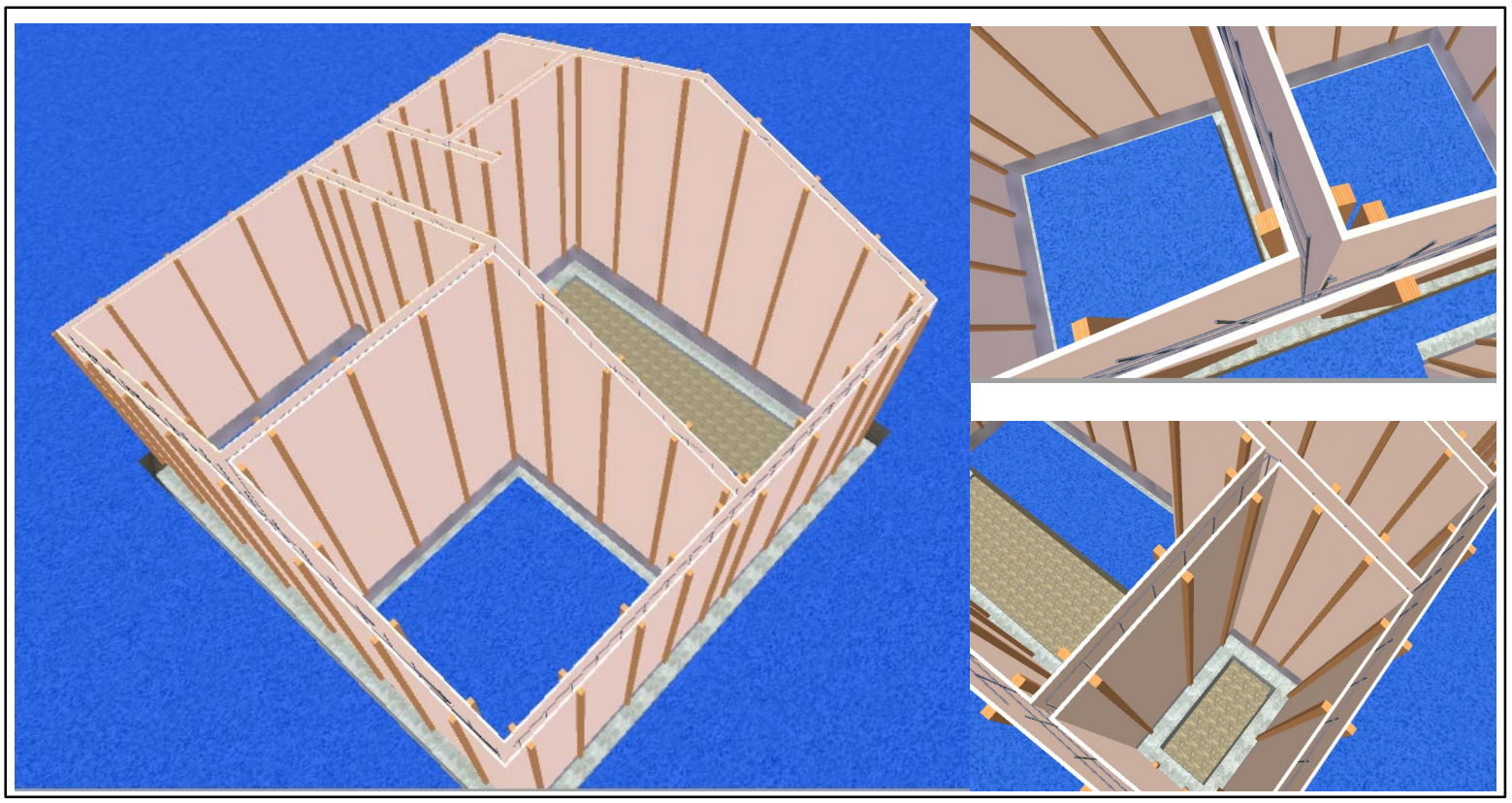

Fuente: (Elaboración propia).

La imagen 37 muestra la actividad de encofrado de muros, esta actividad es desarrollada como sucesora de los trabajos de sobrecimiento, según la programación se desarrolla el encofrado y vaciado de muros de una unidad de vivienda por día.

Imagen 38: Simulación muros de concreto.

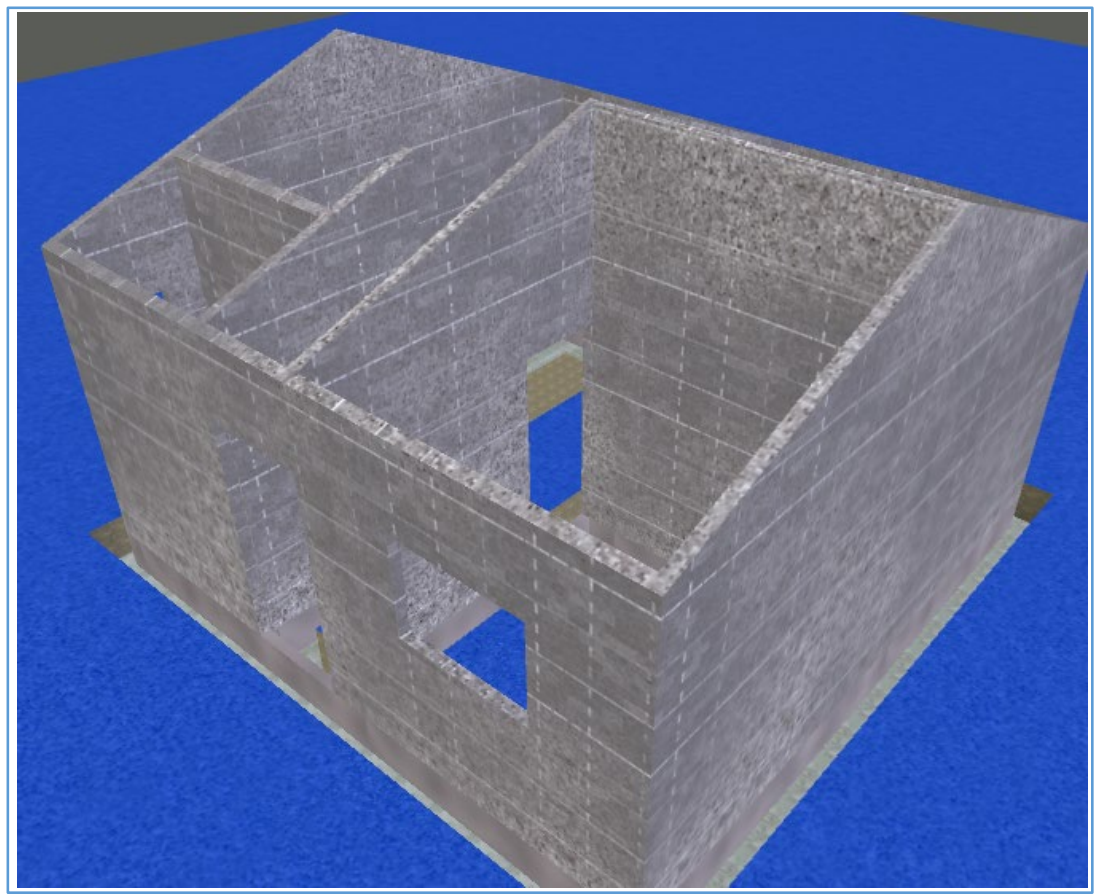

Fuente: (Elaboración propia).

En la imagen 38 se muestra los muros de la vivienda posterior al desencofrado. 
Imagen 39: Simulación de las instalaciones sanitarias.

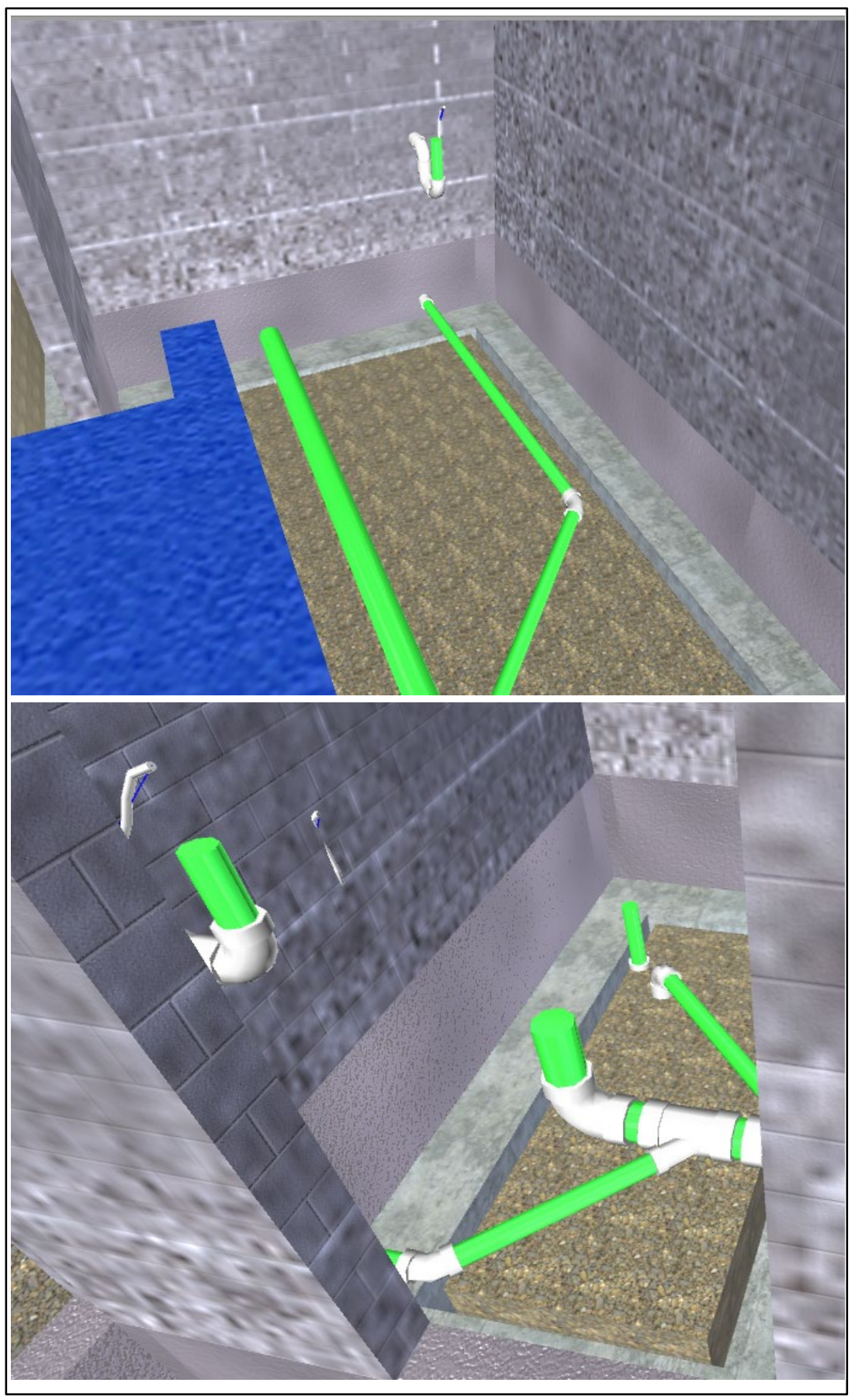

Fuente: (Elaboración propia).

En la imagen 39 se muestra la simulación de la construcción de las instalaciones sanitarias, es de gran utilidad la visualización del modelo BIM 4D, facilita prever los componentes necesarios para desarrollar la partida adecuadamente. 
Imagen 40: Simulación construcción de la cobertura.

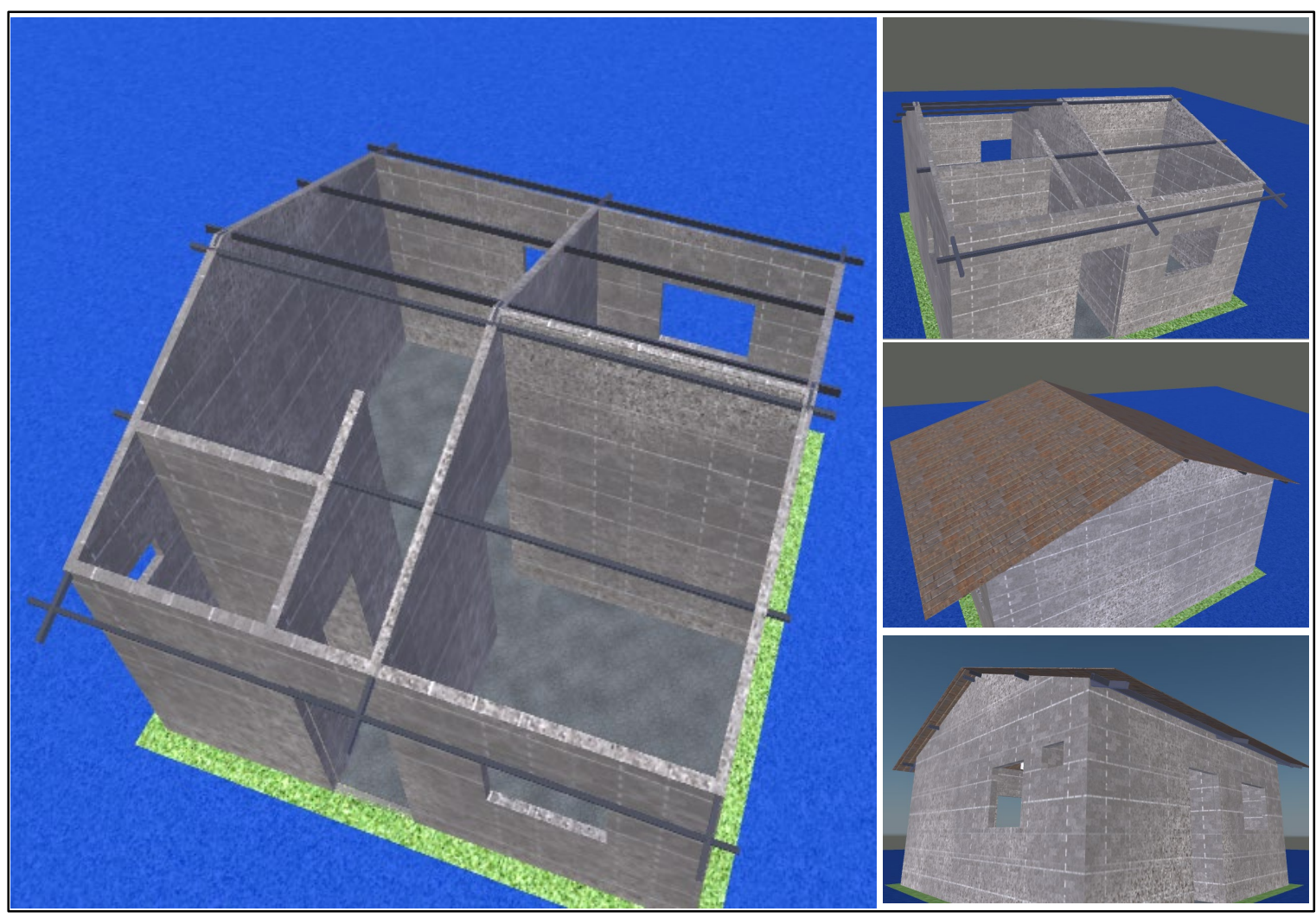

Fuente: (Elaboración propia).

La imagen 40 muestra la ejecución de la cobertura de la vivienda

Imagen 41: Simulación del proyecto concluido.

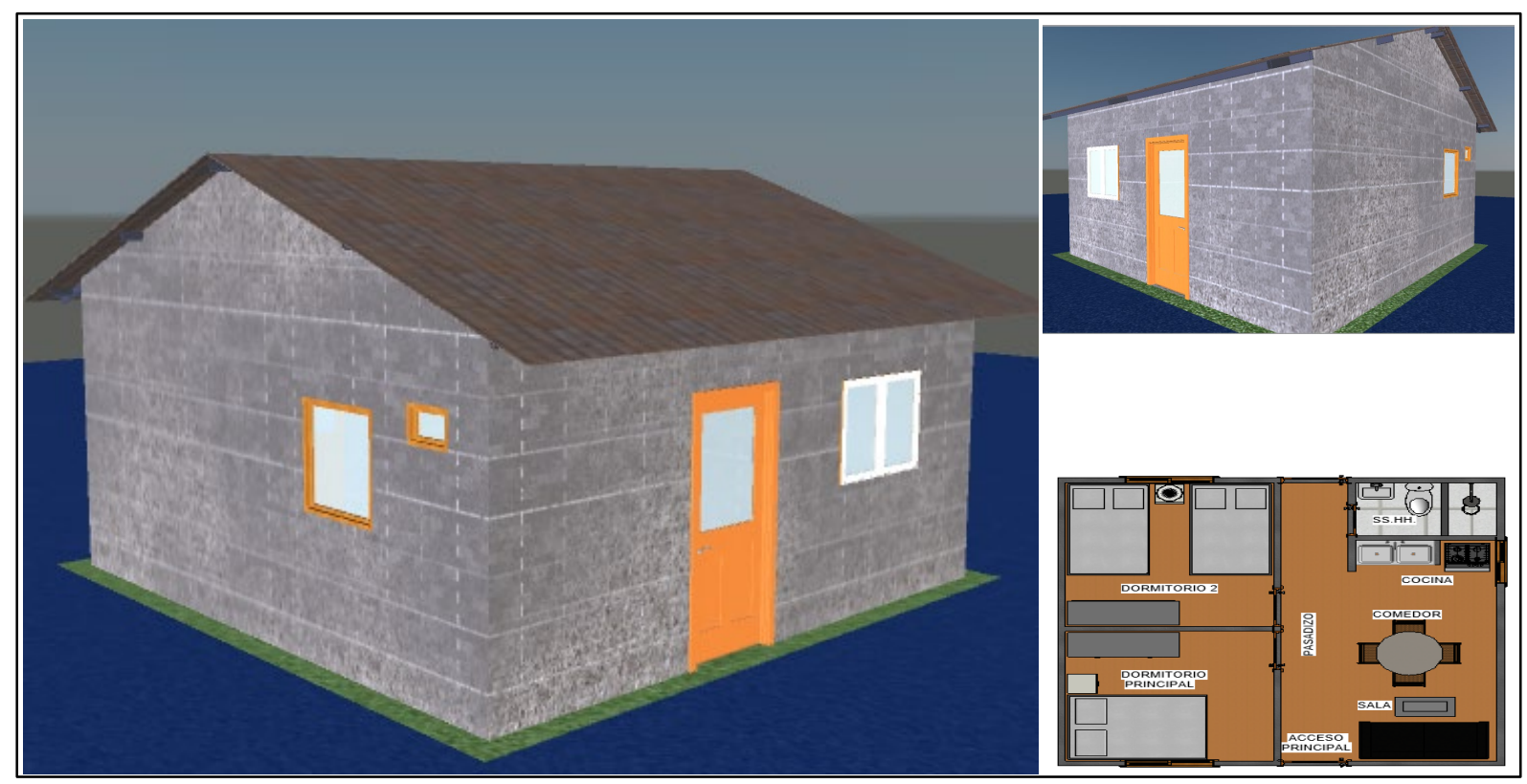

Fuente: (Elaboración propia).

La imagen 41 muestra la visualización del proyecto concluido. 


\subsubsection{Logros obtenidos del Planeamiento}

A partir de lo analizado, se obtuvo la planificación completa del proyecto con la información necesaria para realizar una adecuada gestión en la construcción, la cual es importante para garantizar el cumplimiento de las metas propuestas. En primer lugar, se obtiene el cronograma general con los hitos principales los cuales permiten controlar, a nivel general, el cumplimiento de lo planificado.

En segundo lugar, se propone el sistema LAST PLANNER con la utilización de la herramienta $L O O K A H E A D$, donde se determina las cantidades de producción diarias por sectores y por módulos de vivienda, el cual permite el control diario de la ejecución del proyecto, elaborando reportes diarios con la ayuda del modelamiento con BIM.

En tercer lugar, se identifican las posibles restricciones que se puedan presentar en los proyectos, basados en la información de los proyectos de viviendas sociales ejecutados actualmente; de esta manera se prevé, en la etapa de construcción, aquellos posibles inconvenientes, de esta manera se reduce la cantidad de paralizaciones, atrasos, incumplimiento de plazos, altos costos, entre otros.

En cuarto lugar, con la información brindada en la etapa de planeamiento se procede a realizar la construcción en el programa NAVISWORKS, para tener una mejor visualización de la construcción y prever otros aspectos de constructibilidad facilitando la construcción.

Asimismo, realizar la planificación muy detallada a largo plazo es innecesaria ya que produce gran incertidumbre.

Por otro lado, un factor importante es la capacitación de los trabajadores para no rehacer actividades por errores constructivos.

Una nueva propuesta de gestión será asegurar que lo planeado sea igual a lo ejecutado con la finalidad de incrementar la confiabilidad y los plazos propuestos, mitigando los impactos de variabilidad.

Finalmente, a través de la filosofia $L E A N C O N S T R U C T I O N$ y el uso de la herramienta $L O O K A H E A D$ y la metodología $B I M$, se puede disminuir el plazo y costo del proyecto comparándose con la construcción de forma tradicional. En nuestro caso de estudio se logró rebajar 4 meses en el diseño, 2 años en el planeamiento y 6 meses en construcción 


\subsection{Etapa de construcción}

4.4.1 Análisis de la gestión de construcción convencional.

Ratios de construcción

En los proyectos actuales de vivienda social en la zona rural de la sierra sur del Perú, el precio de venta promedio por $\mathrm{m} 2$ es de $\mathrm{S} / .1,400.00^{2}$.

Cuadro 5: Costo por $m 2$ de proyectos de vivienda social - Sierra Sur.

\begin{tabular}{|c|l|l|c|c|}
\hline No & Nombre de Proyecto & \multicolumn{1}{|c|}{ Ubicación } & $\begin{array}{c}\text { Área de } \\
\text { construcción }\end{array}$ & $\begin{array}{c}\text { Precio de } \\
\text { venta } \\
\text { por m2 }\end{array}$ \\
\hline $\mathbf{1}$ & Inkaq Samanan & $\begin{array}{l}\text { C.C. Yanamayo, } \\
\text { Urubamba - Cusco }\end{array}$ & 24.75 & $\begin{array}{c}\mathrm{S} / . \\
958.30\end{array}$ \\
\hline $\mathbf{2}$ & Tirikway & $\begin{array}{l}\text { C.C. Qelqanqa, Urubamba } \\
\text { - Cusco }\end{array}$ & 27.5 & $\begin{array}{c}\mathrm{S} / . \\
1,370.91\end{array}$ \\
\hline $\mathbf{3}$ & $\begin{array}{l}\text { Residencial Torres de } \\
\text { Anta }\end{array}$ & $\begin{array}{l}\text { Valle Cachimayo, Anta - } \\
\text { Cusco }\end{array}$ & 64.3 & $\begin{array}{c}\mathrm{S} / . \\
1,181.96\end{array}$ \\
\hline $\mathbf{4}$ & $\begin{array}{l}\text { Urb. Praderas del Inka } \\
\text { Fundo Esquén Tariachi }\end{array}$ & 52 & $\begin{array}{c}\mathrm{S} / . \\
1,826.92\end{array}$ \\
\hline $\mathbf{5}$ & $\begin{array}{l}\text { Condominio San } \\
\text { Jacinto I Etapa }\end{array}$ & $\begin{array}{l}\text { Sector Corape, Tacna - } \\
\text { Tacna }\end{array}$ & 38.2 & $\begin{array}{c}\mathrm{S} / . \\
1,986.91\end{array}$ \\
\hline
\end{tabular}

La propuesta de vivienda planteada en este trabajo de investigación considera el precio de venta por $\mathrm{m}^{2}$ de $\mathrm{S} / .1,432.00$, considerando los costos de habilitación urbana, las obras de saneamiento y obras viales. Sólo la construcción de la vivienda tiene un costo de $\mathrm{S} / .1,100.00$ por $\mathrm{m}^{2}$, con una utilidad de $10 \%$ aproximadamente.

\subsubsection{Propuesta de mejora para la etapa de construcción.}

La incorporación de Tecnologías de Información es cada día más necesaria en la construcción porque permite el incremento de la producción, difusión de nuevas tecnologías, reducción de costos, tiempos, mejora continua de procesos.

Es necesario incentivar el uso efectivo de la herramienta para poder involucrar positivamente a toda la organización de la obra y la integración de los procesos.

El uso de la TIC promueve buscar la integración de nuestros procesos

La Tecnología de la Información de la Construcción (TIC) que sugerimos para la construcción de proyectos de Vivienda Social son los siguientes:

> BUILDING INFORMATION MODELING (BIM).

Con la metodología $B I M$ se puede modelar maquetas virtuales con información tecnológica como metrados, costos tiempos; que integra las etapas del proyecto como diseño, planeamiento y construcción para que los proyecto sean más rentables ya que,

\footnotetext{
${ }^{2}$ Se toma de referencia los proyectos "Inkaq Samanan" y "Tirikway"
} 
se reducen costos causados por desperdicios en la ejecución del proyecto debido a las incompatibilidades en el modelo.

\section{$>$ Capacitación.}

Para tener un mejor manejo de las herramientas de BIM y LEAN CONSTRUCTION es necesario realizar charlas de capacitación a los jefes de obra para el correcto uso de la red en obras, donde se deben explicar sobre como ejecutar los proyectos con éxito.

$>$ Telecámaras en obra.

Se deben implementar cámaras, que generen bitácoras digitales, en imágenes y en videos, siendo un factor importante para agilizar las decisiones con los proyectistas y supervisores.

$>$ Uso de pantallas de visualización.

Se deben hacer uso de pantallas de visualización para poder aprovechar todas las vistas del modelo BIM y de las telecámaras.

$>$ SOFTWARE de Planeamiento.

Se deben utilizar SOFTWARE para el control de productividad de Mano de Obra con el objetivo de consolidar la información, generar reportes y estadísticas de resultados.

$>$ Uso del ZOOM para comunicaciones a distancia.

Es muy importante este ítem ya que como se ejecutan proyectos en la sierra sur del Perú, las zonas del proyecto son muy lejanas e inaccesibles por lo que se recomienda tener reuniones virtuales a través del ZOOM para las coordinaciones del proyecto.

$>$ Visual Management.

En obra todos debemos tener conocimiento de lo que se tiene que ejecutar por lo que se hace uso de gráficos, banners, señales, gigantografías, que puedan dar información del proyecto a distintos usuarios.

$>$ Uso de Smartphone.

Los Smartphone con acceso a internet permiten compartir información en tiempo real.

$>$ Portal del conocimiento.

Se debe difundir la información del proyecto mediante el uso del portal del conocimiento.

$>$ Registro de experiencias.

Este ítem es muy importante ya que con ello conlleva a la mejora continua con la bitácora de experiencias y conocimientos del proyecto como charlas de conocimientos, videos con información del proyecto. 


\section{CAPÍTULO 5: EVALUACIÓN DE LA RENTABILIDAD}

\subsection{Análisis de sensibilidad.}

\subsubsection{Costo de terreno}

El costo de terreno se determina según la modalidad de adquisición del terreno; por ejemplo, si el terreno es comprado, dependerá del costo por $\mathrm{m} 2$ de la zona, si el terreno es donado el costo será determinado por los trámites necesarios para la adjudicación del mismo a la empresa.

Para el trabajo de investigación, se consideró que el costo del terreno será del $5 \%$ del costo total del proyecto, ya que los proyectos estarán ubicados en zonas rurales de la sierra sur del Perú.

\subsubsection{Precio de venta}

Según el Fondo MiVivienda, el precio de venta máximo de las viviendas sociales será de S/. 83,000.00 para que se considere como proyecto de Techo Propio. Además, el precio de venta de otros proyectos de viviendas sociales es de $\mathrm{S} / .1,400.00$ por $\mathrm{m}^{2}$ aproximadamente.

El precio de venta de las viviendas se determinó según el flujo de caja, considerando los gastos del proyecto, gastos de construcción, gastos generales, gastos por ventas, impuestos, entre otros. Por lo que se estableció que el precio de venta de la vivienda será de $\mathbf{S} / \mathbf{5 3 , 0 0 0 . 0 0}$

Cuadro 6: Datos generales de costo de vivienda.

\begin{tabular}{|l|r|}
\hline COSTO DE VIVIENDA: & S/. 53,000.00 \\
\hline BFH: & S/.33,200.00 \\
\hline AHORROS: & S/. 19,800.00 \\
\hline Cuota Inicial & S/.3,000.00 \\
\hline Crédito & S/. 16,800.00 \\
\hline
\end{tabular}

Fuente: (Elaboración propia.)

Además, se consideró el monto máximo que las familias puedan pagar como ahorro el cual es de S/. 19,800.00 para lo cual pueden acceder a un crédito hipotecario con una cuota inicial de $\mathrm{S} / .3,000.00$

\subsubsection{Costo de construcción}

El costo de construcción de las viviendas, utilizando los enfoques BIM y LEAN CONSTRUCTION optimizando los procesos constructivos, minimizando pérdidas, etc., será de $\mathrm{S} / .810 .00$ por $\mathrm{m}^{2}$ 


\subsubsection{Velocidad de ventas}

El flujo de ventas de las viviendas dependerá de la velocidad de calificación de las familias al programa Techo Propio ya que el Fondo Mivivienda es el que otorga el bono familiar habitacional el cual representa al $63 \%$ del ingreso por cada vivienda. Es por ello que es importante tramitar la calificación de los beneficiarios con al menos 4 meses antes del inicio de obra, de esta manera se podrá tener liquidez para empezar la construcción.

A continuación se muestra un cuadro resumiendo la cantidad de ventas por mes según la velocidad de calificación de los beneficiarios.

Cuadro 7: Flujo de ventas.

\begin{tabular}{|l|r|r|r|r|r|r|r|r|r|r|}
\hline & jul-18 & ago-18 & sep-18 & oct-18 & nov-18 & dic-18 & ene-19 & feb-19 & mar-19 & abr-19 \\
\hline Ventas Men. & 10 & 20 & 20 & 20 & 20 & 10 & & & & \\
\hline Ventas Men. Acum. & 10 & $\mathbf{3 0}$ & $\mathbf{5 0}$ & $\mathbf{7 0}$ & $\mathbf{9 0}$ & $\mathbf{1 0 0}$ & $\mathbf{1 0 0}$ & $\mathbf{1 0 0}$ & 100 & 100 \\
\hline Desemb. Hip. & & & & & 10 & 10 & 25 & 25 & 25 & 5 \\
\hline Desemb. Hip. Acum. & 0 & 0 & 0 & 0 & 10 & 20 & 45 & 70 & 95 & 100 \\
\hline Desemb. Bonos & & & & 10 & 20 & 20 & 20 & 20 & & 10 \\
\hline Desemb. Bonos Acum. & 0 & 0 & 0 & 10 & 30 & 50 & 70 & 90 & 90 & 100 \\
\hline
\end{tabular}

Fuente: (Elaboración propia.)

Se considera que para iniciar la construcción del proyecto se debe tener al menos el $70 \%$ de viviendas vendidas. Además, considerando que la calificación demora mínimo 3 meses, el primer bono se desembolsará en octubre, un mes antes de la construcción, permitiendo tener la liquidez necesaria todos los meses de construcción.

\subsection{Flujo Económico - Evaluación de alternativas.}

Para elaborar el flujo de caja económico se consideraron:

\subsubsection{Ingresos:}

Ahorros: Consta de dos montos principales, el primero es el monto en efectivo que dan los beneficiarios al momento de firmar la minuta de compra y venta de las viviendas con la empresa, este monto es de S/. 2,500 mínimo; el segundo monto es el préstamo que otorga el banco a los beneficiarios, se considera en el momento que inicia la construcción ya que demora aproximadamente otros 3 meses para que el banco otorgue estos créditos a las familias y desembolse el dinero.

Bonos Familiares Habitacionales: Es otorgado por el Fondo Mivivienda dependiendo de la calificación de los beneficiarios al programa Techo Propio y a la capacidad de la empresa de solicitar carta fianza a los bancos. El primero puede demorar hasta tres meses, para ello es importante que se realice una pre evaluación a las familias desde la etapa inicial del proyecto, de esta manera se garantiza que para la etapa de construcción las familias obtengan el bono con facilidad y se logre el flujo planeado. Para el segundo requisito, la empresa debe solicitar la aprobación de carta fianza al banco de por lo menos el monto de 20 viviendas, es decir de S/. 860,000.00, de esta manera la empresa podrá lograr tener la liquidez necesaria para la construcción. 
Aporte Propio: Es el monto requerido como capital de la empresa para invertir en dicho proyecto. Éste puede ser por aporte de socios, dinero de caja propia de la empresa, etc.

\subsubsection{Egresos:}

Gastos del Proyecto: En este ítem se consideran los gastos de terreno, planeamiento integral, habilitación urbana y el expediente para el ministerio de vivienda, construcción y saneamiento. Para el caso del terreno, se consideran los gastos, ya sea por compra de terreno o donación en cuyo caso es necesario considerar todos los gastos por trámites de independización, titulación, entre otros. En el caso de planeamiento integral, se considera todos los gastos que involucra los estudios preliminares para el diseño del proyecto, ya sea estudio de mecánica de suelos, levantamiento topográfico, estudio de factibilidad de servicios, estudio de mercado, entre otros, además se considera el costo de trámites municipales para la aprobación del planeamiento integral. Para la habilitación urbana se considera los costos de la elaboración de los planos de manzaneo, lotización, vías, entre otros, además se considera los gastos por la elaboración de los expedientes de redes de electrificación, agua potable y alcantarillado para todas las viviendas del proyecto. En el expediente Técnico para el Ministerio de Vivienda Construcción y Saneamiento se considera todos los gastos de diseño y planeamiento del proyecto, es decir, gastos por elaboración de planos de arquitectura, estructura, instalaciones eléctricas e instalaciones sanitarias de los módulos de vivienda, así como el presupuesto por vivienda, cronograma de obra, entre otros.

Construcción: Se consideran los costos de los recursos necesarios para la construcción de las viviendas (mano de obra, materiales y equipos), se ha calculado según el LOOKAHEAD compatibilizado con el modelamiento en NAVISWORKS. Además, se considera las obras de los servicios básicos los cuales son vías y veredas, redes de agua potable, redes de desagüe y redes de electrificación.

Gastos Generales: Considera los gastos del STAFF de profesionales involucrados en el proyectos, éstos son el gerente de proyecto, personal administrativo, logística, BIM $M A N A G E R$, asistente $B I M$, ingeniero de seguridad e ingeniero de calidad; además se ha incluido los gastos de implementación del área BIM en la empresa.

Gastos por Ventas: Considera los gastos por publicidad, personal de ventas, trámites de calificación de beneficiarios, entre otros.

Gastos Financieros: Se incluye los gastos por las cartas fianzas solicitadas al banco, de existir préstamo, se incluye como gasto el pago de las cuotas mensuales.

Gastos Post Proyecto: Incluye todos os gastos necesarios para la entrega de las viviendas a los beneficiarios, trámites notariales y registrales.

Otros: Considera los gastos adicionales por supervisiones del Fondo Mivivienda y de la Municipalidad correspondiente. Además, es importante considerar un monto para eventos no previstos. 


\subsubsection{Análisis de alternativas}

Alternativa 1: Construcción de viviendas 1 por día

Se plantea que la velocidad de construcción será de 1 lote al día; es decir, las actividades se ejecutarán cada día para un solo lote. Por ejemplo, el día 23 se hará las excavaciones y cimentaciones del lote B1, el día 24 se hará el sobrecimiento del lote B1 y la excavación y cimiento del lote B1, el día 25 se hará el armado de acero de muros e instalaciones del lote B1 y el sobrecimiento del lote B2, y así sucesivamente.

Cuadro 8: Flujo caja económico (S/.)

\begin{tabular}{|c|c|c|c|c|c|c|c|c|c|c|c|c|c|c|c|c|}
\hline ACTIVIDADES DE OPERACIÓN & ene-18 & feb-18 & mar-18 & abr-18 & may-18 & jun-18 & jul-18 & ago-18 & sep-18 & oct-18 & nov-18 & dic-18 & ene-19 & feb-19 & mar-19 & abr-19 \\
\hline IGRESOS & $110,000.00$ & $20,000.00$ & $20,000.00$ & $20,000.00$ & $20,000.00$ & $20,000.00$ & $50,000.00$ & $80,000.00$ & $80,000.00$ & $412,000.00$ & $892,000.00$ & $862,000.001$ & $1,084,000.001$ & $1,084,000.00$ & $420,000.00$ & $416,000.00$ \\
\hline 1.- Ingreso por ventas & 0.00 & 0.00 & 0.00 & 0.00 & 0.00 & 0.00 & $30,000.00$ & $60,000.00$ & $60,000.00$ & $392,000.00$ & $892,000.00$ & $862,000.001$ & $1,084,000.001$ & $1,084,000.00$ & $420,000.00$ & $416,000.00$ \\
\hline 2.- Otros Ingresos & 0.00 & 0.00 & 0.00 & 0.00 & 0.00 & 0.00 & 0.00 & 0.00 & 0.00 & 0.00 & 0.00 & 0.00 & 0.00 & 0.00 & 0.00 & 0.00 \\
\hline 3.- Aporte Propio & $110,000.00$ & $20,000.00$ & $20,000.00$ & $20,000.00$ & $20,000.00$ & $20,000.00$ & $20,000.00$ & $20,000.00$ & $20,000.00$ & $20,000.00$ & & & & & & 0.00 \\
\hline \multicolumn{17}{|l|}{ 4.- Préstamo } \\
\hline SRESOS & $122,200.00$ & $22,600.00$ & $16,300.00$ & 0.00 & $19,300.00$ & $25,000.00$ & $13,700.00$ & $12,600.00$ & $12,600.00$ & 845.83 & 387.56 & 2.731 & 374.31 & 277.04 & $258,020.61$ & $92,545.83$ \\
\hline 1.- Gastos de Pre-proyecto & $114,200.00$ & $14,600.00$ & $8,300.00$ & 0.00 & $11,300.00$ & $10,000.00$ & 700.00 & 100.00 & 100.00 & 100.00 & 0.00 & 0.00 & 0.00 & 0.00 & 0.00 & 0.00 \\
\hline 2.- Construcción & 0.00 & 0.00 & 0.00 & 0.00 & 0.00 & 0.00 & 0.00 & 0.00 & 0.00 & 0.00 & $885,795.89$ & $1,021,971.06$ & $969,282.64$ & $907,185.37$ & $228,020.61$ & $50,000.00$ \\
\hline 3.- Gastos Generales & $7,000.00$ & $7,000.00$ & $7,000.00$ & $7,000.00$ & $7,000.00$ & $7,000.00$ & $7,000.00$ & $7,000.00$ & $7,000.00$ & $31,700.00$ & $29,000.00$ & $29,000.00$ & $29,000.00$ & $29,000.00$ & $29,000.00$ & $14,500.00$ \\
\hline 4.- Gastos por Ventas & 0.00 & 0.00 & 0.00 & 0.00 & 0.00 & $7,000.00$ & $5,000.00$ & $4,500.00$ & $4,500.00$ & $4,500.00$ & 0.00 & 0.00 & 0.00 & 0.00 & 0.00 & 0.00 \\
\hline 5.- Gastos Financieros & 0.00 & 0.00 & 0.00 & 0.00 & 0.00 & 0.00 & 0.00 & 0.00 & 0.00 & $1,545.83$ & 091.67 & 091.67 & $3,091.67$ & 091.67 & 0.00 & $1,545.83$ \\
\hline 6.- Gastos Post-Proyecto & 0.00 & 0.00 & $0.00^{\prime \prime}$ & $0.00^{\prime}$ & $0.00^{\prime}$ & $0.00^{\prime}$ & $0.00^{\prime}$ & $0.00^{\prime \prime}$ & $0.00^{\circ}$ & $0.00^{\prime}$ & $0.00^{\prime}$ & $0.00^{\prime}$ & $0.00^{\prime \prime}$ & $0.00^{\prime}$ & 0.00 & $25,500.00$ \\
\hline 7.- Otros & $1,000.00$ & $1,000.00$ & $1,000.00$ & $1,000.00$ & $1,000.00$ & $1,000.00$ & $1,000.00$ & $1,000.00$ & $1,000.00$ & $1,000.00$ & $1,000.00$ & $1,000.00$ & $1,000.00$ & $1,000.00$ & $1,000.00$ & $1,000.00$ \\
\hline 8.- Devolución de capital & 0.00 & 0.00 & 0.00 & 0.00 & 0.00 & 0.00 & 0.00 & 0.00 & 0.00 & 0.00 & 0.00 & 0.00 & 0.00 & 0.00 & 0.00 & 0.00 \\
\hline _UJO DE CAJA MENSUAL & $-12,200.00$ & $-2,600.00$ & $3,700.00$ & $12,000.00$ & 700.00 & $-5,000.00$ & $36,300.00$ & $67,400.00$ & $67,400.00$ & $373,154.17$ & $-26,887.56$ & $-193,062.73$ & $81,625.69$ & $143,722.96$ & $161,979.39$ & $323,454.17$ \\
\hline Impuestos & 0.00 & 0.00 & 0.00 & 0.00 & 0.00 & 0.00 & 0.00 & 0.00 & 0.00 & 0.00 & 0.00 & 0.00 & 0.00 & 0.00 & 0.00 & $222,505.83$ \\
\hline LUJO DE CAJA MEN & $-12,200.00$ & & $3,700.00$ & $12,000.00$ & $I$ & 1.00 & & $67,400.00$ & 67,4 & & .56 & 2.73 & 5.69 & 2.96 & 79.39 & 18.34 \\
\hline FLUJO ACUMULADO & $-12,200.00$ & $-14,800.00$ & $-11,100.00$ & 900.00 & $1,600.00$ & $-3,400.00$ & $32,900.00$ & $100,300.00$ & $167,700.00$ & $540,854.17$ & $513,966.61$ & $320,903.88$ & $402,529.58$ & $546,252.54$ & $708,231.93$ & $809,180.26$ \\
\hline
\end{tabular}

Fuente: (Elaboración propia.)

- Los primeros meses (enero - octubre) como se muestra en el cuadro $\mathrm{N}^{\circ} 8$ representan la etapa inicial del proyecto, comprende la adjudicación de terreno, estudios preliminares, tramites y licencias requeridas, definición de alcance entre otros.

- Los siguientes meses (noviembre - marzo) representan la etapa de construcción.

- El último mes de abril, representa los trámites posteriores a la construcción.

Se observa que los tres primeros meses queda cuentas por pagar ya que no existe el ingreso suficiente, se considera que estas deuda serán para gastos generales los cuales serán pagados en abril. Además, durante la construcción se observa que el flujo acumulado es positivo en todos los meses, es decir que se contará con el dinero suficiente para la construcción, no habrá necesidad de solicitar un préstamo al banco. 
Alternativa 2: Construcción de viviendas 2 por día

Se plantea que la velocidad de construcción será de 2 lotes al día; es decir, las actividades se ejecutarán cada día para un solo lote. Por ejemplo, el día 11 se hará las excavaciones y cimentaciones del lote B1 y B2; el día 12 se hará el sobrecimiento del lote B1 y B2, y a la vez la excavación y cimiento del lote B3 y B4; el día 12 se hará el armado de acero de muros e instalaciones del lote B1 y B2, y el sobrecimiento del lote B3 y B4; y así sucesivamente.

Cuadro 9: Flujo de caja económico.

\begin{tabular}{|c|c|c|c|c|c|c|c|c|c|c|c|c|c|c|}
\hline ACTIVIDADES DE OPERACIÓN & ene-18 & feb-18 & mar-18 & abr-18 & may-18 & jun-18 & jul-18 & ago-18 & sep-18 & oct-18 & nov-18 & dic-18 & ene-19 & feb-19 \\
\hline INGRESOS & $110,000.00$ & $20,000.00$ & $20,000.00$ & $20,000.00$ & $20,000.00$ & $20,000.00$ & $50,000.00$ & $80,000.00$ & $80,000.00$ & $412,000.00$ & $892,000.00$ & $1,198,000.00$ & $1,168,000.00$ & $1,500,000.00$ \\
\hline 1.- Ingreso por ventas & 0.00 & 0.00 & 0.00 & 0.00 & 0.00 & 0.00 & $30,000.00$ & $60,000.00$ & $60,000.00$ & $392,000.00$ & $892,000.00$ & $1,198,000.00$ & $1,168,000.00$ & $1,500,000.00$ \\
\hline 2.- Otros Ingresos & 0.00 & 0.00 & 0.00 & 0.00 & 0.00 & 0.00 & 0.00 & 0.00 & 0.00 & 0.00 & 0.00 & 0.00 & 0.00 & 0.00 \\
\hline 3.- Aporte Propio & $110,000.00$ & $20,000.00$ & $20,000.00$ & $20,000.00$ & $20,000.00$ & $20,000.00$ & $20,000.00$ & $20,000.00$ & $20,000.00$ & $20,000.00$ & & & & \\
\hline \multicolumn{15}{|l|}{ 4.- Préstamo } \\
\hline EGRESOS & $122,200.00$ & $22,600.00$ & $16,300.00$ & $8,000.00$ & $19,300.00$ & $25,000.00$ & $13,700.00$ & $12,600.00$ & $12,600.00$ & $38,845.83$ & $1,970,008.76$ & $1,820,260.91$ & $321,260.90$ & $105,500.00$ \\
\hline 1.- Gastos de Pre-proyecto & $114,200.00$ & $14,600.00$ & $8,300.00$ & 0.00 & $11,300.00$ & $10,000.00$ & 700.00 & 100.00 & 100.00 & 100.00 & 0.00 & 0.00 & 0.00 & 0.00 \\
\hline 2.- Construcción & 0.00 & 0.00 & 0.00 & 0.00 & 0.00 & 0.00 & 0.00 & 0.00 & 0.00 & 0.00 & $1,936,917.10$ & $1,787,169.24$ & $288,169.23$ & $50,000.00$ \\
\hline 3.- Gastos Generales & $7,000.00$ & $7,000.00$ & $7,000.00$ & $7,000.00$ & $7,000.00$ & $7,000.00$ & $7,000.00$ & $7,000.00$ & $7,000.00$ & $31,700.00$ & $29,000.00$ & $29,000.00$ & $29,000.00$ & $29,000.00$ \\
\hline 4.- Gastos por Ventas & 0.00 & 0.00 & 0.00 & 0.00 & 0.00 & $7,000.00$ & $5,000.00$ & $4,500.00$ & $4,500.00$ & $4,500.00$ & 0.00 & 0.00 & 0.00 & 0.00 \\
\hline 5.- Gastos Financieros & 0.00 & 0.00 & 0.00 & 0.00 & 0.00 & 0.00 & 0.00 & 0.00 & 0.00 & $1,545.83$ & $3,091.67$ & $3,091.67$ & $3,091.67$ & 0.00 \\
\hline 6.- Gastos Post-Proyecto & $0.00^{\prime \prime}$ & $0.00^{\prime}$ & $0.00^{\prime \prime}$ & $0.00^{\prime}$ & $0.00^{\prime}$ & $0.00^{\prime \prime}$ & $0.00^{\prime}$ & $0.00^{\prime}$ & $0.00^{\prime}$ & $0.00^{\prime}$ & $0.00^{\prime}$ & $0.00^{\prime}$ & 0.00 & $25,500.00$ \\
\hline 7.- Otros & $1,000.00$ & $1,000.00$ & $1,000.00$ & $1,000.00$ & $1,000.00$ & $1,000.00$ & $1,000.00$ & $1,000.00$ & $1,000.00$ & $1,000.00$ & $1,000.00$ & $1,000.00$ & $1,000.00$ & $1,000.00$ \\
\hline 8.- Devolución de capital & 0.00 & 0.00 & 0.00 & 0.00 & 0.00 & 0.00 & 0.00 & 0.00 & 0.00 & 0.00 & 0.00 & 0.00 & 0.00 & 0.00 \\
\hline FLUJO DE CAJA MENSUAL & $-12,200.00$ & $-2,600.00$ & $3,700.00$ & $12,000.00$ & 700.00 & $-5,000.00$ & $36,300.00$ & $67,400.00$ & $67,400.00$ & $373,154.17$ & $-1,078,008.76$ & $-622,260.91$ & $846,739.10$ & $1,394,500.00$ \\
\hline Impuestos & $S / .0 .00$ & S/. 0.00 & $S / .0 .00$ & $S / .0 .00$ & S/. 0.00 & S/. 0.00 & S/. 0.00 & Sl. 0.00 & $S / .0 .00$ & $S / .0 .00$ & S/. 0.00 & Sl. 0.00 & Sl. 0.00 & S/. 237,547.08 \\
\hline FLUJO DE CAJA MENSUAL & $-12,200.00$ & $-2,600.00$ & $3,700.00$ & $12,000.00$ & 700.00 & $-5,000.00$ & $36,300.00$ & $67,400.00$ & $67,400.00$ & $373,154.17$ & $-1,078,008.76$ & $-622,260.91$ & $846,739.10$ & $1,156,952.92$ \\
\hline FLUJO ACUMULADO & $-12,200.00$ & $-14,800.00$ & $-11,100.00$ & 900.00 & $1,600.00$ & $-3,400.00$ & $32,900.00$ & $100,300.00$ & $167,700.00$ & $540,854.17$ & $-537,154.60$ & $-1,159,415.51$ & $-312,676.41$ & $844,276.52$ \\
\hline
\end{tabular}

Fuente: (Elaboración propia.)

- Los primeros meses (enero - octubre) como se muestra en el cuadro $\mathrm{N}^{\circ} 9$ representan la etapa inicial del proyecto, comprende la adjudicación de terreno, estudios preliminares, tramites y licencias requeridas, definición de alcance entre otros.

- Los siguientes meses (noviembre - enero) representan la etapa de construcción.

- El último mes de febrero, representa los trámites posteriores a la construcción.

En este caso, la etapa inicial es igual al de la alternativa 1, la diferencia se observa en la etapa de construcción en la que existe una falta de liquidez de casi S/. 1'700,000.00, lo cual demuestra que la alternativa 2 es la más rápida ya que termina la construcción en tres meses; sin embargo, es la menos viable ya que conseguir un préstamo por esa cantidad es muy difícil para las medianas empresas. 
Alternativa 3: Construcción de viviendas con baños prefabricados

En este caso se considera que la velocidad de construcción será de 1 por día y además se utilizarán las instalaciones para baños prefabricados.

Cuadro 10: Flujo de caja económico.

\begin{tabular}{|c|c|c|c|c|c|c|c|c|c|c|c|c|c|c|c|c|}
\hline ACTIVIDADES DE OPERACIÓN & ene-18 & feb-18 & mar-18 & abr-18 & may-18 & jun-18 & jul-18 & ago-18 & sep-18 & oct-18 & nov-18 & dic-18 & ene-19 & feb-19 & mar-19 & abr-19 \\
\hline INGRESOS & $110,000.00$ & $20,000.00$ & $20,000.00$ & $20,000.00$ & $20,000.00$ & $20,000.00$ & $50,000.00$ & $80,000.00$ & $80,000.00$ & $412,000.00$ & $892,000.00$ & $862,000.00$ & $1,084,000.00$ & $1,084,000.00$ & $420,000.00$ & $416,000.00$ \\
\hline 1.- Ingreso por ventas & 0.00 & 0.00 & 0.00 & 0.00 & 0.00 & 0.00 & $30,000.00$ & $60,000.00$ & $60,000.00$ & $392,000.00$ & $892,000.00$ & $862,000.001$ & $1,084,000.00$ & $1,084,000.00$ & $420,000.00$ & $416,000.00$ \\
\hline 2.- Otros Ingresos & 0.00 & 0.00 & 0.00 & 0.00 & 0.00 & 0.00 & 0.00 & 0.00 & 0.00 & 0.00 & 0.00 & 0.00 & 0.00 & 0.00 & 0.00 & 0.00 \\
\hline 3.- Aporte Propio & $0,000.00$ & $20,000.00$ & $20,000.00$ & $20,000.00$ & $20,000.00$ & $20,000.00$ & $20,000.00$ & $20,000.00$ & $20,000.00$ & $20,000.00$ & & & & & & 0.00 \\
\hline \multicolumn{17}{|l|}{ 4.- Préstamo } \\
\hline GRESOS & $122,200.00$ & $22,600.00$ & $16,300.00$ & $8,000.00$ & $19,300.00$ & $25,000.00$ & $13,700.00$ & $12,600.00$ & $12,600.00$ & $38,845.83$ & $864,423.54$ & $874,313.48$ & $865,701.45$ & $902,830.40$ & $818,146.71$ & $97,545.83$ \\
\hline 1.- Gastos de Pre-p & $114,200.00$ & $14,600.00$ & $8,300.00$ & 0.00 & $11,300.00$ & $10,000.00$ & 700.00 & 100.00 & 100.00 & 100.00 & 0.00 & 0.00 & 0.00 & 0.00 & 0.00 & 0.00 \\
\hline 2.- Construcción & 0.00 & 0.00 & 0.00 & 0.00 & 0.00 & 0.00 & 0.00 & 0.00 & 0.00 & 0.00 & $831,331.87$ & $841,221.81$ & $832,609.78$ & $869,738.73$ & $788,146.71$ & $50,000.00$ \\
\hline 3.- Gastos Generales & $7,000.00$ & $7,000.00$ & $7,000.00$ & $7,000.00$ & $7,000.00$ & $7,000.00$ & $7,000.00$ & $7,000.00$ & $7,000.00$ & $31,700.00$ & $29,000.00$ & $29,000.00$ & $29,000.00$ & $29,000.00$ & $29,000.00$ & $19,500.00$ \\
\hline 4.- Gastos por Ventas & 0.00 & 0.00 & 0.00 & 0.00 & 0.00 & $7,000.00$ & $5,000.00$ & $4,500.00$ & $4,500.00$ & $4,500.00$ & 0.00 & 0.00 & 0.00 & 0.00 & 0.00 & 0.00 \\
\hline 5.- Gastos Financieros & 0.00 & 0.00 & 0.00 & 0.00 & 0.00 & 0.00 & 0.00 & 0.00 & 0.00 & $1,545.83$ & 091.67 & $3,091.67$ & $3,091.67$ & 091.67 & 0.00 & $1,545.83$ \\
\hline 6.- Gastos Post-Proyecto & 0.00 & 0.00 & $0.00^{\prime}$ & 0.00 & $0.00^{\prime}$ & 0.00 & 0.00 & $0.00^{\prime}$ & $0.00^{\prime}$ & $0.00^{\prime \prime}$ & $0.00^{\prime}$ & $0.00^{\prime}$ & 0.00 & 0.00 & 0.00 & $25,500.00$ \\
\hline 7.- Otros & 000.00 & $1,000.00$ & 000.00 & $1,000.00$ & 000.00 & $1,000.00$ &, 000.00 & 000.00 & $1,000.00$ & 000.00 &, 000.00 & $1,000.00$ & $1,000.00$ & $1,000.00$ & $1,000.00$ & $1,000.00$ \\
\hline 8.- Devolución de capital & 0.00 & 0.00 & 0.00 & 0.00 & 0.00 & 0.00 & 0.00 & 0.00 & 0.00 & 0.00 & 0.00 & 0.00 & 0.00 & 0.00 & 0.00 & 0.00 \\
\hline UJO DE CAJA MENSUAL & $-12,200.00$ & $-2,600.00$ & $3,700.00$ & $12,000.00$ & 700.00 & $-5,000.00$ & $36,300.00$ & $67,400.00$ & $67,400.00$ & $373,154.17$ & $27,576.46$ & $-12,313.48$ & $218,298.55$ & $181,169.60$ & $398,146.71$ & $318,454.17$ \\
\hline Impuestos & S/. 0.00 & S/. 0.00 & S/. 0.00 & S/. 0.00 & S/. 0.00 & S/. 0.00 & S/. 0.00 & $S / .0 .00$ & $S / .0 .00$ & $S / .0 .00$ & $S / .0 .00$ & $S / .0 .00$ & S/. 0.00 & S/. 0.00 & S/. 0.00 & /. $168,117.83$ \\
\hline JO DE CAJA MEN & $-12,200.00$ & $-2,600.00$ & $3,700.00$ & $12,000.00$ & 700.00 & $-5,000.00$ & $36,300.00$ & $67,400.00$ & $67,400.00$ & $373,154.17$ & $27,576.46$ & $-12,313.48$ & 218,298.55 & $181,169.60$ & 46.71 & $150,336.34$ \\
\hline UJO ACUMULADO & $-12,200.00$ & $-14,800.00$ & $-11,100.00$ & 900.00 & $1,600.00$ & $-3,400.00$ & $32,900.00$ & $100,300.00$ & $167,700.00$ & $540,854.17$ & $568,430.63$ & $556,117.15$ & $774,415.70$ & $955,585.30$ & $557,438.59$ & $707,774.93$ \\
\hline
\end{tabular}

Fuente: (Elaboración propia.)

- Los primeros meses (enero - octubre) como se muestra en el cuadro $\mathrm{N}^{\circ} 10$ representan la etapa inicial del proyecto, comprende la adjudicación de terreno, estudios preliminares, tramites y licencias requeridas, definición de alcance entre otros.

- Los siguientes meses (noviembre - marzo) representan la etapa de construcción.

- El último mes de abril, representa los trámites posteriores a la construcción.

El costo de construcción de esta alternativa 3 es mayor y no reduce mucho el tiempo de construcción ya que la duración de la instalación de los prefabricados es el mismo que el convencional, y el costo es mucho mayor por el flete. 
Según las alternativas evaluadas anteriormente, se tienen los siguientes resultados:

Cuadro 11: Indicadores financieros del flujo económico

\begin{tabular}{|c|r|c|c|}
\cline { 2 - 4 } \multicolumn{1}{c|}{} & Alternativa 1 & Alternativa 2 & Alternativa 3 \\
\hline TASA ANUAL & $15.00 \%$ & $15.00 \%$ & $15.00 \%$ \\
\hline TASA & & & \\
MENSUAL & $1.17 \%$ & $1.17 \%$ & $1.17 \%$ \\
\hline TIR & $62.51 \%$ & $32.46 \%$ & $64.57 \%$ \\
\hline VAN & $\mathrm{S} / .704,630.71$ & $\mathrm{~S} / .697,177.84$ & $\mathrm{~S} / .629,650.69$ \\
\hline UTILIDAD & $9.29 \%$ & $9.78 \%$ & $7.47 \%$ \\
\hline
\end{tabular}

Fuente: (Elaboración propia.)

En el cuadro 11 se observa que la alternativa 2 tienen el mayor porcentaje de utilidad; sin embargo, tiene muy bajo TIR y VAN, principalmente por la alta falta de liquidez para la construcción. Por otro lado, la alternativa 3 es la que presenta menor utilidad, aunque el valor de TIR sea mayor, esto sucede porque el costo de construcción es mayor y el tiempo es el mismo que en la alternativa 1 . Por lo que se optó por elegir a la alternativa 1 ya que tiene buen porcentaje de utilidad y resulta la más factible. 
Cuadro 12: Flujo de Caja de la Gestión Convencional.

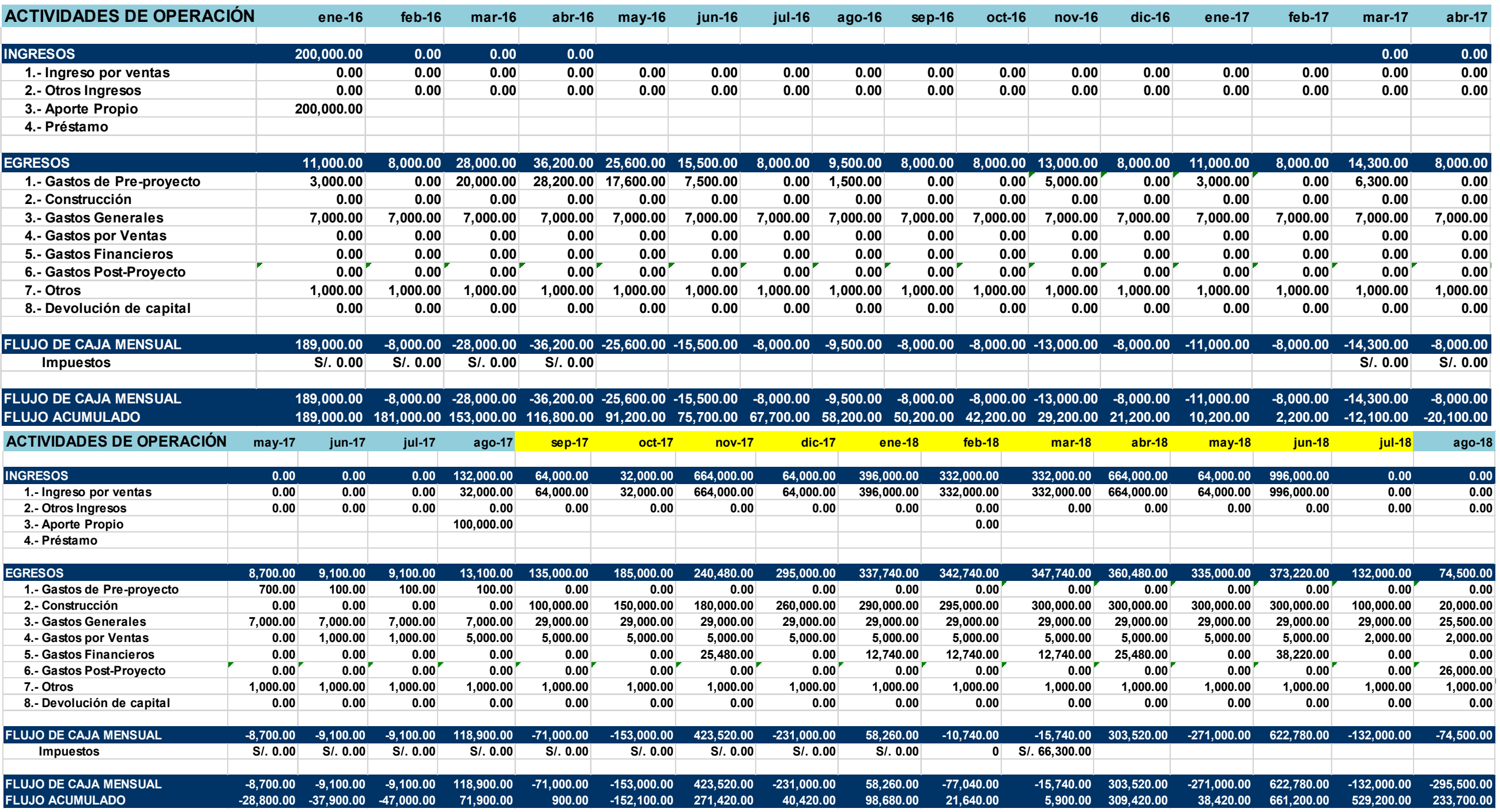

Fuente: (Elaboración propia.) 
En el sistema de gestión convencional la etapa de ante proyecto dura 1 año y 8 meses, debido a la mala gestión. Además, la construcción de 100 viviendas se realizó en 11 meses debido principalmente a la mala planificación inicial.

Cuadro 13: Indicadores financieros del flujo económico.

\begin{tabular}{|c|c|}
\hline TASA MENSUAL & $1.17 \%$ \\
\hline TIR & $2.58 \%$ \\
\hline VAN & S/.29,481.56 \\
\hline UTILIDAD & $4.25 \%$ \\
\hline
\end{tabular}

Fuente: (Elaboración propia.)

En la gestión convencional, según el cuadro 13, con una tasa de $15 \%$ se obtiene un TIR de $2.58 \%$, un VAN de S/. 29,481.56; es decir, que el proyecto resulta rentable. Sin embargo, la utilidad resultó un $4.25 \%$, un valor menor al obtenido con la propuesta del trabajo de investigación.

\subsection{Análisis de resultados de los indicadores.}

Cuadro 14: Comparación de indicadores entre las alternativas 1, 2 y 3.

\begin{tabular}{|c|r|r|r|}
\cline { 2 - 4 } \multicolumn{1}{c|}{} & Alternativa 1 & Alternativa 2 & Alternativa 3 \\
\hline TASA ANUAL & $15.00 \%$ & $15.00 \%$ & $15.00 \%$ \\
\hline TASA MENSUAL & $1.17 \%$ & $1.17 \%$ & $1.17 \%$ \\
\hline TIR & $62.51 \%$ & $32.46 \%$ & $64.57 \%$ \\
\hline VAN & S/.704,630.71 & S/.697,177.84 & S/.629,650.69 \\
\hline UTILIDAD & $9.29 \%$ & $9.78 \%$ & $7.47 \%$ \\
\hline
\end{tabular}

Fuente: (Elaboración propia.)

En el cuadro 14 se hace un comparativo de los indicadores financieros de las tres alternativas planteadas. Según los valores de la TIR y el VAN, las tres propuestas tienen rentabilidad. Sin embargo, la primera alternativa resulta ser la más conveniente debido a que en las alternativas 2 y 3 se requiere mayor inversión inicial; además, la alternativa 3 tiene menor porcentaje de utilidad.

Cuadro 15: Comparación de indicadores entre la alternativa 1 y la construcción convencional.

\begin{tabular}{|c|r|r|}
\cline { 2 - 3 } \multicolumn{1}{c|}{} & Alternativa 1 & Convencional \\
\hline TASA ANUAL & $15.00 \%$ & $15.00 \%$ \\
\hline TIR & $62.51 \%$ & $2.58 \%$ \\
\hline VAN & S/.704,630.71 & S/. 29,481.56 \\
\hline UTILIDAD & $9.29 \%$ & $4.25 \%$ \\
\hline
\end{tabular}

Fuente: (Elaboración propia.)

Se observa, en el cuadro 15 , el incremento de la utilidad de $4.25 \%$ a $9.29 \%$, teniendo un incremento de 5.04\%. 


\section{CAPÍTULO 6: CONCLUSIONES Y RECOMENDACIONES.}

\subsection{Conclusiones}

- Con la alternativa 1 propuesta en la evaluación de rentabilidad y, con respecto a la gestión convencional de proyectos de vivienda social, se obtuvo la mejora de la rentabilidad en 5.04 puntos porcentuales, reduciendo el costo y tiempo para los proyectos de vivienda social en la sierra sur del Perú, aplicando las metodologías BIM- LEAN CONSTRUCTION para las medianas empresas.

- Con la aplicación de la filosofía LEAN CONSTRUCTION, se pudo disminuir el plazo y costo del proyecto comparándose con la gestión de la construcción actual. En nuestro caso de estudio se logró rebajar 4 meses en el diseño, 2 años en el planeamiento y 6 meses en construcción

- En todas las etapas del proyecto, diseño, planeamiento y construcción, se logró la sinergia de la metodología BIM y la filosofía LEAN CONSTRUCTION.

- Con respecto al costo de construcción de las viviendas sociales, se consiguió reducir en un $25 \%$ comparado con la gestión de construcción convencional, utilizando la metodología BIM y la fillosofía LEAN CONSTRUCTION. 


\subsection{Recomendaciones}

- Se recomienda que en la etapa de construcción se utilicen las herramientas $L E A N$ como PPC, LAST PLANNER, entre otras para controlar de manera adecuada, de manera que se cumpla la planificación planteada.

- Trabajar con materiales estandarizados, accesibles en el mercado local.

- Para lograr éxito en la implementación del $B I M$ y $L E A N$, es necesario tener conocimiento de las herramientas, procesos y personas, y así obtener mejoras en la rentabilidad del proyecto.

- Parte del LEAN CONSTRUCTION es el LPDS (LEAN PROJECT DELIVERY SYSTEM) que nos permite planificar las etapas del ciclo productivo secuencialmente, constituyéndose como una herramienta de gran importancia.

- Aplicando la herramienta $L O O K A H E A D$ del sistema Ultimo Planificador en los proyectos de medianas empresas, son muy óptimos ya que logra enormes resultados con respecto al tiempo y costo, disminuyendo los plazos contractuales determinando ahorro en los gastos generales de obra por ende mejoras en la rentabilidad.

- El equipo técnico del diseño, planeamiento y ejecución de proyectos debe estar actualizado, capacitado y tener sólidos conocimientos formativos en la implementación de BIM y LEAN CONSTRUCTION, así también todo el equipo de trabajo.

- En la etapa de planeamiento se debe tener holguras del tiempo final en la ruta crítica además de planear óptimamente con respecto a la implementación Tecnológicas.

- Las empresas constructoras que ejecutan viviendas sociales no deben enfocarse en bajar la calidad de insumos y mano de obra lo que recomendamos es reducir las actividades que no generan valor de esta manera lograrían mayores utilidades. 


\section{BIBLIOGRAFÍA}

Arbulu, R. (2012). Definición ICE. VDC Certificate Program. Lima, Perú.

Ballard, G. (2008). The Lean Project Delivery System. An Update. Lean Construction Journal 2008.

BIM Forum. (2018). Definición BIM. Obtenido de http://www.bimforum.cl/definicion-bim/

Casa Ribé, E. (2008). Diccionario de administración y contabilidad de empresa. Barcelona: J.M. BOSCH EDITOR

CERESIS. (2015). Proyecto Adobe. Obtenido de http://www.ceresis.org/proyecto-adobe/limitaciones-delreforzamiento/index.html

Comercio, E. (2015). Reconocen a Cosapi por la nueva sede del Banco de la Nación. Lima, Perú. Obtenido de https://elcomercio.pe/economia/peru/reconocen-cosapi-nueva-sede-banco-nacion-203931

Court M., E., Aching G., C., \& Aching Samatelo, J. (2009). Matemáticas Financieras. Argentina: CENGAGE Learning.

Delgado Barrio de Mnedoza, C. (2013). Productividad en obras. Productividad en obras. Lima: Universidad Peruana de Ciencias Aplicadas.

Diario Gestión. (15 de Enero de 2018). Gobierno proyecta entregar 27,500 bonos para adquirir vivienda nueva en el 2018. Obtenido de https://gestion.pe/economia/gobierno-proyecta-entregar-27-500-bonosadquirir-vivienda-nueva-2018-224942

El Peruano. (5 de setiembre de 2017). Resolución Ministerial $N^{o}$ 327-2017-Vivienda. Obtenido de https://www.mivivienda.com.pe/PORTALCMS/archivos/documentos/8586964493309015369.PDF

EMAGISTER. (2017). Guía de Orientación. Obtenido de https://www.emagister.com/blog/formato-archivoifc-interoperabilidad-bim-ifc-sirve-relacion-bim/

Fondo MiVieienda. (2018). Viviendas a tasas más bajas. La revista inmobiliaria del Perú. MiVivienda., 35-36.

Fondo MiVivienda. (2013). Techo Propio. Obtenido de https://www.mivivienda.com.pe/PortalWEB/promotores-constructores/pagina.aspx?idpage=81

Fondo MiVivienda. (2017). Techo Propio. Obtenido de https://www.mivivienda.com.pe/PORTALWEB/usuario-busca-viviendas/buscador-proyectos-techopropio.aspx

Fondo MiVivienda. (2018). Techo Propio. Obtenido de https://www.mivivienda.com.pe/portalweb/usuariobusca-viviendas/pagina.aspx?idpage $=30$

Garcia Diaz, O. A. (2012). Aplicación de la Metodología LEAN CONSTRUCTION en la Vivienda de Interes Social. Aplicación de la Metodología LEAN CONSTRUCTION en la Vivienda de Interes Social. Bogotá.

Glogster. (2018). Medio Geográfico del Perú. Obtenido de https://edu.glogster.com/glog/peru/1lmu5x31kmt

INEI. (2007). Censos Nacionales 2007. Obtenido de http://censos.inei.gob.pe/cpv2007/tabulados/

INEI. (2009). Perú: Mapa del Déficit Habitacional a Nivel Distrital, 2007. Lima: INEI. Obtenido de https://www.inei.gob.pe/media/MenuRecursivo/publicaciones_digitales/Est/Lib0868/libro.pdf

Institute, C. I. (1986)

Irías Giron, J. M. (2002). Catálogo de Términos y sus Definiciones utilizadas en Administración Financiera y Administración Tributaria. Guatemala.

Lean Bim Construction. (14 de Mayo de 2015). Los contratos colaborativos (IPD). Obtenido de http://leanbimconstruction.com/los-contratos-colaborativos-ipd?lang=ca

Ministerio de Vivienda, Construcción y Saneamiento. (2015). Programa Nacional de Vivienda Rural. Obtenido de http://www.vivienda.gob.pe/pnvr_/inicio

Ohno, T. (1995). Toyota Production System: Beyond Large-scale Production, Productivity Press Inc., ISBN $0_{-}$ 915299-14-3.

Oroz Tito, C. F. (2015). Aplicación de herramientas de planeamiento LOOK AHEAD en construcción de proyecto inmobiliario multifamiliar de 10 pisos. 88. Lima: Universidad Ricardo Palma.

Perú, C. B. (2014). ¿Qué es BIM?, Beneficios y Aplicación. Obtenido de http://www.comitebimdelperu.com/2014/bim.html

Quiroz, F. (s.f.). BIM para acelerar la industrialización de la construcción - Primer Congreso Virtual BIM . Perú. Obtenido de https://www.youtube.com/watch?v=HBjMMK1tYvY

Rischmoller, D. L. (2017).

Saavedra, J. S. (2017). Conceptos de VDC y sus componentes. VDC Traducción por Leonardo Rischmoller. Perú.

Salinas, J.R. \& Ulloa Román, K.A. (2014). Implementación de BIM en Proyectos Inmobiliarios. Sinergia e Innovacion. Lima, Perú.

Serpell B., A. (2002). Administración de operaciones de construcción 2da Edición. Administración de operaciones de construcción 2da Edición. Mexico DF: Alfaomega Grupo Editor. 
ANEXO 1: FLOJOGRAMA DE PROCESOS DE LA ETAPA INICIAL

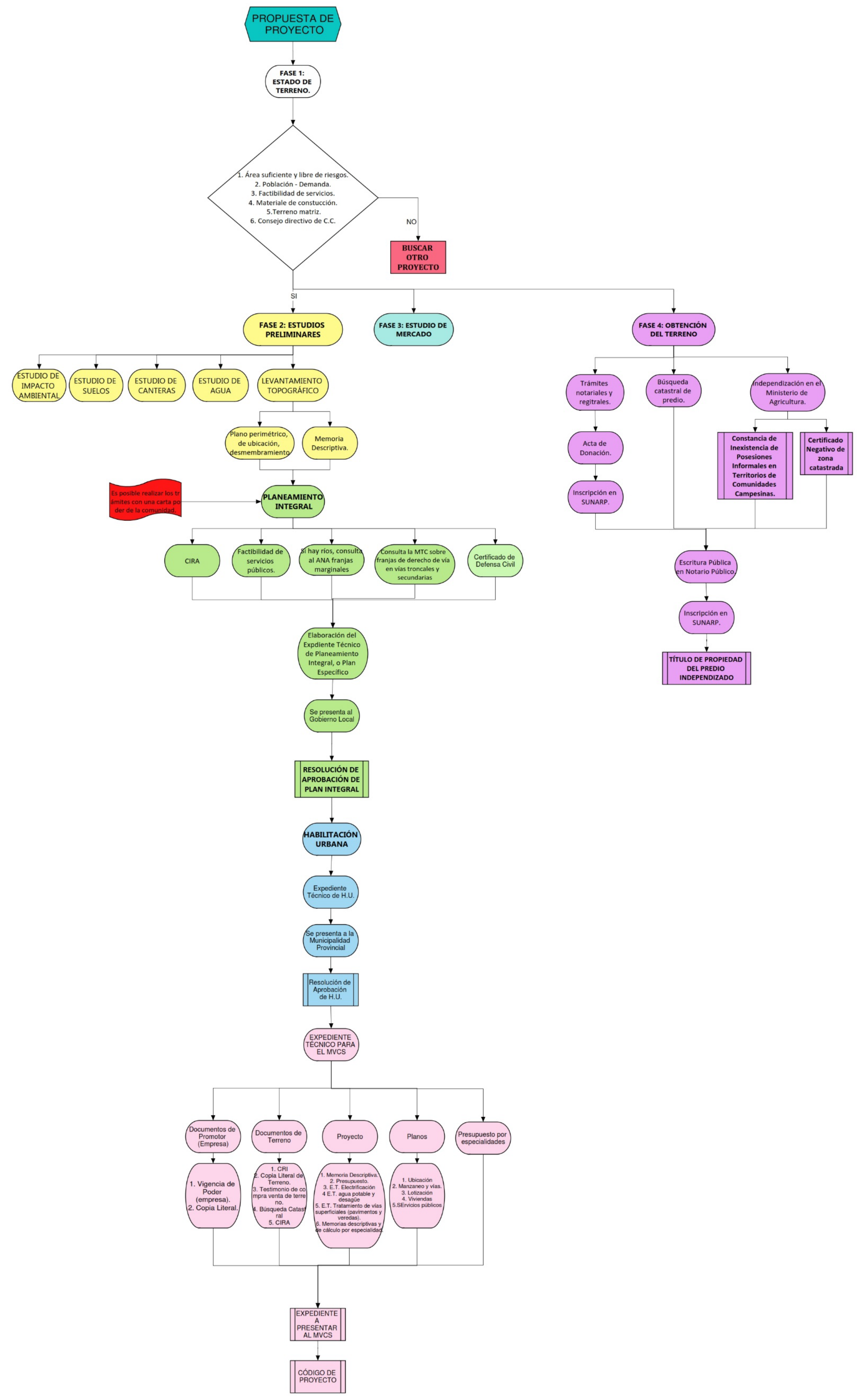


ANEXO 2: PLANO DE ARQUITECTURA DE LA ALTERNATIVA DE DISEÑO No 1

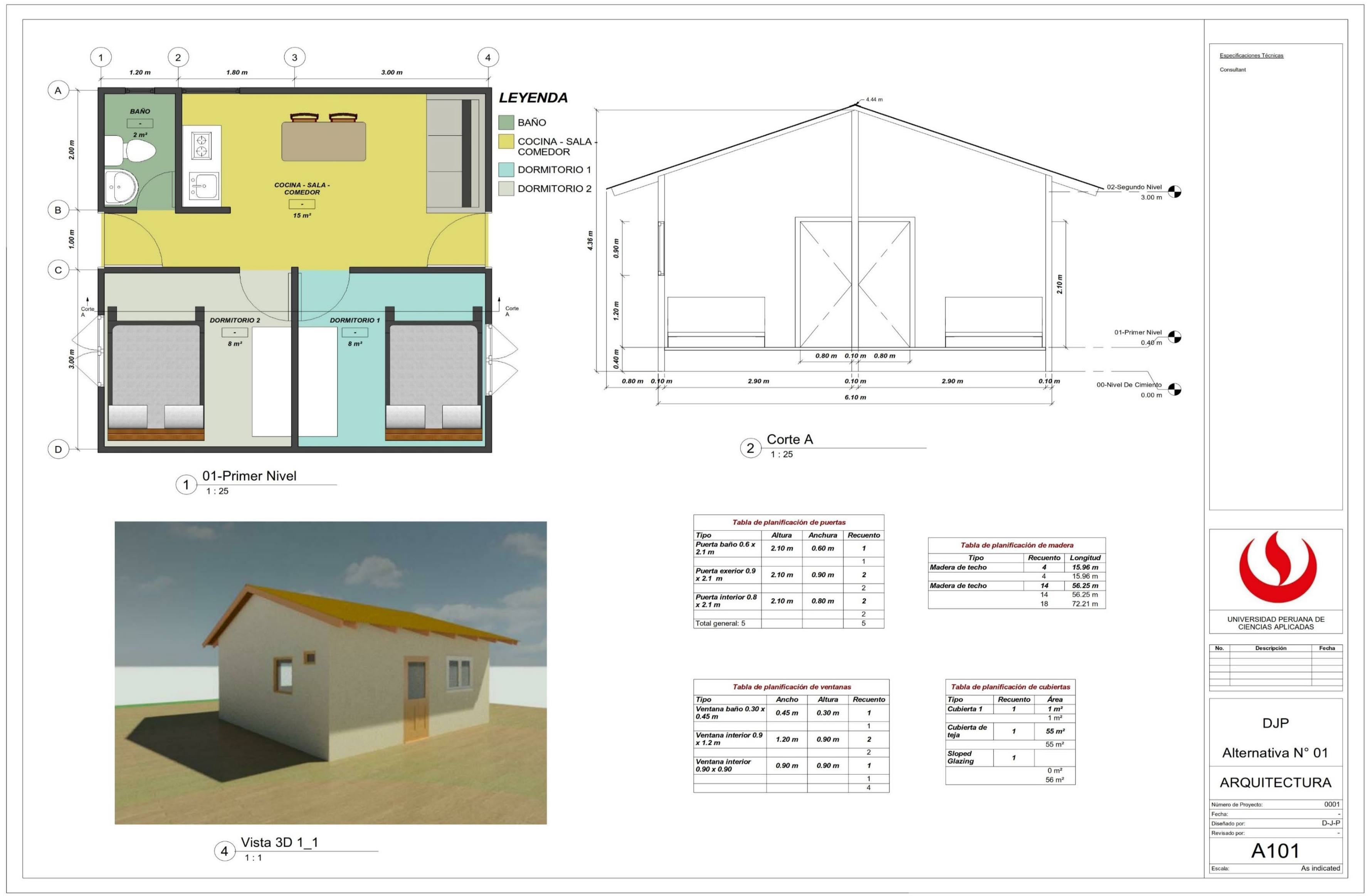


ANEXO 3: PLANO DE ARQUITECTURA DE LA ALTERNATIVA DE DISEÑO N 2

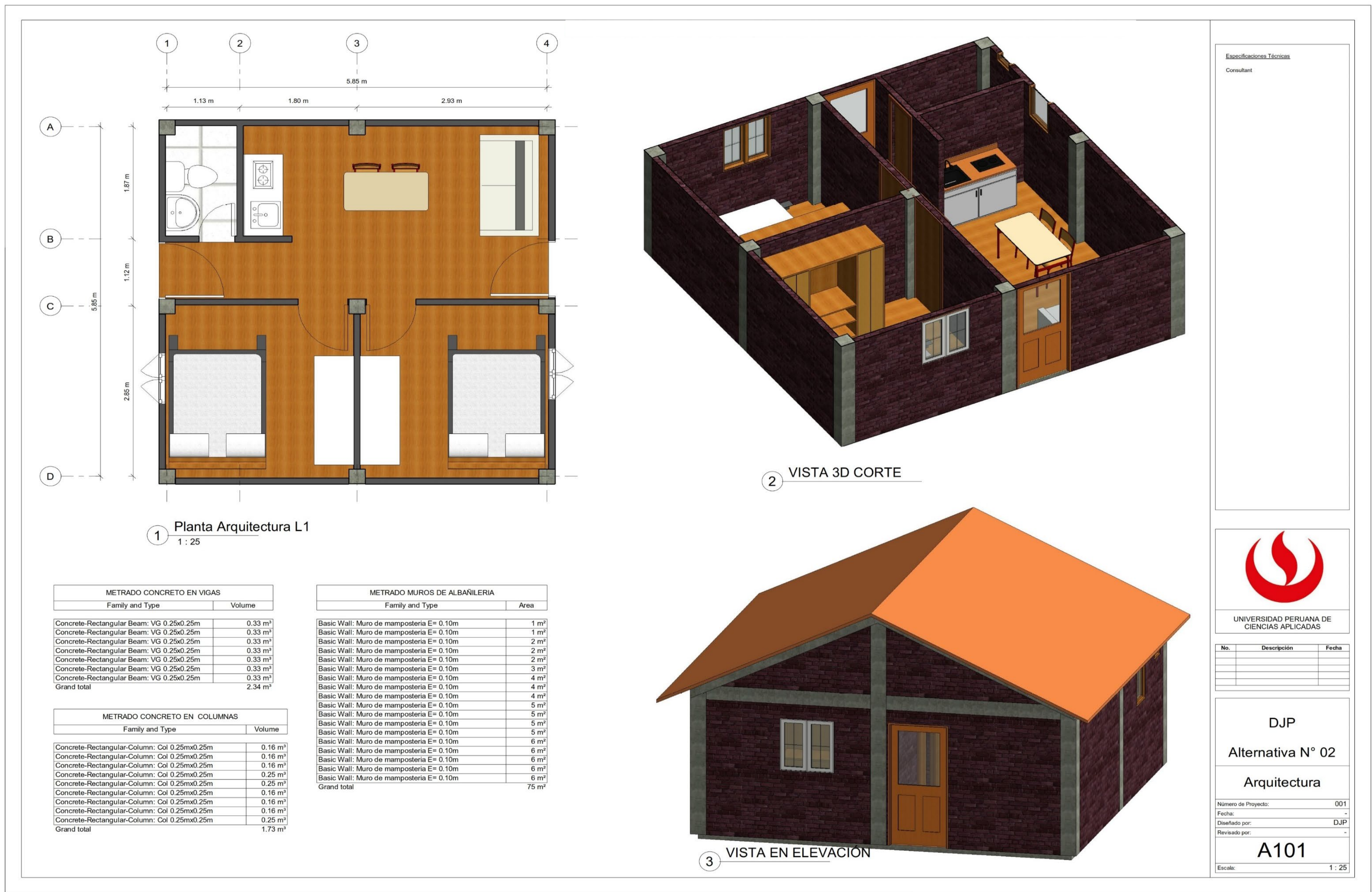


ANEXO 4: PLANO DE ESTRUCTURAS DE LA ALTERNATIVA DE DISEÑO Nº 1

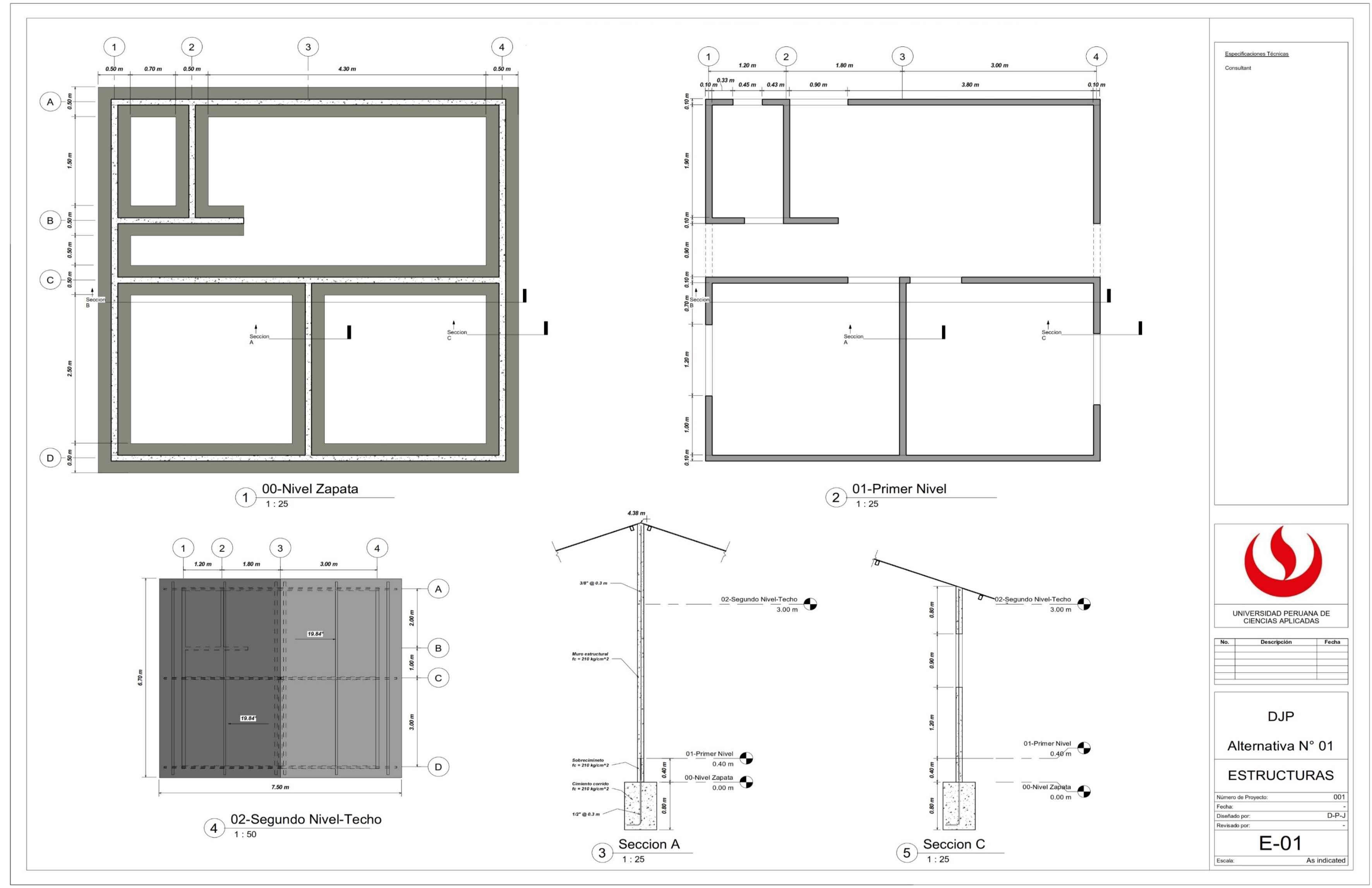


ANEXO 5: PLANO DE ESTRUCTURAS DE LA ALTERNATIVA DE DISEÑO N 1 : E-2

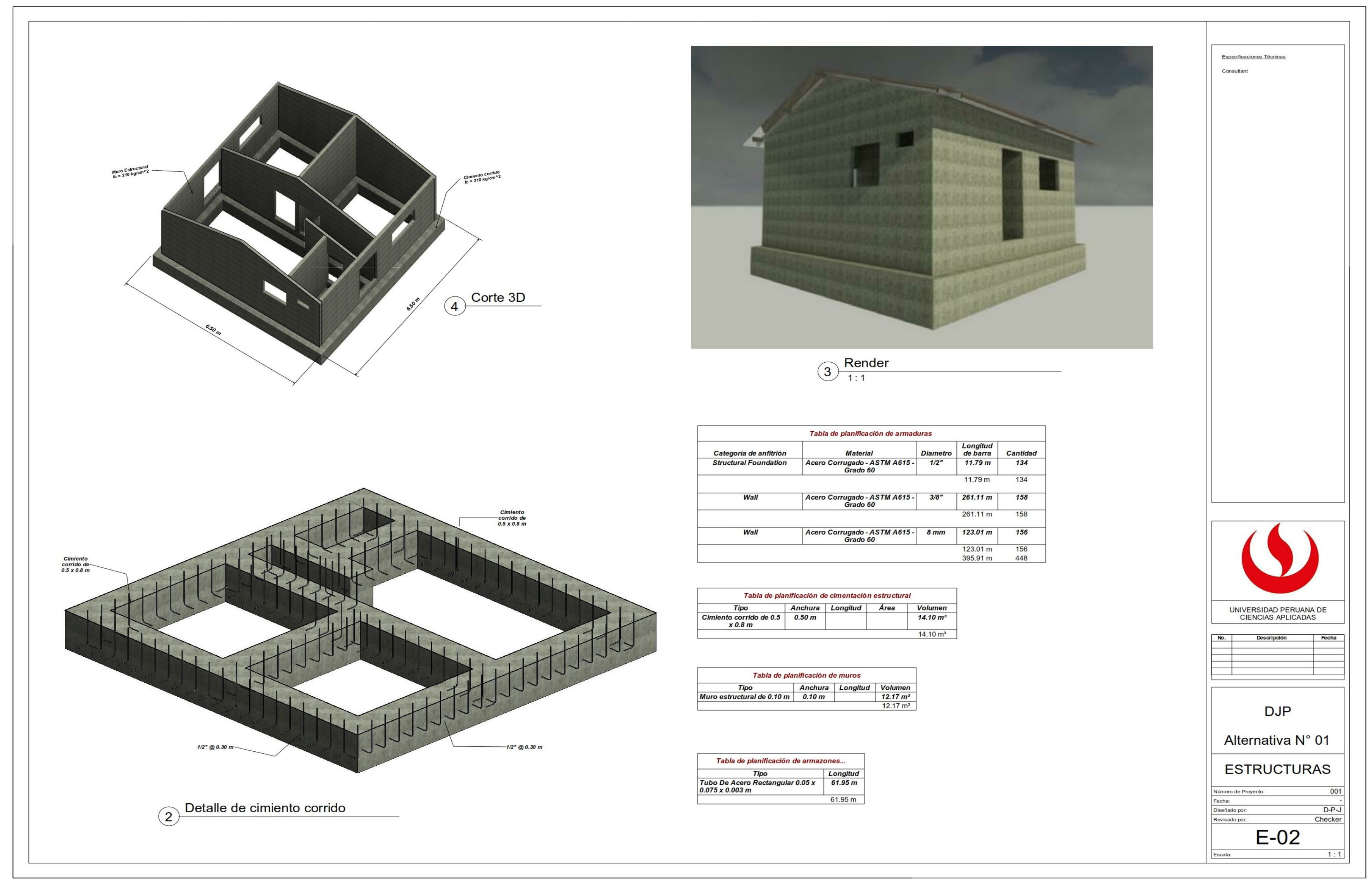


ANEXO 6: PLANO DE INSTALACIONES DE AGUA FRÍA DE LA ALTERNATIVA DE DISEÑO No 1

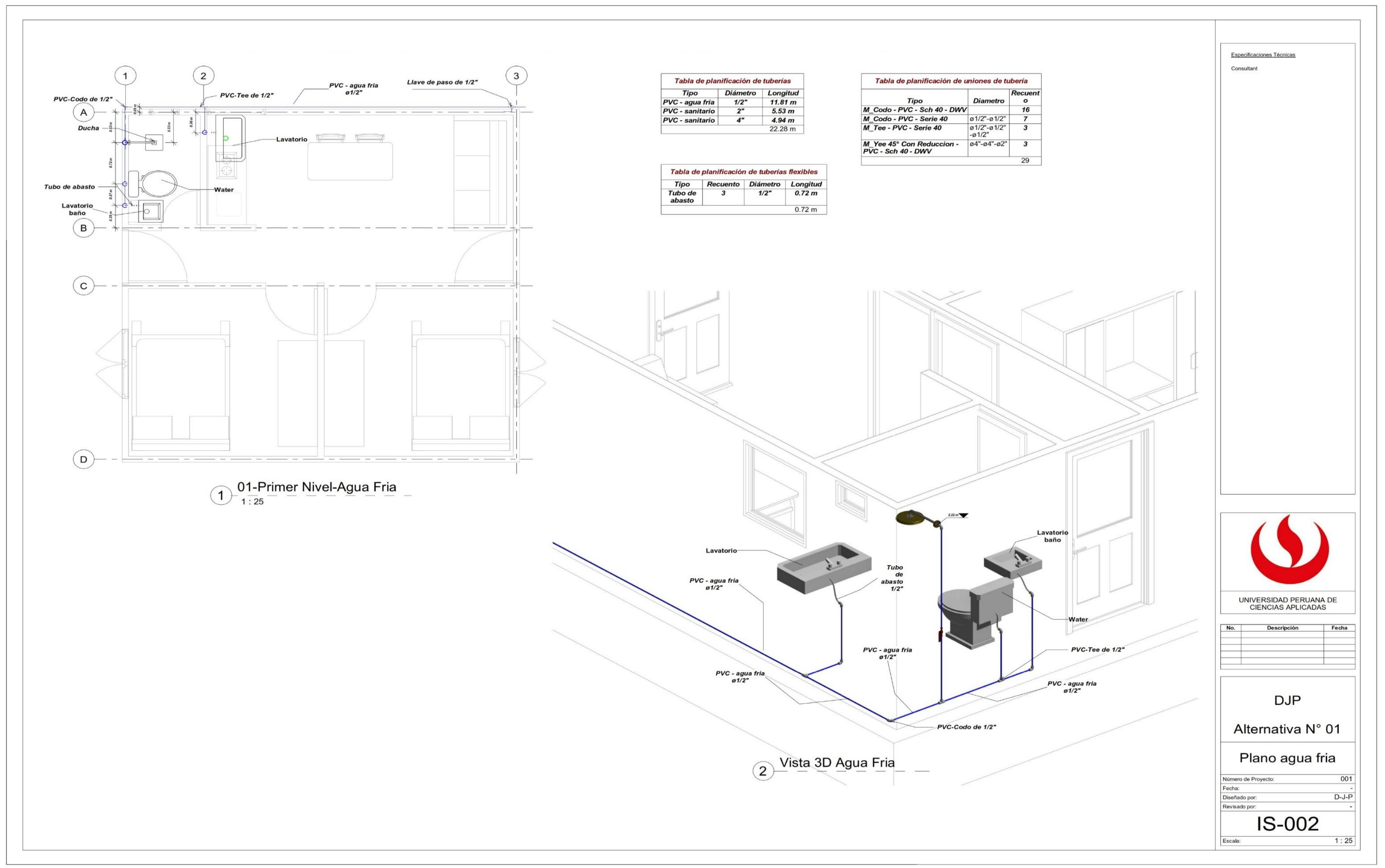


ANEXO 7: PLANO DE AGUA FRÍA Y DESAGÜE DE LA ALTERNATIVA DE DISEÑO Nº 1

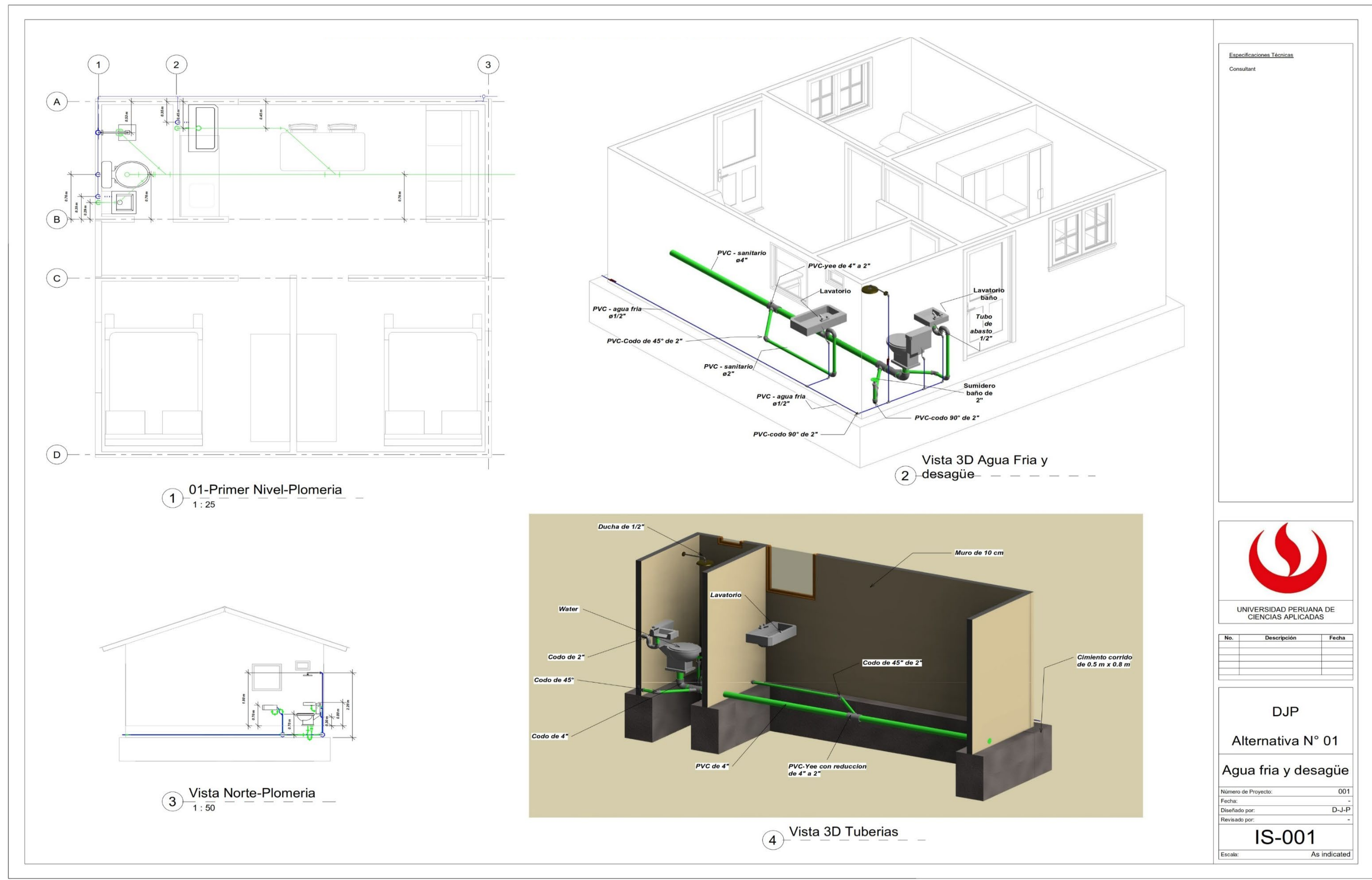


ANEXO 8: PLANO DE DESAGÜE DE LA ALTERNATIVA DE DISEÑO No 1

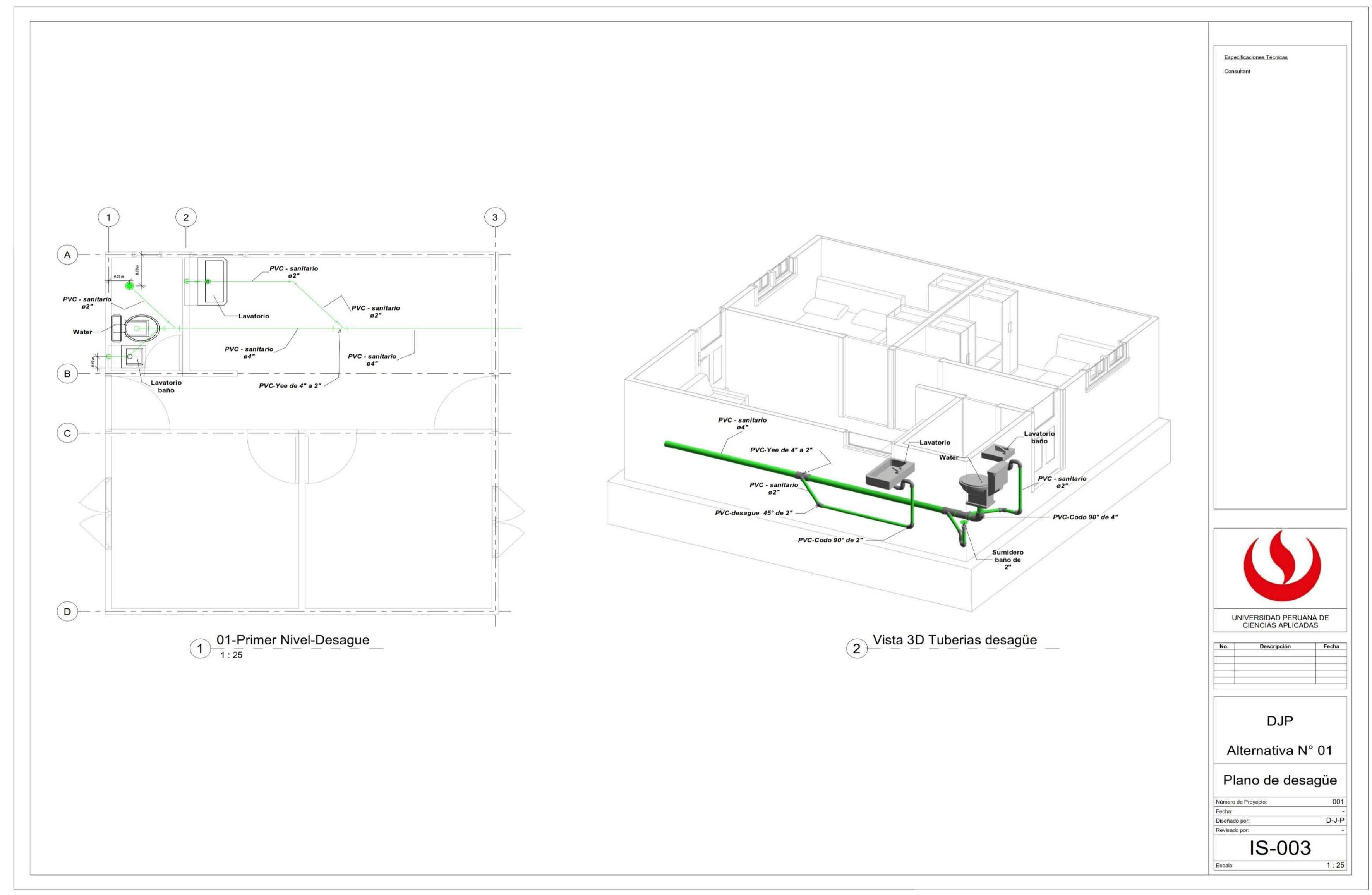




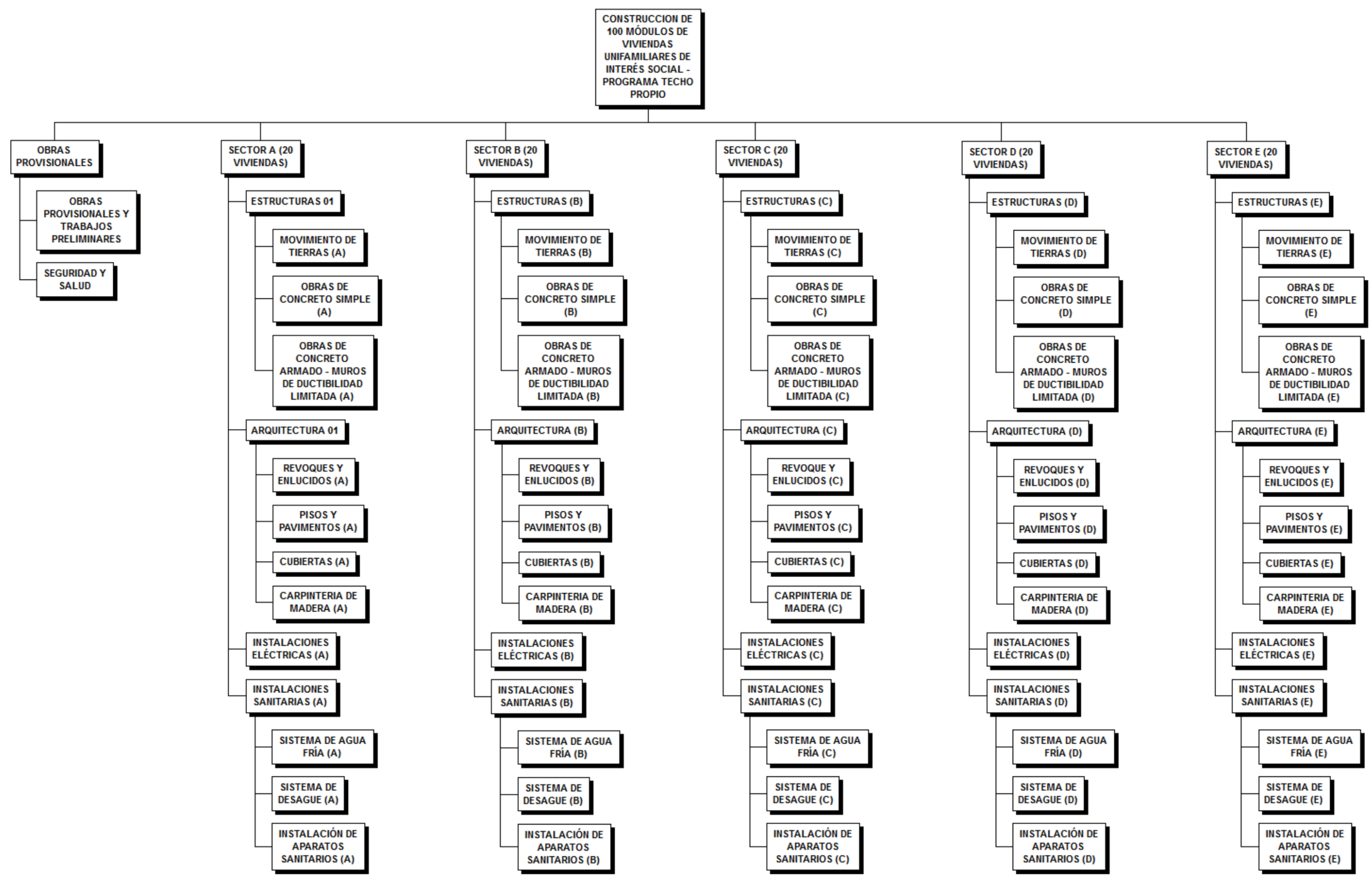


ANEXO 10: CRONOGRAMA GENERAL

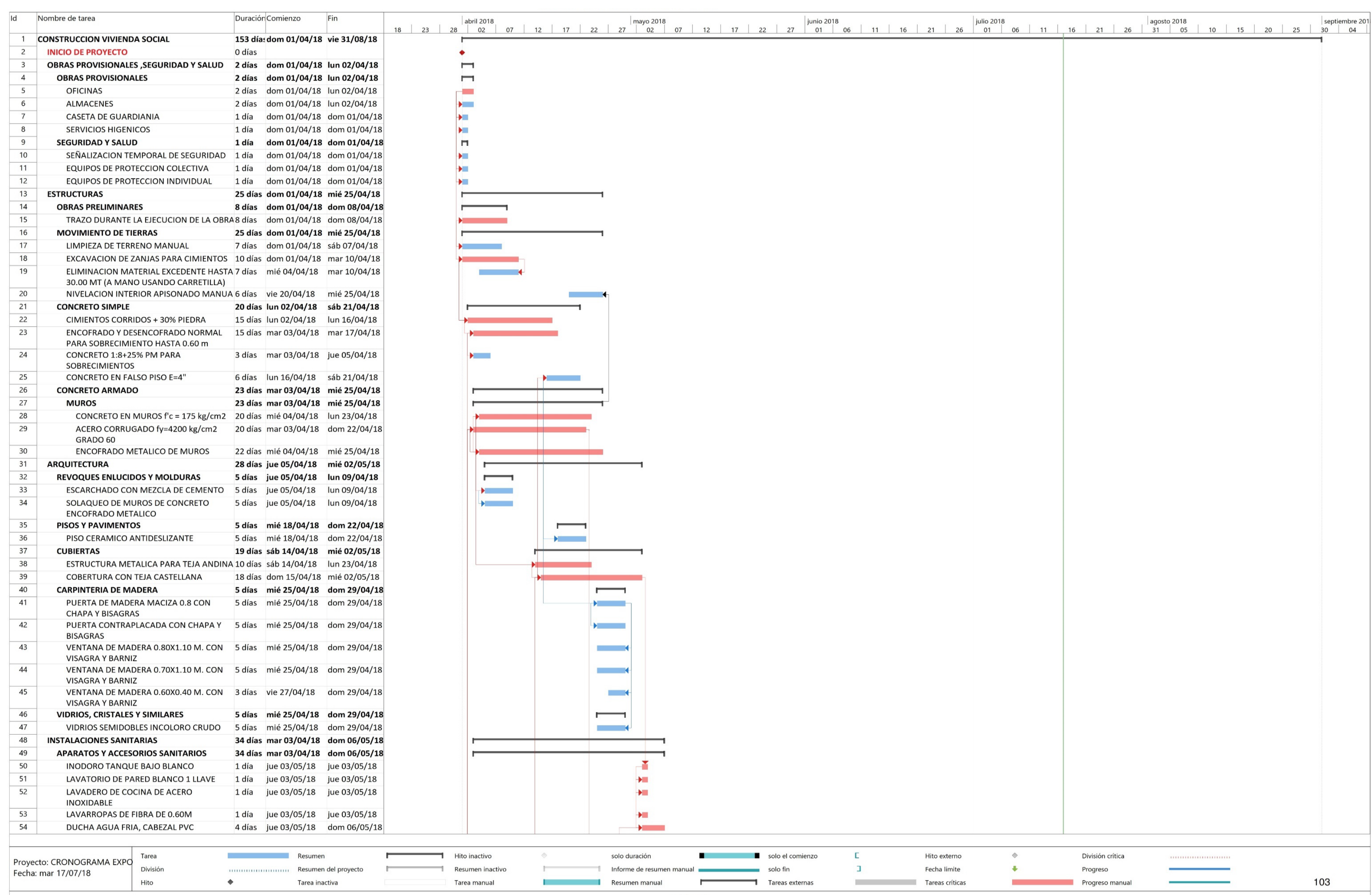




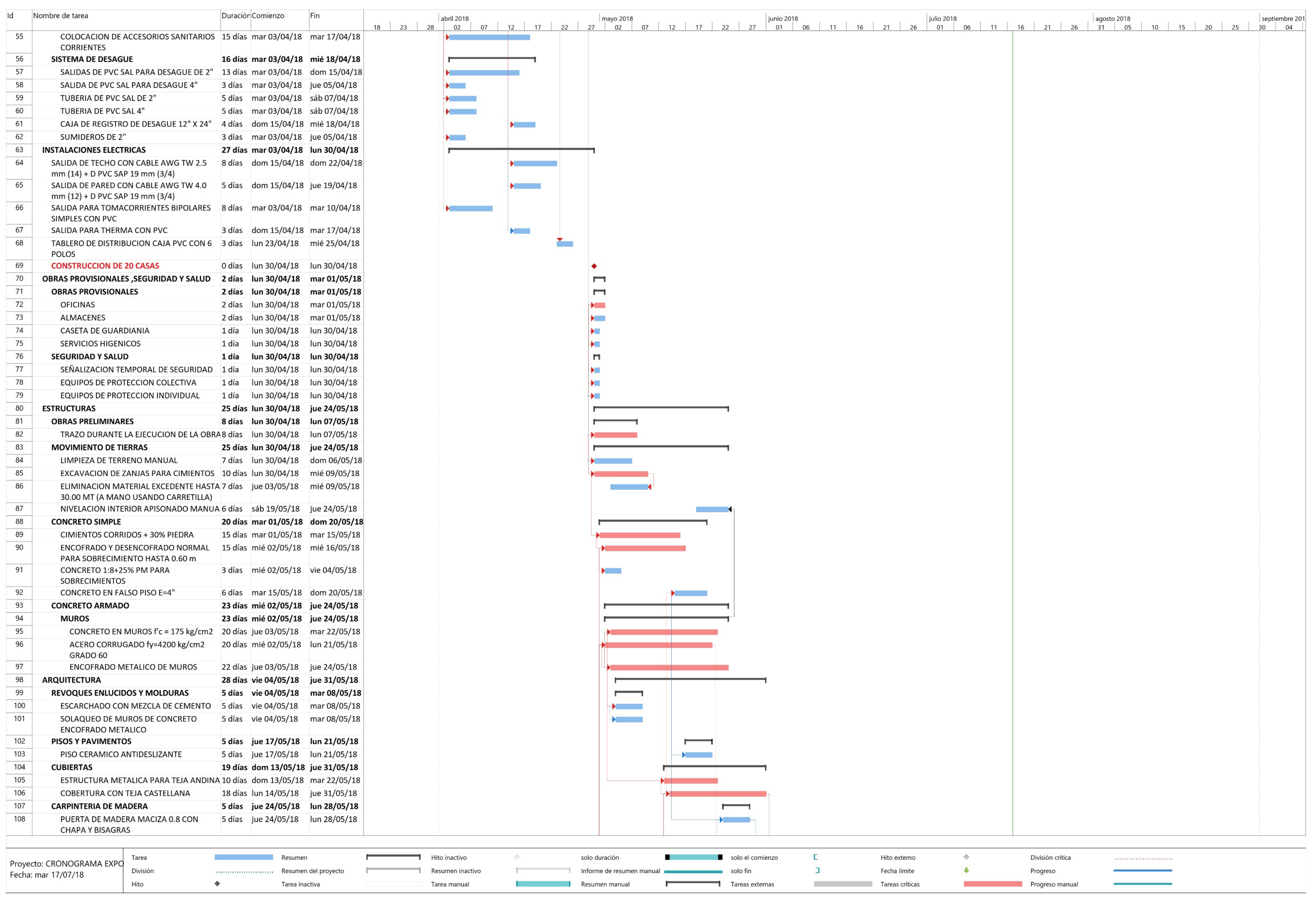


\begin{tabular}{l|l} 
Duración Comienzo & Fin \\
\hline
\end{tabular} PUERTA CONTRAPLACADA CON CHAPAY 5 días jue 24/05/18 lun 28/05/18 VENTANA DE MADERA 0.80X1.10 M. CON 5 dias jue 24/05/18 lun 28/05/18 VENTANA DEMADEPA 0.70X110 M. CON 5 días jue 24/05/18 Iun 2805/18

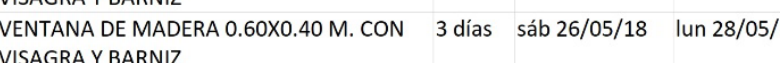
VIDRIOS, CRISTALES Y SIMLILARES 5 dias jue 24/05/18 lun 28/05/18 VIDRIOS SEMIDOBLES INCOLORO CRUDO 5 días jue 24/05/18 lun 28/05/18 INSTALACIONES SANITARIAS 34 dias mie 02/05/18 lun 04/06/18 APARATOS Y ACCESORIOS SANITARIOS 34 dias mié 02/05/18 lun 04/06/18 LAVATORIO DE PARED BANCO1HAYE 1 did Vie 01/06/18 ve $01 / 00 / 18$ LAVADERO DE COCINA DE ACERO 1 día vie 01/06/18 vie 01/06/18 NOXIDABLE \begin{tabular}{llll}
\hline LAVARROPAS DE FIBRA DE 0.60M & 1 día vie $01 / 06 / 18$ & vie $01 / 06 / 18$
\end{tabular} Colocalonda, 4 días vie $01 / 06 / 18$ lun 04/06/18 $\begin{array}{ll}\text { CORRIENTES } & 16 \text { dias mié } 02 / 05 / 18 \text { jue 17/05/18 } \\ \text { ISTTEMA DE DESAGUE } & \end{array}$ SALDAS DE PVC SAL PARA DESAGUE DE 2" 13 dias miée 02/05/18 lun 14/05/18

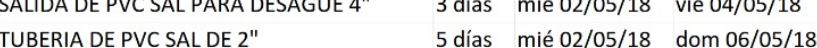
5 dias mié $02 / 05 / 18$ dom $06 / 05 / 18$ CAJA DE REGISTRO DE DESAGUE 12" X 24" 4 dias lun 14/05/18 jue 17/05/18 SUMIDEROS DE $2^{\prime \prime}$. 3 das mie 02/05/18 vie 04/05/18 SAULADE TCHOCOAS 27 dias mile $20205 / 18$ mar 29/105/18 SALDA DE PARED CON CABLE AWG TW $4.0 \quad 5$ dias lun 14/05/18 vie 18/05/18

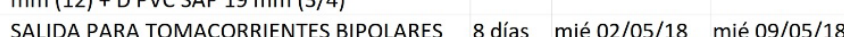
SIMPLES CON PVC SALDA PARA THERMA CON PVC 3 dias lun 14/05/18 mié 16/05/18 TABLERO DE DISTRBUCONCAAPUCCONG Jol
POLS CONSTRUCCION DE 40 CASAS Odías mar 29/05/18 mar 29/05/18 OBRAS PROVISIONALES, SEGURIDAD Y SALUD 2 dias mar 29/05/18 mié 30/05/18 OBRAS PROUSAOALES 2 dias mar 29/05/18 mié 30/05/18

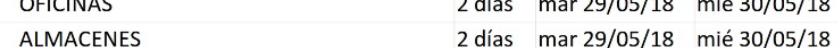
CASETA DE GUARDIANIA $\quad 1$ día $\operatorname{mar} 29 / 05 / 18$ mar 29/05/18 SERVICIOS HIIENICOS 1 dia mar 29/55/18 mar 29/05/18 SEGURIDAD Y SALUD 1 día $\operatorname{mar} 29 / 05 / 18$ mar 29/05/18 SENALZACION TEMPORAL DE SEGURIDAD 1 dia mar 29/55/18 mar 29/05/18

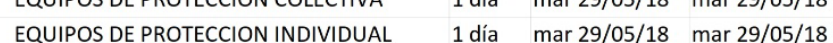
25 dias mar $29 / 05 / 18$ vie $22 / 06 / 18$ OBRAS PRELIMINARES 8 dias mar 29/05/18 mar 05/06/18 TRAZO DURANTE LA EIECUCION DE LA OBRA 8 dias mar 29/05/18 mar 05/06/18 MOVIMIENTO DE TIERRAS 25 dias mar $29 / 05 / 18$ vie 22/06/18 EXCAVACION DE ZANAS PARA CIMIENTOS 10 dias mar 29/05/18 ju 007/06/18 ELIMINACION MATERIAL EXCEDENTE HASTA 7 dias vie 01/06/18 jue 07/06/18 30.00 MT (A MANO USANDO CARRETTLLA)

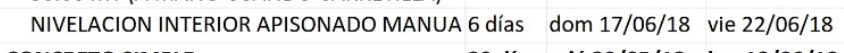
20 dias mié 30/05/18 lun 18/06/18 ENCOFRADO Y DESENCOFRADO NORMAL 15 días jue 31/05/18 jue 14/05/18

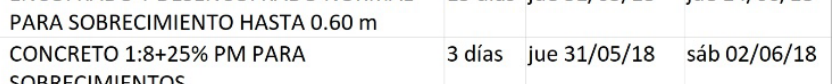
CONCRETO EN FALSO PISO E=4"
CONCRETO ARMADO 6 dias mié $13 / 06 / 18$ lun $18 / 06 / 18$ $\begin{array}{ll}23 \text { dias jue } 31 / 05 / 18 & \text { vie } 22 / 06 / 18 \\ 23 \text { dias jue } 31 / 05 / 18 & \text { vie } 22 / 06 / 18\end{array}$

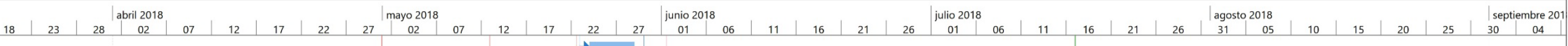
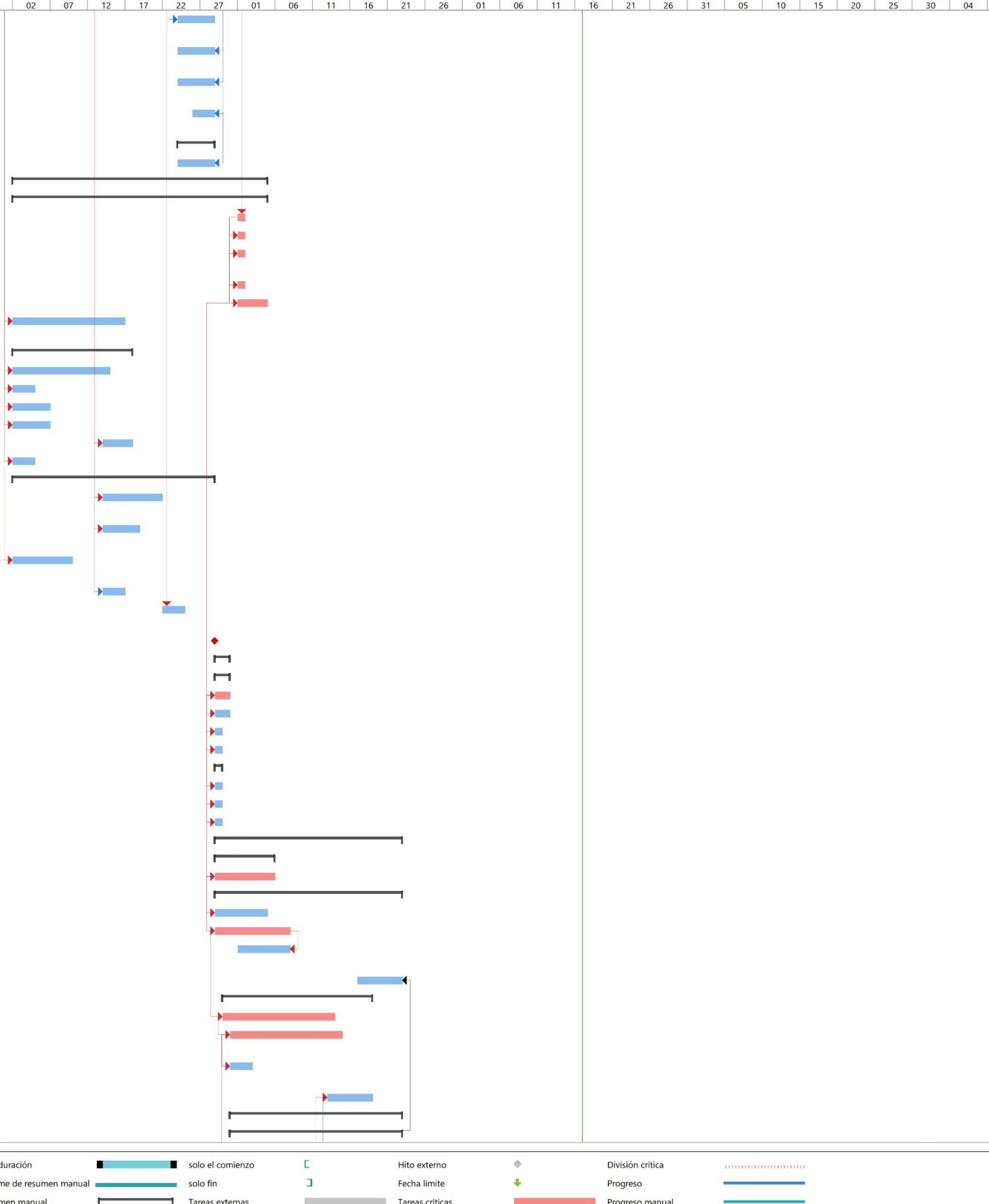


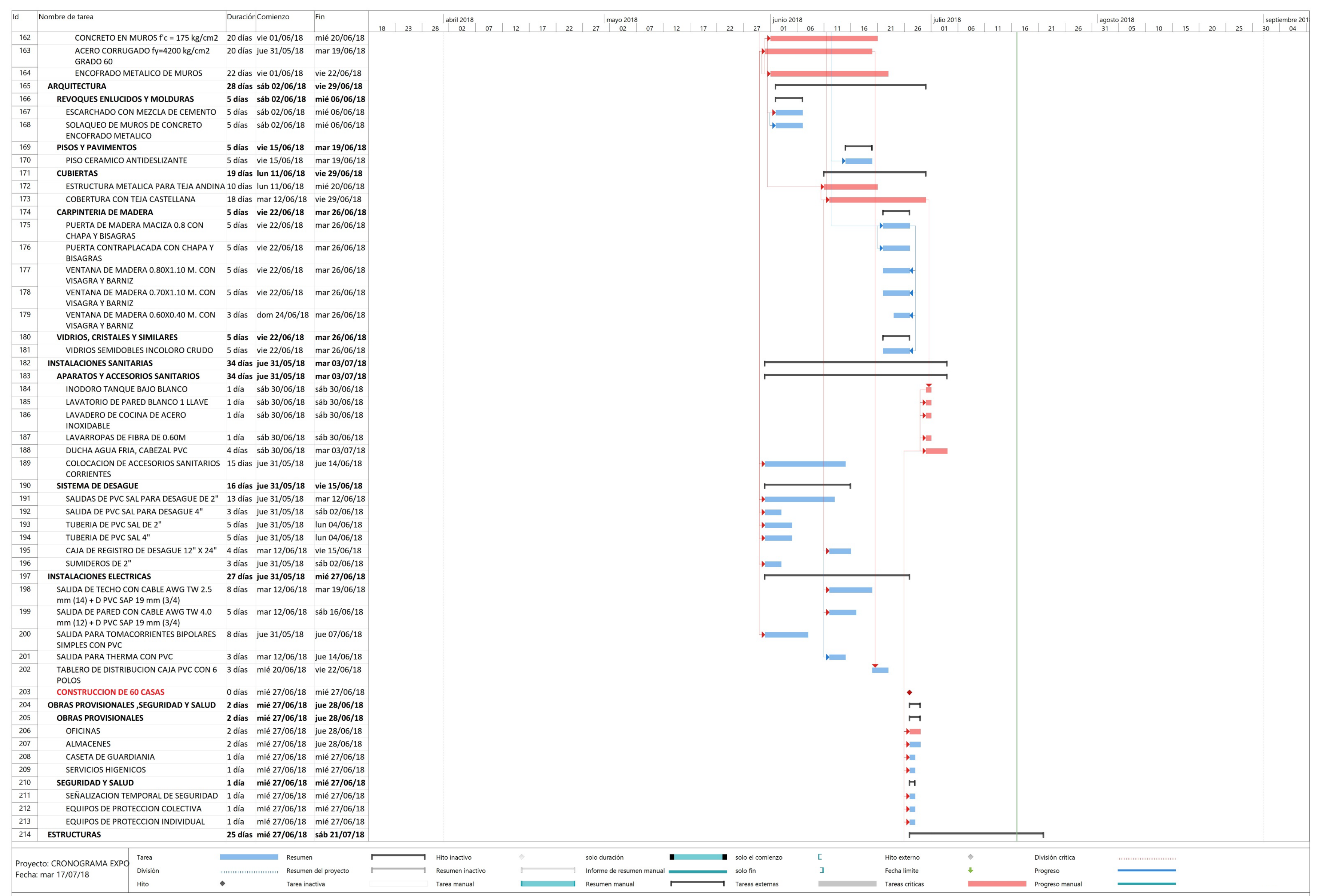




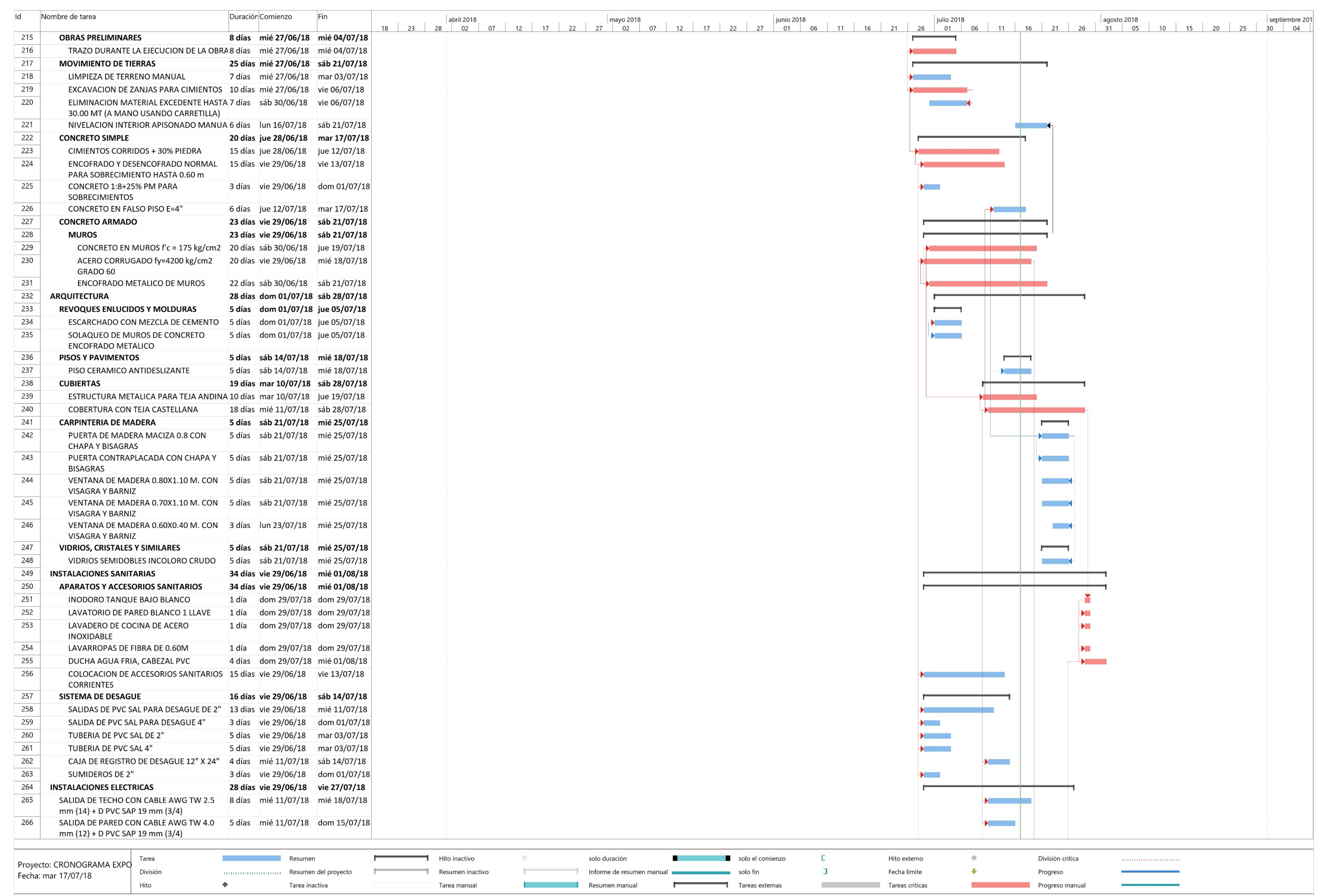


Duración Comienzo $\quad$ Fin SALDA PARA TOMACORRIENTES BIPOLARES 8 días vie 29/06/18 vie 06/07/18
SIMPIES CON PVC SALDA PARA THERMA CON PVC 3 dias mié 11/07/18 vie 13/07/18 TABLERO DE DISTRRB UCLON CAIA PVC CON 6 3 dias jue 19/07/18 sáb 21/07/18 CONSTRUCCION DE 80 CASAS OBRAS PROVISIONALES, SEGURIDAD Y SALUD OBRAS PROVISIONALES

$$
\begin{aligned}
& \text { OFLIINAS } \\
& \text { ALMACENES }
\end{aligned}
$$

Odías vie $27 / 07 / 18$ vie $27 / 07 / 18$

2 dias vie 27/07/18 sáb 28/07/18

$\begin{array}{ll}2 \text { dias vie } 27 / 07 / 18 & \text { sáb 28/07/18 } \\ 2 \text { dias vie 27/07/18 } & \text { śb } 28 / 07 / 18\end{array}$

2 días vie 27/07/18 sub $28 / 07 / 18$

1 día vie 27/07/18 vie 27/07/18

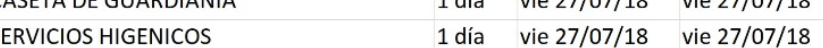

$\begin{array}{llll}\text { SEGURIDAD Y SALUD } & 1 \text { dia } & \text { vie 27/07/18 vie 27/07/18 }\end{array}$

SENAALZZACION TEMPORAL DE SEGURIDAD 1 día vie 27/07/18 vie 27/07/18

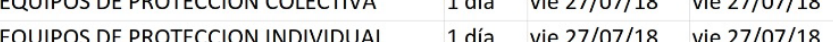

$\begin{array}{lll}\text { ESTRUCTURAS } & 25 \text { dias vie 27/07/18 } & \text { lun 20/08/18 }\end{array}$

$\begin{aligned} 8 \text { OBdas vie } 27 / 07 / 18 & \text { vie } 03 / 08 / 18 \\ \text { TRAZO DURANTE LA EEECUCION DE LA OBRA d dias vie } 27 / 07 / 18 & \text { vie } 03 / 08 / 18\end{aligned}$

MOVIMIENTO DE TIERRAS 25 das vie 27/07/18 lun 20/08/18

IMPIEZA DE TERRENO MANUAL_ 7 dias vie 27/07/18 jue 02/08/18

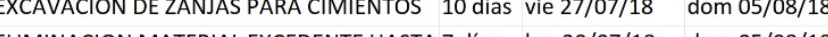
30.0O MT (A MANO USANDO CARRETLLA) NIVELACION INTERIOR APISONADO MANUA G dias mié 15/08/18 lun 20/08/18
CONCRETO SIMPLE $\begin{array}{lll}\text { CONCRETO SIMPLE } & 20 \text { dias sáb 28/07/18 } & \text { jue 16/08/18 } \\ \text { CIMIENTOS CORRIDOS + 30\% PIEDRA } & 15 \text { días sáb 28/07/18 } & \text { sáb 11/08/18 }\end{array}$

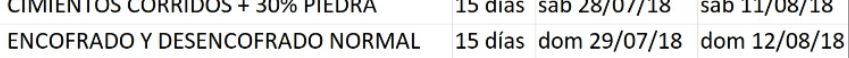

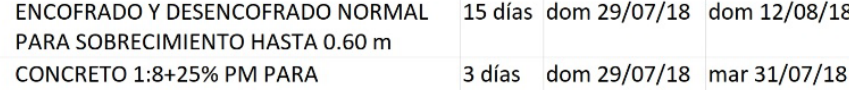
SOBRECIMIENTSS

6 dias sth $11 / 08$ 18 CONCRETO EN FALSO PISO E=4" 6 dias sáb 11/0118 jue 16/08/18 CONCRES
MUROS CONCRETO EN MUROS $\mathrm{f}^{\prime}=175 \mathrm{~kg} / \mathrm{cm} 2 \quad 20$ días lun 30/07/18 sáb 18/08/18 ACERO CORRUGADO fy=4200 kg/cm2 20 días dom $29 / 07 / 18$ vie $17 / 08 / 18$ ENCOFADO METALICO DE MUROS 22 días IUn 30/07/18 Un 20/08/18 ARQUITECTURA REVOQUES ENLUCIDOS Y MOLDURAS $\quad \begin{array}{ll}28 \text { dias } \operatorname{mar} 31 / 07 / 18 & \text { sáb 04/08/18 }\end{array}$ ESCARCHADO CON MEZCLA DE CEMENTO 5 días mar 31/07/18 sáb 04/08/18 SOLAQUEO DE MUAOSDE CONCRETO 5 días mar 31/07/18 sáb 04/08/18 PISOS Y PAVIMENTOS

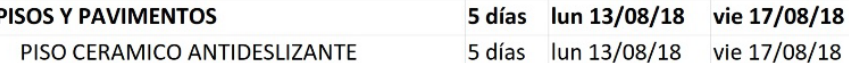
\begin{tabular}{lll} 
CUBIERTAS & 19 dias jue 09/08/18 & lun 27/08/18 \\
\hline
\end{tabular} ESTRUCTURA METALICA PARA TEA ANDINA 10 dias jue 09/08/18 sáb 18/08/18 COBERTURA CON TEA CASTELLANA 18 dias vie 10/08/18 lun 27/08/18 PUERTADEMADEAMACIZAOSCON 5 dias lun 20/08/18 vie 24/08/18 PUERTA CONTRAPLACADA CON CHAPAY 5 días lun 20/08/18 vie 24/08/18 VENTANA DE MADERA 0.80X1.10 M CON 5 dias lun 20/08/18 vie 24/08/18 VENTANA DE MADERA 0.70X1.10 M. CON 5 dias lun 20/08/18 vie 24/08/18 VENTANA DE MADERA 0.60X0.40 M. CON 3 días mié 22/08/18 vie 24/08/18 VISAGRA Y BARNIZ

VIDRIOS, CRISTALES Y SIMLLARES 5 dias lun 20/08/18 vie 24/08/18 Instan $20 / 08 / 18$ vie 24//88/18 APARATOS Y ACCESORIOS SANITARIOS 34 dias dom 29/07/18 vie $31 / 08 / 18$ INODORO TANQUE BAJO BLANCO 1 día mar 28/08/18 mar 28/08/18

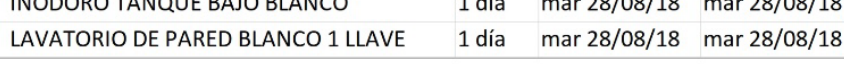

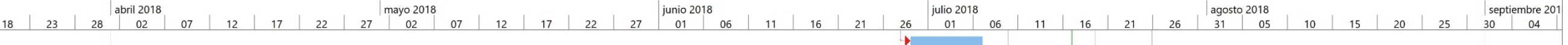

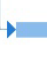

$\checkmark$
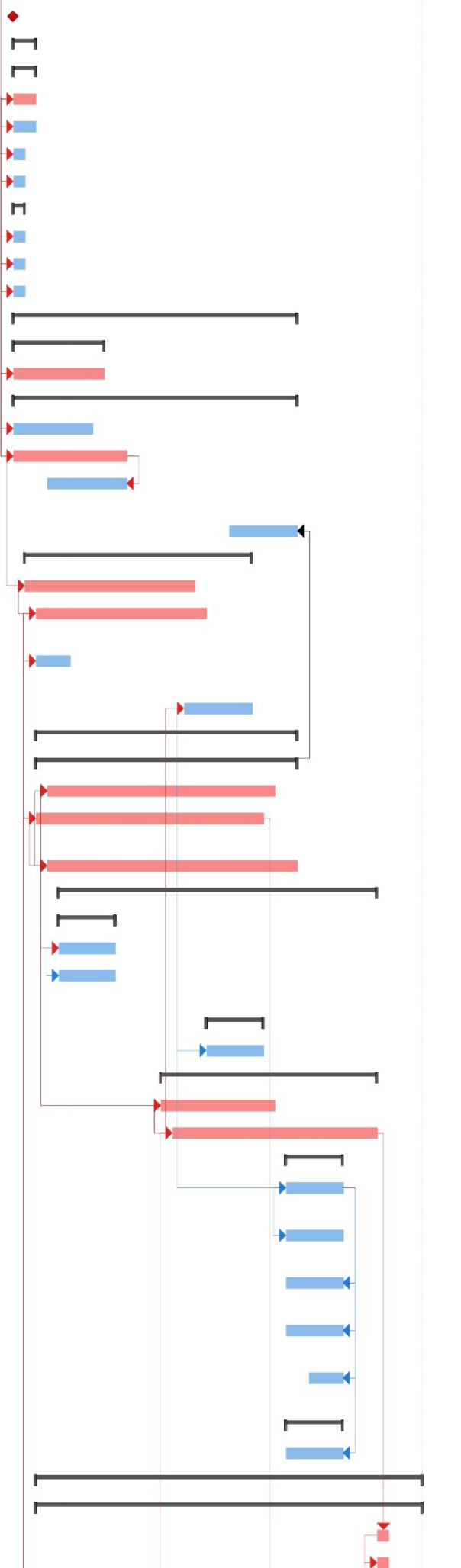

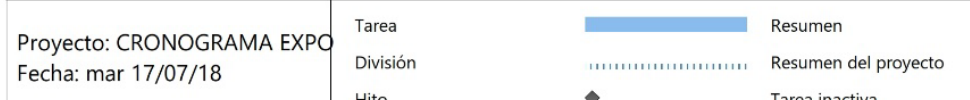

$\longmapsto \begin{aligned} & \text { Resumen inactivo } \\ & \text { Thenativo }\end{aligned}$

solo duración
informe de resumen
Resumen manual

solelcomienze

J

Fecha limite
Tareas criticas

$\substack{\text { División nitica } \\ \text { Progoreso }}$
. 


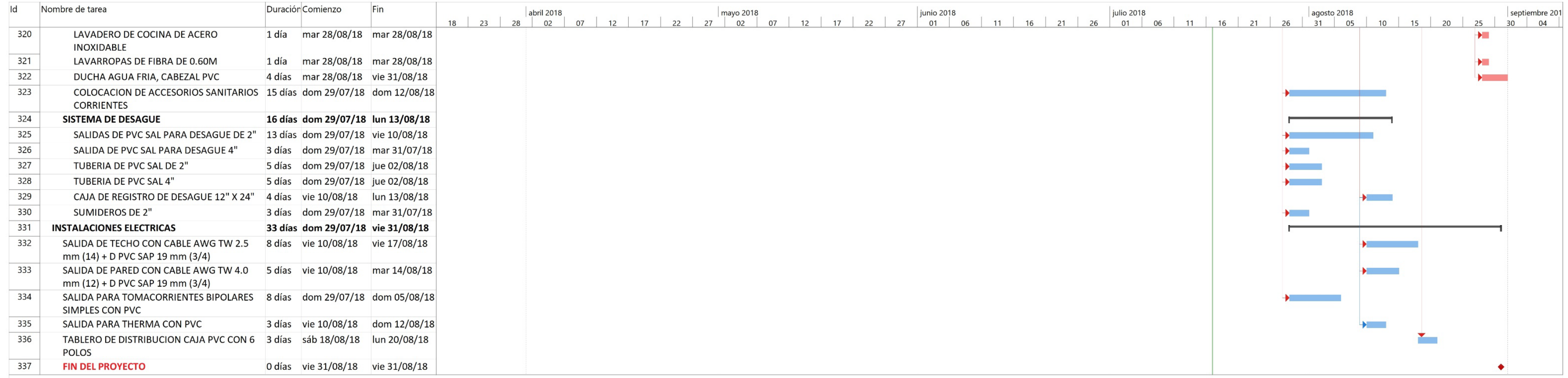

\begin{tabular}{|c|c|c|c|c|c|c|c|c|c|c|c|c|c|c|}
\hline $\begin{array}{l}\text { Proyecto: CRONOGRAMA EXPC } \\
\text { Fecha: mar 17/07/18 }\end{array}$ & $\begin{array}{l}\text { Tarea } \\
\text { División } \\
\text { Hito }\end{array}$ & , & $\begin{array}{l}\text { Resummen } \\
\text { Resumen del proyecto } \\
\text { Tarea inactiva }\end{array}$ & Ґ & $\begin{array}{l}\text { Hitio inartivo } \\
\text { Resumen inactivo } \\
\text { Tarea manual }\end{array}$ & $\square$ & $\begin{array}{l}\text { solod duración } \\
\text { Informe de ersumer } \\
\text { Resumen manual }\end{array}$ & " & $\begin{array}{l}\text { soloe comienzo } \\
\text { solof fin } \\
\text { Taraese extemas }\end{array}$ & $\begin{array}{l}\text { [ } \\
\text { J }\end{array}$ & $\begin{array}{l}\text { Hitio extemono } \\
\text { Fechal limite } \\
\text { Tareas stricas }\end{array}$ & $i$ & $\begin{array}{l}\text { Divisibo critica } \\
\text { Progerso } \\
\text { iprogeso manual }\end{array}$ & ב \\
\hline
\end{tabular}


Presupuesto $0706072 \quad$ MODULO DE VIVIENDAS SOCIALES

Cliente Ministerio de Vivienda, Construccion y Saneamiento

Lugar CUSCO-CUSCO-CUSCO

Item Descripción

01

01.01

01.01 .01

01.01 .02

01.01 .03

01.01 .04

01.02

01.02 .01

01.02 .02

01.02 .03

02

02.01

02.01 .01

02.02

02.02 .01

02.02 .02

02.02 .03

02.02.04

02.03

02.03 .01

02.03 .02

02.03 .03

02.03 .04

02.04

02.04.01

02.04.01.01

02.04.01.02

02.04.01.03

03

03.01

03.01.01

03.01 .02

03.02

03.02.01

03.03

03.03.01

03.03.02

03.04

03.04 .01

03.04 .02

03.04 .03

03.04.04

03.04 .05

03.05

03.05 .01

04

04.01

04.01 .01

04.01 .02

04.01 .03

04.01 .04

04.01 .05

04.01 .06

OBRAS PROVISIONALES ,SEGURIDAD Y SALUD OBRAS PROVISIONALES

OFICINAS

ALMACENES

CASETA DE GUARDIANIA

SERVICIOS HIGENICOS

SEGURIDAD Y SALUD

SEÑALIZACION TEMPORAL DE SEGURIDAD

EQUIPOS DE PROTECCION COLECTIVA

EQUIPOS DE PROTECCION INDIVIDUAL

ESTRUCTURAS

OBRAS PRELIMINARES

TRAZO DURANTE LA EJECUCION DE LA OBRA

MOVIMIENTO DE TIERRAS

LIMPIEZA DE TERRENO MANUAL

EXCAVACION DE ZANJAS PARA CIMIENTOS

ELIMINACION MATERIAL EXCEDENTE HASTA 30.00 MT (A MANO

IISANIO C.ARRFTIIAI

NIVELACION INTERIOR APISONADO MANUAL

CONCRETO SIMPLE

CIMIENTOS CORRIDOS + 30\% PIEDRA

ENCOFRADO Y DESENCOFRADO NORMAL PARA SOBRECIMIENTO HA.STA $\cap$ Gก $\mathrm{m}$

CONCRETO 1:8+25\% PM PARA SOBRECIMIENTOS

CONCRETO EN FALSO PISO E=4"

CONCRETO ARMADO

MUROS

CONCRETO EN MUROS fC $=175 \mathrm{~kg} / \mathrm{cm} 2$

ACERO CORRU GADO fy $=4200 \mathrm{~kg} / \mathrm{cm} 2$ GRADO 60

ENCOFRADO METALICO DE MUROS

ARQUITECTURA

REVOQUES ENLUCIDOS Y MOLDURAS

ESCARCHADO CON MEZCLA DE CEMENTO

SOLAQUEO DE MUROS DE CONCRETO ENCOFRADO METALICO

PISOS Y PAVIMENTOS

PISO CERAMICO ANTIDESLIZANTE

CUBIERTAS

ESTRUCTURA METALICA PARA TEJA ANDINA

COBERTURA CON TEJA CASTELLANA

CARPINTERIA DE MADERA

PUERTA DE MADERA MACIZA 0.8 CON CHAPA Y BISAGRAS

PUERTA CONTRAPLACADA CON CHAPA Y BISAGRAS

VENTANA DE MADERA 0.80X1.10 M. CON VISAGRA Y BARNIZ

VENTANA DE MADERA 0.70X1.10 M. CON VISAGRA Y BARNIZ

VENTANA DE MADERA 0.60X0.40 M. CON VISAGRA Y BARNIZ

VIDRIOS, CRISTALES Y SIMILARES

VIDRIOS SEMIDOBLES INCOLORO CRUDO

INSTALACIONES SANITARIAS

APARATOS Y ACCESORIOS SANITARIOS

INODORO TANQUE BAJO BLANCO

LAVATORIO DE PARED BLANCO 1 LLAVE

LAVADERO DE COCINA DE ACERO INOXIDABLE

LAVARROPAS DE FIBRA DE 0.60M

DUCHA AGUA FRIA, CABEZAL PVC

COLOCACION DE ACCESORIOS SANITARIOS CORRIENTES
Und. Metrado Precio S/. Parcial S/

Costo al

$01 / 07 / 2018$

$4,481.1$

$4,027.72$

$\mathrm{m} 2$

gl

gl

glb

$\mathrm{m} 2$

37.00

94.77

$1,421.55$

$2,179.71$

151.63

274.83

453.42

220.77

173.65

59.00

$18,812.55$

112.85

112.85

$1,404.18$

135.42

671.58

496.38

100.80

$5,019.60$

$2,396.36$

$1,244.88$

375.59

$1,002.77$

$12,275.92$

$12,275.92$

357.02

$3,984.34$

$1,915.38$

$6,376.20$

$6,866.54$

$1,343.07$

m2

$\mathrm{m} 2$

223.10

3.45

2.5

769.70

573.37

92.36

92.36

$4,071.38$

396.45

$3,674.93$

1,198.98

277.90

471.32

192.50

187.90

69.36

160.75

160.75

1,576.51

499.00

94.90

63.90

60.00

60.00

30.00

190.20 
54.02

04.02.01

04.02 .02

04.02 .03

04.02 .04

04.02 .05

04.02 .06

05

05.01

05.02

05.03

05.04

05.05
SISTEMA DE DESAGUE

SALIDAS DE PVC SAL PARA DESAGUE DE 2"

SALIDA DE PVC SAL PARA DESAGUE 4"

TUBERIA DE PVC SAL DE 2"

TUBERIA DE PVC SAL 4"

CAJA DE REGISTRO DE DESAGUE 12" X 24"

SUMIDEROS DE 2"

INSTALACIONES ELECTRICAS

SALIDA DE TECHO CON CABLE AWG TW $2.5 \mathrm{~mm}$ (14) + D PVC SAP $19 \mathrm{~mm}$ SALIDA DE PARED CON CABLE AWG TW $4.0 \mathrm{~mm}$ (12) + D PVC SAP $19 \mathrm{~mm}$

SALIDA PARA TOMACORRIENTES BIPOLARES SIMPLES CON PVC

SALIDA PARA THERMA CON PVC

TABLERO DE DISTRIBUCION CAJA PVC CON 6 POLOS

COSTO DIRECTO
$1,077.51$

pto

58.94

65.76

15.22

19.33

52.45

50.45

67.32

64.91

56.31

60.00

94.90

1.00
294.70

65.76

182.64

328.61

104.90

100.90

714.33

269.28

64.91

225.24

60.00

94.90

$32,451.07$ 
ANEXO 12: LOOK AHEAD DEL SECTOR 1

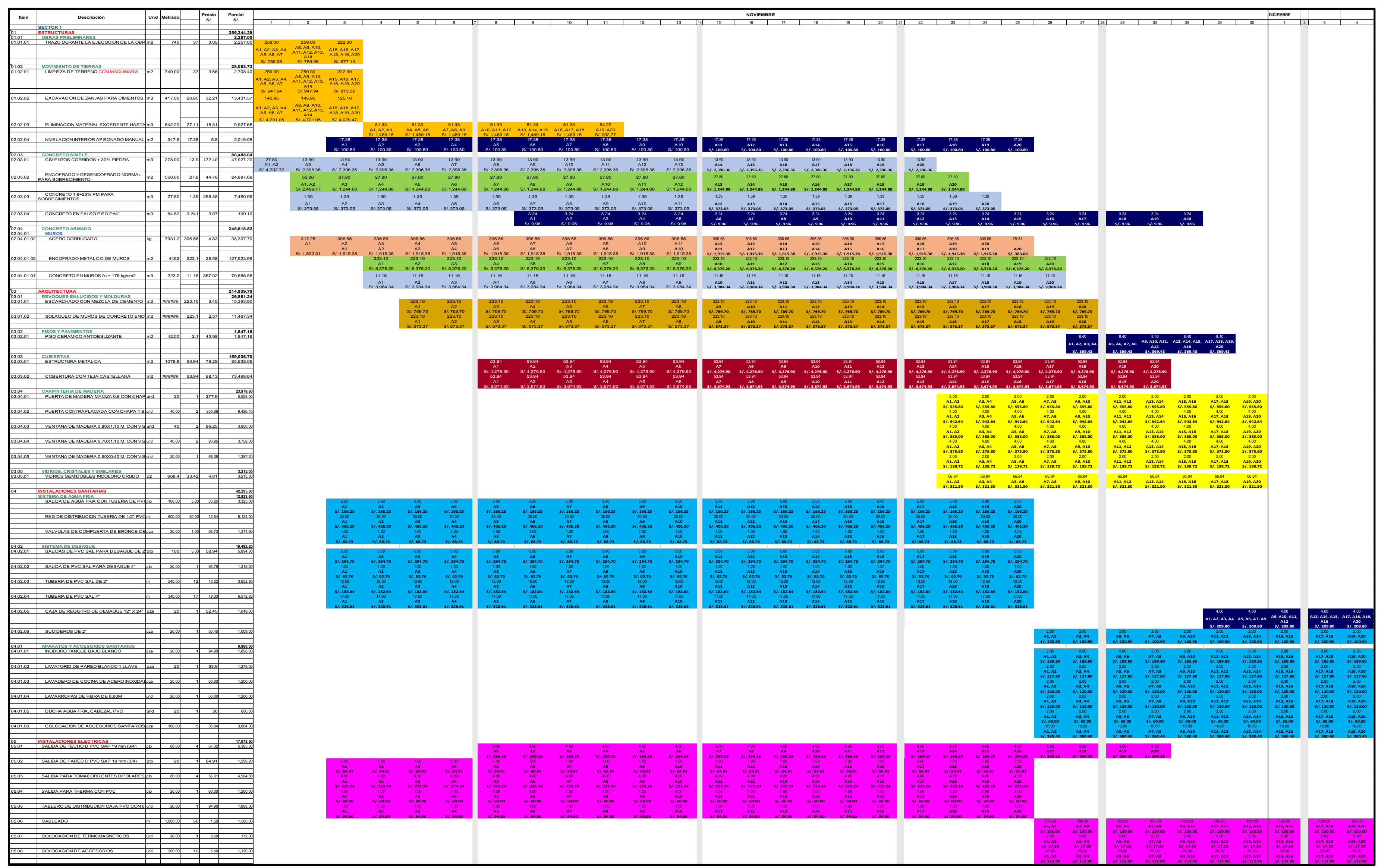


ANEXO 13: LOOK AHEAD DEL SECTOR 2

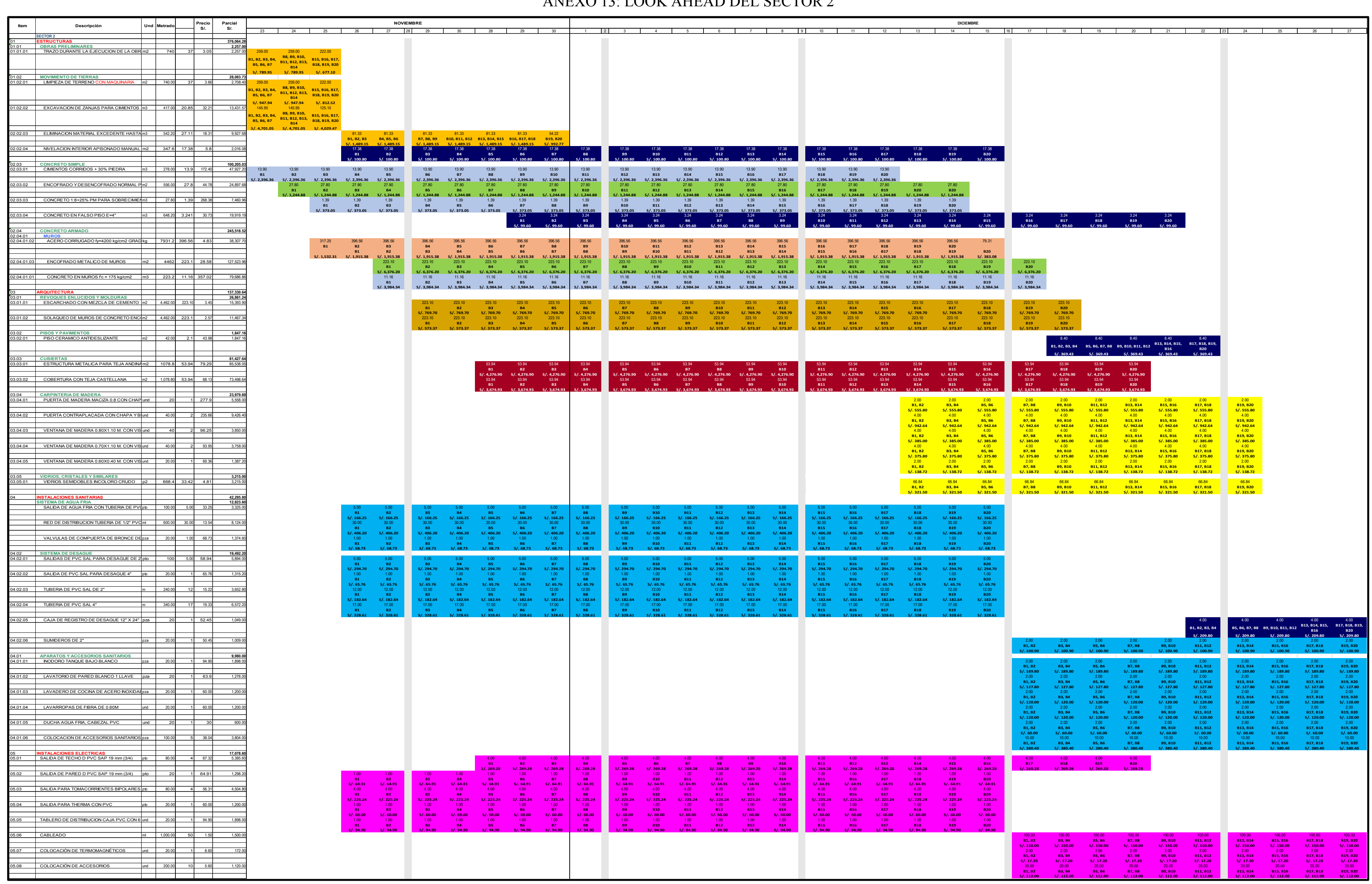


ANEXO 14: LOOK AHEAD DEL SECTOR 3

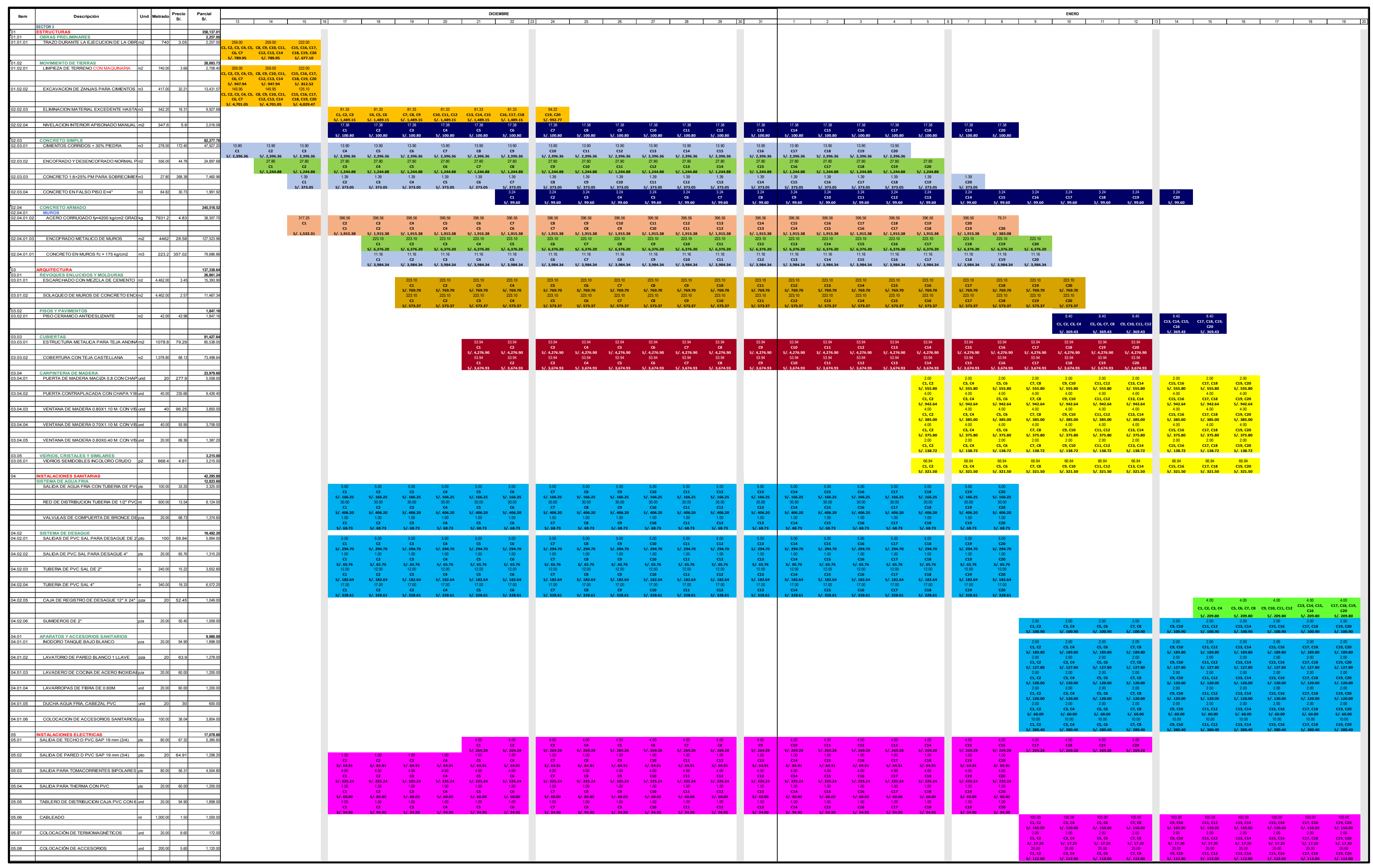


ANEXO 15: LOOK AHEAD DEL SECTOR 4

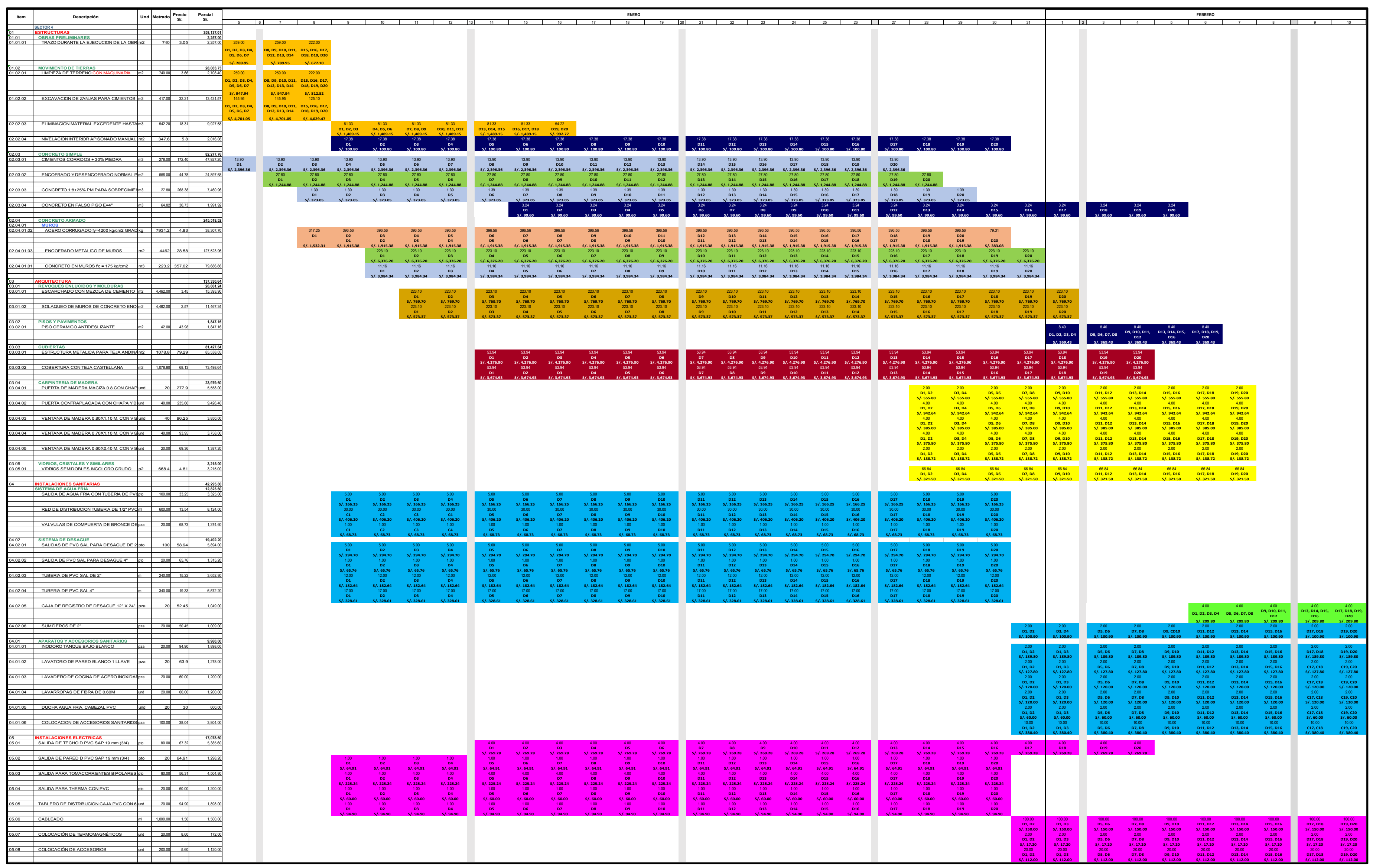


ANEXO 16: LOOK AHEAD DEL SECTOR 5

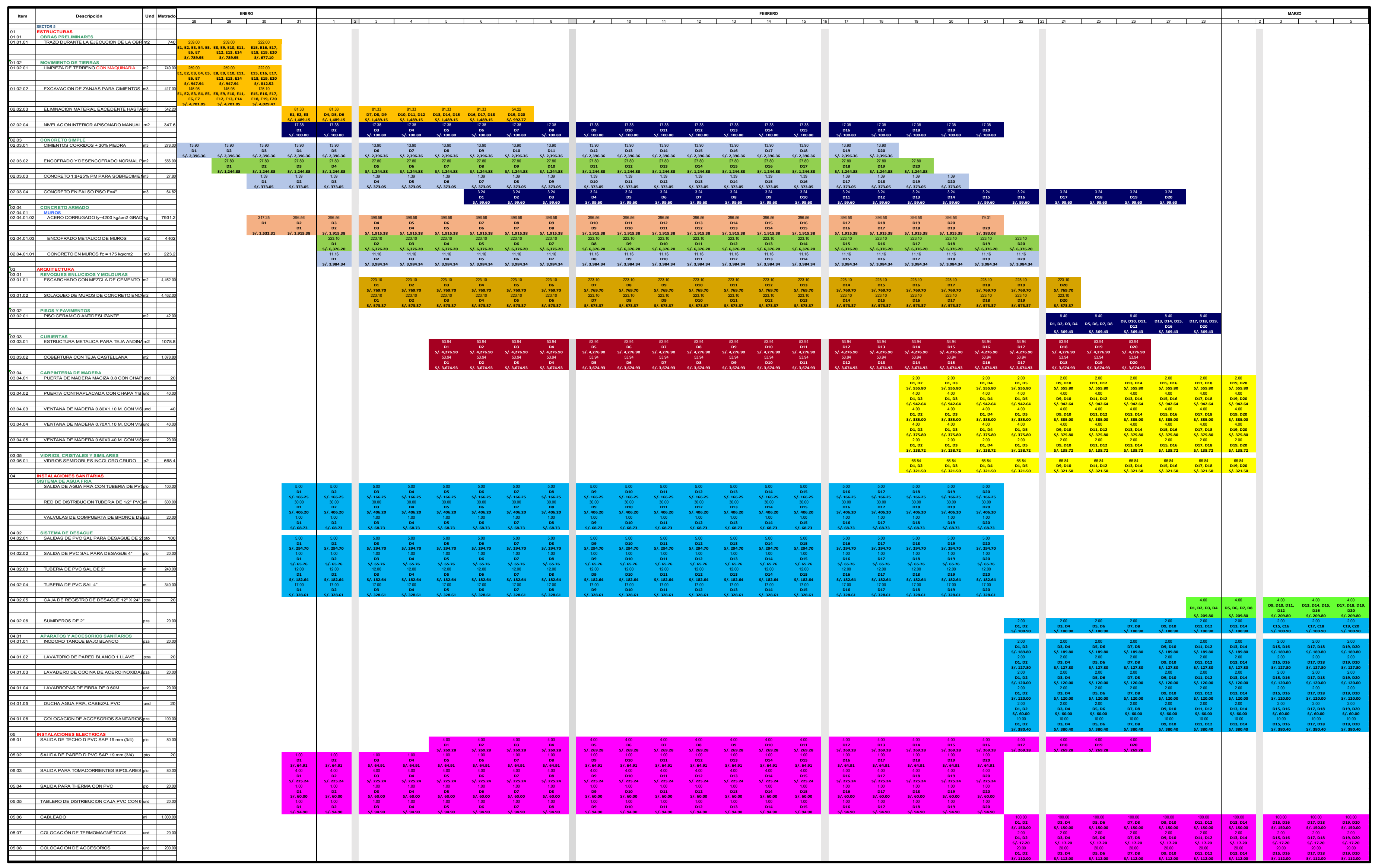

